\title{
EVALUATING BIOLOGICAL CHANGE IN NEW ZEALAND MARINE RESERVES
}

By

Anjali Pande

\author{
A thesis \\ Submitted to the Victoria University of Wellington \\ in fulfilment of the \\ requirements for the degree of \\ Doctor of Philosophy \\ in Zoology
}

Victoria University of Wellington

2001 


\section{Fromtispiece}

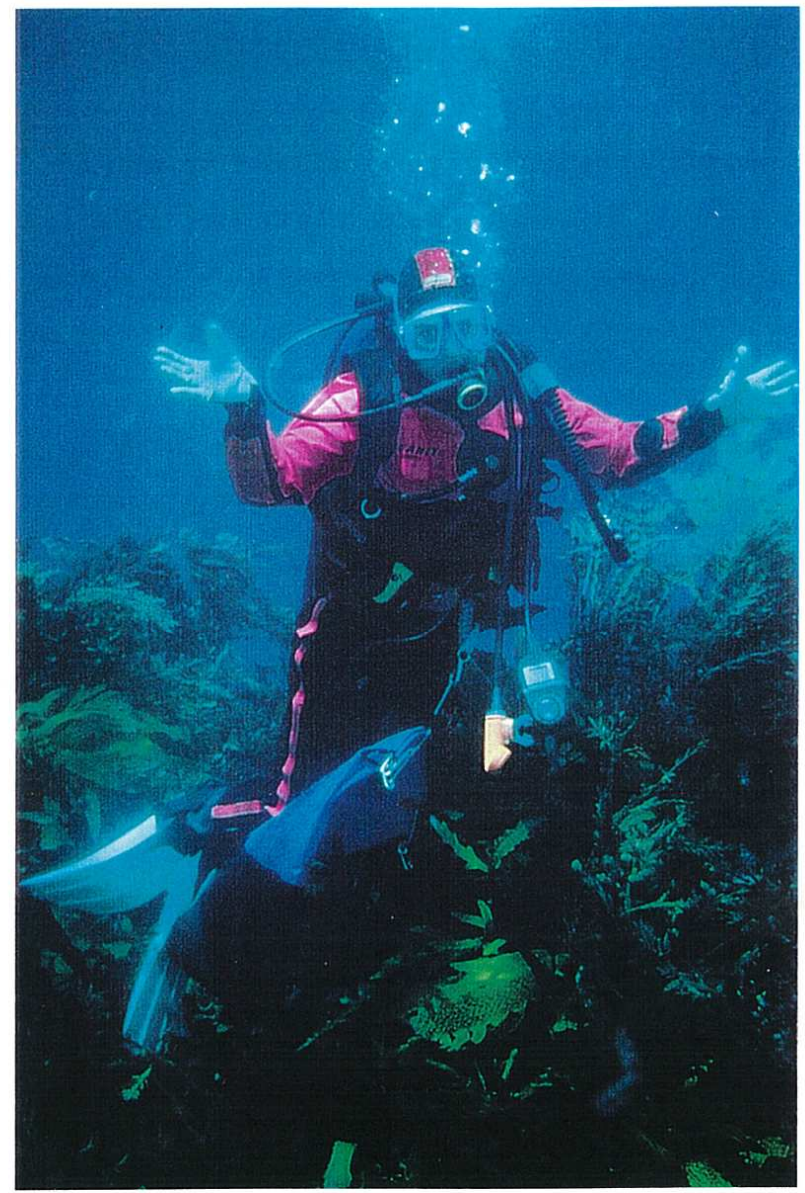

Enjoying field work on one of the rare nice days! 


\begin{abstract}
This study illustrates the importance of baseline surveys, why they are necessary and how best to conduct them. A proposed marine reserve site (the south coast of Wellington) was monitored for three years to establish a comprehensive baseline study. The results were used to recommend appropriate methodology for sampling in this area and also to establish which species are the best to use as indicator species to detect any possible change occurring in this area due to future reservation status. The $11 \mathrm{~km}$ stretch of coast surveyed, which included future reserve and control sites, was tested for heterogeneity, to prevent any future differences in sites being attributed to reservation status as opposed to natural variation. It was determined that an environmental gradient exists along the south coast, from east to west, most likely due to increasing wave exposure and increasingly strong tides and currents towards the west.
\end{abstract}

An established marine reserve (Kapiti Marine Reserve) was also monitored over the same period of time to establish what differences existed in size and abundance of key species between reserve and control sites. The data collected in this investigation were also compared to data collected immediately prior to reserve establishment to determine what changes had occurred over time. Results showed that sites inside the marine reserve supported a greater species abundance, and in some cases, larger size classes. There was some evidence for a general shift in the community structure particularly in algal plants. However, these results may have been confounded by the effect of one site that appeared to have a very high natural species diversity and abundance (even before reservation status). It was concluded that the one-off survey conducted before establishment of this reserve was inadequate to use as a baseline against which to detect changes. No changes were found between the present study and the preliminary survey, although specific data analysis indicated a reserve effect. Continued sampling methodology for Kapiti Marine Reserve area was suggested.

Raw data, on two key species (blue cod and rock lobster) from six marine reserves in New Zealand were investigated in an attempt to perform a statistical "meta-analysis" of the effects of marine reserves in New Zealand. A meta-analysis is different from a narrative review as it uses statistical methods to compare results across studies. This methodology has not been applied to studies of marine reserves before. The meta analysis conducted in the present investigation showed that generally marine reserves in New 
Zealand are having a positive effect, in terms of increasing size and abundance of individual species, as compared to control areas. There is some evidence for a latitudinal trend influencing the "effect size" (a statistical term indicating the magnitude of the treatment tested - in this case, reservation) of the reserves. 


\section{Acknowledgements}

I could not have produced this thesis without the help of many people. Acknowledging them here hardly begins to express my gratitude to them.

Thank you to my supervisor Dr. Jonathan Gardner, for setting up this project, convincing me to apply for it and then doing all that a supervisor is supposed to do.

Thanks to the late Andy Ritchie for helping to organise funding for this thesis and thanks to Kathy Walls for organising the funding from DOC (Department of Conservation). Thanks go to Victoria University of Wellington for providing the scholarship that enabled me to complete this thesis.

Field work would have been even more impossible than it was, without the expert knowledge and boat driving skills of our skipper Robert Williamson. Thanks too, to Graham Weakley and Ollie Moeller for filling in when Robert was unavailable.

I could never have collected all my data without all those volunteer divers who gave up their free time to help me. Some who deserve a special mention are: definitely Trevor Willis and Justine Saunders who came all the way down from Auckland to help me learn the ropes. When they left, Andy Maloney and Vicky Froude dived with me almost from day one to day end, and also thanks to Sri Lloyd, Dave Payne and Dave Shanks who during the time that they were available were almost always there too. My import crew from the UK- Rick, Dan and Dave - you guys were great! To all the others, thank you again - it never would have happened without you.

Thank you to the team at Splash Gordon's dive shop, for letting me into the shop at silly hours to fill tanks and borrow gear and sending volunteer divers my way. It would have been a nightmare if you hadn't been so accommodating!

Jeff - without your computer expertise, I would have been struggling to keep my data in line and would probably have resorted to pen and paper!!!! You taught me a lot. Thanks too for all those last minute weather forecasts - it would have been great had you been able to control the weather too!! 
Huge thank you's to Rob Davidson, for giving me faith in my project, letting me bounce ideas off him and for all the millions of proof reads! I really appreciate it.

Special thanks to Ali MacDiarmid for helping me formulate the idea of a meta-analysis and for being the first to provide me with data to carry it out. Thanks to Clinton Duffy, Debbie Freeman, Russell Cole and Rob Davidson also for providing me with much needed data.

I must thank Charlie Daugherty and Helen Neil for convincing me not to quit, when I got to that phase that apparently most $\mathrm{PhD}$ students go through....

Not being a mathematical genius I am very grateful to Edith Hodgen and Peter Smith for all their help with the statistics I had to wade through!

The list goes on - I must thank my flatmates for their support, especially Tom who let me whinge and cry on his shoulder when the going got tough.

Thank you to George Gibbs and Bruce Dix for your comments on the manuscript, and many many thanks especially to Kerstin, but also Brent and Rhys for all the last minute proof reads and excellent suggestions!!!

Finally, thanks to my father for keeping me on the straight and narrow during the three years I was working on this thesis, always hassling me to do my schoolwork....I hope I make you proud.

N.B. Maps are reproduced from Department of Conservation discussion documents, The Taputeranga Marine Reserve application document by the Royal Forest and Bird Society and Battershill et al. (1993). Thank You! 


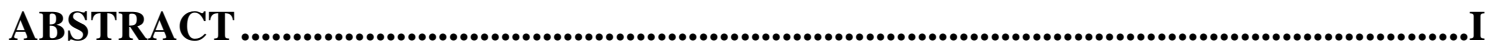

ACKNOWLEDGEMENTS................................................................................

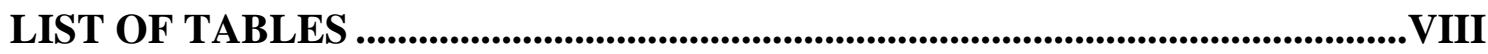

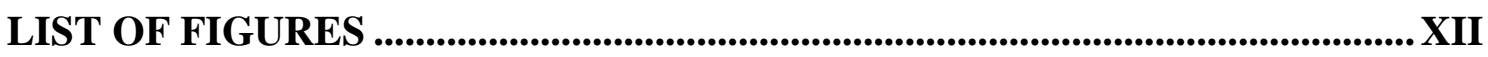

CHAPTER 1 - INTRODUCTION ..................................................................... 1

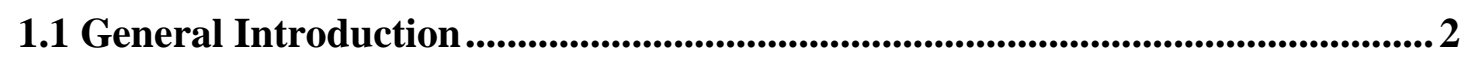

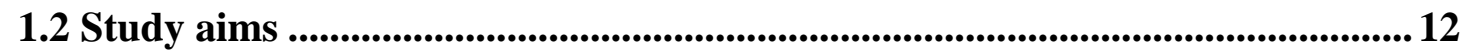

1.3 The layout of this thesis ...................................................................................13

CHAPTER 2 - METHODS.................................................................................. 15

2.1 Site Selection - South Coast .................................................................................... 16

2.2. Site Selection - Kapiti Marine Reserve.................................................................... 20

2.3. Species surveyed.......................................................................................223

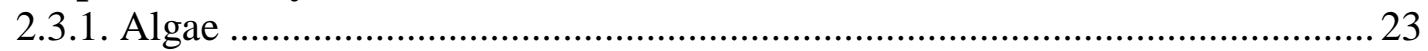

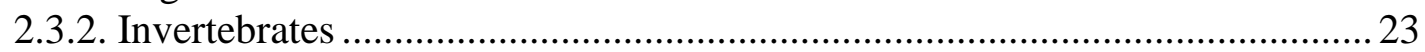

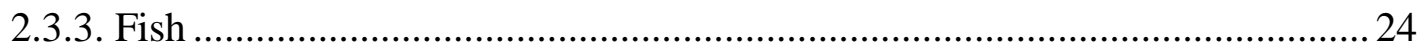

2.4. Survey Methods.......................................................................................227

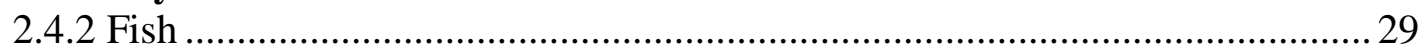

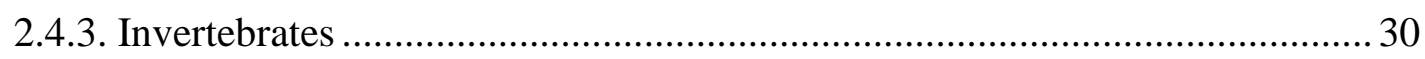

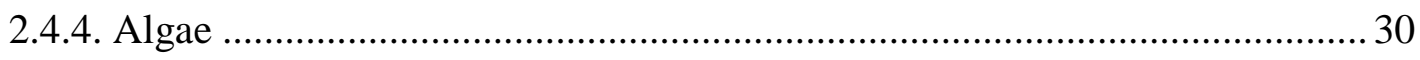

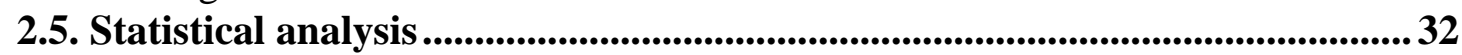

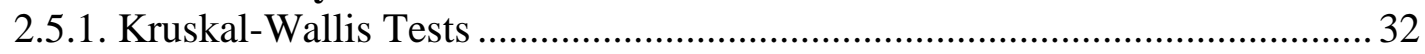

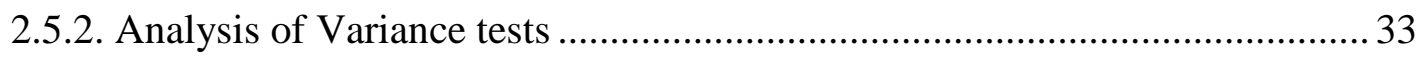

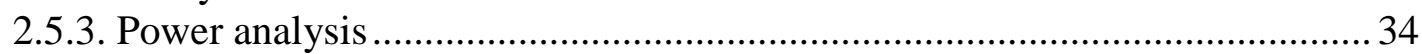

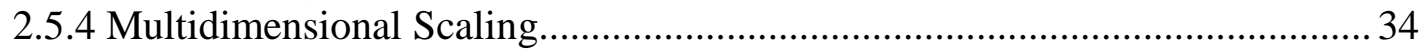

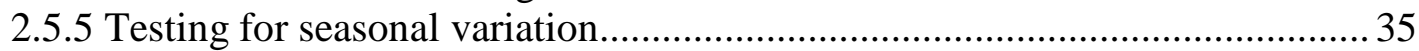

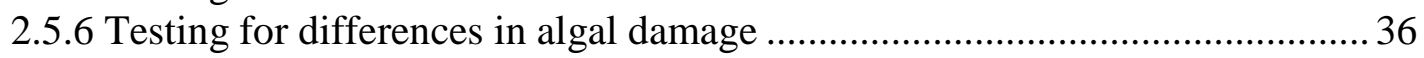

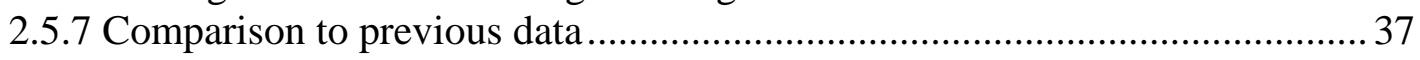

CHAPTER 3 - THE SOUTH COAST OF WELLINGTON ......................................38

3.1 Introduction...............................................................................................................39

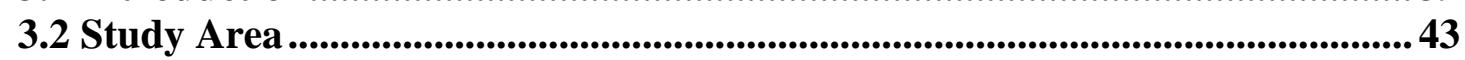

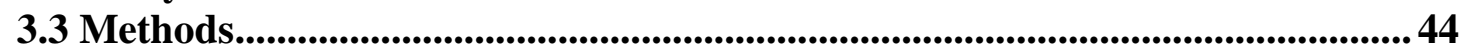

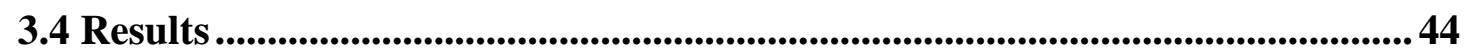

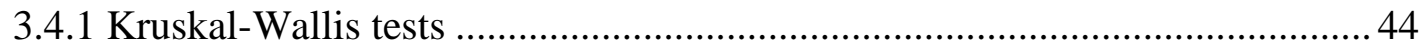

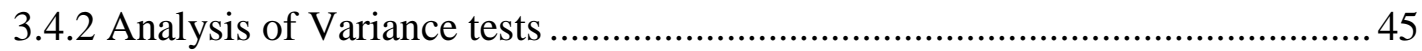

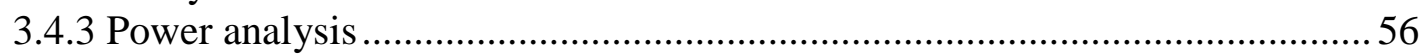

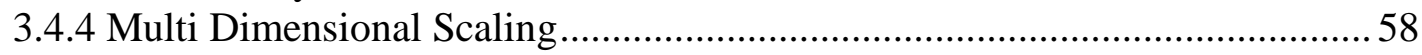

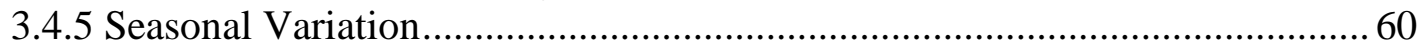

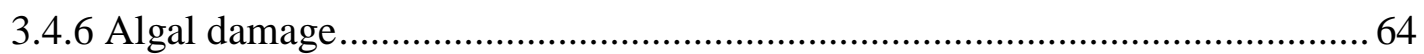

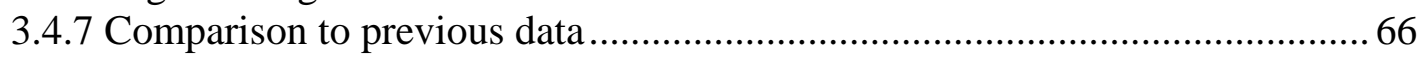

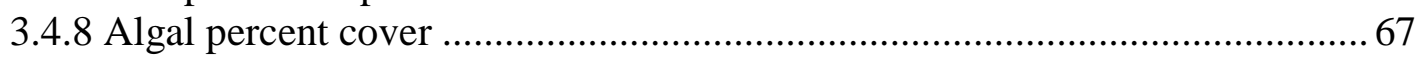

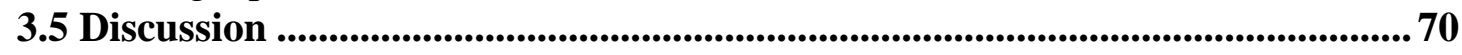

3.5.1 Site Similarity ...................................................................................................

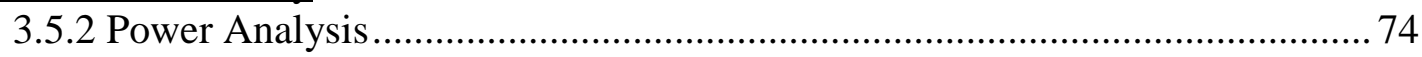

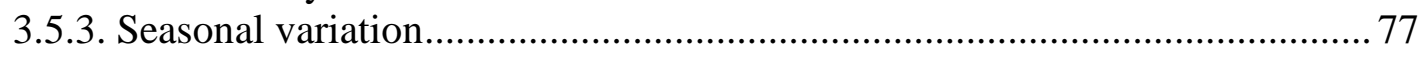

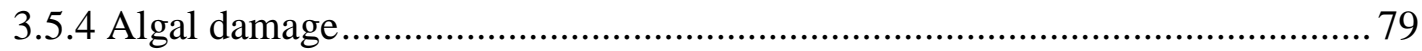




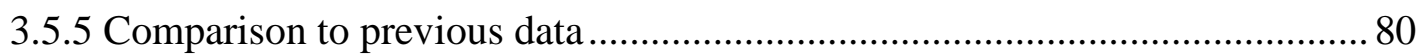

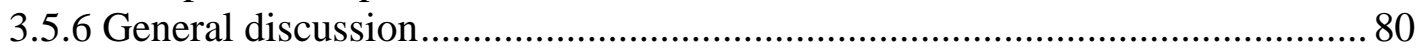

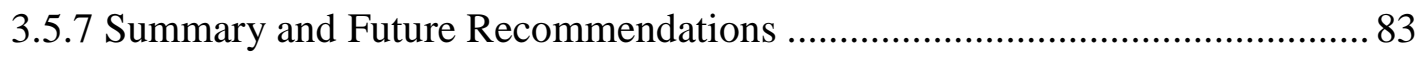

CHAPTER 4 - KAPITI MARINE RESERVE .......................................................84

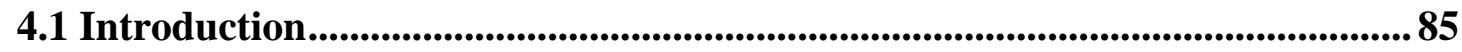

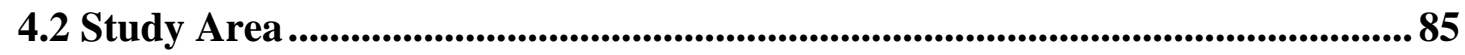

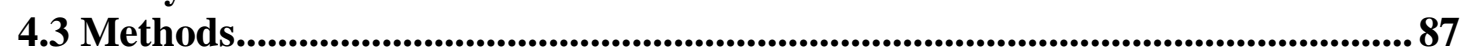

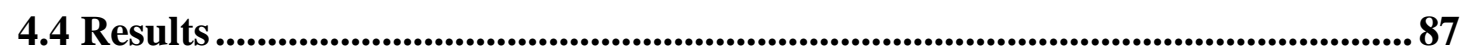

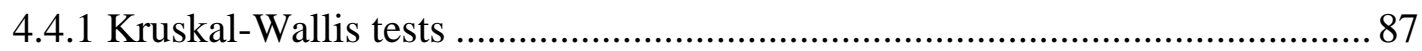

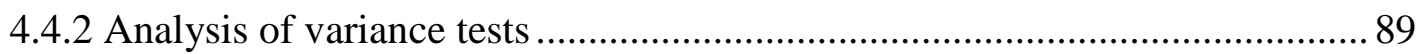

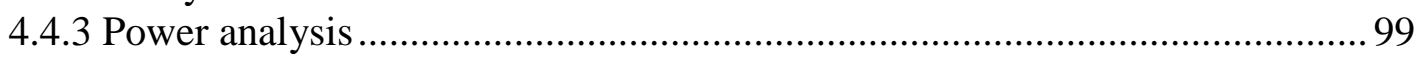

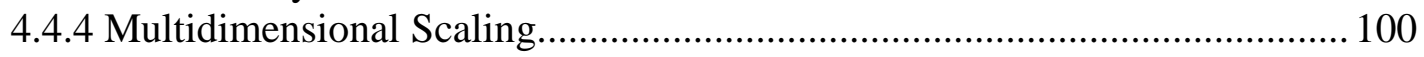

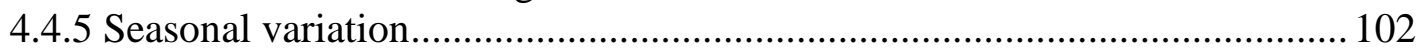

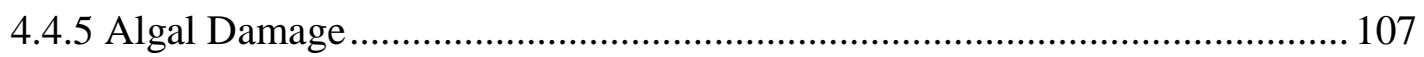

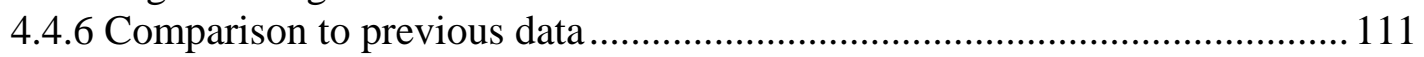

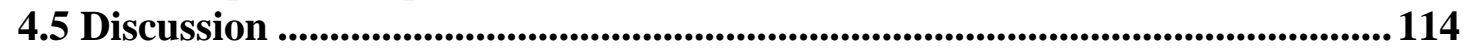

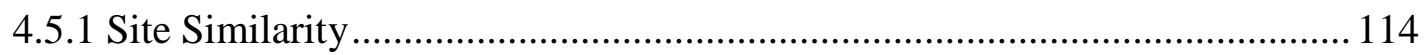

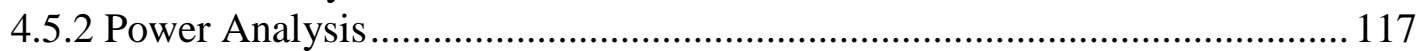

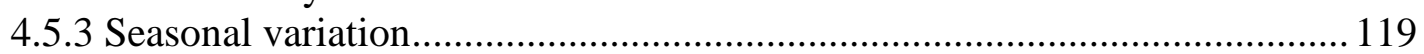

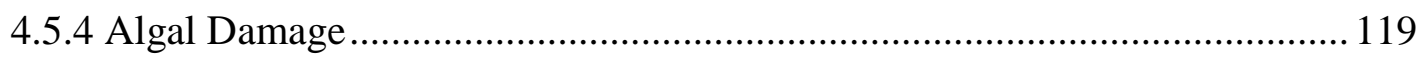

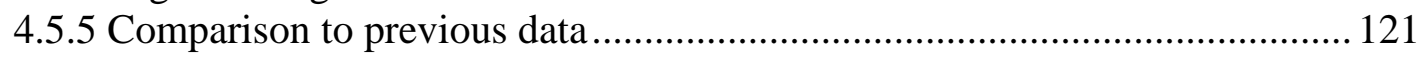

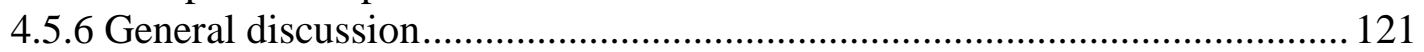

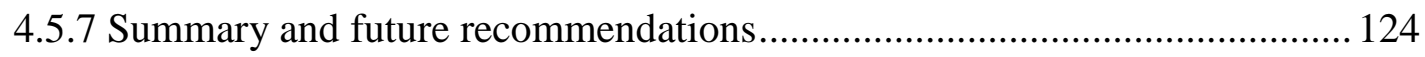

CHAPTER 5 - THE EFFECTS OF NEW ZEALAND MARINE RESERVES ON THE MEAN SIZE AND ABUNDANCE OF ROCK LOBSTER AND BLUE COD:

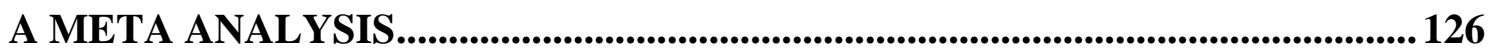

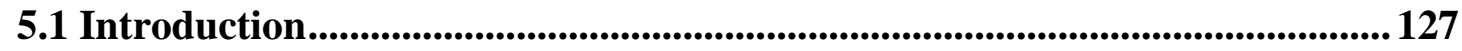

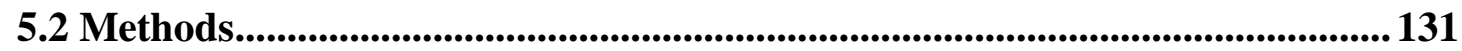

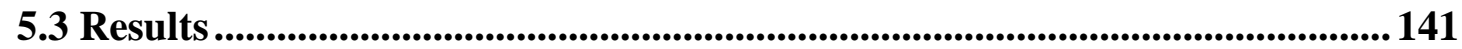

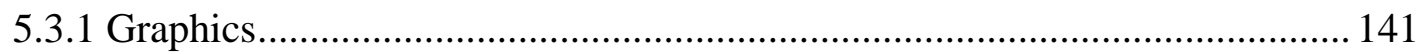

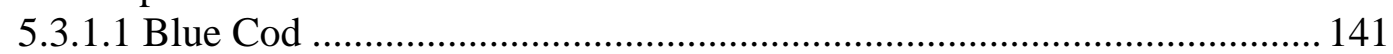

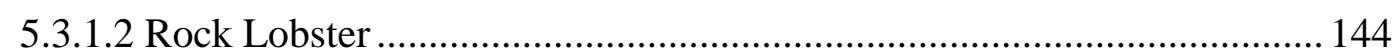

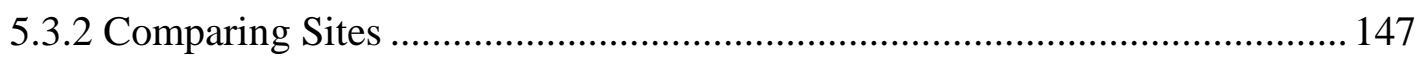

5.3.2.1 Blue cod abundance ..................................................................... 147

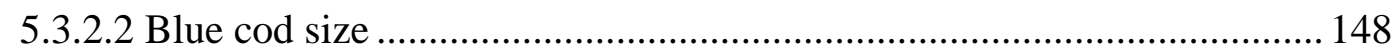

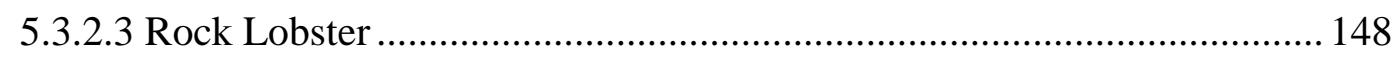

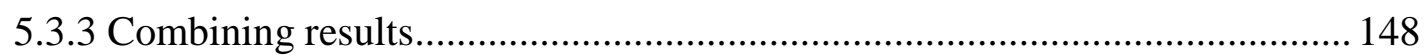

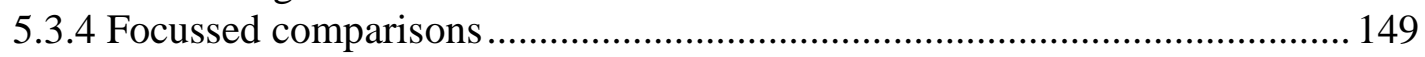

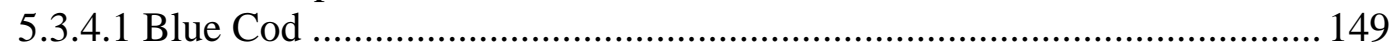

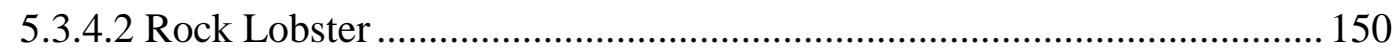

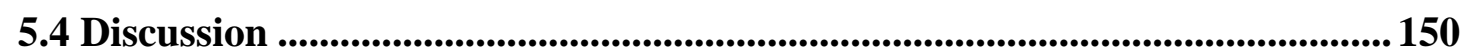

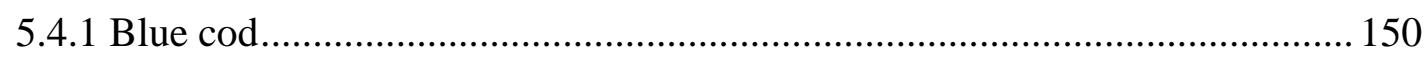

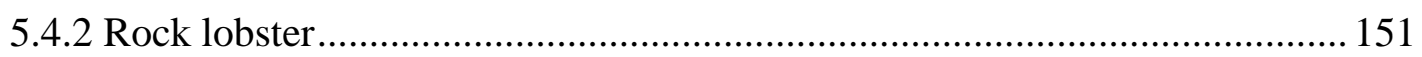

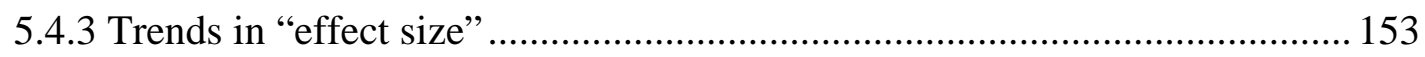

CHAPTER 6 - GENERAL DISCUSSION ................................................................. 156

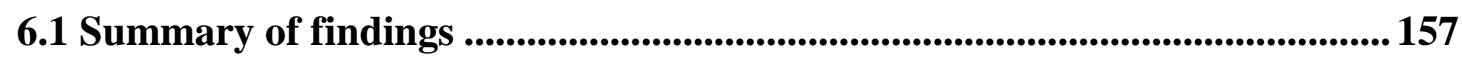

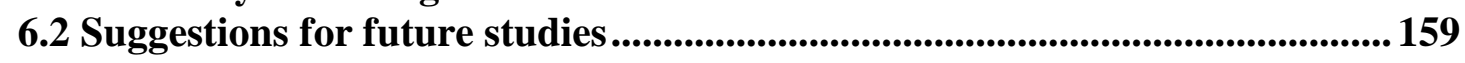

6.3 Specific Conclusions ............................................................................................. 162

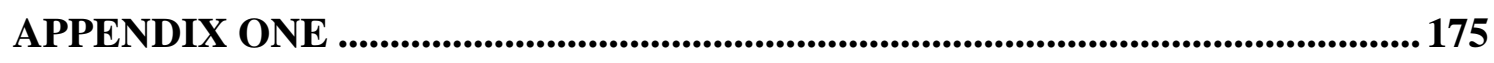




\section{LIST OF TABLES}

Table 1.1. Marine Reserves in New Zealand 3

Table 2.1. Sampling periods on the South Coast of Wellington. Alternate sampling periods shown by differing colours. 17

Table 2.3. Species surveyed on the Wellington South Coast........................................25

Table 2.4. Species surveyed at Kapiti Marine Reserve. 26

Table 3.1. Significant results (both before and after correction for multiple testing) from Kruskal-Wallis tests on differences in abundance (and size) among sites on the south coast of Wellington. 44

Table 3.2. Significant results (before and after correction for multiple testing) for ANOVA testing for differences among sites on the south coast of Wellington, on $\log _{\mathrm{e}}$ transformed count data.

Table 3.3. Average abundance $\left(\right.$ per $\left.\mathrm{m}^{2}\right) \pm$ standard error at each site on the south coast, for all the species for which ANOVA tests showed a significant difference in abundance among sites. Sites are arranged west to east. 46

Table 3.4. Significant results (before and after correction for multiple testing) of ANOVA testing for differences among sites on the Wellington south coast on square root transformed size data. 56

Table 3.5. Power of the data collected on the Wellington south coast to detect a change in species abundance.

Table 3.6. Results of 2 factor ANCOVA for spotty abundance on the Wellington south coast indicating which factors are significant in explaining variability.....

Table 3.7. Results of 2 factor ANCOVA for Kina abundance on the Wellington south coast, indicating which factors are significant in explaining variability....

Table 3.8. Results of 2 factor ANCOVA for Trevally abundance on the Wellington south coast, indicating which factors are significant in explaining variability....

Table 3.9. Results of 2 factor ANCOVA for Lessonia variegata on the Wellington south coast, indicating which factors are significant in explaining variability.....

Table 3.10. Results of 2 factor ANCOVA for Ecklonia radiata on the Wellington south coast, indicating which factors are significant in explaining variability....

Table 3.11. Results of 2 factor ANCOVA for Carpophyllum maschalocarpum on the Wellington south coast, indicating which factors are significant in explaining variability. 
Table 3.12. Results from a 3-factor ANCOVA for Lessonia variegata on the Wellington south coast, indicating the significance of each factor in the model.

Table 3.13. Results from a 3 -factor ANCOVA for Ecklonia radiata on the Wellington south coast, indicating the significance of each factor in the model

Table 3.14. Results of a 3-factor ANOVA for Carpophyllum maschalocarpum on the Wellington south coast, indicating the significance of each factor in the model.....65

Table 3.15. ANOVA results testing for differences in species abundance between 1997 and this investigation at Princess Bay.

Table 3.16. ANOVA results testing for differences in species abundance between 1997 and this investigation at the Yungh Pen.

Table 3.17. ANOVA results testing for differences in species abundance between 1997 and this investigation at the Sirens.

Table 3.18. Percent cover of algal species at Breaker Bay. .67

Table 3.19. Percent cover of algal species at Barretts Reef. .68

Table 3.20. Percent cover of algal species at Palmer Head. 68

Table 3.21. Percent cover of algal species at Princess Bay. 68

Table 3.22. Percent cover of algal species at The Sirens. 69

Table 3.23. Percent cover of algal species at the Yungh Pen. 69

Table 3.24. Percent cover of algal species at Red Rocks .69

Table 3.25. Percent cover of algal species at Sinclair Head .70

Table 4.1. Significant Kruskall-Wallis test results (before and after correction for multiple testing) after testing for differences in species abundance and size among sites at Kapiti Marine Reserve. .88

Table 4.2. Significant Kruskall-Wallis test results (before and after correction for multiple testing) after testing for differences in species abundance and size between reserve and control sites at Kapiti Marine Reserve. .88

Table 4.3. Significant ANOVA results (before and after correction for multiple testing)after testing for differences in species abundance among sites at Kapiti Marine Reserve.

Table 4.4. Average count values $\left(\right.$ per $\left.\mathrm{m}^{2}\right) \pm$ standard error, at each site at Kapiti Marine Reserve, for those species where ANOVA tests showed a significant difference in abundance among sites.

Table 4.5. Significant ANOVA results (before and after correction for multiple testing) after testing for differences in species abundance, using site nested with reserve as a factor. 
Table 4.6. Significant ANOVA results (before and correction for multiple testing) testing for differences in species abundance between reserve and control sites at Kapiti Marine Reserve. 95

Table 4.7. Significant ANOVA results (before and after multiple testing) from testing for differences in species size amongst sites at Kapiti Marine Reserve.

Table 4.8. Significant ANOVA results (before and after correction for multiple testing) from testing for differences in size, in reserve versus control sites at Kapiti Marine Reserve. 97

Table 4.9. Power of the data using the sampling regime in this investigation to detect a change in species abundance at Kapiti Marine Reserve.

Table 4.10. Results of 3-factor ANCOVA for scarlet wrasse at Kapiti Marine Reserve, indicating which factors are significant in explaining variability. 104

Table 4.11. Results of 3-factor ANCOVA for kina at Kapiti Marine Reserve, indicating which factors are significant in explaining variability. 104

Table 4.12. Results of 3-factor ANCOVA for spotty at Kapiti Marine Reserve, indicating which factors are significant in explaining variability. 105

Table 4.13. Results of 3-factor ANCOVA for Black foot paua at Kapiti Marine Reserve, indicating which factors are significant in explaining variability. .105

Table 4.14.Results of 3-factor ANCOVA for Carpophyllum maschalocarpum at Kapiti Marine Reserve, indicating which factors are significant in explaining variability.105

Table 4.15. Results of 3-factor ANCOVA for Ecklonia radiata at Kapiti Marine Reserve, indicating which factors are significant in explaining variability. 106

Table 4.16. Results of 3-factor ANCOVA for banded wrasse at Kapiti Marine Reserve, indicating which factors are significant in explaining variability.

Table 4.17. Results of 3-factor ANCOVA for blue cod at Kapiti Marine Reserve, indicating which factors are significant in explaining variability. 106

Table 4.18. Results of 3-factor ANCOVA for butterfish at Kapiti Marine Reserve, indicating which factors are significant in explaining variability.

Table 4.19. Results of a 4-factor ANCOVA for damage to Ecklonia radiata plants at Kapiti Marine Reserve, indicating which factors explain variability. 108

Table 4.20. Results of ANOVA testing for differences in species abundance, at Arapawaiti Point, between 1992 and this investigation.

Table 4.21. Results of ANOVA testing for differences in species abundance, at Onepoto Point, between 1992 and this investigation. 
Table 4.22. Results of ANOVA testing for differences in species abundance, at Kaiwharawhara Point, between 1992 and this investigation.

Table 4.23. Results of ANOVA testing for differences in species abundance, at Tokahaki Point, between 1992 and this investigation.

Table 4.24. Results of ANOVA testing for differences between 1992 and this investigation, in average species size at Arapawaiti Point.

Table 4.25. Results of ANOVA testing for differences between 1992 and this investigation, in average species size at Onepoto Point.

Table 4.26. Results of ANOVA testing for differences between 1992 and this investigation, in average species size at Kaiwharawhara Point.

Table 4.27. Results of ANOVA testing for differences between 1992 and this investigation, in average species size at Tokahaki Point.

Table 5.1. Marine Reserves in New Zealand. 130

Table 5.2. Studies used in blue cod meta-analysis. 132

Table 5.3. Studies used in rock lobster meta-analysis 133

Table 5.4. Distances of marine reserves used in this meta analysis from the North Cape.

Table 5.5. Summary of mean size and average abundance (per $\mathrm{m}^{2}$ ) values from each reserve and their respective control sites for blue cod.

Table 5.6. Summary of mean size and average abundance (per $\mathrm{m}^{2}$ ) values from each reserve and their respective control sites for rock lobster. 140

Table 5.7. Variables used in pictorial "time line" of marine reserves 141

Marine Reserve 141

Table 5.8. Comparison of "effect size" of marine reserves 147

Table 5.9. Combined results for blue cod abundance 149

Table 5.10. Results for a focussed comparison to test for a latitudinal trend (decreasing effect further south) in "effect size". 


\section{LIST OF FIGURES}

Fig. 1.1. Location of all Marine Reserves in New Zealand 4

Fig 2.1. Previous boundary proposals for the Taputeranga Marine Reserve. Sites chosen were based on the 1996 boundary proposal. .18

Fig. 2.2. Sites chosen to survey, on the Wellington south coast, in this investigation....19

Fig. 2.3. Sites Surveyed at Kapiti Marine Reserve in this investigation and by NIWA (1992). Numbered sites are sites surveyed in this investigation (also surveyed by NIWA), all other sites surveyed by NIWA only. Marine Reserve Boundaries are marked.

Fig. 3.1. Current boundary proposal for Taputeranga Marine Reserve. 41

Fig. 3.2. Line diagram showing the location of the significant differences among sites on the Wellington south coast for abundance of Carpophyllum maschalocarpum.

Fig. 3.3. Line diagram showing the location of significant differences among sites on the Wellington south coast for abundance of Ecklonia radiata. .47

(sites 1,2,3 and 6 are significantly different from sites 5,7 and 4)

Fig. 3.4. Line diagram showing the location of significant differences among sites on the Wellington south coast for abundance of Lessonia variegata.

Fig. 3.5. Line diagram showing location of significant differences among sites on the Wellington south coast for spotty abundance. .48

Fig. 3.6. Line diagram showing the location of significant differences among sites on the Wellington south coast for black foot paua abundance. .48

Fig 3.7. Line diagram showing the location of significant differences among sites on the Wellington south coast for kina abundance.

Fig. 3.8. Carpophyllum maschalocarpum abundance at all 8 sites on the south coast at each survey period. .50

Fig. 3.9. Ecklonia radiata abundance at all 8 sites on the south coast at each survey period.

Fig. 3.10. Lessonia variegata abundance at all 8 sites on the south coast at each survey period. .52

Fig. 3.11. Spotty abundance at all 8 sites on the south coast at each survey period........53

Fig. 3.12. Black foot paua abundance at all 8 sites on the south coast at each survey period. .54

Fig. 3.13. Kina abundance at all 8 sites on the south coast at each survey period. .55

Fig. 3.14. MDS of all 8 sites on the Wellington south coast using data from all species across all time periods. 
Fig. 3.15. MDS using fish abundance data only from all 8 sites on the Wellington south coast (across all time periods).

Fig. 3.16. MDS using invertebrate abundance data only from all the sites on the Wellington south coast (across all time periods).

Fig. 3.17. MDS using algae abundance data only from all 8 sites on the Wellington south coast (across all time periods).

Fig. 3.18. Actual sea surface temperatures recorded over the course of this study vs the average temperatures historically recorded.

Fig. 4.1. Line diagram showing significant differences in abundance among sites for Ecklonia radiata at Kapiti Marine Reserve..

Fig. 4.2. Line diagram showing significant differences in abundance among sites for banded wrasse at Kapiti Marine Reserve. .91

Fig 4.3. Line diagram showing significant differences in abundance among sites for blue cod at Kapiti Marine Reserve.

Fig. 4.4. Line diagram showing significant differences in abundance among sites for scarlet wrasse at Kapiti Marine Reserve. 92

Fig. 4.5. Line diagram showing significant differences in abundance among sites for kina at Kapiti Marine Reserve.

Fig. 4.6. Abundance of banded wrasse at all 4 sites at Kapiti Marine Reserve for each survey period.

Fig. 4.7. Abundance of blue cod at all 4 sites at Kapiti Marine Reserve for each survey period.

Fig. 4.8. Abundance of scarlet wrasse at all 4 sites at Kapiti Marine Reserve for each survey period.

Fig. 4.9. Abundance of kina at all 4 sites at Kapiti Marine Reserve at each survey period.

Fig. 4.10. Abundance of Ecklonia radiata at all 4 sites at Kapiti Marine Reserve for each survey period. .95

Fig. 4.11. Blue cod abundance at reserve and control sites at Kapiti Marine Reserve at each survey period. 96

Fig. 4.12. Banded wrasse abundance at reserve and control sites at Kapiti Marine Reserve at each survey period. .96

Fig. 4.13. Mean sizes for butterfish in reserve and control sites at Kapiti Marine Reserve at all survey periods. .98 
Fig. 4.14. Mean sizes for blue moki in reserve and control sites at Kapiti Marine Reserve at all survey periods.

Fig. 4.15. MDS of sites surveyed at Kapiti Marine Reserve using average abundance data from all species, across all time periods

Fig. 4.16. MDS of all sites surveyed at Kapiti Marine Reserve using average fish abundance data (across all time periods) only. 101

Fig. 4.17. MDS of all sites surveyed at Kapiti Marine Reserve using average algae abundance data (across all time periods) only. 101

Fig. 4.18. MDS of all sites surveyed at Kapiti Marine Reserve using average invertebrate abundance data (across all time periods) only. 102

Fig. 4.19. Actual sea surface temperatures recorded over the course of this study vs the average temperatures historically recorded. 103

Fig 4.20. Abundance of algal (Ecklonia radiata) damage at Arapawaiti Point, at all survey periods, at Kapiti Marine Reserve.

Fig. 4.21. Abundance of algal (Ecklonia radiata) damage at Onepoto point, at all survey periods, at Kapiti Marine Reserve.

Fig. 4.22. Abundance of algal (Ecklonia radiata)damage at Kaiwharawhara Point, at all survey periods, at Kapiti Marine Reserve.

Fig. 4.23. Abundance of algal (Ecklonia radiata) damage at Tokahaki Point at all survey periods at Kapiti Marine Reserve.

Fig. 5.1. Reserve size as a variable for effects on blue cod size. 142

Fig. 5.2. Age of reserve as a variable for effects on blue cod size. 142

Fig. 5.3. Location of reserve as a variable for effects on blue cod size. 143

Fig. 5.4. Reserve size as a variable for effects on blue cod abundance. 143

Fig. 5.6. Location of reserve as a variable for effects on blue cod abundance. 144

Fig. 5.7. Age of reserve as a variable for effects on rock lobster size. .144

Fig. 5.8. Reserve size as a variable for effects on rock lobster size .145

Fig. 5.9. Location of reserve as a variable for effects on rock lobster size. 145

Fig. 5.10. Age of reserve as a variable on the effects on rock lobster abundance 146

Fig. 5.11. Size of reserve as a variable for effects on rock lobster abundance. .146

Fig. 5.12. Location of reserve as a variable for effects on rock lobster abundance 147 
CHAPTER 1

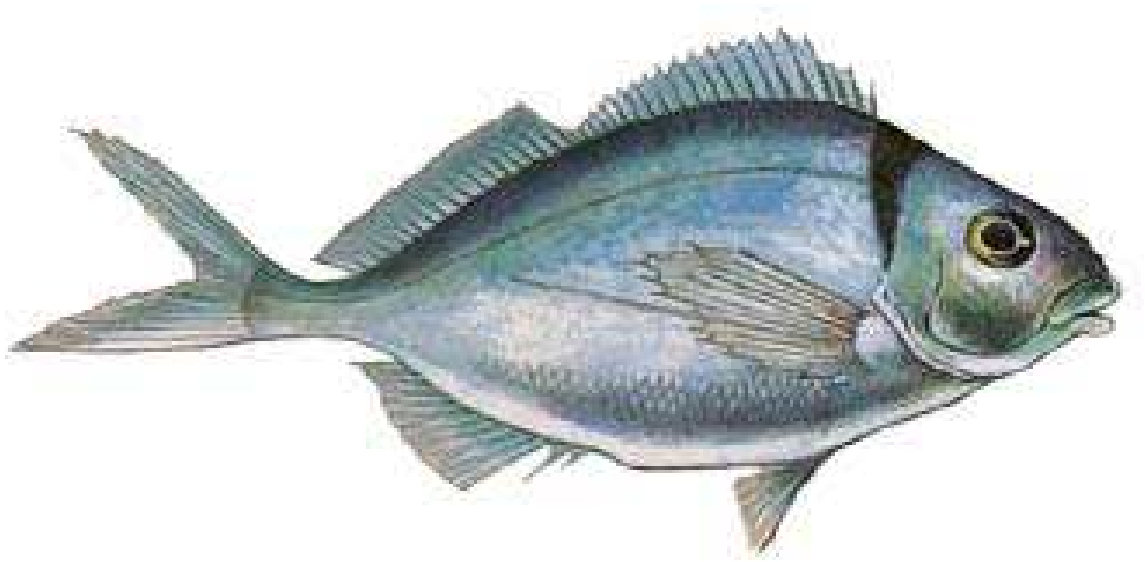

INTRODUCTION 


\section{CHAPTER 1 - INTRODUCTION}

\subsection{General Introduction}

Marine reserves in New Zealand, and in other parts of the world, are established for a variety of reasons, and under a variety of legislation. Unfortunately, little work has been done to establish baselines before the establishment of reserves, and consistent monitoring of effects inside and outside the reserves after their establishment is rare.

Marine reserves exist for many reasons such as research, conservation and fisheries management purposes (although to date the latter justification has not been cited as a reason for marine reserve establishment in New Zealand). Recent recognition of increased demands and profound human influence on marine resources has led to a strong impetus for marine conservation (Hockey and Branch, 1997, Lubchenco, 1997). The value of marine protected areas, particularly marine reserves, and the importance of gaining information on coastal marine environments is gradually being recognised by politicians, scientists, conservationalists, recreational and commercial fishers (Attwood et al., 1997a, Kingsford and Battershill, 1998, Conover et al., 2000). Concurrent with this increasing recognition is the crucial need to define and demonstrate the effect of marine reserves.

There is a growing interest in protecting representative parts of marine ecosystems as an insurance policy against a progressive degradation of the marine environment known as the 'precautionary principle' (Ballantine, 1994, 1995). This entails leaving an area undisturbed for their intrinsic worth for future generations, to provide reference points by which to evaluate effects of human activities on the environment and to increase an understanding of the ecosystem (Bohnsack, 1998) because the absence of scientific certainty should not be used as a reason for postponing measures to establish marine protected areas. If a marine reserve is 'no-take' then the reserve operates by allowing natural processes to survive and this provides a benchmark community that acts as a control against which to gauge human impacts in unprotected areas (Attwood et al., 1997a). Marine reserves therefore act as controls or natural baselines and are thus important, both for marine science and management of the marine environment (Ballantine,1994). A reserve provides an opportunity to study a habitat and populations with minimal human disturbance. Studying these areas creates a better understanding of 
natural ecological processes, and therefore allows more informed decisions about marine conservation (Creese and Jeffs, 1992).

For the purpose of the present investigation I will refer to marine reserves as being areas where all forms of extraction are banned (i.e no-take), following the New Zealand definition of 'marine reserve'. Cape Rodney-Okakari Point Marine Reserve was the first marine reserve in New Zealand and also one of the first established wordwide. It was lobbied for by local marine scientists and eventually established in 1977. This reserve has had a dramatic impact on the marine life and subsequently on the attitudes towards marine resource management (Ballantine, 1995, Roberts, 2000). Since 1977, 16 marine reserves of differing sizes have been established in New Zealand. See Table 1.1 and Fig. 1.1.

Table 1.1. Marine Reserves in New Zealand

\begin{tabular}{lll}
\hline Marine Reserve & Date of establishment & Size (ha) \\
\hline Cape Rodney-Okakari Point & 1977 & 518 \\
Poor Knights Islands & 1981 & 2400 \\
Kermadec Islands & 1990 & 748000 \\
Kapiti & 1992 & 2167 \\
Te Whanganui A Hei (Cathedral Cove) & 1992 & 840 \\
Tuhua (Mayor Island) & 1992 & 1060 \\
Long Island-Kokomohua & 1993 & 619 \\
Piopiotahi (Milford Sound) & 1993 & 690 \\
Te Awaatu (The Gut) & 1993 & 93 \\
Tonga Island & 1993 & 1835 \\
Te Tai Tapu (Westhaven or Whanganui & 1994 & 536 \\
Inlet) & & \\
Motu Manawa-Pollen Island & 1995 & 500 \\
Long Bay- Okura & 1995 & 980 \\
Te Angiangi & 1997 & 446 \\
Pohatu (Flea Bay) & 1999 & 215 \\
Te Tapuwae o Rongokako & 1999 & 2450 \\
\hline
\end{tabular}


Fig. 1.1. Location of all Marine reserves in New Zealand

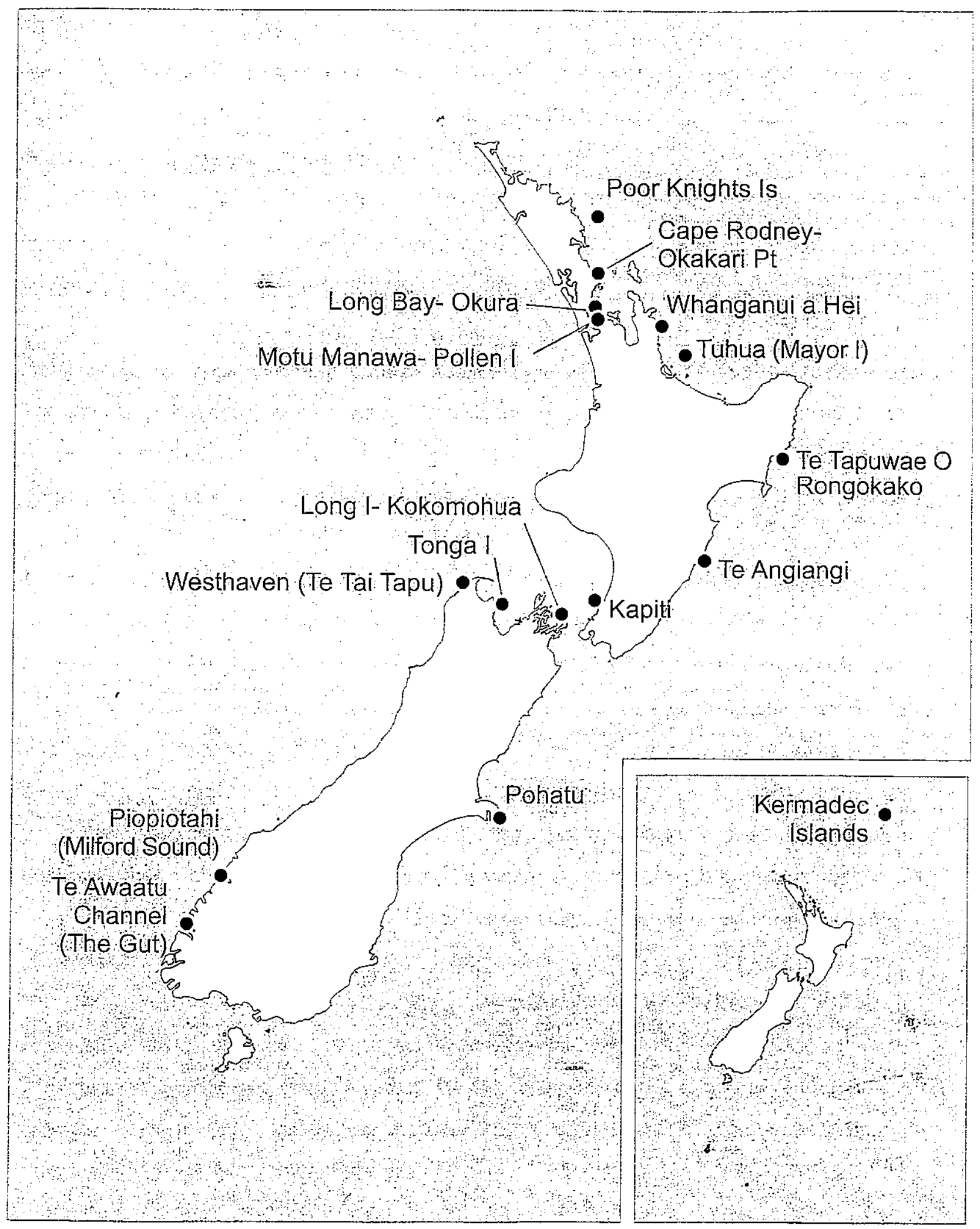


A marine reserve is generally expected to have a "positive" effect, through the protection of unique or endangered species, protecting breeding stocks and resulting in "spillover" of individuals into neighbouring areas (Jones et al., 1992). "Spillover", for example, occurs when individuals of a species increase both within and outside the reserve. Numbers increase outside the reserve as a result of fish moving out of the marine reserve, because the protection has allowed fish stock size to increase (Agardy, 2000). Russ and Alcala (1996) found evidence of "spillover" in the Phillipines, where two small marine reserves around islands were shown to increase fish yields in adjacent areas also. Abundance of large predatory fish were measured both inside and outside the marine reserve areas over the course of several years, during which time the reserves were alternately open and closed to fishing for varying periods. Results from this study indicated that the abundance of large predatory fish increased in areas both inside and outside the reserve, following periods of protection from fishing. Subsequently, the abundance of predatory fish declined both within and outside the reserve during times when the reserve was opened to fishing. These results implied that the increasing abundance of fish in the control areas was directly linked to the even larger increase in biomass inside the reserve. This is supported by a study of the Mombasa Marine National Park in Kenya, where catch per unit effort (CPUE) in fishing areas adjacent to the marine reserve increased by $110 \%$ (MacClanahan and Kaundra-Arara, 1996). In another example of the positive effects of protection, Kelly et al. (2000a) compared catch rates around the local Cape Rodney-Okakari Marine Reserve with adjacent unfished areas and confirmed that lobsters from the protected area 'spilled over' into the surrounding fished areas. This phenomenon maintained catch rate levels similar to those of adjacent fishing areas (by fewer, but larger lobsters), thus indicating that opposition to marine reserves on the basis that catch of lobsters would be reduced, is unfounded. Kelly et al. (2000a) suggested that reservation ultimately benefited the fishery, because protection allowed lobster size, abundance and egg production to increase, thereby increasing spawning stock biomass and providing a buffer against recruitment failure. Studies such as that by Russ and Alcala (1996) and MacClanahan and Kaundra-Arara (1996) support this theory. This is why marine reserves are often touted as fisheries management tools, as the theories of "spillover" and marine reserves as "harvest refugia" imply that marine reserves will help sustain local fisheries.

The theory of "Harvest Refugia" has been cited as another potential benefit of marine reserves, by increasing spawning stock biomass, increasing larval recruitment and 
dispersal, and thus enhancing regional fisheries (Chiappone and Sealey, 2000). Chiappone and Sealey (2000) found evidence that the Exuma Cays Land and Sea Park in the Bahamas, which has been closed to fishing since 1986, was an important source of larval export to adjacent areas, but few data showed evidence of adult emigration or "spillover". Kelly et al. (2000b) stated that increased lobster egg production definitely occured within reserves, but that it may be difficult to determine what impact, if any, this would have on recruitment levels, as stock-recruitment relationships are very difficult to demonstrate. Despite this issue, the authors stated that a system of marine reserves may be a prudent management strategy to ensure that adequate lobster spawning biomass is maintained. This means that the siting and design of marine reserves should incorporate consideration of larval dispersal distances, and protection of larval habitat (Warner et al., 2000).

The possibility of wider benefits of reservation, resulting from a network of marine reserves representing all different types of marine habitats is currently being advocated (Ballantine, 1994, 1997, 1998). Most political parties in New Zealand now propose protection of $10 \%$ of the New Zealand coastline to ensure adequate representation of all marine habitats. The Reef Fishing Plan Development Team in the USA also recommended closing $20 \%$ of the shelf area of the USA to fishing (Roberts, 2000). The theory of marine networks came about because a large number of marine species have a planktonic or larval phase which are highly dispersive (unlike species in terrestrial reserves), so a single marine reserve is therefore unlikely to be self sustaining (i.e. if single reserves have a large amount of spillover and larval export, then fish stocks may not build up inside the reserve in order to maintain the population and the current rate of export). A system or network of marine reserves can be self sustaining and turn remote dispersal into an advantage. In terrestrial reserves, single large reserves may allow sufficient volume of plant seeds and spores to be dispersed that the reserve will be self sustaining and indeed export these outside the reserve. However, in the marine environment, single marine reserves are likely to produce increases in spawning biomass and fertilisation rates (both via increase in density and size), which in combination are likely to enhance recruitment somewhere downcurrent. The idea behind a network of reserves is not just to supply these extra recruits, but to provide a place for them to settle and somehow "magnify" the effect (Ballantine, 1997). This is possible because the 'connectivity' of water allows these small dispersive propagules to migrate from one reserve to another. The more reserves there are in the network and the less distance 
between them, the greater the 'hit' rate of the dispersing organisms (Roberts and Hawkins, 2000). This "single large or several small" (SLOSS) reserves debate exists both in terrestrial and marine conservation ecology and must be considered when designing marine reserves and what sizes, shapes and systems will be most effective (Allison et al., 1998, Agardy, 2000). This network policy therefore takes into account the importance of protecting contiguous habitat used by different life stages of target species, protecting spawning stock biomass to facilitate the dispersal of larvae and linking marine reserves by physical processes (Chiappone and Sealey, 2000). Currently most marine reserves in New Zealand are clustered in the north of the North Island, so to create a network of marine reserves around New Zealand that is self sustaining, reserves must be well spread throughout the coastline.

Other criteria for "success" have been shown by marine reserves in New Zealand, Tasmania, South Africa and Kenya, all of which show evidence for increasing species size and abundance within each reserve (Buxton and Smale, 1989, Cole et al., 1990, Jones et al., 1992, MacDiarmid and Breen, 1992, Attwood et al., 1997a, Edgar and Barrett, 1997, Edgar and Barrett, 1999) but often the outcome of a marine reserve in terms of species diversity and composition are different from that expected (Jones et al., 1992). The definition of "success" of a marine reserve depends largely on the objectives for which it was established (Conover et al., 2000). There are "successful" marine protected areas in Thailand, USA, Kenya, Australia and South Africa where these are designed not to exclude human usage (i.e. fishing), but to protect coral reefs (Attwood et al., 1997a).

Marine reserves have been created in more than 20 different countries (including, amongst others New Zealand, Tasmania, Australia, South Africa, USA and Belize). The terminology and the level of protection of these, however, has not been standardised. In Britain, for example, 'marine reserves' and in the USA 'marine sanctuaries' allow fishing as normal unless there are some specific regulations made to the contrary. Most of the literature discusses 'marine protected areas', which are effectively any part of the sea where special regulations to protect biotic and abiotic resources might apply (Ballantine,1997, Attwood et al., 1997a). As a result, a variety of legislation has been developed internationally under which marine protected areas can be established (Attwood et al., 1997b). Within New Zealand there is a continuum of protection ranging from total 'no-take' to selective management by specific regulations. 
The current Marine Reserves Act (MRA, 1971) in New Zealand focuses on establishing marine reserves for scientific study, not specifically for conservation or as a fisheries management tool. This Act is currently under review, to potentially refocus the MRA as a protection mechanism and remove the focus on scientific study, amongst other issues (DOC (Department of Conservation) publication, 2000). Other 'marine protected areas', that are not marine reserves, in New Zealand include the Tawharanui Marine Park and the Mimiwhangata Marine Park. These are designed to conserve certain aspects (such as specific species, or a unique habitat) of the area, and restrictions or specific guidelines can apply to some or all activities, such as fishing or mining, that might occur in these areas. Marine Parks were established under a variety of legislation, including the Resource Management Act, the Fisheries Act and the Harbours Act, as a one-off, specific legislation for that particular area, so are unlikely to be established in the same way again. (DOC publication, 2000). The Sugarloaf Islands Marine Protected Area and the Hauraki Gulf Marine Park are one-off marine protected areas managed under placespecific laws. Restrictions vary and are specific to each Act. There are two marine mammal sanctuaries in New Zealand, established under the Marine Mammals Protection Act (1978). These protect only particular marine mammal species within each area. They are situated in the subantarctic Auckland Islands, where New Zealand sea lions and southern right whales are protected, and Banks Peninsula in mainland South Island. The latter includes bans on set nets to protect the rare endemic Hector's dolphin. Other legislation in New Zealand includes restrictions on fishing in certain areas and Regional Coastal Plans which under the Resource Management Act (1992) must address issues such as preservation of the natural character of a given area and limitations on adverse environmental effects. Specific to New Zealand are also 'Taiapure' areas, where specific rules apply to all, but because they are recognised to be traditionally important to local iwi (tribe), are managed by a committee (empowered by the fisheries act) who are nominated by the local Maori community. Lastly, 'Mataitai' reserves are areas where the tangata whenua (people of the land) are recognised to have a special relationship with the place. These too are managed by a Maori committee, and commercial fishing is banned.

As one can see that the justification for establishing marine reserves can be difficult to define, not just because of the complex biological and physical factors, but also the social factors that must be considered (Bohnsack, 1997). For example goals of a "better understanding of a marine ecosystems" or "protecting areas for their intrinsic worth" will 
meet with resistance from those who rely on fisheries for their sole livelihood, and for these reasons the practical benefits of marine reserves will need to be 'proven' before they can be widely used (Bohnsack, 1997).

It is critical, but difficult to demonstrate the effects and benefits of marine reserves. Jones et al. (1992) stated that worldwide "the current ad hoc approach to the establishment and monitoring of marine reserves has made interpretation of the ecological effects of marine reservation difficult." Field investigations vary in quality and studies are often confounded by intrinsic ecological differences between sites investigated inside and outside reserves, lack of site and reserve replication, and the lack of information about the biota as it existed at the time of reserve establishment (Edgar and Barrett, 1999). This ad hoc approach is at least in part due to the fact that siting of marine reserves is not always purely on the basis of scientific criteria, but often the boundaries are defined by a "complex mix of aesthetics, opportunism, a little science and a large helping of compromise" (Roberts, 2000). This may lead to suboptimal performance of the reserve and disorganised monitoring regimes. For example, the reserves may be very small, thus not protecting a large enough area of a certain habitat to allow adequate replication of sample sites or the habitat they protect may not be represented as control (unprotected) areas in the immediate vicinity, which are necessary as a comparison. In New Zealand, despite the stipulation of the MRA (1971) requiring marine reserves to be established for scientific research objectives, this is rarely the driving force behind the establishment of a marine reserve. Even if the original proposal was justified under these criteria, the power of the Minister of Conservation to move boundaries at will, means the end result rarely resembles the original proposal. An example of this was the establishment of the Tonga Island Marine Reserve in Abel Tasman National Park, New Zealand. The preferred option by the Department of Conservation scientists for the marine reserve boundaries was to include Separation Point, an area known to support a large rock lobster population and five areas of ecological interest to protect (Davidson and Chadderton, 1994, Abel Tasman National Park Marine Reserve discussion documents). These points of interest are Separation Point horse mussel bed, Separation Point high current area, part of the Separation Point bryozoan 'coral' beds, Totoranui high current habitat and the Totaranui rhodolith (calcified algae) bed. However, due to high recreational fishing usage of this area there was a strong objection to this area becoming 'no-take' from the local community, such that Tonga Island was the compromise agreed upon (Andrew Baxter, pers. comm., Abel Tasman National Park Marine Reserve discussion documents). 
Baseline studies are those that collect data to define the present state of species assemblages in an area (Kingsford and Battershill, 1998). In the case of a marine reserve investigation, a baseline study would be the "before" part of a BACI (Before, After, Control, Impact) study, the impact being the establishment of the marine reserve. In a review of the effects of marine reserves on reef fisheries, Roberts and Polunin (1991) did not find any studies that included quantitative data on the biota of reserves prior to their establishment, and most of the published studies compared only one site within the reserve to one site outside. From the literature, my own observations and conversations with colleagues in New Zealand, very few marine reserves were monitored before their establishment. For those areas that were investigated before reservation status, work was generally restricted to short one-off investigations. For example, Kapiti Marine Reserve, New Zealand, was surveyed in January 1992, before its official establishment in April 1992 (Battershill et al., 1993). For the Long Island-Kokomohua Marine Reserve (New Zealand), blue cod (Parapercis colias) abundance data was collected in March 1992 and March 1993, while invertebrate datasets and lobster counts were also collected in March 1992, before its establishment in April 1993. Subsequent sampling was all after establishment of the reserve (Davidson, 1995, 1997, in submission, pers. comm.). A baseline survey was planned for Pohatu Marine Reserve, but due to adverse weather conditions the first survey at this reserve was carried out one year after its establishment (R. Davidson pers. comm.). Halpern (in press) as part of the NCEAS (National Centre for Ecological Analysis and Synthesis) in a review of effects of marine reserves indicated that the biological responses to protection were rapid, becoming evident in 1-2 years after reserve establishment. Since the marine environment has been shown to respond so swiftly to reservation status, it is even more imperative that long term baseline surveys be conducted before the establishment of the reserve and not be left until after reservation status has been conferred to an area.

However, inadequate baseline surveys can lead to poor monitoring of marine reserves. Monitoring refers to repeated sampling over time, where the replication should be adequate to detect variation over both short and long time spans, and the sampling should be at more than one location (Kingsford and Battershill, 1998). Without adequate baseline data of a proposed reserve area, it is difficult to establish the effect of reservation (i.e. data points outside the normal range of environmental variability), or to determine the magnitude (i.e. the scale by which data points are outside the normal range of 
environmental variability) of this effect. Studies investigating the effectiveness of a marine reserve usually involve the comparison of a reserve with a control area. This is a way of trying to establish whether the communities inside the reserve area differ significantly from those in a similar habitat outside a reserve area. Therefore, the areas being compared must be identical in habitat type and physical oceanography (i.e. currents, wave exposure and water temperature) so as not to confound the results. This gives an indication of a reserve effect, however without the a priori data, one may then run the risk of attributing reserve effects to a natural spatial variation, or natural variability or patchiness of populations. Garcia-Charton and Perez-Ruzafa (1999) described the spatial heterogeneity of selected Mediterranean rocky reefs to illustrate how the "reserve effect" can be confounded by a "habitat effect". The authors stated that organisms show a heterogeneous distribution at various spatial scales, from 10's to 1000 's of metres. To my knowledge there is no literature indicating any knowledge of inherent spatial variation existing in an area of an established marine reserve.

There have been many studies conducted on the effects of marine reserves on particular species (e.g. Cole et al., 1990, MacDiarmid and Breen, 1992, Creese and Jeffs, 1993, Russ and Alcala, 1996, Davidson, 1997, Edgar and Barrett, 1997, Babcock et al., 1999, Chapman and Kramer, 1999, Cole et al., 2000, Kelly et al., 2000a). Each of these studies has been conducted using methodology tailored to the species and the marine reserve in question. The choice of study animal has often been influenced by whether it is commercially, recreationally or culturally important or to a lesser extent whether it represents a keystone species (i.e. Key species influencing habitat or community structure). Key species studied in New Zealand, have been common edible reef fish, especially those of commercial value, such as snapper (Pagrus auratus) and blue cod (Parapercis colias), and rock lobster (Jasus edwardsii), which is also a commercially valuable species. Kina (New Zealand name for sea urchin, Evechinus chloroticus), although commercially less important, have often been investigated as they may be a keystone species. It has been shown in the literature that they can have dramatic effects on the surrounding habitat when present in large numbers, and a change in their abundance within a reserve area has shown a corresponding change in habitat. For example, the relationship between algae and echinoids (dominant invertebrate herbivores) is described as straightforward and abrupt by Choat and Schiel (1982). The authors described how whole forests of algae can be removed, resulting in considerable changes in the community composition. Post reserve establishment, the densities of kina 
decreased inside the Cape Rodney-Okakari Point Marine Reserve, in areas where this species formerly dominated. Consequently, the kelp forests (mainly Ecklonia radiata and Carpophyllum sp.) became more extensive inside the reserve and rock flat urchin barrens (an area almost completely denuded of kelp due to kina grazing) occupied less of the reef substratum as compared to control areas. This decrease in kina abundance and subsequent change to the habitat is attributed to higher levels of predation (by snapper and rock lobster) on kina inside the marine reserve. A shift in community structure such as this, is an indirect effect of reservation, due to increased numbers of the top predators (Babcock et al., 1999, Shears and Babcock, 2000). However, without documentation of the habitat and species assemblages in the reserve before its establishment this conclusion was based purely on investigations comparing control and reserve sites, or data collected at different time periods after reservation status. This is not nearly as robust as a data set that could/should have been collected prior to reservation.

The present investigation is, to my knowledge, the first time detailed baseline data has been collected and evaluated to adequately describe an area before reservation. Since the methodology for continued monitoring of this area post reservation, has now been established, accurate comparisons of habitat and species composition change such as that described above can be made in the future, thus establishing a more accurate "reservation" effect. This combined with evaluation of the effect or "success" of an established marine reserve has enabled me to make recommendations on future national monitoring protocols. Using a statistical meta-analysis I have trialled a new way to evaluate effects of marine reserves in general.

\subsection{Study aims}

The aims of this investigation were threefold:

a) To create a detailed baseline for a proposed marine reserve area (i.e. the Taputeranga Marine Reserve located on the south coast of Wellington, New Zealand). This included gathering quantitative data on an assemblage of species and testing for heterogeneity along the coastline. This will enable the effects of the marine reserve in the future to be identified without being confounded by any natural spatial variability that already exists. This information was also used to establish the most appropriate monitoring regime for this area, should it continue to be monitored in the future. 
b) To investigate the effects of an established marine reserve (i.e. Kapiti Marine Reserve). This included monitoring sites both inside and outside the marine reserve. These data were then used to test for differences in species abundance and size inside and outside the reserve (i.e. to test for changes in the Kapiti Marine Reserve).

c) To carry out a meta-analysis of several marine reserves in New Zealand in order to come to a generalised conclusion about the effects and prospects of marine reserves. This is a statistical way of combining many studies using the same "treatment" to evaluate the effect of this "treatment" overall. This has never been applied to studies of marine reserves before.

\subsection{The layout of this thesis}

Each of the three aims stated above has been described in a separate chapter, to allow for ease of publication at a later date. Chapter Two describes the sampling and analytical methodology used in both Chapters Three and Four. Since the methodology was virtually identical I hoped to reduce repetition for the reader by amalgamating this into a single chapter. Logistical problems in monitoring marine reserves have also been addressed. Chapter Three addresses the findings from analysis of the baseline data gathered for the south coast of Wellington. Suggestions are made for future monitoring protocols. Chapter Four deals with the effects of the Kapiti Marine Reserve, as based on data gathered in this study. Chapter Five presents the results from the meta analysis on two key species looked at from six different marine reserves in New Zealand.

Each chapter has a brief introduction appropriate to the particular investigation, an outline of the study area, results and a discussion of the results found. Due to the interlinked nature of these topics there has been parts where unavoidable repetition in the introduction and discussion of these chapters has occurred. Where possible I have made reference to previous chapters where common themes exist.

Chapter Six consists of a summary overview and conclusions focussing on the findings from the previous three chapters. It discusses the future of marine reserves in New Zealand, stressing the importance of baseline studies and how best to apply them. I present some of my own ideas of potential ways to monitor marine reserves in the hope that comparing marine reserves nationally and learning from each case can be made a 
little easier. Specific conclusions relating to future monitoring of the Taputeranga and Kapiti Marine Reserves are outlined. 
CHAPTER 2

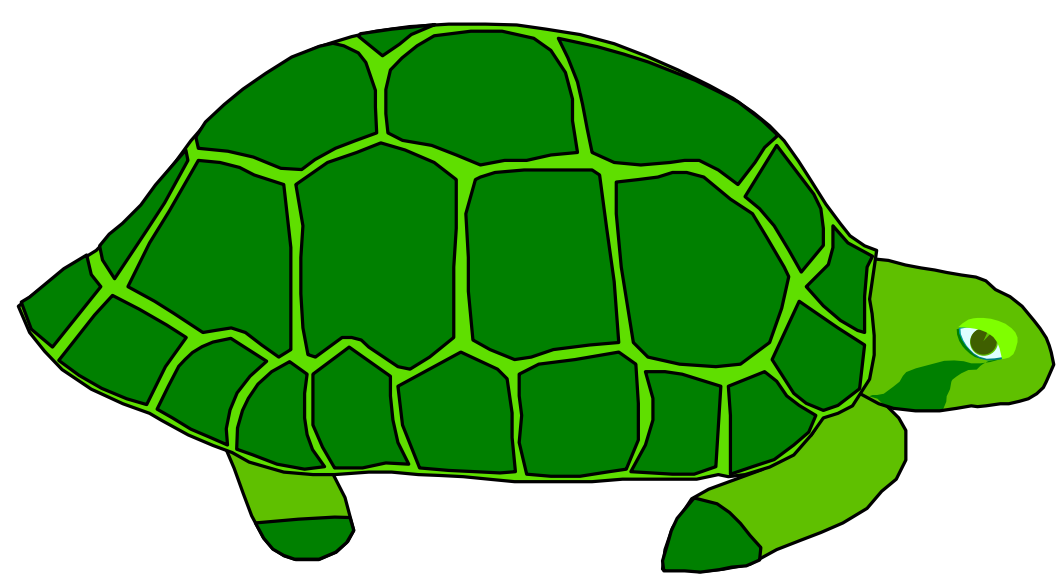

METHODS 


\section{CHAPTER 2 - METHODS}

Detailed information about the Wellington south coast and Kapiti Marine Reserve is found in chapters Three and Four respectively. Methodology used was identical, so it is described here to avoid later repetition. Slight differences in statistical analyses are described in section 2.5 in this chapter.

\subsection{Site Selection - South Coast}

In 1998, at the start of this investigation, sites were selected to incorporate an equal number of sites both within and outside the proposed reserve area. The sites outside the reserve were to act as a spatial control. An equal number of reserve and control sites should be surveyed as this gives a statistically balanced design and multiple impact and control sites also provide a true representation of an "average" response or an "average" normal variation (Jennifer Brown, pers.comm., Edgar and Barrett 1997, Underwood 1981)

The sites chosen on the South Coast were based on the proposed boundaries of the Taputeranga Marine Reserve at the beginning of the study (Fig 2.1. - 1996). (See Chapter Three for further explanation). This proposal stated that the reserve would include everything from the first point within the Quarry gates to Palmer Bay and it would extend $2 \mathrm{~km}$ offshore. The sites chosen were (from west to east):

Sinclair Head, Red Rocks, Yungh Pen, The Sirens, Princess Bay, Palmer Head, Breaker Bay and Barretts Reef. (Fig 2.2)

Red Rocks, Yungh Pen, The Sirens and Palmer Head were all sites that would have been inside the proposed marine reserve boundaries. The other four sites were selected to be used as controls after establishment of the reserve.

Surveys were undertaken as often as feasible each year, working within constraints of weather and also equipment and personnel availability.

All eight sites were investigated on a total of 11 sampling events, over a three year period. These were carried out on the following dates: Jan-Feb 1998, Sep-Dec 1998, Jan 1999, March 1999, May-July 1999, Sep-Oct 1999, Nov 1999, Feb 2000, April 2000, June 2000 and Dec 2000. See Table 2.1. 
Table 2.1. Sampling periods on the South Coast of Wellington. Alternate sampling periods shown by differing colours.

\begin{tabular}{llllll}
\hline $\mathbf{1 9 9 8}$ & $\begin{array}{l}\text { Survey } \\
\text { Code }\end{array}$ & $\mathbf{1 9 9 9}$ & $\begin{array}{l}\text { Survey } \\
\text { Code }\end{array}$ & 2000 & $\begin{array}{l}\text { Survey } \\
\text { Code }\end{array}$ \\
\hline January & S-1998-1 & January & S-1999-1 & January & \\
February & & February & & February & S-2000-1 \\
March & & March & S-1999-2 & March & \\
April & & April & & April & S-2000-2 \\
May & & May & S-1999-3 & May & \\
June & & June & & June & S-2000-3 \\
July & & July & & July & \\
August & & August & & August & \\
September & S-1998-2 & September & S-1999-4 & September & \\
October & & October & & October & \\
November & & November & S-1999-5 & November & \\
December & & December & & December & S-2000-4 \\
\hline
\end{tabular}


Fig. 2.1. Previous boundary proposals for the Taputeranga Marine Reserve. Sites chosen were based on the 1996 boundary proposal.

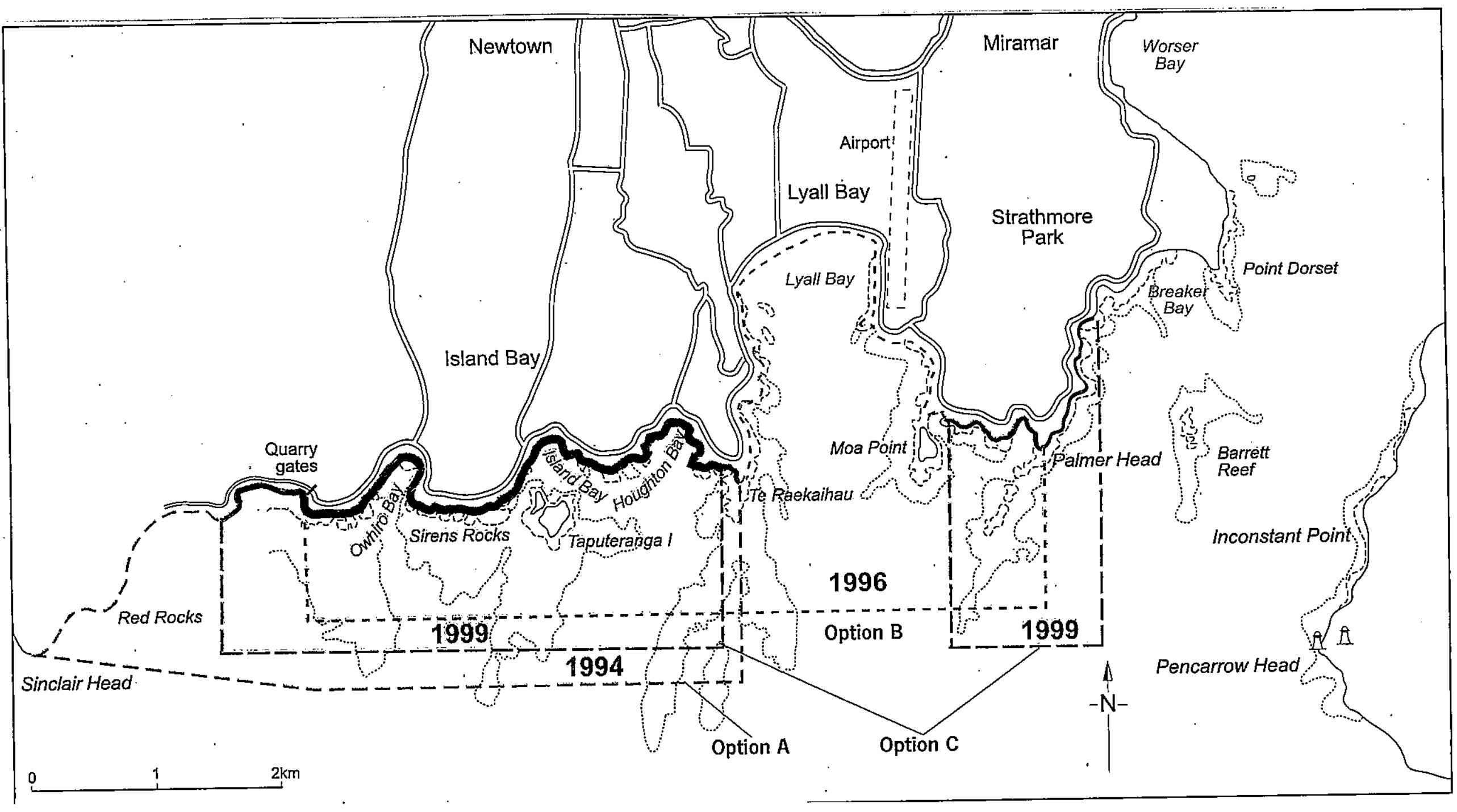


Fig. 2.2. Sites chosen to survey, on theWellington south coast, in this investigation.

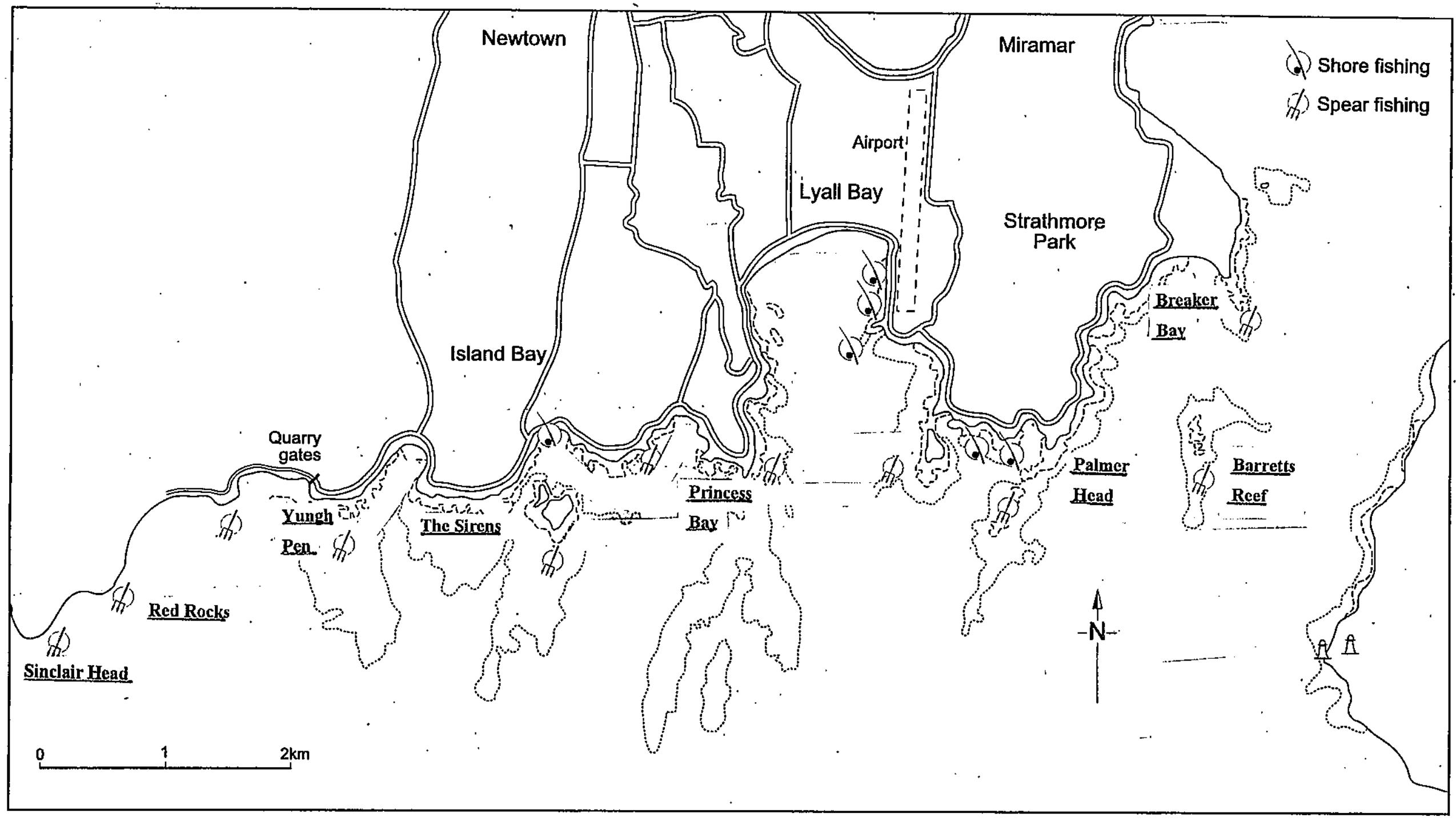




\subsection{Site Selection - Kapiti Marine Reserve}

As with the south coast of Wellington, sites were selected to incorporate an equal number of sites both within and outside the reserve area. The sites outside the reserve were to act as a spatial control and to enable comparisons of changes in species abundance and size in reserve sites in relation to changes at control sites. Similarly, as with the south coast of Wellington, an equal number of reserve and control sites were surveyed to give a statistically balanced design (see section 2.1). These sites were chosen based on the Battershill et al. (1993) preliminary survey carried out in 1992 (See Chapter Four for further information) (See Fig. 2.3.). All sites selected for this investigation had been surveyed by NIWA in 1992. Thus the NIWA survey served to provide some comparison of the area before it became protected.

The sites chosen were Kaiwharawhara Point and Tokahaki Point as control sites and Onepoto Point and Arapawaiti Point as reserve sites. (See Fig. 2.3.).

Surveys were undertaken as often as feasible each year, working within constraints of weather and also equipment and personnel availability. All four sites were investigated at a total of 12 sampling events, over three years. These were carried out on the following dates: July-Sep 1998, Feb 1999, March 1999, April 1999, Sep 1999, Oct 1999, Jan 2000, March 2000, May 2000, July 2000, Sep 2000 and Nov 2000. See Table 2.2. 
Table 2.2. Sampling periods at Kapiti Marine Reserve. Alternate sampling periods shown by differing colours.

\begin{tabular}{|c|c|c|c|c|c|}
\hline 1998 & $\begin{array}{l}\text { Survey } \\
\text { Code }\end{array}$ & 1999 & $\begin{array}{l}\text { Survey } \\
\text { Code }\end{array}$ & 2000 & $\begin{array}{l}\text { Survey } \\
\text { Code }\end{array}$ \\
\hline January & & January & & January & K-2000-1 \\
\hline February & & February & K-1999-1 & February & \\
\hline March & & March & K-1999-2 & March & K-2000-2 \\
\hline April & & April & K-1999-3 & April & \\
\hline May & & May & & May & K-2000-3 \\
\hline June & & June & & June & \\
\hline July & K-1998-1 & July & & July & K-2000-4 \\
\hline August & & August & & August & \\
\hline September & & September & K-1999-4 & September & K-2000-5 \\
\hline October & & October & K-1999-5 & October & \\
\hline November & & November & & November & K-2000-6 \\
\hline December & & December & & December & \\
\hline
\end{tabular}




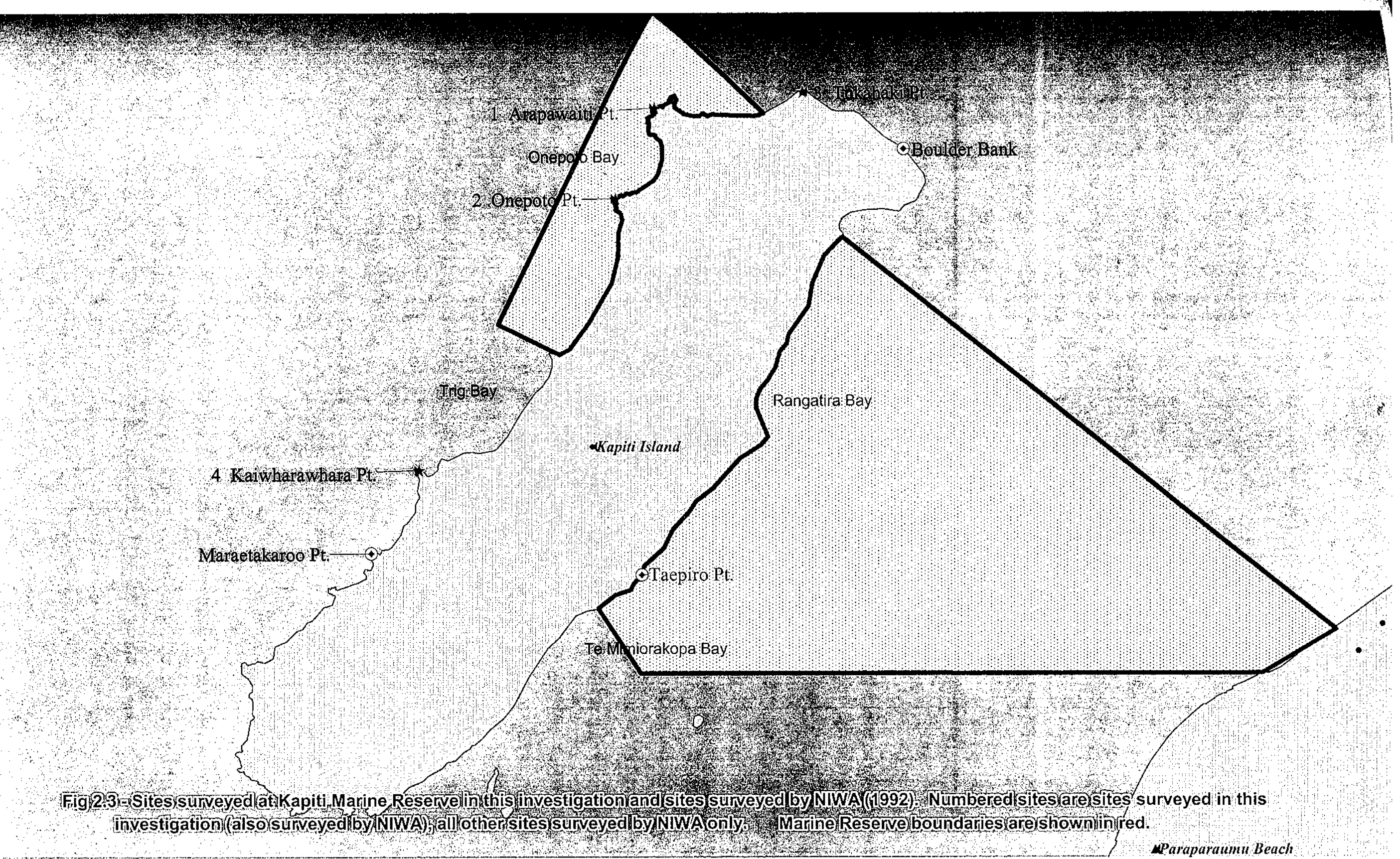




\subsection{Species surveyed}

The key species surveyed were:

\subsubsection{Algae}

Undaria pinnatifida (Asian kelp) This is a South East Asian seaweed introduced into Wellington harbour sometime between 1978 and 1987 (Hay and Luckens, 1987). Several studies are being carried out on the spread of this seaweed. This species was included in the study so that a spread to any of the chosen survey sites would be detected early on.

Ecklonia radiata (paddleweed)

Macrocystis pyrifera (giant kelp)

Carpophyllum maschalocarpum (narrow flapjack)

Lessonia variegata

The latter four species are all shallow subtidal species that are common throughout New Zealand (Adams, 1994). They were chosen for this survey because they are common and widespread in this area. A large part of the rocky substrate is covered with these macroalgae and they are probably an important food source for many of the herbivorous organisms, such as butterfish and kina. They are easily identifiable and it was hoped that they would show a quick response to the implementation of reservation status. Since these species are abundant in this area it was hoped that by monitoring any changes in abundance of these species, indications of seasonal trends might be detected. Changes in algal abundance may change if abundance of herbivorous organisms using them as a food source change with reservation, as has been found at Cape Rodney-Okakari Point Marine Reserve (Babcock et al., 1999).

\subsubsection{Invertebrates}

Haliotis iris (black foot paua)

Haliotis australis (yellow foot paua)

Evechinus chloroticus (kina or sea urchin)

Jasus edwardsii (rock lobster)

These species were chosen because they are some of the largest invertebrates inhabiting the two areas investigated. They are all commercial and recreationally important species. Poaching of these species does occur (pers. obs.), which would influence the effect reservation has on these species. Customary collection can also alter the abundance of 
these species. Since these species are under fishing pressure, providing poaching is kept to a minimum, a change in these species size and abundance is likely to occur with reservation. Sea urchins, or kina, have been known to show very pronounced responses to reservation (see section 1.1). Rock lobster have also been shown to have marked increases in other marine reserves within New Zealand (MacDiarmid and Breen, 1992, Kelly et al., 2000b), hence it was thought that these species would be good indicators of a change.

\subsubsection{Fish}

Odax pullus (butterfish)

Parapercis colias (blue cod)

Latridopsis ciliaris (blue moki)

Cheilodactylus spectabilis (red moki)

Notolabrus fucicola (banded wrasse)

Nemadactylus macropterus (tarakihi)

Pseudocaranx dentex (trevally)

These species, with the exception of the banded wrasse, are all commercially important species and most are reasonably common on the Wellington south coast and and around Kapiti Island. Some, like the red moki are known to show a marked response to reservation (Cole et al., 1990). The banded wrasse was chosen because of the abundance of this fish in the study area. Studying changes in this species size or abundance due to reservation status would provide a contrast to those changes that may occur in a species more subject to fishing pressure. There were many other fish species observed and noted also. See Tables 2.3. and 2.4. 
Table 2.3. Species surveyed on the Wellington South Coast.

\begin{tabular}{|c|c|c|}
\hline Common name & Scientific Name & Category \\
\hline Paddleweed* & Ecklonia radiata & Algae \\
\hline * & Lessonia variegata & Algae \\
\hline Asian kelp & Undaria pinnatifida & Algae \\
\hline Giant kelp & Macrocystis pyrifera & Algae \\
\hline Narrow flapjack* & Carpophyllum maschalocarpum & Algae \\
\hline Banded wrasse* & Notolabrus fucicola & Fish \\
\hline Blue $\operatorname{cod}^{*}$ & Parapercis colias & Fish \\
\hline Blue moki* & Latridopsis ciliaris & Fish \\
\hline Butterfish* & Odax pullus & Fish \\
\hline Butterfly perch & Caesioperca lepidptera & Fish \\
\hline Copper moki & Latridopsis forsteri & Fish \\
\hline Girdled wrasse & Notolabrus cinctus & Fish \\
\hline Jack mackerel & Trachurus declivis & Fish \\
\hline Kawhai & Arripis trutta & Fish \\
\hline Leatherjacket & Parika scaber & Fish \\
\hline Marblefish* & Aplodactylus arctidens & Fish \\
\hline Moari chief & Notothenia angusta & Fish \\
\hline Parorae & Girella tricuspidata & Fish \\
\hline Pigfish & Congiopodus leucopaecilus & Fish \\
\hline Red banded perch & Hypoplectrodes huntii & Fish \\
\hline Red cod & Pseudophycis bachus & Fish \\
\hline Red moki* & Cheilodactylus spectabilus & Fish \\
\hline Scarlet wrasse* & Pseudolabrus miles & Fish \\
\hline Scorpionfish & Scorpaena papillosus & Fish \\
\hline Spotty* & Notolabrus celidotus & Fish \\
\hline Sweep & Scorpis lineolatus & Fish \\
\hline Tarakihi* & Nemadactylus macropterus & Fish \\
\hline Trevally* & Pseudocaranx dentex & Fish \\
\hline Yellow eyed mullett & Aldrichetta forsteri & Fish \\
\hline Black foot paua* & Haliotis iris & Invertebrate \\
\hline Rock lobster* & Jasus edwardsii & Invertebrate \\
\hline Kina* & Evechinus chloroticus & Invertebrate \\
\hline Yellow foot paua* & Haliotis australis & Invertebrate \\
\hline
\end{tabular}

* denotes species that were used in statistical analyses 
Table 2.4. Species surveyed at Kapiti Marine Reserve.

\begin{tabular}{|c|c|c|}
\hline Common name & Scientific Name & Category \\
\hline \multirow[t]{2}{*}{ Paddleweed* } & Ecklonia radiata & Algae \\
\hline & Lessonia variegata & Algae \\
\hline Asian kelp & Undaria pinnatifida & Algae \\
\hline Giant kelp & Macrocystis pyrifera & Algae \\
\hline Narrow flapjack* & Carpophyllum maschalocarpum & Algae \\
\hline Banded wrasse* & Notolabrus fucicola & Fish \\
\hline Blue cod* & Parapercis colias & Fish \\
\hline Blue moki* & Latridopsis ciliaris & Fish \\
\hline Butterfish* & Odax pullus & Fish \\
\hline Butterfly perch & Caesioperca lepidptera & Fish \\
\hline Common roughy & Paratrachichthys trailli & Fish \\
\hline Copper moki & Latridopsis forsteri & Fish \\
\hline Girdled wrasse & Notolabrus cinctus & Fish \\
\hline Jack mackerel & Trachurus declivis & Fish \\
\hline Kingfish & Seriola lalandi & Fish \\
\hline Koheru & Decapterus koheru & Fish \\
\hline Kawhai & Arripis trutta & Fish \\
\hline Leatherjacket* & Parika scaber & Fish \\
\hline Maomao & Scorpis violaceus & Fish \\
\hline Marblefish* & Aplodactylus arctidens & Fish \\
\hline Moari chief & Notothenia angusta & Fish \\
\hline Red banded perch & Hypoplectrodes huntii & Fish \\
\hline Red cod & Pseudophycis bachus & Fish \\
\hline Red moki* & Cheilodactylus spectabilus & Fish \\
\hline Scarlet wrasse* & Pseudolabrus miles & Fish \\
\hline Spotty* & Notolabrus celidotus & Fish \\
\hline Sweep & Scorpis lineolatus & Fish \\
\hline Tarakihi* & Nemadactylus macropterus & Fish \\
\hline Trevally* & Pseudocaranx dentex & Fish \\
\hline Yellow eyed mullett & Aldrichetta forsteri & Fish \\
\hline Black foot paua* & Haliotis iris & Invertebrate \\
\hline Rock lobster* & Jasus edwardsii & Invertebrate \\
\hline Kina* & Evechinus chloroticus & Invertebrate \\
\hline Yellow foot paua* & Haliotis australis & Invertebrate \\
\hline
\end{tabular}


Average sea surface temperature data were provided by Jeff Copeland from NIWA (National Institute of Water and Atmospheric research). These data were obtained to be used in subsequent analyses.

\subsection{Survey Methods}

Identical methodology was used to survey both the Wellington south coast and Kapiti Marine Reserve. This was so that volunteer divers, once trained, could be used to perform censuses both on the Wellington south coast and at Kapiti Marine reserve without needing to learn two separate survey techniques. Additionally, the same equipment (transect lines, data sheets and quadrats) could be used for all surveys.

Willis and Babcock (1997) suggest several methods for assessing reef fish populations as an alternative to the common visual census technique performed by SCUBA divers. This technique has been used in many studies as a way to gather data on reef fish populations (McCormick and Choat, 1987, Buxton and Smale, 1989, Cole, 1990, Russ and Alcala, 1996, Chapman and Kramer, 1999, Edgar and Barrett, 1999, Cole et al., 2000). Although there are inherent biases in this technique due to varying degrees of skill of fish sighting and recognition of the SCUBA diver, and possible altered fish behaviour (McCormick and Choat, 1987, Thompson and Mapstone, 1997, Willis and Babcock, 1997) this is still considered to be the most versatile, inexpensive, easily repeatable non-destructive fish counting technique. Hence this technique was chosen for gathering fish abundance data in the present study. Two other methods of using SCUBA divers to perform visual censuses are timed counts (Jones and Thompson, 1978, Cole et al., 2000) and the roving diver technique (Schmitt and Sullivan, 1996). These techniques had no obvious advantages over visual census techniques along a strip transect, so these were not adopted.

Alternative methods are Catch Per Unit Effort (CPUE) or Catch, Measure and Release, where fishing effort (number of fishers and fishing time) is recorded until a pre-set number of fish are caught. All fish are measured, kept until the end of the sampling time and then released (Davidson, 1997). However, this requires a large number of skilled anglers available at one time, fish holding tanks and the necessary fishing equipment. This method, although having been shown to be useful to estimate abundance of blue cod populations (Davidson 1997), is not suitable for assessing a whole suite of species as 
competition between species for the baited hooks can lead to bias, as was found with snapper and blue cod at Cape Rodney-Okakari Point Marine Reserve (Willis and Babcock, 1997). This method was not used in the present investigation due to lack of skilled personnel, possible mortality of fish and the inability to survey multiple species using this method.

Underwater remote baited video camera systems have been used at Cape RodneyOkakari Point to assess fish populations (Willis and Babcock, 1997). These were shown to be most useful to obtain accurate data for blue cod and snapper populations. A trial of this method was conducted on the Wellington south coast by Trevor Willis (Auckland University). Due to the topography of the site surveyed, and remnant sea swell the camera was difficult to place and retrieve. Additionally, this method requires a large amount of post-survey laboratory time and the appropriate software to analyse the video data. Due to the prohibitive cost of a remote camera system and the software, plus the possibility that the data would not accurately represent all fish species present, this methodology was not used in the present investigation.

Fish tagging methods have also been used as by Willis (1997) and Cole et al. (2000). Tags are usually external, where fish are marked by plastic tags, fin clips or subcutaneous dyes. Internal tags such as chemicals or internal transponders are also used (Willis, 1997). However these methods are species specific and appear more suitable for tracking movements of individual fish. Tagging methodologies can be limited by the small range over which tags are detectable and sometimes by the necessity to sacrifice the fish in order to read the tag (Willis, 1997). Hence these methods were not deemed appropriate for the current investigation.

An underwater stereo video camera system recently developed by Euan Harvey (1998) was seriously considered as an alternative to visual diver censuses. This allowed accurate size data for all fish recorded whilst swimming along a strip transect to be recorded by a single diver. However, the cost of the initial camera set up and the associated software was prohibitive to this method being used. The software developed by Harvey (1998) also still had flaws that needed addressing before this method could be used without problems. 
Typically there were three teams of two divers performing visual fish censuses. One diver would swim in a random direction from the start point and the other diver, after indicating the start of the transect at $5 \mathrm{~m}$, would follow behind with the transect line, so as not to scare the fish away before the diver counting the fish could record them. The diver with the transect would indicate to the other diver that the transect was finished by pulling their fin. The transect line was then tied off and each diver would then swim back to the start point intensively searching a one metre strip on their side of the tape for invertebrates. At the start point, the process was repeated in another direction. The tape was moved before starting the third transect. On the third transect, only fish were counted, not invertebrates. One team of divers usually had a third diver working on the same transect line with a quadrat doing the algal counts. If there were three teams of two divers in the water at one time following this procedure then at the end of one dive count data from nine fish transects, six invertebrate transects and thirty algae quadrats had been collected. These sampling methods allowed fish, invertebrates and algae surveys to be combined maximising sampling efficiency from diver time in the water. On occasion, due to lack of personnel, these proceedings were modified to enable the same work to be carried out with less divers.

In order to address the issue of variability in ability to estimate fish sizes, divers were tested to determine their average error in fish size estimation (Trevor Willis, pers. comm.). This was carried out in January 2000 in the Island Bay lagoon. A transect line was laid out, with numbered plastic cut out fish positioned on either side of the transect line. The divers swam along the transect line estimating the size of each fish and these estimates were then compared with the actual value. The cut outs ranged in size from $14 \mathrm{~cm}$ to $50 \mathrm{~cm}$. The average error was found to be $\pm 4.3 \mathrm{~cm}$. Therefore, the error was smaller than the $5 \mathrm{~cm}$ size interval used in the estimation of fish sizes. Where possible the same group of trained divers were used for conducting surveys, however this was not always possible.

\subsubsection{Fish}

To survey reef fish a visual census along transect lines was used. This is the most common method of reef fish survey (McCormick and Choat, 1987, Willis and Babcock, 1997, Kingsford and Battershill, 1998). Divers swam a $25 \mathrm{~m}$ strip transect along a measuring tape, counting fish $2.5 \mathrm{~m}$ either side of the tape, thus counting fish in a $25 \mathrm{~m} \mathrm{x}$ $5 \mathrm{~m}$ corridor (e.g. Cole 1994). When the tape was tied off, the diver commenced counting 
fish at the $5 \mathrm{~m}$ mark. This was to reduce skewed counts due to fish disturbance while divers were tying off the tapes (Trevor Willis, University of Auckland, pers comm.). The sampling was carried out whilst the transect tape was being set rather than retrieved to avoid counting fish that had followed the diver (Cole, 1994). The seven key fish species were estimated in size (to the nearest $5 \mathrm{~cm}$ ), other fish species were counted only.

Nine replicate fish count transects were made at each site at each sampling date. Thus the total area sampled per site per time was 9 replicates $\mathrm{x} 25 \mathrm{~m}$ x $5 \mathrm{~m}=1125 \mathrm{~m}^{2}$. This was found to be an adequate number of transects of identical size by Trevor Willis (pers. comm., 1997) in his monitoring of Cape Rodney-Okakari Point Marine Reserve. There were no a priori expectations for the south coast or Kapiti Marine Reserve.

\subsubsection{Invertebrates}

Invertebrates were sampled along six replicate strip transects. Divers laid out a $25 \mathrm{~m}$ transect line, then swam alongside it searching $1 \mathrm{~m}$ either side of the tape for the four target invertebrate species. Paua specimens found were measured for length along the longest axis of the shell, while teste diameter was measured in kina. Specimens were measured with plastic rulers on the side of the slates used to record the data. Rock lobster, which were not measured, were just noted as being adult or juvenile, so as to prevent disturbance to the animal by pulling it out of its hole.

The total area sampled per site per sampling time was 6 replicates x $25 \mathrm{~m}$ x $2 \mathrm{~m}=300$

$\mathrm{m}^{2}$. Battershill et al. (1993) sampled the same area for invertebrates in their survey of Kapiti Marine Reserve in 1992. There were no a priori expectations for the south coast.

\subsubsection{Algae}

Algae were surveyed by dropping a $250 \mathrm{~cm}^{2}$ quadrat every three metres (this distance was chosen to space quadrats equally along transect) along a $30 \mathrm{~m}$ transect line (i.e. ten quadrats per transect). Three transects were carried out per site, giving a total of 30 quadrats per site. The use of the transect was purely to avoid diver bias when selecting a site to place the quadrat.

Only the stipes of the five target algal species were counted. Numbers of algal plants visibly damaged by herbivore browsing were also counted. The damage was quantified as (a) partial damage to fronds (frond damage) or (b) total removal of fronds leaving 
only the stipe (stipe damage). This was recorded in case the damage to algal plants was seasonal, and that subsequent data analysis might show this. In this arbitrary assignment of categories into frond or stipe damage, frond damage was less severe than stipe damage.

Additionally video surveys were conducted in order to establish percent cover of the various algal species at each site. Only one set of video surveys were carried out on the Wellington south coast and none at Kapiti marine reserve, due to logistical problems. These video surveys on the Wellington south coast were carried out between May and July 2000. At each site bottom composition was filmed along three thirty metre transects. Using Matrox PC Remote Video software six frames were analysed from each transect. Using a transparent sheet with 100 randomly assigned dots, the dots covering each species of algae (or bare rock) were counted. The total number of dots per site per algal species was then added up and divided by 18 to give a percent cover of that algal species.

\section{Problems}

In this thesis, field work was always at the mercy of weather, and lack of trained personnel made it very difficult to carry out sampling and subsequently not every planned survey was carried out. Sometimes availability of the boat and skipper due to great demands on his time was also a limiting factor. Access to a boat, and a skipper with good local knowledge of the area is vital to this type of work. Using a boat provides easy access to dive sites, and with availability of trained divers one can make more efficient use of time. This is important in areas such as the Wellington south coast where periods of settled weather are rare.

There are other problems associated with SCUBA based fieldwork. Visibility needs to be a minimum of a certain distance for fish counts to be carried out. Even if the visibility is enough to meet the requirements of seeing the "corridor" in which fish counts are carried out, in marginal visibility the fish tend to scare easier and often swim away from a noisy diver (R. Davidson pers. comm., pers. obs.). This could potentially skew counts. This was the case in the last two surveys undertaken at Kapiti Marine Reserve. Visibility was marginal. All due care was taken to swim quietly and avoid scaring fish, but there is a possibility that the data weren't truly representative of the fish that were present. Dives must be kept to a certain time and depth to allow repetitive dives to be carried out in one 
day. Winter diving in this area particularly, needed to take consideration of time spent in the water as divers would become cold quickly after multiple dives.

Additionally choice of sampling units was partially based on the fact that these were underwater surveys. Transect size chosen was based on previous studies and also because of the fact that transects of the size utilised could be replicated multiple times on a single dive. Similarly the choice of quadrat size was determined by the ability of a single diver to handle the quadrat underwater. In both cases these sampling units were chosen to enable a multi species survey. If a single species only was being surveyed the size of the sampling unit would necessarily have been tailored to suit to help reduce variance because of patchy distribution of the species.

The areas surveyed were both coastal reef areas with no defined shelf or slope. Hence the sampling was always carried out within a depth range of $3-15 \mathrm{~m}$. These surveys were not depth stratified as the habitat did not lend itself to easily and consistently sampling at certain depths.

\subsection{Statistical analysis}

The statistical package 'Systat 9' by SPSS and 'Power and Precision' by Biostat were used for data analysis. The data collected from both the Wellington south coast and Kapiti Marine Reserve were subject to the same statistical tests. Statistical tests were applied to the suite of species for which data was collected in this investigation. Only those species where enough data was available to make statistical tests meaningful were used.

\subsubsection{Kruskal-Wallis Tests}

Biological data often do not fit the assumptions of normality required to perform parametric statistical tests, therefore firstly a Kruskal-Wallis non-parametric test was performed on these data to test the null hypotheses that there is no difference in abundance (or, where appropriate, size) separately for each species concerned, among sites on the south coast. The tests were performed separately for each species, and afterwards the results were adjusted using Bonferroni sequential correction for multiple testing. The data collected for Kapiti Marine Reserve was subject to the same Kruskal - 
Wallis non-parametric test to test the null hypothesis of no difference amongst sites at Kapiti Marine Reserve. The test was then repeated pooling data choosing 'reserve' as a factor to additionally test the null hypotheses that there is no difference between reserve and control sites.

\subsubsection{Analysis of Variance tests}

The data were then transformed to enable Analysis of Variance (ANOVA) tests to be performed on this data. Parametric ANOVA tests are more powerful than the nonparametric Kruskal-Wallis tests, but the data must meet certain assumptions such as normality and equality of variance. The residuals (difference between observed value and estimated value for the model) of the data were plotted to select the best transformations. To check for equality of variance, a plot of the residuals against the estimated data should form a straight horizontal band across the page. To check for normality the plot of the residuals against the quantiles of the normal distribution should form a straight line. Abundance data were $\log _{\mathrm{e}}$ transformed and size data were square root transformed.

For the south coast, these transformed data were then subject to one factor (site) ANOVA tests using the software package Systat 9 testing for differences among sites, using the general linear model function. Any significant results were then put through Post Hoc Tukey tests (pairwise comparisons) to establish which sites were significantly different from each other (i.e the location of the significant differences). These tests were perfomed, as with the Kruskal-Wallis tests, to test the null hypotheses that there is no difference in abundance (or, where appropriate, size) separately for each species concerned, among sites on the south coast.

The data collected from Kapiti Marine Reserve, these transformed data were also subject to one factor (site) ANOVA tests using the software package Systat 9 testing for differences among sites, using the general linear model function. These tests were then repeated to test for differences between reserve and control sites and also for differences amongst sites nesting reserve in this variable. This is because the differences between sites need to take into account "reserveness" of the site. As for the south coast, any significant results were then put through Post Hoc Tukey tests (pairwise comparisons) to establish which sites were significantly different from each other (i.e the location of the significant differences). These tests were performed, as with the Kruskal-Wallis tests, to test the null hypotheses that there is no difference in abundance (or, where appropriate, 
size) separately for each species concerned, among sites at Kapiti Marine Reserve. These tests, as with the Kruskall-Wallis tests, were repeated using 'reserve' as a factor to test the null hypotheses that there is no difference between reserve and control sites.

Both Kruskal-Wallis non-parametric tests and ANOVA tests were performed on these data because transforming the data reduces the variability, thus using both tests checks that the transformations do not alter the results. In all cases usual convention is followed and the $\alpha$-level 0.05 is accepted as being significant.

\subsubsection{Power analysis}

Power analysis was performed on the results from these ANOVA tests. This was done using the package "Power and Precision" by Michael Borenstein. This analysis tests the power of the data to detect a change in average species size or abundance should there be one. This was done by selecting the one way ANOVA option in the statistical package. The mean square error from the ANOVA results was the variance within cells (or variance within a site) and the effect size was computed by the package after entering the means (in this case $\log _{\mathrm{e}}$ transformed abundance) from each site. The correct number of factors was chosen (i.e number of sites) and the average number of cases per site. The programme then calculated the power of these data, as a percentage, to detect a change (in this case in abundance). The object of this was to establish whether the sampling regime in the present investigation was suitable to detect any future changes in the reserves, (should the Taputeranga reserve become established).

\subsubsection{Multidimensional Scaling}

The average abundance (and size where applicable) of each species (all fish, invertebrates and algae together) per site at each survey period was collated into a data matrix. This was then used to do a multidimensional scaling (MDS) analysis of the data to provide a picture of the similarities or dissimilarites of sites on the south coast and at Kapiti Marine Reserve. MDS is a powerful data reduction technique that computes coordinates for a set of points in a space such that the distances between pairs of these points fit as closely as possible to measured dissimilarity between a corresponding set of objects (Borenstein, 1997). The MDS was then repeated for algae only, invertebrates only and fish only to determine if there was any difference using these groups of species by themselves. The aim of this analysis was to examine the null hypotheses that each site is equally similar, or dissimilar, to each other. However, this pictorial representation of 
site similarity or dissimilarity is specific to species examined in this investigation only and should not be confused with a complete community analysis.

\subsubsection{Testing for seasonal variation}

To test for seasonal effects, each survey was coded as belonging to a certain time of year (e.g. all surveys conducted between May and July in any year, were given the same code, all surveys conducted between October and December in any year, were given the same code. The samples were broken into five categories). These categories were used as the 'time' factor. A correlation analysis was run between sea surface temperature and the variable being tested (in this case $\log _{\mathrm{e}}$ transformed average count data). If there was a significant correlation then sea surface temperature was included in the model and a 2factor (site and time) ANCOVA (analysis of covariance) test was carried out using this coding of time periods as a factor to see whether there were significant differences among time periods in this investigation. Interaction between site and time of year was used as a factor to test whether the differences between sites are the same at differing times of year. Sea surface temperature was used as a covariate for these tests, to determine if it played an important role in explaining any variability that might be found on the south coast. This analysis of the whole model was performed in a stepwise manner, taking out each non-significant effect in the model. This involved fitting a full model and a reduced model (with one of the effects omitted). The difference between the models is used to test the significance of the omitted effect. Systat cannot run a stepwise analysis separately for each species so this process had to be done manually, taking out each factor in turn, until a parsimonious model was obtained. The model used for the south coast initially tested these factors:

Time

Site

Time*Site (interaction between time and site)

Sea surface temperature (co-variate)

In the case of data from Kapiti Marine Reserve, if there was a significant correlation with sea surface temperature and $\log _{\mathrm{e}}$ transformed count data, a 3-factor (site(reserve), reserve and time) ANCOVA (analysis of covariance) test was carried out to determine whether there were significant differences among time periods in the present investigation. Interaction between site and time of year was used as a factor to test whether the differences between sites are the same at differing times of year. The model for Kapiti 
Marine Reserve also used site nested within reserve instead of testing for differences amongst sites only as the two are interlinked. As for the south coast, sea surface temperature was used as a covariate for these tests, to determine if it played an important role in explaining any variability that might be found at Kapiti Marine Reserve. The model used for Kapiti Marine Reserve initially tested these factors:

Time

Site(reserve)

Reserve

Time*Site(reserve)

Sea surface temperature

\subsubsection{Testing for differences in algal damage}

Lastly, ANCOVA tests were performed on $\log _{\mathrm{e}}$ transformed data for damage to algal plants. During the course of the data collection, it was noted that the algal plants sometimes had visible damage to the fronds and/or stipes. The damage was arbitrarily categorised into frond or stipe damage, where frond damage was less severe than stipe damage. This was tested to see if there was a significant difference in amounts of damage to algal plants at certain times or whether there was more damage at some sites than others. The model used was:

Site

Damage

Time

Time* Damage (interaction)

Site*Damage (interaction)

Site*Damage*Time (interaction)

Sea surface temperature (co-variate)

The model used for the Kapiti Marine Reserve was:

Site(reserve)

Reserve

Time

Sea surface temperature (co-variate)

Damage

Damage*Reserve (interaction)

Damage*time (interaction) 
Damage*Site(reserve) (interaction)

Damage*Site(reserve)*time (interaction)

A manual stepwise analysis was performed for this, as for seasonal variation (see previous section).

\subsubsection{Comparison to previous data}

In 1997, a team of UK navy divers were recruited to do some preliminary surveys of the Wellington south coast. These surveys were relatively simple and concentrated on a few species only. Abundance of blue cod, blue moki and butterfish were surveyed as well as black foot paua, yellow foot paua and kina that were both counted and sized. These data were added into the dataset from the present study, but were given a different time coding. These data were then appropriately transformed, $\log _{\mathrm{e}}$ transformed for abundance data and square root transformed for size data. These data were then tested for a hypothesis of no difference between 1997 and the average data counts from similar months from the present study. Data from each site that was common to both studies were analysed separately. These data were tested using a one factor ANOVA (time).

The raw data gathered in the Battershill et al.(1993) survey at Kapiti Marine Reserve were used to perform ANOVA tests against the data from this investigation to establish if there were any significant differences in sizes and abundances of common species surveyed between the two studies (i.e. before and after reservation). The count and size data for species and sites that both studies had in common were selected

The Battershill et al. (1993) raw data were added into the dataset from the present study and given a different time coding. These data were then appropriately transformed, $\log _{\mathrm{e}}$ transformed for abundance data and square root transformed for size data. A null hypothesis of no difference between 1992 (before reservation) and the average data counts from similar months from this study (after reservation) was then tested. Data from each site was analysed separately. These data were tested using a One factor (time) ANOVA. 
CHAPTER 3

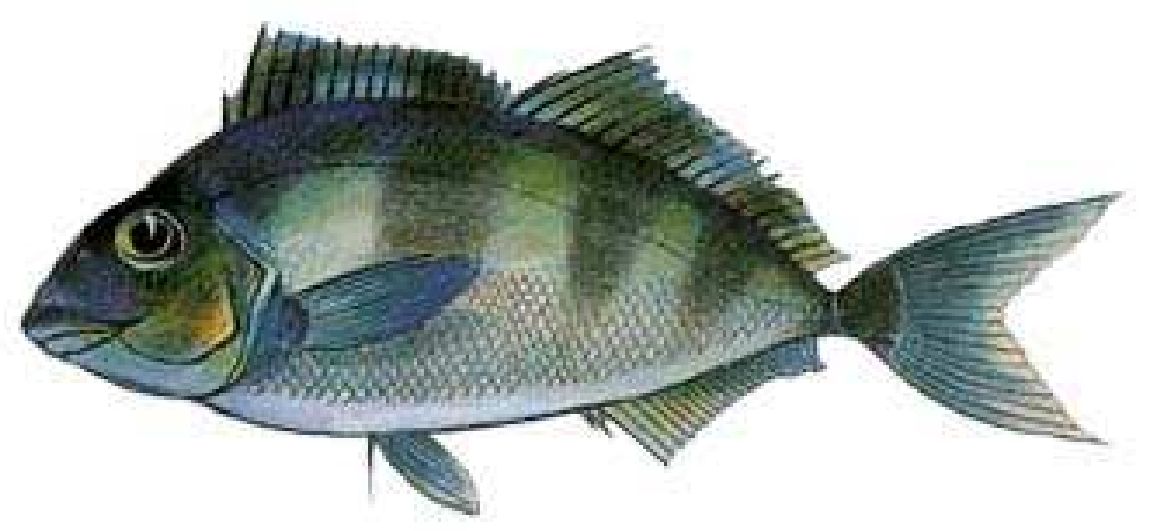

THE SOUTH COAST OF WELLINGTON 


\section{CHAPTER 3 - THE SOUTH COAST OF WELLINGTON}

\subsection{Introduction}

A marine reserve has been proposed for the south coast of Wellington. This was first proposed in the early 1990's, but since this date the proposed boundaries have changed several times (Chapter 2, Fig. 2.1). This is mostly due to the fact that many different user groups, such as iwi, the general public, commercial and recreational fishers, needed to be consulted and a compromise arrived at to meet the needs of all these different groups (Taputeranga Marine Reserve Application). Political compromise and consultation is a problem with the establishment of virtually all marine reserves, hence presenting one of the biggest hurdles to establishing baseline data, because if a baseline survey is to be carried out, the questions of when and where are difficult to answer. At the time of writing, a formal application has been submitted (18 Oct 2000) and is presently with the Department of Conservation awaiting a recommendation from the Director General of Conservation to the Minister of Conservation.

The principle for establishing a marine reserve on the south coast of Wellington is threefold. Firstly, the Cook Strait is a unique body of water, that separates New Zealand's two largest islands. If the goal is to create an interlinking network of marine reserves (Ballantine, 1994, 1995) as described in the general introduction, then this is an important area to have a reserve as a stepping stone between the two islands. Currently in New Zealand there are many more marine reserves around the North Island (as seen in Chapter 1, Fig 1.1) than the South Island, and having a marine reserve in central New Zealand will help to shift the balance slightly. Secondly, Island Bay is a strategic place to create this reserve as the Victoria University Island Bay Marine Laboratory is located on this coast. The Cape Rodney-Okakari Point Marine Reserve is being, and has been, intensively studied due to the fact that Leigh Marine Laboratory was located nearby, and establishing a marine reserve on the Wellington south coast so close to a marine laboratory would encourage scientific study of the area. Under the current legislation (MRA, 1971) this fufills the criteria of scientific study. Lastly, Island Bay is a high recreational use area. Divers would be able to experience the changes taking place in the marine reserve first hand, which would potentially increase public support. This is important as the criteria in section 3 (d) of the MRA states that "the public shall have freedom 
of access and entry to the reserves, so that they may enjoy in full measure the opportunity to study, observe and record marine life in its natural habitat." If the "spillover" effect occurs here then they may notice the benefits in increased numbers of rock lobsters available for recreational catch outside the reserve. The commercial fishermen may also notice increased, or at least no decline, in yield, as has been the case at the Cape Rodney-Okakari Marine Reserve (Kelly et al., 2000a).

Based on the lack of scientific study on how to establish an adequate baseline for marine reserve monitoring, one of the aims of this thesis is to determine what should be considered appropriate. When the idea of creating a baseline was conceptualised, the proposed boundaries were those from the 1996 boundary proposal (Chapter 2, Fig. 2.1.). This is what the site selection was based upon. It was anticipated that the marine reserve might be implemented during the time of this investigation so that there would be approximately one and a half year's baseline, or pre-reserve, data collected and then another year and a half's data collection following the implementation of the reserve. This would allow determination of how suitable the baseline protocol had been in detecting any change due to reservation. Unfortunately this was not possible as the reserve was not implemented during the course of this study. This is an example of the uncertainty in establishment of marine reserves which is often why baseline data is not collected, or if so is done only in the early years after reserve establishment.

An equal number of sites was chosen inside and outside the proposed reserve boundaries. However, during the course of this investigation the boundaries were changed to those shown in Fig. 3.1. This meant that the sites chosen (see Chapter 2, Fig. 2.2) were no longer equally spread amongst the proposed reserve and control areas. However, these sites are well spread over the $11 \mathrm{~km}$ stretch of coast and provide a good representation of the south coast so they were monitored over this three year investigation. 
Fig. 3.1. Current boundary proposal for Taputeranga Marine Reserve.

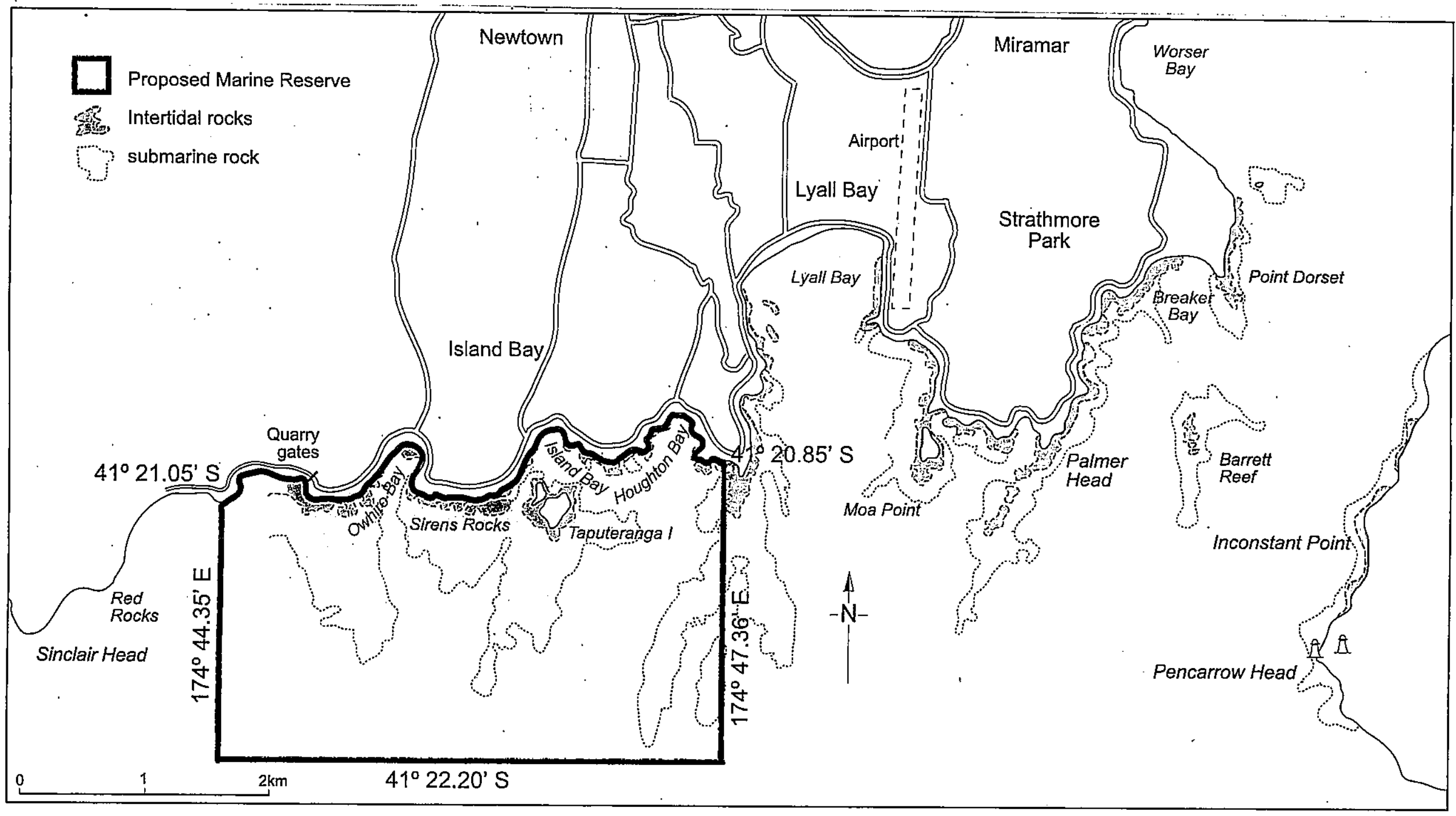


Despite the fact that the marine reserve was not established during this investigation, the collection of this 3 year comprehensive baseline data provides valuable information on the populations of selected species found on the south coast. Underwood and Atkinson (1992) state that it is imperative to collect enough information to be able to estimate the magnitude of natural fluctuations in population densities. Since this investigation was carried out over a long duration, it was hoped that any patterns in natural seasonal variation would be identified. This is important as it means that subsequent monitoring of the marine reserve would not attribute reserve status as being the cause of what are actually seasonal and/or other longer term cyclical changes.

There are a few cases where baseline data has been collected prior to reserve establishment in New Zealand, such as Davidson (in submission) where data on blue cod abundance was collected 13 months prior to establishment of Long Island-Kokmohua Marine Reserve (established 1993), and subsequent monitoring continued for seven years. To date, this is the longest published time series of data for continued monitoring of a marine reserve, but only a small part of these surveys were carried out before reserve establishment. A marine reserve was proposed for Paterson inlet, Stewart Island, New Zealand. Lindsay Chadderton (DOC) and Rob Davidson (Davidson Environmental) carried out a baseline survey at this site from 1992 to 1997. However, the sites were only monitored annually and only fish abundance data via catch, measure and release methods were gathered. Additionally, a one-off rock lobster survey was performed (R. Davidson, pers.comm.). A marine reserve was also proposed for Kaikoura, yet this application has been awaiting approval for many years. DOC, in collaboration with Canterbury University funded a one-off baseline survey for 2 years in the early 1990's, but since then no more monitoring has been undertaken. This baseline surveyed fish species only ( $R$. Davidson, pers.comm.). Therefore the present investigation is unique as it is the only baseline study which consists of continual monitoring throughout the year, for three years continually, before establishment of a marine reserve and also investigates a whole suite of species. Therefore the scientific underpinning for this research is to create, for the first time, an extensive baseline database for a marine reserve in New Zealand before the establishment of the reserve. Using results from these findings will enable creation of a guideline for baseline study protocols for all future marine reserves. It will help decisions as to how to conduct baseline surveys, in terms of sampling effort required and methodology, what species should be used as key indicator species and how to address associated problems. 


\subsection{Study Area}

The south coast of Wellington is a high energy environment. It is known for the severity of its storms and tides (Carter and Lewis, 1995). Wellington borders the Cook Strait which is subject to deep ocean, southerly swell and storm generated waves and currents due to local meteorological events. The winds and tides are also intensified through constriction by Cook Strait (Carter and Lewis, 1995, Carter and Heath 1975). Additionally, local wind waves compound the persistent southerly swell. These winds are funneled either north or south by local topography. As a result, the coastline is constantly exposed to high energy swell coming from the south (Heath, 1985). Weather in Wellington is very changeable and there are rarely long settled periods. Windspeeds are on average $27 \mathrm{~km} /$ hour, but per year there are on average 173 days recorded with wind gusts of more than $63 \mathrm{~km} / \mathrm{hour}$ and 32.5 days that have wind gusts greater than 96 $\mathrm{km} /$ hour (NZ meteorological service). Wellington is subject to Gale force $(17.2 \mathrm{~m} / \mathrm{s}$ ) winds $4 \%$ of the time (Carter and Lewis, 1995) and these are usually oriented northwesterly or southeasterly (Bowman et al., 1983a). Tidal flow is vigorous and highly variable depending on meteorological conditions, and currents are sufficiently powerful to keep sand in near constant motion (Carter and Lewis, 1995, Heath, 1985). In a southerly wind direction the coastal waters quickly become rough and the residual swell lasts several days after the winds have died down. In a strong northerly, particularly when gusty, driving a boat around the coast becomes very hazardous. It is a rocky shoreline making access to dive sites difficult therefore diving in this area is predominantly from a boat, although some sites were accessible from the shore (pers. obs.). The coastline is strongly indented and boulder lined rocky reefs project seawards from headlands. The coast is rugged and indented because it cuts across the structural trends of an active convergent plate boundary zone (Carter and Lewis, 1985).

Subtidally, this coast is a temperate reef environment consisting of four major habitat types, which are rock, boulders and cobbles, coarse sand to fine pebble gravel and finemedium sand (Carter and Lewis, 1985). Commonly the reef areas are interspersed with patches of sand and cobbles and are covered with brown macroalgae and some crustose coralline algae. This area is used by both commercial and recreational fishermen. Diving and snorkeling along this coast is a common activity. Depths range from 6-15 m at 100$200 \mathrm{~m}$ distance from the shore, and about a kilometre off shore, depths can reach about 
$30 \mathrm{~m}$. At this depth the few small reefs that exist are devoid of macroalgae and the substrate is predominantly sand (pers. obs.).

\subsection{Methods}

Refer to Chapter Two.

\subsection{Results}

All tests were performed on count data for seventeen species and on size data for ten species. In all cases significance is denoted by $P<0.05$.

\section{$\underline{\text { 3.4.1 Kruskal-Wallis tests }}$}

$\mathrm{H}_{0}=$ There is no difference in species abundance (or size) amongst sites on the south coast.

A Kruskal-Wallis test was performed on each species individually to test for differences amongst sites on the south coast of Wellington. Both average abundance and size data (where applicable) for all eleven sampling periods, were tested. Significant results are presented in Table 3.1 .

Table 3.1. Significant results (both before and after correction for multiple testing) from Kruskal-Wallis tests on differences in abundance (and size) among sites on the south coast of Wellington.

\begin{tabular}{lll}
\hline Species & Data tested & $P$-value \\
\hline Carpophyllum maschalocarpum & count & 0.004 \\
Ecklonia radiata & count & $0.000^{*}$ \\
Lessonia variegata & count & $0.000^{*}$ \\
Spotty & count & 0.034 \\
Black foot paua & count & $0.000^{*}$ \\
Black foot paua & size & 0.036 \\
Yellow foot paua & count & 0.011 \\
Kina & size & 0.073 \\
\hline * denotes significance after correction for multiple testing.
\end{tabular}


For the algae Ecklonia radiata and Lessonia variegata and black foot paua, there was a significant difference in abundance among the eight sites along the south coast, across all time periods.

\subsubsection{Analysis of Variance tests}

$\mathrm{H}_{0}=$ There is no difference in species abundance (or size) amongst sites on the south coast.

Following these Kruskal-Wallis tests (Table 3.1.), the data were transformed as described in the methods section, so that ANOVA tests could be performed.

The significant results of the ANOVA tests performed on $\log _{\mathrm{e}}$ transformed count data are presented in Table 3.2.

Table 3.2. Significant results (before and after correction for multiple testing) for ANOVA testing for differences among sites on the south coast of Wellington, on $\log _{\mathrm{e}}$ transformed count data.

\begin{tabular}{ll}
\hline Species & $P$-value \\
\hline Carpophyllum maschalocarpum & $0.001^{*}$ \\
Ecklonia radiata & $0.000^{*}$ \\
Lessonia variegata & $0.000^{*}$ \\
Banded Wrasse & 0.048 \\
Spotty & $0.000^{*}$ \\
Black foot paua & $0.000^{*}$ \\
Kina & $0.000^{*}$ \\
Yellow foot paua & 0.012 \\
\hline
\end{tabular}

*denotes significance after correction for multiple testing

Ecklonia radiata, Lessonia variegata and black foot paua abundances were significantly different among sites on the south coast, as was shown by the Kruskall-Wallis tests. Additionally, these ANOVA results showed kina, spotty and Carpophyllum maschalocarpum, to have significantly different abundances amongst sites. 
Table 3.3. Average abundance $\left(\right.$ per $\left.\mathrm{m}^{2}\right) \pm$ standard error at each site on the south coast, for all the species for which ANOVA tests showed a significant difference in abundance among sites. Sites are arranged west to east.

\begin{tabular}{lllllllll}
\hline Species & $\begin{array}{l}\text { Sinclair } \\
\text { Head }\end{array}$ & $\begin{array}{l}\text { Red Rocks Yungh } \\
\text { Pen }\end{array}$ & \multicolumn{2}{l}{$\begin{array}{l}\text { The Sirens } \\
\text { Bay }\end{array}$} & $\begin{array}{l}\text { Palmer } \\
\text { Head }\end{array}$ & $\begin{array}{l}\text { Breaker } \\
\text { Bay }\end{array}$ & $\begin{array}{l}\text { Barretts } \\
\text { Reef }\end{array}$ \\
\hline $\begin{array}{llllll}\text { Ecklonia } \\
\text { radiata }\end{array}$ & $3.96 \pm 0.62$ & $1.84 \pm 0.4$ & $7.76 \pm 1.91$ & $3.32 \pm 0.71$ & $2.8 \pm 0.96$ & $12.92 \pm 1.6$ & $9.2 \pm 0.67$ & $12 \pm 0.9$ \\
Lessonia & $3.32 \pm 0.24$ & $3.12 \pm 0.27$ & $2.72 \pm 0.27$ & $2.12 \pm$ & $2 \pm 0.27$ & $0.92 \pm 0.25$ & $2.84 \pm 0.2$ & $1.12 \pm 0.2$ \\
variegata & & & & 0.196 & & & & \\
Carpoph- & $1.56 \pm 0.75$ & $2.96 \pm 0.46$ & $2.2 \pm 1.04$ & $4.2 \pm 1.04$ & $4.28 \pm 0.43$ & $2.04 \pm 0.7$ & $4.92 \pm$ & $3.2 \pm 1.1$ \\
yllum & & & & & & & 0.002 & \\
maschalo- & & & & & & & & \\
carpum & & & & & & & & \\
Black foot & $0.024 \pm$ & $0.027 \pm$ & $0.035 \pm$ & $0.0812 \pm$ & $0.0778 \pm$ & $0.1336 \pm$ & $0.0344 \pm$ & $0.167 \pm$ \\
paua & 0.012 & 0.006 & 0.009 & 0.03 & 0.02 & 0.034 & 0.01 & 0.03 \\
Kina & $0.0216 \pm$ & $0.022 \pm$ & $0.0578 \pm$ & $0.0466 \pm$ & $0.0336 \pm$ & $0.0978 \pm$ & $0.0312 \pm$ & $0.1836 \pm$ \\
& 0.007 & 0.005 & 0.013 & 0.03 & 0.008 & 0.03 & 0.008 & 0.04 \\
Spotty & $0.0092 \pm$ & $0.1027 \pm$ & $0.0106 \pm$ & $0.0158 \pm$ & $0.0176 \pm$ & $0.0282 \pm$ & $0.0618 \pm$ & $0.0391 \pm$ \\
& 0.002 & 0.006 & 0.002 & 0.004 & 0.004 & 0.007 & 0.02 & 0.013 \\
\hline
\end{tabular}

Post Hoc Tukey tests (pairwise comparisons) were performed to try to establish the location of these differences among sites. Line diagrams (Figs. 3.2.-3.7.) are used to show which sites were significantly different from each other. Sites joined by a line are not significantly different from each other, but those sites that are never grouped together (i.e. are never joined by a line) are significantly different from each other.

Sites are labelled 1-8, 1 being the easternmost site and 8 being the westernmost.

1 Barretts Reef

2 Breaker Bay

3 Palmer head

4 Princess Bay

5 The Sirens

6 Yungh Pen

7 Red Rocks

8 Sinclair Head 
Fig. 3.2. Line diagram showing the location of the significant differences among sites on the Wellington south coast for abundance of Carpophyllum maschalocarpum.

(sites 2 and 4 are significantly different from sites 6 and 8).

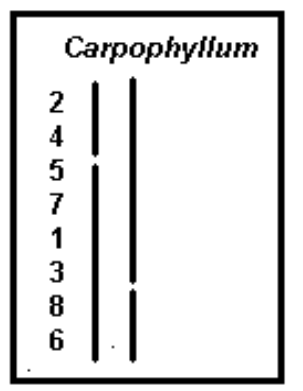

Fig. 3.3. Line diagram showing the location of significant differences among sites on the Wellington south coast for abundance of Ecklonia radiata.

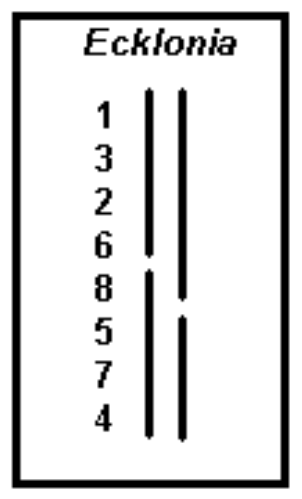

(sites 1,2,3 and 6 are significantly different from sites 5,7 and 4)

Fig. 3.4. Line diagram showing the location of significant differences among sites on the Wellington south coast for abundance of Lessonia variegata.

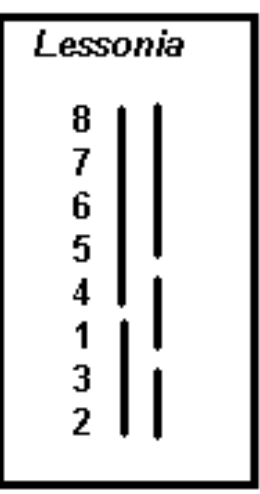

(sites 8,7,6 and 5 are significantly different from sites 1,3 and 2. Sites 2 and 3 are significantly different from 4 ). 
Fig. 3.5. Line diagram showing location of significant differences among sites on the Wellington south coast for spotty abundance.

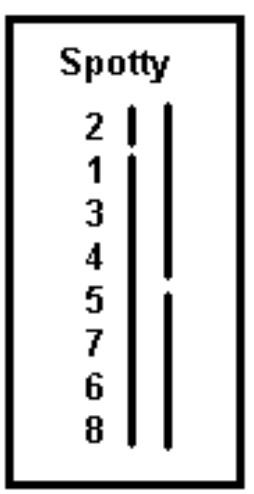

(site 2 is significantly different from sites 5, 7,6 and 8).

Fig. 3.6. Line diagram showing the location of significant differences among sites on the Wellington south coast for black foot paua abundance.

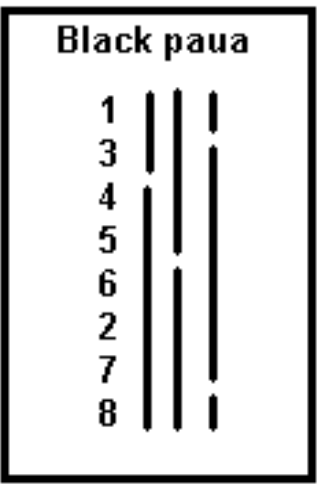

(sites 1 and 3 are significantly different from site 8 . Site 1 is also significantly from 6,2 and 7 )

Fig 3.7. Line diagram showing the location of significant differences among sites on the Wellington south coast for kina abundance.

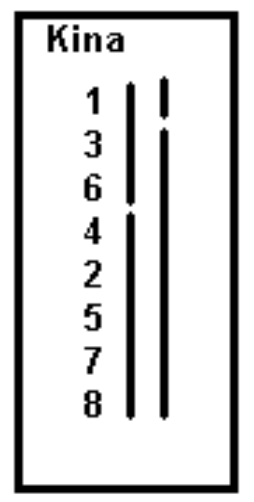

(Site 1 is significantly different from sites 4,2,5,7 and 8). 
The mean counts for these species are shown below in Figs. 3.8.-3.13. The categories on the $\mathrm{x}$-axis of these charts represent each survey period, in sequential order. Error bars are one standard error. 
Fig. 3.8. Carpophyllum maschalocarpum abundance at all 8 sites on the south coast at each survey period.

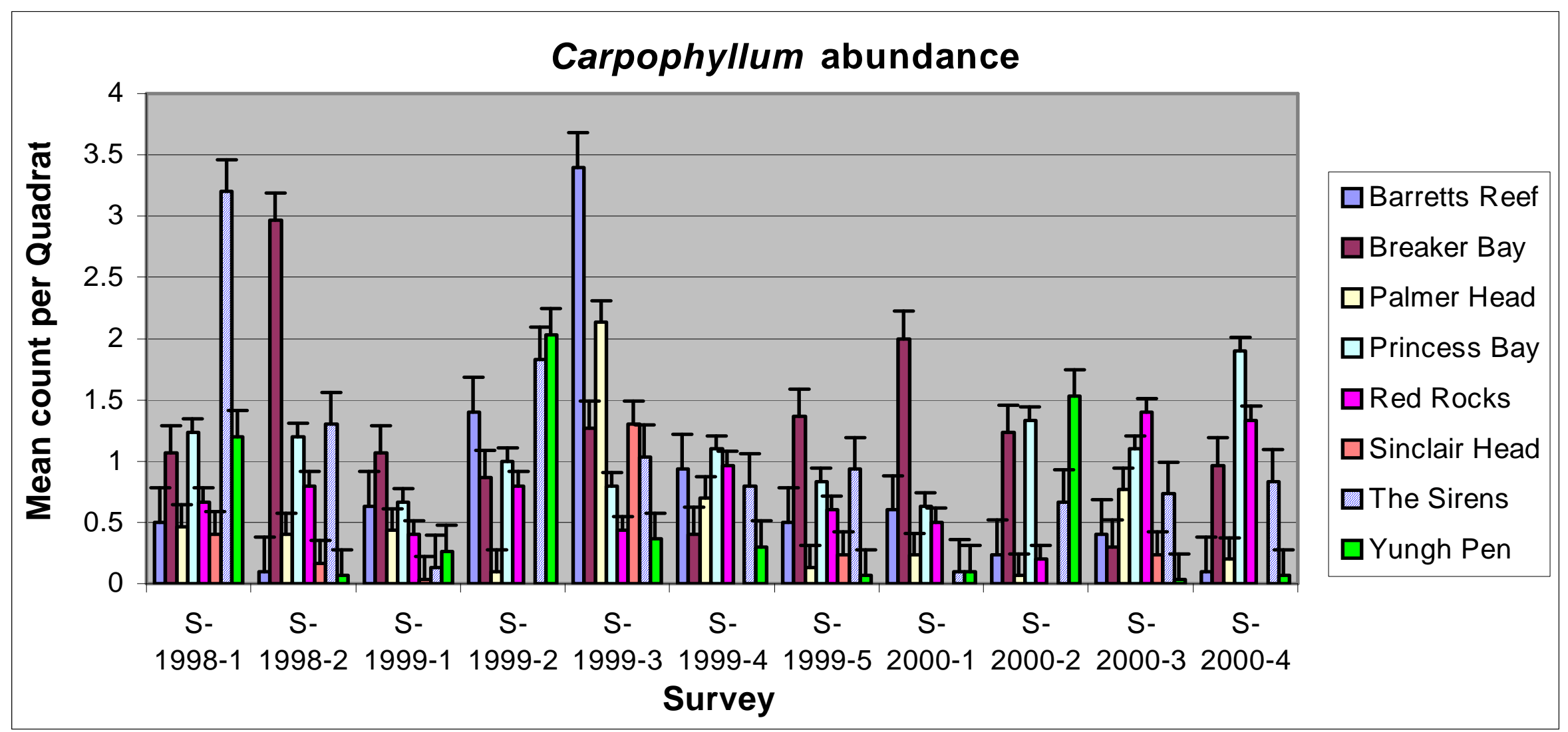


Fig. 3.9. Ecklonia radiata abundance at all 8 sites on the south coast at each survey period.

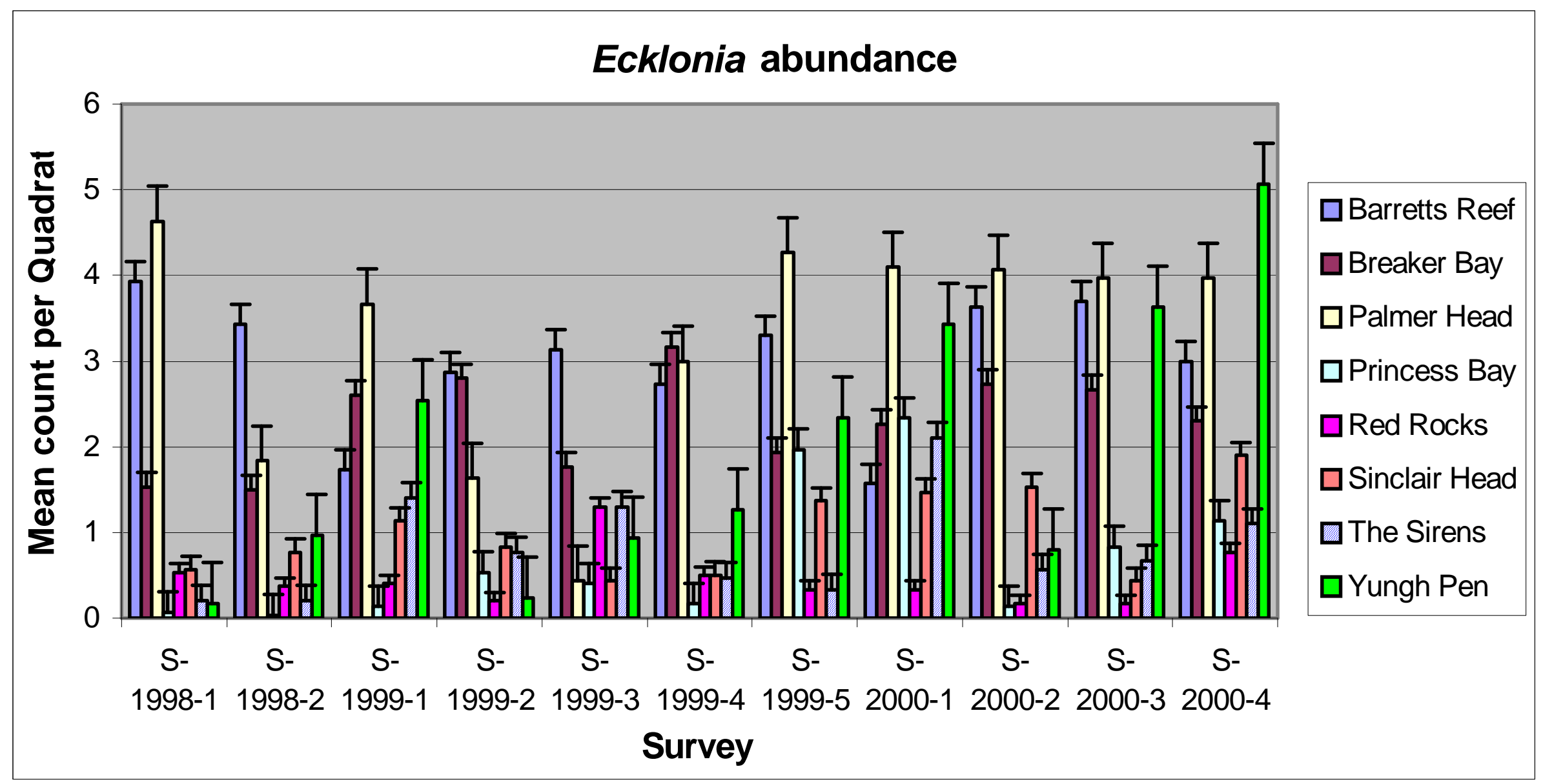


Fig. 3.10. Lessonia variegata abundance at all 8 sites on the south coast at each survey period.

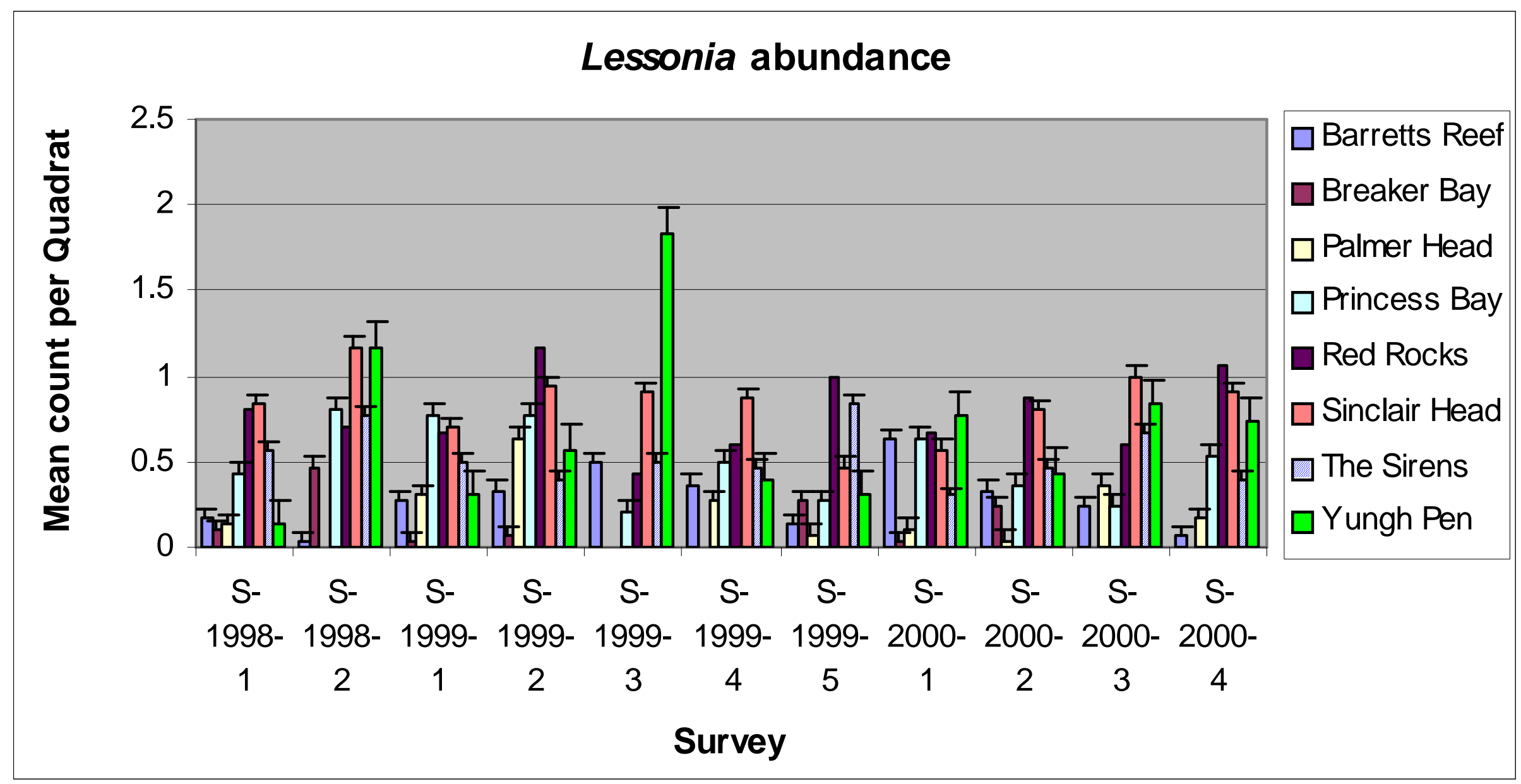


Fig. 3.11. Spotty abundance at all 8 sites on the south coast at each survey period.

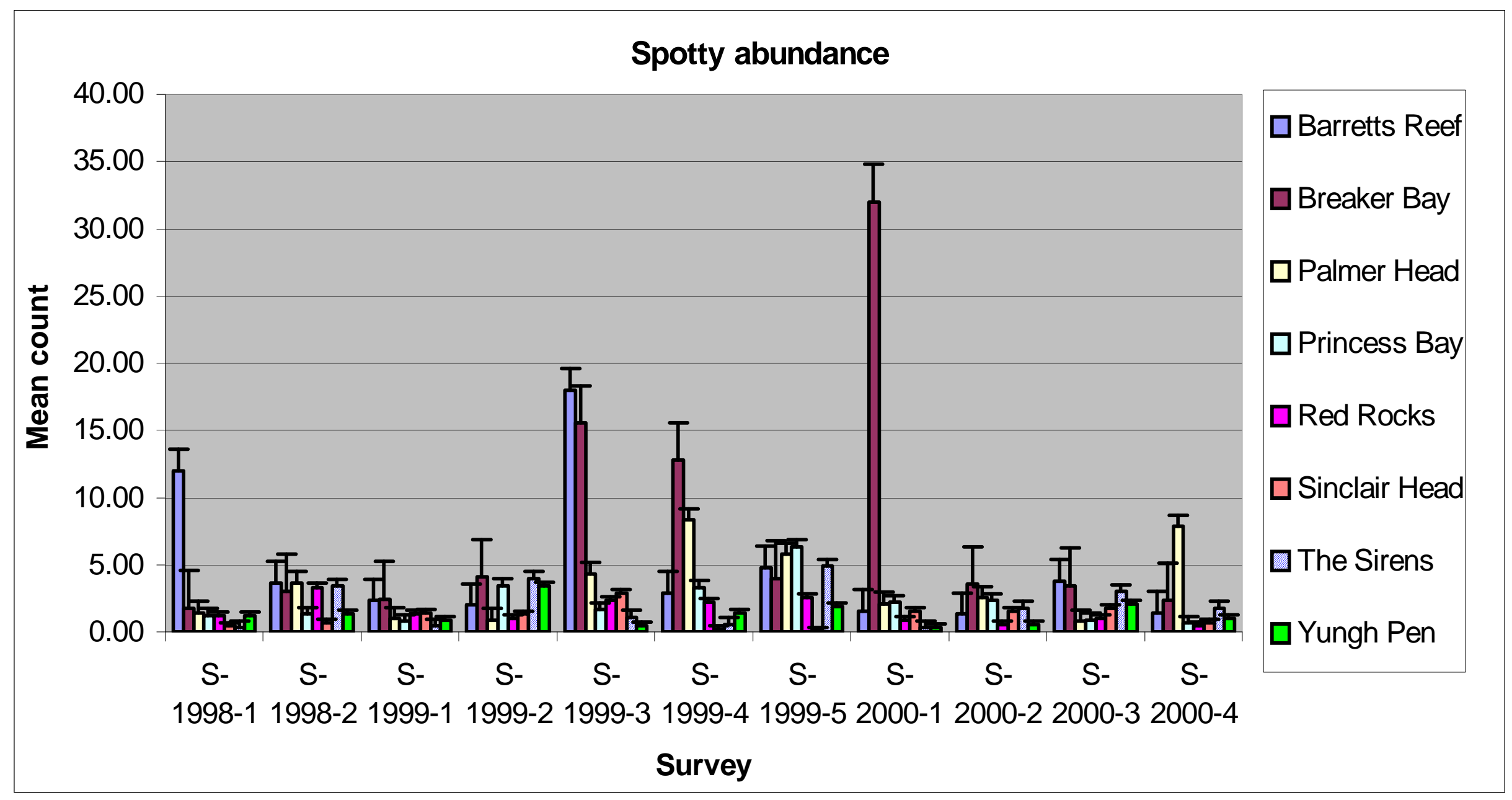


Fig. 3.12. Black foot paua abundance at all 8 sites on the south coast at each survey period.

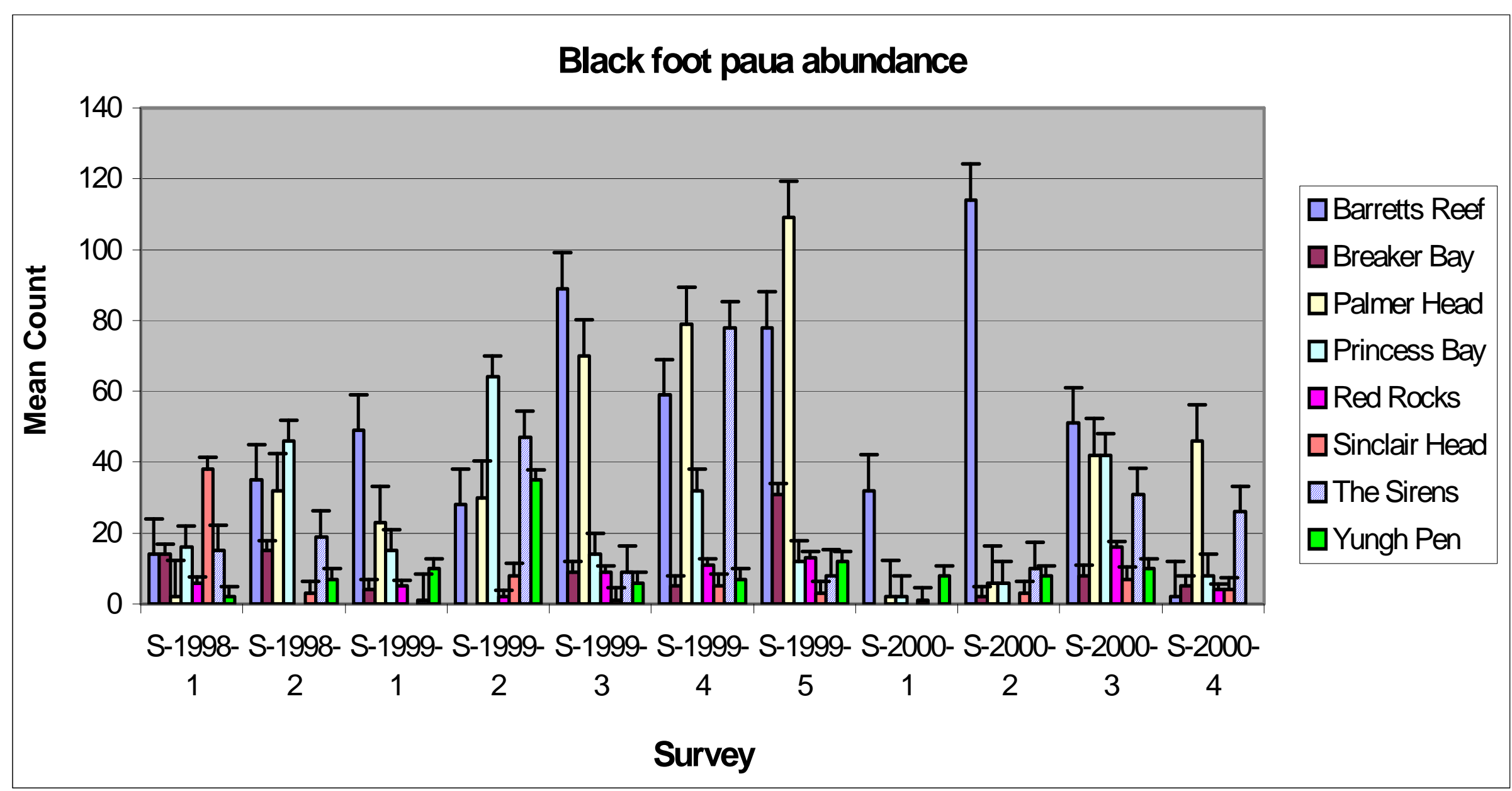


Fig. 3.13. Kina abundance at all 8 sites on the south coast at each survey period.

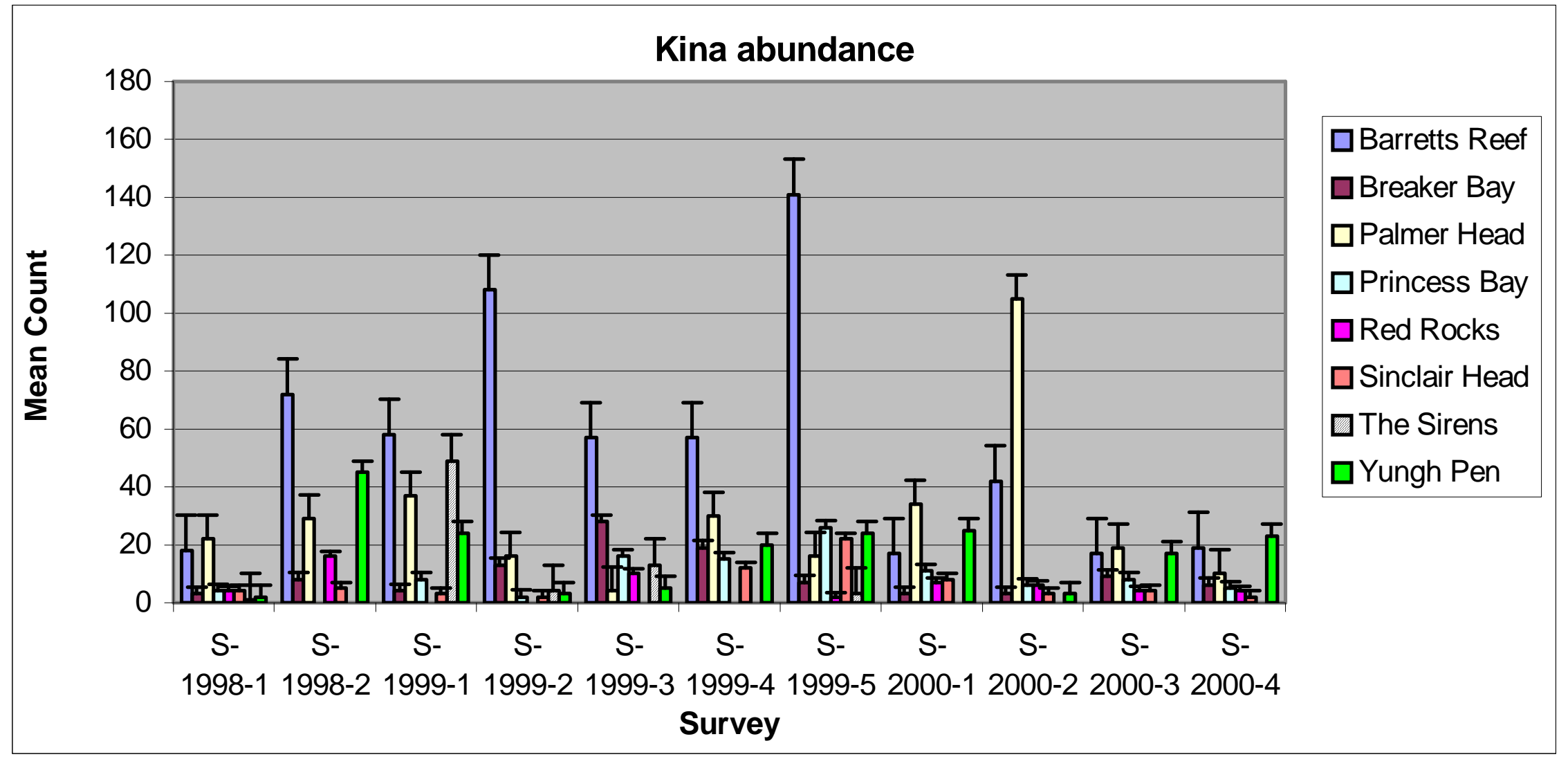


ANOVA tests were then carried out on square root transformed size data to test for differences among sites. Significant results are presented in Table 3.4.

Table 3.4. Significant results (before and after correction for multiple testing) of ANOVA testing for differences among sites on the Wellington south coast on square root transformed size data.

\begin{tabular}{ll}
\hline Species & $P$-value \\
\hline Kina & 0.011 \\
\hline
\end{tabular}

For size, kina was the only species that showed a significant difference in size among sites. However, this was not significant after correction for multiple testing.

\section{$\underline{\text { 3.4.3 Power analysis }}$}

These ANOVA results were subject to a power analysis to test whether the data collected from this investigation would be powerful enough to detect a change in species abundance should it occur. The power analysis was performed using results from ANOVA tests on $\log _{\mathrm{e}}$ transformed data only.

These results are presented in Table 3.5. 
Table 3.5. Power of the data collected on the Wellington south coast to detect a change in species abundance.

\begin{tabular}{llll}
\hline Species & Power & Effect size & $\begin{array}{l}\text { Change in sampling effort } \\
\text { required to get 80\% power }\end{array}$ \\
\hline Carpophyllum & & & $0.33 \mathrm{X}$ \\
maschalocarpum & $98 \%$ & 0.6 & \\
Ecklonia radiata & & & N/A (software limitation) \\
Lessonia variegata & $100 \%$ & 1 & N/A (software limitation) \\
Banded wrasse & $100 \%$ & 1 & $1.09 \mathrm{X}$ \\
Blue cod & $79 \%$ & 0.42 & $3.5 \mathrm{X}$ \\
Blue moki & $24 \%$ & 0.41 & $1.25 \mathrm{X}$ \\
Butterfish & $69 \%$ & 0.45 & $3 \mathrm{X}$ \\
Marblefish & $28 \%$ & 0.28 & $4.5 \mathrm{X}$ \\
Spotty & $14 \%$ & 0.52 & $0.45 \mathrm{X}$ \\
Trevally & $100 \%$ & 0.67 & $3.3 \mathrm{X}$ \\
Red moki & $22 \%$ & 0.48 & $2 \mathrm{X}$ \\
Tarakihi & $39 \%$ & 0.5 & $3.3 \mathrm{X}$ \\
Scarlet wrasse & $22 \%$ & 0.46 & $3.2 \mathrm{X}$ \\
Black foot paua & $26 \%$ & 0.32 & $0.6 \mathrm{X}$ \\
Rock lobster & $99 \%$ & 0.63 & $1.5 \mathrm{X}$ \\
Kina & $59 \%$ & 0.63 & $0.4 \mathrm{X}$ \\
Yellow foot paua & $100 \%$ & 0.81 & $1.1 \mathrm{X}$ \\
\hline & $89 \%$ & 0.49 & \\
\hline & & & 0.5 \\
\hline
\end{tabular}

Data collected for Carpophyllum maschalocarpum, Ecklonia radiata, Lessonia variegata, spotty, black foot paua, kina and yellow foot paua had a power of more than $80 \%$ (which is the standard power considered suitable) to detect a significant change in species abundance. Banded wrasse has a power of $79 \%$ and blue moki has a power of $69 \%$, both of which are relatively high. Power of the data for other species falls well below the threshold mark of $80 \%$.

These results can be used to determine the sampling effort required to reach $80 \%$ power to detect a change in a certain species. For example for red moki the increase in sampling effort required is twofold. In this investigation nine replicate transects were used, therefore $9 \times 2=18$. Eighteen transects of the same size as in this investigation, would need to be surveyed to reach $80 \%$ power in sampling effort. 


\subsubsection{Multi Dimensional Scaling}

$\mathrm{H}_{0}=$ All sites are equally similar or dissimilar to one another.

Multidimensional scaling was used to examine relationships among all eight sites using abundance data from all species, across all time periods. The MDS procedure was then repeated using the data from fish, invertebrates and algae separately to examine the relationships among sites for each of these groups independently.

Fig. 3.14. MDS of all 8 sites on the Wellington south coast using data from all species across all time periods.

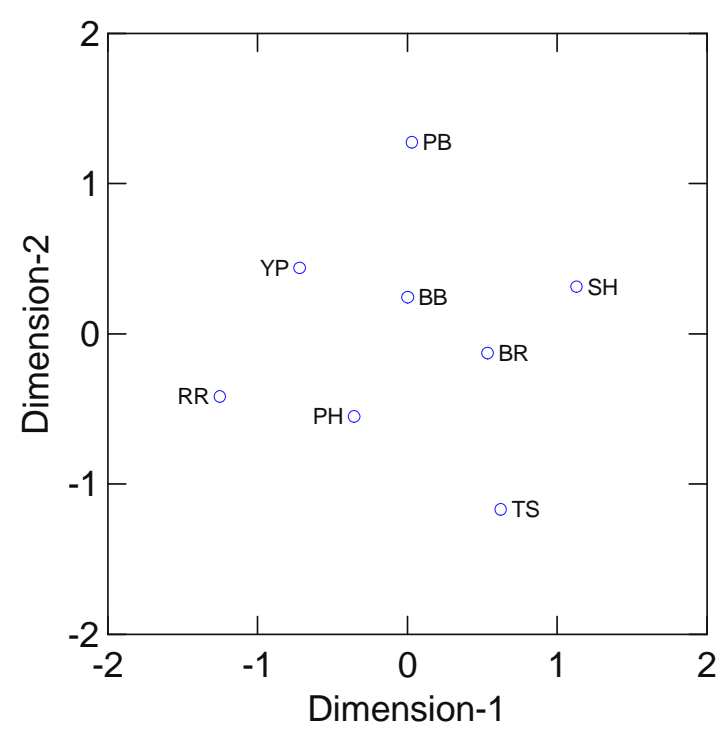


Fig. 3.15. MDS using fish abundance data only from all 8 sites on the Wellington south coast (across all time periods).

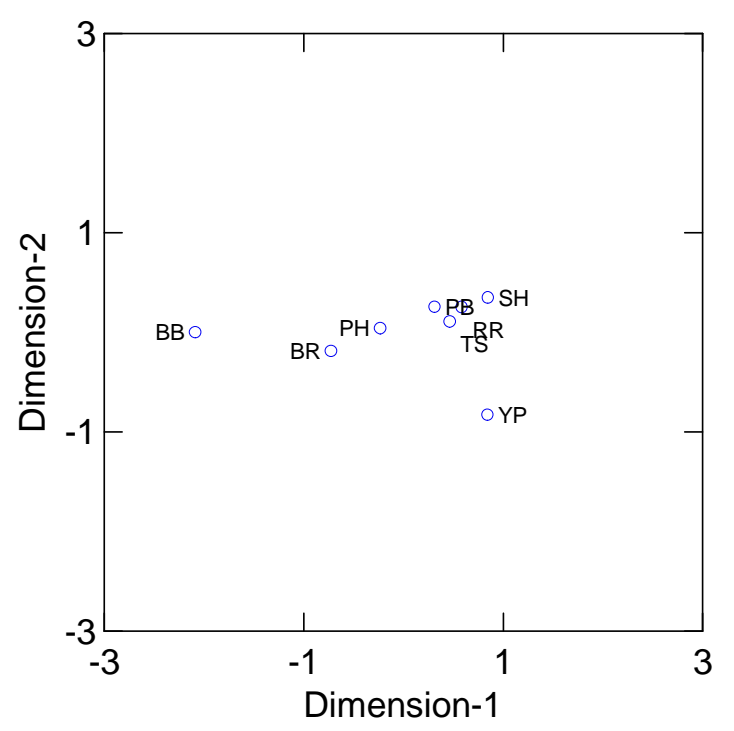

Fig. 3.16. MDS using invertebrate abundance data only from all the sites on the Wellington south coast (across all time periods).

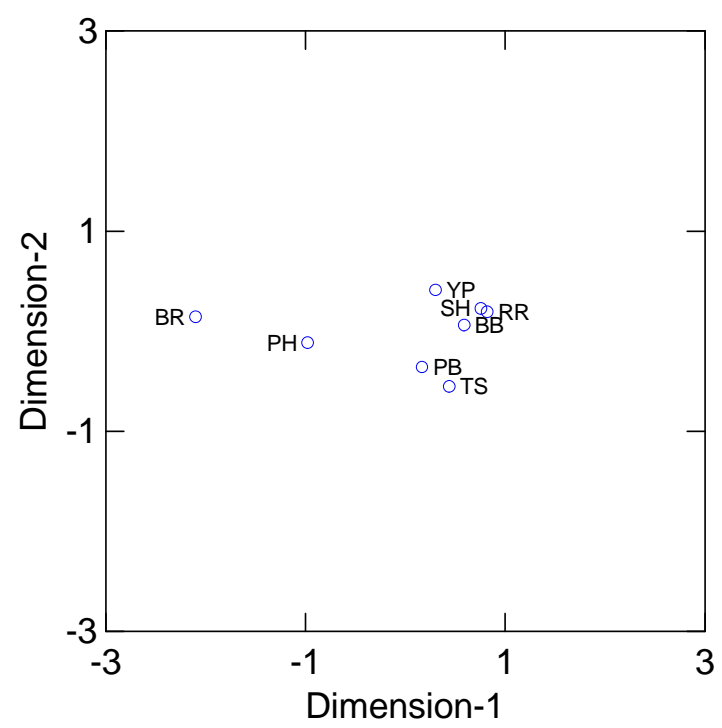


Fig. 3.17. MDS using algae abundance data only from all 8 sites on the Wellington south coast (across all time periods).

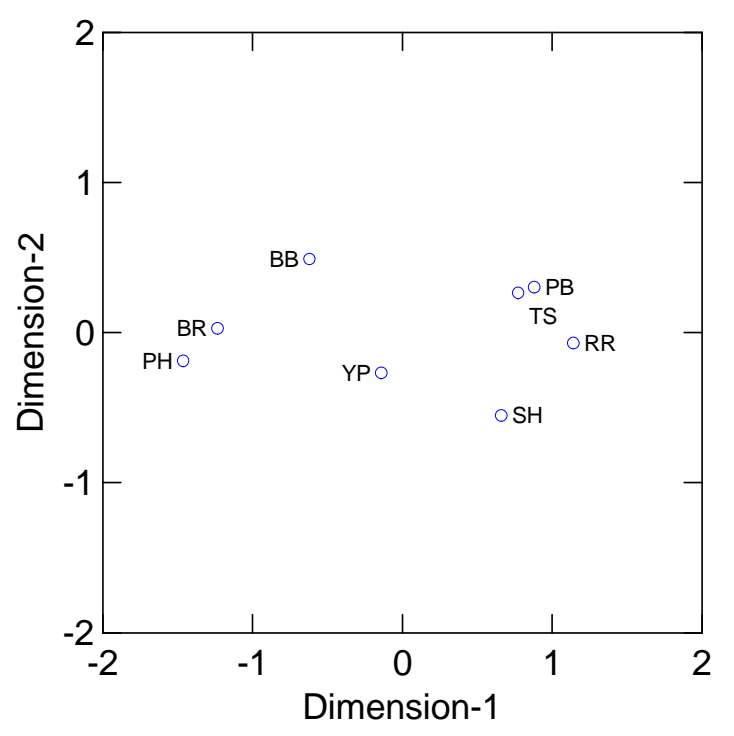

As can be seen from these diagrams, using the whole suite of species for the MDS Fig. (3.14.), the sites are fairly well distributed in both dimensions and there is no immediately obvious similarity or dissimilarity between any given pair sites.

However, when the MDS picture is split into its component species, there is evidence for a west to east spread along dimension one. It is most obvious in the fish dataset where Breaker Bay and Barretts Reef, the two eastern most sites are separated along dimension one followed then by Palmer Head, which is the next easternmost site. Barretts Reef and Palmer Head are separated along this axis for both invertebrates and algae also. Breaker Bay is likewise separated for algae, however for invertebrates it is clustered with the more western situated sites. The four western sites are clustered closer together and are not as spread out along dimension one, but all four are definitely separated from the eastern most sites. This would indicate that dimension one represents a geographical component, but there is no obvious indication what dimension two might represent.

\section{$\underline{\text { 3.4.5 Seasonal Variation }}$}

$\mathrm{H}_{0}=$ There is no significant difference in abundance among time periods. 
Fig. 3.18. Actual sea surface temperatures recorded over the course of this study vs the average temperatures historically recorded.

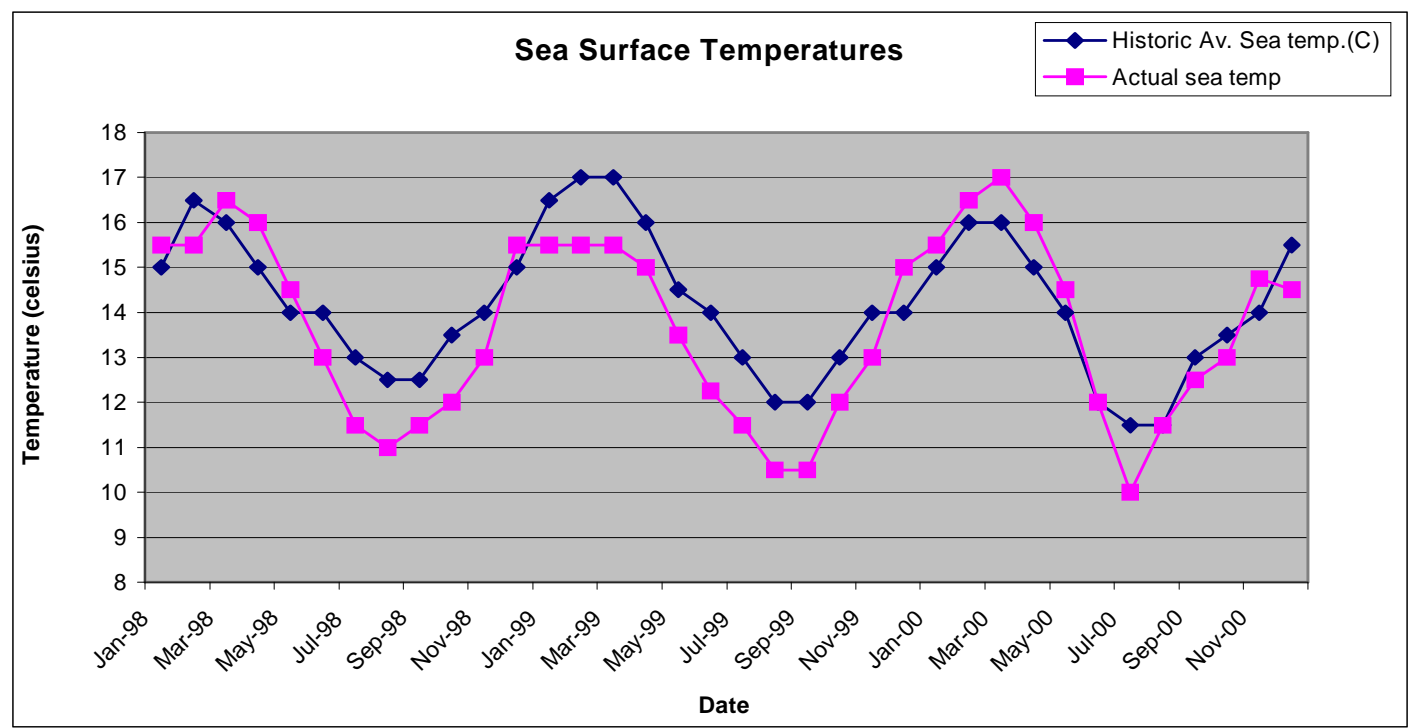

As explained in the methods a correlation analysis was performed between $\log _{\mathrm{e}}$ transformed count data and sea surface temperature. A significant correlation was found for ten species, so it was included in the model. The first model using time as a factor was:

Time

Site

Time*Site (interaction between time and site)

Sea surface temperature (co-variate)

Using the whole model, the results for the following species were significant:

Spotty

Carpophyllum maschalocarpum

Ecklonia radiata

Lessonia variegata

Trevally

Kina

So for these species the stepwise analysis was performed to determine which of the factors contributed significantly to the model. 
Table 3.6. Results of 2 factor ANCOVA for spotty abundance on the Wellington south coast indicating which factors are significant in explaining variability.

\begin{tabular}{lll}
\hline Factor & $P$-value & Significance \\
\hline Time & 0.334 & NS \\
Site & 0.000 & Sig \\
Time*Site (interaction) & $>0.05$ & NS \\
Sea surface temperature (co-variate) & 0.270 & NS \\
\hline
\end{tabular}

Table 3.7. Results of 2 factor ANCOVA for Kina abundance on the Wellington south coast, indicating which factors are significant in explaining variability.

\begin{tabular}{lll}
\hline Factor & $P$-value & Significance \\
\hline Time & 0.561 & $\mathrm{NS}$ \\
Site & 0.000 & $\mathrm{Sig}$ \\
Time*Site (interaction) & $>0.05$ & $\mathrm{NS}$ \\
Sea surface temperature (co-variate) & 0.707 & $\mathrm{NS}$ \\
\hline
\end{tabular}

Table 3.8. Results of 2 factor ANCOVA for Trevally abundance on the Wellington south coast, indicating which factors are significant in explaining variability.

\begin{tabular}{lll}
\hline Factor & $P$-value & Significance \\
\hline Time & 0.141 & NS \\
Site & 0.231 & NS \\
Time*Site (interaction) & $>0.05$ & NS \\
Sea surface temperature (co-variate) & 0.719 & NS \\
\hline
\end{tabular}


Table 3.9. Results of 2 factor ANCOVA for Lessonia variegata on the Wellington south coast, indicating which factors are significant in explaining variability.

\begin{tabular}{lll}
\hline Factor & $P$-value & Significance \\
\hline Time & 0.556 & $\mathrm{NS}$ \\
Site & 0.000 & $\mathrm{Sig}$ \\
Time*Site (interaction) & $>0.05$ & $\mathrm{NS}$ \\
Sea surface temperature (co-variate) & 0.313 & $\mathrm{NS}$ \\
\hline
\end{tabular}

Table 3.10. Results of 2 factor ANCOVA for Ecklonia radiata on the Wellington south coast, indicating which factors are significant in explaining variability.

\begin{tabular}{lll}
\hline Factor & $P$-value & Significance \\
\hline Time & 0.606 & NS \\
Site & 0.000 & Sig \\
Time*Site (interaction) & 0.173 & NS \\
Sea surface temperature (co-variate) & $>0.05$ & NS \\
\hline
\end{tabular}

Table 3.11. Results of 2 factor ANCOVA for Carpophyllum maschalocarpum on the Wellington south coast, indicating which factors are significant in explaining variability.

\begin{tabular}{lll}
\hline Factor & $P$-value & Significance \\
\hline Time & 0.116 & NS \\
Site & 0.001 & Sig \\
Time*Site (interaction) & $<0.05$ & Sig \\
Sea surface temperature (co-variate) & 0.037 & Sig \\
\hline
\end{tabular}

Carpophyllum maschalocarpum was the only species where the time-site interaction was significant. This implies that time and site cannot be interpreted as independent factors. Carpophyllum maschalocarpum was also the only species where sea surface temperature was significant. For all species site was significant, except Trevally. This indicates that no seasonal variation (i.e. significant change in species abundance over time) was detected over the time which this data was collected. 


\subsubsection{Algal damage}

$\mathrm{H}_{0}=$ There is no difference in algal damage among sites.

ANCOVA tests on algal damage were run using the following model.

Site

Damage

Time

Time* Damage (interaction)

Site*Damage (interaction)

Site*Damage*Time

Sea surface temperature

The whole model was significant for Lessonia variegata, Carpophyllum maschalocarpum and Ecklonia radiata.

The results were as follows.

Table 3.12. Results from a 3-factor ANCOVA for Lessonia variegata on the Wellington south coast, indicating the significance of each factor in the model.

\begin{tabular}{lll}
\hline Factor & $P$-value & Significance \\
\hline Time & 0.899 & $\mathrm{NS}$ \\
Site & 0.000 & $\mathrm{Sig}$ \\
Damage & 0.000 & $\mathrm{Sig}$ \\
Time*Damage (interaction) & $<0.05$ & $\mathrm{Sig}$ \\
Site*Damage (interaction) & $>0.05$ & $\mathrm{NS}$ \\
Site*Damage*Time (interaction) & $>0.05$ & $\mathrm{NS}$ \\
Sea surface temperature & $>0.05$ & $\mathrm{NS}$ \\
\hline
\end{tabular}


Table 3.13. Results from a 3-factor ANCOVA for Ecklonia radiata on the Wellington south coast, indicating the significance of each factor in the model.

\begin{tabular}{lll}
\hline Factor & $P$-value & Significance \\
\hline Time & 0.656 & NS \\
Site & 0.000 & Sig \\
Damage & 0.000 & Sig \\
Time*Damage (interaction) & $>0.05$ & NS \\
Site*Damage (interaction) & $<0.05$ & Sig \\
Site*Damage*Time (interaction) & $>0.05$ & NS \\
Sea syrface temperature & $>0.05$ & NS \\
\hline
\end{tabular}

Table 3.14. Results of a 3-factor ANOVA for Carpophyllum maschalocarpum on the Wellington south coast, indicating the significance of each factor in the model.

\begin{tabular}{lll}
\hline Factor & $P$-value & Significance \\
\hline Time & 0.543 & NS \\
Site & 0.003 & Sig \\
Damage & 0.000 & Sig \\
Time*Damage (interaction) & $>0.05$ & NS \\
Site*Damage (interaction) & $<0.05$ & Sig \\
Site*Damage*Time (interaction) & $>0.05$ & NS \\
Sea surface temperature & $<0.05$ & Sig \\
\hline
\end{tabular}

For Lessonia variegata the time-damage interaction was found to be significant (i.e. that the amount of types of damage was not the same at all times) and there was a significant difference in amounts of damage among sites. For the two other species the damage-site interaction was significant, indicating that the site was correlated to the amount of damage found at different sites. Where the interaction between two factors is significant one cannot easily interpret the effects of each factor alone as they are correlated in a fashion that may not be obvious.

The algal damage for the different species at the different sites are displayed graphically in Appendix 1. 
3.4.7 Comparison to previous data

$\mathrm{H}_{0}=$ There is no difference between the two time periods.

The comparisons between the data collected in 1997 and 1998-2000 generally showed no significant difference. The results are presented below in Tables 3.15.-3.17.

Table 3.15. ANOVA results testing for differences in species abundance between 1997 and this investigation at Princess Bay.

\begin{tabular}{lll}
\hline Species & $P$-value & Significance \\
\hline Black foot paua & N/A & N/A \\
Yellow foot paua & 0.464 & NS \\
Kina & 0.075 & NS \\
Blue moki & 0.073 & NS \\
Blue cod & 0.064 & NS \\
Butterfish & N/A & N/A \\
\hline
\end{tabular}

Table 3.16. ANOVA results testing for differences in species abundance between 1997 and this investigation at the Yungh Pen.

\begin{tabular}{lll}
\hline Species & $P$-Value & Significance \\
\hline Black foot paua & 0.179 & NS \\
Yellow foot paua & 0.407 & NS \\
Kina & 0.964 & NS \\
Blue moki & 0.025 & Sig \\
Blue cod & 0.031 & Sig \\
Butterfish & 0.118 & NS \\
\hline
\end{tabular}


Table 3.17. ANOVA results testing for differences in species abundance between 1997 and this investigation at the Sirens.

\begin{tabular}{lll}
\hline Species & $P$-value & Significance \\
\hline Black foot paua & N/A & N/A \\
Yellow foot paua & N/A & N/A \\
Kina & N/A & N/A \\
Blue moki & 0.023 & NS \\
Blue cod & 0.094 & NS \\
Butterfish & 0.023 & NS \\
\hline
\end{tabular}

When size data were tested, all results were non significant.

These results show that there has been no significant change in species abundance (for most of those species tested) at the sites examined since 1997 and during the present investigation.

\subsubsection{Algal percent cover}

The breakdown of algal percent cover for each site on the south coast is given in tables 3.18.-3.25.

Table 3.18. Percent cover of algal species at Breaker Bay.

\begin{tabular}{ll}
\hline Algal species & Percent cover \\
\hline Carpophyllum maschalocarpum & 30.5 \\
Ecklonia radiata & 30 \\
Bare rock & 29.7 \\
Lessonia variegata & 9.38 \\
Macrocystis pyrifera & 0.83 \\
\hline
\end{tabular}


Table 3.19. Percent cover of algal species at Barretts Reef.

\begin{tabular}{ll}
\hline Algal species & Percent cover \\
\hline Ecklonia radiata & 40.11 \\
Lessonia variegata & 31.22 \\
Carpophyllum maschalocarpum & 10.83 \\
Landsbergia quercifolia & 7.61 \\
Bare rock & 7.61 \\
Marginariella urvilliana & 2.5 \\
\hline
\end{tabular}

Table 3.20. Percent cover of algal species at Palmer Head.

\begin{tabular}{ll}
\hline Algal species & Percent cover \\
\hline Ecklonia radiata & 69.5 \\
Bare rock & 19 \\
Carpophyllum maschalocarpum & 7.67 \\
Lessonia variegata & 1.94 \\
Landsbergia quercifolia & 1.89 \\
\hline
\end{tabular}

Table 3.21. Percent cover of algal species at Princess Bay.

\begin{tabular}{ll}
\hline Algal species & Percent cover \\
\hline Bare rock & 26.11 \\
Carpophyllum maschalocarpum & 19.83 \\
Lessonia variegata & 18 \\
Carpophyllum flexuosum & 13.56 \\
Cystophora retroflexa & 12.83 \\
Caulerpa brownii & 8.17 \\
Ecklonia radiata & 1.5 \\
\hline
\end{tabular}


Table 3.22. Percent cover of algal species at The Sirens.

\begin{tabular}{ll}
\hline Algal species & Percent cover \\
\hline Bare rock/cobble & 24.22 \\
Lessonia variegata & 22.89 \\
Carpophyllum maschalocarpum & 21 \\
Ecklonia radiata & 14.67 \\
Caulerpa brownii & 11.67 \\
Other & 4.17 \\
Cystophora retroflexa & 2.22 \\
\hline
\end{tabular}

Table 3.23. Percent cover of algal species at the Yungh Pen.

\begin{tabular}{ll}
\hline Algal species & Percent cover \\
\hline Carpophyllum flexuosum & 34.72 \\
Bare rock & 25 \\
Lessonia variegata & 13.78 \\
Caulerpa brownii & 9.22 \\
Ecklonia radiata & 8.78 \\
Cystophora retroflexa & 5.83 \\
Other & 1.55 \\
Carpophyllum maschalocarpum & 1.22 \\
\hline
\end{tabular}

Table 3.24. Percent cover of algal species at Red Rocks.

\begin{tabular}{ll}
\hline Algal species & Percent cover \\
\hline Lessonia variegata & 29.22 \\
Bare rock & 18.11 \\
Carpophyllum maschalocarpum & 7 \\
Carpophyllum flexuosum & 6.61 \\
Marginariella urvilliana & 6.61 \\
Caulerpa brownii & 1.67 \\
Ecklonia radiata & 0.44 \\
\hline
\end{tabular}


Table 3.25. Percent cover of algal species at Sinclair Head.

\begin{tabular}{ll}
\hline Algal species & Percent cover \\
\hline Lessonia variegata & 53.89 \\
Bare rock & 21.33 \\
Ecklonia radiata & 10.06 \\
Marginariella urvilliana & 5.22 \\
Landsbergia quercifolia & 2.39 \\
Carpophyllum flexuosum & 2.22 \\
Caulerpa brownii & 1.72 \\
Carpophyllum maschalocarpum & 1.56 \\
\hline
\end{tabular}

In general the most common algal species present at the 8 sites on the south coast are Lessonia variegata, Carpophyllum maschalopcarpum, C. Flexuosum and Ecklonia radiata. Breaker Bay was the only site where Macrocystis pyrifera was recorded.

\subsection{Discussion}

\subsubsection{Site Similarity}

Both the Kruskal-Wallis and ANOVA tests on the data from the present investigation showed that Ecklonia radiata, Lessonia variegata and black foot paua abundance was significantly different among sites. Additionally the ANOVA tests for Carpophyllum maschalocarpum, kina and spotty abundance also showed significant differences between sites. Post Hoc pairwise comparisons showed that the sites that significantly differed from each other were often sites that were spatially well separated. Usually Breaker Bay and Barretts Reef were clustered together and were significantly different from another site cluster that often included Sinclair Head. This pattern was not perfect as an eastern site would often be grouped together with a western site. In general, however, the more western sites tended to be grouped together and these would be significantly different from one or all of the eastern sites.

A similar trend was shown in the MDS diagrams. When the whole suite of species (all fish, invertebrates and algae) was included, the sites were all equally similar (or dissimilar), but the MDS diagrams using only fish, algae or invertebrates all showed a more pronounced clustering of sites in dimension-2 and a separation of the eastern from the western sites. Specifically, Breaker Bay and Barretts Reef were well separated from 
the other sites, and although the pattern was not perfect, the next sites to be separated were generally the next most eastern located ones, such as Palmer Head and Princess Bay.

These results suggest the existence of a community structure gradient from east to west. Table 3.3 shows mean abundances for those species for which statistical tests showed a significant difference among sites. The results in this table also indicate an east to west pattern as the species abundance in the more easterly located sites is often greater than the more westerly located sites. Although the sites on the MDS diagram were distinctly separated along dimension one, the sites were very well clustered together along dimension two. There is a possibility that this east to west gradient is related to the nutrient levels along the coastline. A current study at the Island Bay Marine Laboratory is examining whether nutrient depletion is the cause of lack of mussels on the Wellington south coast (J. Helson, pers. comm.). This study has shown that chlorophyll content, particulate and percent organic matter are higher in harbour sites than coastal sites ( $\mathrm{J}$. Helson, pers.comm.). Therefore, the eastern sites in the present study which are located closer to the harbour entrance are likely to have higher nutrient levels than the rest of the south coast. Moa Point, a site of a sewer outfall, is also likely to be an area containing high nutrient levels, as is common in areas of effluent discharge (Stephen and Fitzmaurice Consulting Civil and Sanitary Engineers, 1976). Bowman et al., 1983b stated that the seas in Cook Strait are strongly influenced by both wind and tides and therefore it is an area of mixing for waters of both subtropical and subantarctic origins. Under increasing wind stress, prevailing patterns are easily upset and slope currents develop that eject warm nutrient depleted subtropical waters into the surface layers of Cook Strait. This could indicate that as one moves further west of the harbour entrance, the waters become less nutrient rich.

Tidal flows also decrease erratically eastwards along the Wellington south coast away from the notorious Terawhiti Rip of Cook Strait Narrows (i.e. tides become progressively stronger to the west) (Carter and Lewis, 1995).These habitat characteristics indicate that the east to west gradient observed during the present study, may contain a geographical component. Cotsilinis (1999) found evidence for a diversity gradient in intertidal organisms, increasing from west to east along the Wellington south coast. He suggested that the larvae and/or spores of certain species are unable to reach certain sites to settle and recruit due to the westward flow of the prevailing currents. He also suggested that wave exposure could be a factor affecting intertidal community diversity. Since the south 
coast is generally characterised by exposure tolerant organisms, as exposure decreases, these species may be less abundant, but may be replaced by another suite of species.

Particular species of macroalgae are good indicators of environmental variables and can be used to distinguish differences in community composition for the sites in the present study. For example, when sites were examined individually, Breaker Bay was the only site where Macrocystis pyrifera was recorded regularly during this investigation. This alga is very common in the harbour, yet apart from this one site was not recorded anywhere on the south coast. Macrocystis pyrifera is known to occur in calmer bays and harbours (Adams, 1994). Breaker Bay is a relatively sheltered site compared to the other sites as it is located in a large bay. It is located very close to the harbour entrance. Thus it is possible that this site is more similar to the harbour habitat in terms of wave exposure and nutrient levels than other sites on the south coast, and was therefore shown to be significantly different from the other sites.

Barretts Reef is an exposed site as it is an offshore reef, but it is directly in line with the harbour entrance. Therefore it is possible that this site is an anomaly (i.e. it is an exposed site but probably still receives relatively high nutrient levels). Most exposed sites on the south coast are located far away from the harbour entrance and therefore are unlikely to have high nutrient levels. Anecdotally, it has been reported that a higher diversity and abundance of fish are seen here compared to other areas on the south coast (R. Williamson pers. comm.). Of the species that were significantly different in abundance amongst sites, Barretts Reef supported the highest average number of black foot paua, kina and spotty.

Sinclair Head is the westernmost site surveyed in this investigation. This site is very exposed and subject to strong currents and a large tidal amplitude. Compared to the other sites, it is located furthest away from the harbour entrance. Therefore it is unlikely that much of the harbour water mass reaches this site. Due to this harsh environment, the site might support a different suite of species compared to the two sites mentioned above. Conversely to Barretts Reef, of the species that were significantly different in abundance among sites, Sinclair Head had the lowest mean number of black foot paua, kina and spotty. These three sites are at the extreme ends of the coastline surveyed and with these distinct differences in habitat characteristics, it was to be expected that the biological communities were found to be significantly different to other sites. 
When the percent algal cover at the various sites was examined, it was evident that Lessonia variegata was the dominant alga found at both Sinclair Head and Red Rocks, which are the two westernmost and therefore most exposed sites investigated in the present study. This alga is described by Adams (1994), as a plant of exposed coasts. It was also the dominant species at The Sirens, which is the fourth most western site. Although it was not dominant at the Yungh Pen (the third most western site) this was not entirely unexpected as parts of the Yungh Pen site are slightly protected by an offshore reef. Ecklonia radiata was present at all sites as its habitat range is subtidal on both moderately sheltered and exposed coasts in New Zealand (Adams, 1994). Similarly, Carpophyllum maschalocarpum and C. flexuosum, which are also abundant on this coast, have a habitat range from very sheltered to very exposed coasts (Adams, 1994). Thus it was highly probable that these species would be found at most sites on the south coast of Wellington.

Jennings et al. (1996) stated that fish distributions vary with respect to local topography, current flow and exposure, algal cover and other habitat variables. Therefore, the understanding of habitat effects on fish distribution can explain unusual or unexpected variance in fish distribution in studies that seek to determine the effects (such as reservation) of other processes on fish distribution. For example Rakitin and Kramer (1996) found a gradient of decreasing fish catch rate with increasing distance from the centre of the Barbados marine reserve. They hypothesized that this was due to net movement of fish from the reserve to fished areas outside the reserve. However, Chapman and Kramer (1999) stated that Rakitin and Kramer (1996) did not examine the effects of habitat variables on fish density or catch rate. The observed spatial gradient may therefore have been due to spatial gradients in factors that affect density and catch rate such as habitat characteristics like those mentioned previously. Good temporal and spatial data collected before reservation would eliminate speculation as to whether a gradient such as the one found by Rakitin and Kramer (1996) was due to a reservation effect, or due to habitat variables affecting the natural distribution of fish populations, thus highlighting the importance of baseline studies.

There are important implications for marine reserve monitoring with respect to the presence of such a gradient and distinctive differences amongst sites. Should a reserve be established on the south coast of Wellington and monitoring is aimed at detecting changes 
due to a reserve, these intrinsic differences must be taken into account and where possible quantified. Ideally the control sites should be close to the reserve sites monitored on an east/west scale, so that a potential gradient does not confound the results found at a later date when sites are compared. Even if there is a lack of a significant difference in habitat characteristics between reserve and control sites, it does not rule out the possibility that differences in fish (or other species) density are attributable to variations in habitat characteristics (Chapman and Kramer, 1999). Edgar and Barret (1999) stated that habitat variability was one of the major sources of bias in their visual censuses. Detailed investigations should be carried out on the relationships between key species and environmental characteristics. This would help to explain the presence of certain species at certain areas and their absence at others, thus avoiding attributing any natural spatial variations to reservation status. For instance, any relationship between an organism and a variable habitat characteristic such as sea surface temperature could explain seasonal changes in species abundance. This potential interannual variation in populations is another factor that should be quantified before monitoring of a reserve commences. This is examined further in section 3.5.3.

\subsubsection{Power Analysis}

The power analysis showed that the sampling effort for many of the species surveyed in this investigation had a low power to detect any future change in abundance (i.e. would be unlikely to detect a change even if it did occur). The sampling effort for three species of brown macroalgae (Carpophyllum maschalocarpum, Ecklonia radiata and Lessonia variegata) had a very high power to detect change. From a statistical perspective, these species would therefore be good indicators of any change. However, high statistical power to detect change should not be the only reason to monitor these key species. Species subject to much fishing pressure are more likely to show rapid responses to reservation as a major factor (i.e. fishing) affecting population densities has been removed. Thus, species monitored should be those that are expected to benefit the most from reservation. Since algal species are not generally subject to any major form of harvesting, the rationale for monitoring these is to detect indirect changes due to reservation such as a change in community structure. The best known example of this in New Zealand is in the Cape Rodney-Okakari Point Marine Reserve, where the regeneration of kelp forests has been observed inside the reserve, due to increased predation on kina by snapper and rock lobster (Choat and Schiel, 1982, Babcock et al., 1999, Shears and Babcock, 2000). A similar occurance has been documented in a marine 
reserve that protects coral reefs, the Mombasa Marine National Park in Kenya. McClanahan (1994) found that the density of sea urchins was many times higher in areas of high fishing pressure than inside the reserve. The author concluded that this was because fishing removed some of the key predators on sea urchins, such as triggerfish. Due to this high grazing intensity of sea urchins in fishing areas, the reefs were being eroded and coral cover reduced. The degradation of the coral reefs and high urchin numbers that could out-compete fish herbivores, meant that these reefs were supporting fewer fish than healthy ones (McClanahan, 1994). Another example is the marine reserve at Maria Island in Tasmania, which showed a pronounced shift in the algal community (Edgar and Barrett, 1999). Edgar and Barrett (1999) found that the percent cover of Sargassum fallax and Cystophora retroflexa decreased inside reserve areas, corresponding to an increase in percent cover of Ecklonia radiata in respect to control sites. This type of shift may well be expected in the south coast marine reserve if it is established.

From personal observations there seemed to be a relationship between the abundance of Ecklonia radiata and Carpophyllum flexuosum at some sites. It was observed that whenever the abundance of Ecklonia radiata decreased, the abundance of Carpophyllum flexuosum increased. Since Carpophyllum flexuosum was not monitored from the start of this investigation, it was not added to the suite of species investigated, as it would have had to be left out of the analysis in most cases due to a lack of data. Therefore the relationship between these two species could not be tested as no empirical data was collected. Future monitoring should include this species, as a change in algal community structure seems likely to include a relationship between Ecklonia radiata and Carpophyllum flexuosum.

Based on the intensity of sampling adopted during the present study, kina and any paua species would also make good indicators of change (i.e. high power to detect change). Additionally, these species are relatively sessile so the results would not be confounded by their movement between sites or across reserve boundaries. According to Edgar and Barrett (1999) the effectiveness of a marine reserve depends on the mobility of the target species, so that relatively sessile species like abalone (paua) are the most likely to be protected in a small reserve. Edgar and Barrett (1999) also found that increasing numbers of large abalone within the reserve, corresponded with decreasing numbers of smaller individuals. Thus one could expect that paua would show a detectable response to 
reservation status, even if the established reserve is small compared to other reserves in New Zealand. Urchin (kina) barrens were a common feature of the Cape Rodney-Okakari Point Marine Reserve, where, as mentioned previously, an increase in algal cover was seen in the reserve, which was attributed to decreased numbers of kina (Choat and Schiel, 1982, Babcock et al., 1999). Urchin barrens are not a common feature of the south coast, as there are few echinoids present. Although in relatively sheltered areas these echinoids may actively forage and clear large areas of macroscopic algae, in turbulent areas such as the south coast, they are sedentary, feeding in very localised areas and on drift material (Choat and Schiel,1982). Effects that marine reserve establishment would have on kina numbers on the south coast are likely be very different from the Cape Rodney-Okakari Point Marine Reserve. Edgar and Barrett (1997) found that abundance of sea urchins increased inside the Maria Island Marine Reserve in Tasmania. The current investigation showed the abundance of kina in the Kapiti Marine Reserve to have increased (see chapter 4). This is the type of change I would expect in the Taputeranga Marine Reserve, so continued monitoring of kina is recommended.

A large increase in sampling effort of rock lobster is needed to reach a sufficient level of power. Since rock lobster are a commercially important species, it is recommended that a new monitoring methodology be adopted for rock lobster, or an increase in the sampling effort be implemented. Anecdotally, fishermen and recreational SCUBA divers report that greater numbers of rock lobsters are found at depths greater than those sampled in this study. However, it was impracticable to survey these depths $(25-30 \mathrm{~m})$ due to limited time available during SCUBA based surveys. It has also been shown that rock lobster show seasonal depth changes (MacDiarmid,1991). To obtain more powerful data on rock lobster abundance this species should be sampled at a variety of depths. Size data should also be collected as rock lobster have been known to show a marked increase in size within a reserve, notably the Cape Rodney-Okakari Point Marine Reserve (MacDiarmid and Breen, 1992). Edgar and Barrett (1999) concluded that rock lobsters must be very site attached as they grew to a large size even in two of the smaller marine reserves in Tasmania that were investigated. Data obtained from other reserves in New Zealand have also shown an increase in rock lobster size and abundance though not quite as marked (see chapter 5). This suggests that increases in rock lobster size are to be expected in the marine reserve on the south coast if it is established. 
The sampling regime employed in the present investigation for many of the reef fish species, did not show a high power to detect change. Only the data collected for spotty and banded wrasse showed a high enough power to easily detect change. These species, however, are not subject to fishing pressure, so are unlikely to show a change directly related to the implementation of a reserve. It would be more sensible to use blue moki as an indicator species. Blue moki are widespread and relatively abundant on the Wellington south coast and are also commercially and recreationally fished. Blue moki is therefore likely to show a change in size and/or abundance after fishing restrictions are enforced. The power analysis showed that the sampling effort in this investigation had a $69 \%$ power to detect a change, which was considerably higher than any of the other commercial species surveyed. If reservation does result in increasing species abundance in commonly fished species, the power of the data for these species would be expected to increase without any increase in sampling effort. While performing visual fish censuses, it is possible to monitor all species of fish seen. Therefore this is a cost effective, and simple, way to gather data for multiple species, even if certain species such as snapper, can be more accurately surveyed by other methods (Willis and Babcock, 1997). Russ and Alcala (1996) found that the density of large predatory reef fish acted as excellent indicators of the effect of marine reserve protection at two different marine reserves in the Phillipines. Snapper and blue cod have been known to show pronounced responses to the effects of marine reserve protection at different marine reserves in New Zealand (Babcock et al., 1999, Davidson, 1997). Thus several fish species are likely to be good indicators of change in the Taputeranga Marine Reserve should it be established. If all species of fish in this area are monitored, this will become evident over time.

\subsubsection{Seasonal variation}

In order to quantify interannual variation in populations before reservation status, species data was tested for seasonal variation. However, the analysis testing for seasonal variation showed no significant differences, in abundance of species, between the arbitrary seasonal classes. ANCOVA tests on data for Carpophyllum maschalocarpum showed the interaction between site and season to be significant. Since the interaction is significant, one cannot isolate the effect that either site or season individually, is having on the abundance of this species. The co-variate, sea surface temperature was also found to be a significant factor in explaining the variation in abundance of this species amongst sites. If the abundance of Carpophyllum maschalocarpum (Fig. 3.2.) is compared to (Fig. 3.18.) which shows sea surface temperatures, the peaks in Carpophyllum maschalocarpum 
abundance seem to coincide with the peaks in temperature, suggesting that abundance of this species increases with increased water temperature. Cotsilinis (1999) found that an alga previously identified as a seasonal alga (Porphyra columbina) maintained its biomass year round at sites on the south coast of Wellington. This implies that species known to show seasonal variation, might not show such distinct seasonal patterns in other locations, where it may be affected by other species present or habitat characteristics of the area. For example, it is known that algal communities may show rapid temporal changes, but this is often only in areas of high echinoid activity (Choat and Schiel, 1982), therefore indicating that change in algal communities is affected by the presence of herbivores.

It was surprising that no other species showed indications of a seasonal trend as some species are known to display seasonal changes. For example, rock lobster show marked changes in depth distribution relating to moulting, reproductive and feeding cycles (MacDiarmid, 1991). In South Africa, Buxton and Smale (1989), found Chrysoblephus laticeps (a sparid reef fish), one of the important fishes in the recreational and commercial fishery, showed seasonal differences in abundance. Seasonal changes in the abundance of Penicipelta vittiger (leatherjacket), Heliocidaris erythrogramma (sea urchin) and particularly Notolabrus tetricus (wrasse) were found by Edgar and Barrett (1997). There could be a number of reasons why no seasonal variation was found during the present study. For example, Edgar and Barrett (1997) suggested that reduced species numbers at certain times of year could be due to emigration of migratory species. Lower visibility during the colder months may influence the data collected during visual census of fish species. On the Wellington south coast, there are not many migratory species and underwater visibility is rarely good, even during summer. Seasonal effects may be small and the power of the data may not be enough to detect trends that may exist. Davidson et al. (in submission) counted, sized and measured lobsters over a period of 24 months in the Tonga Island Marine Reserve and control sites. The authors did not document any obvious seasonal changes in abundance, even though rock lobsters have been documented to show seasonal changes as previously mentioned (MacDiarmid, 1991). The authors, however, did observe a change in behaviour. In the summer months lobsters were often in the entrances to holes or completely outside the holes, compared to other times of year when they were most often well hidden. This indicates that identical species may have different behavioural patterns at varying locations, and may not always show seasonal trends. In the case of rock lobster on the south coast, no size data was collected and 
abundance data was collected only at one depth stratum, therefore any seasonal changes are unlikely to have been identified in the analysis. Therefore more detailed monitoring of rock lobster should be undertaken, inluding collection of size and sex data and sampling at different depth strata where possible.

During the course of this survey, weather patterns, such as dominant wind directions, wind speeds and temperatures were not necessarily the recorded average normal (as can be seen in Fig. 3.18.). The year 1998 was an El Nino period and 1999 was a La Nina year, and these abnormal weather patterns may affect local species distribution (Tegner and Dayton, 1987, Warwick et al., 1990). The time period for data collection in this study was probably too short to run a meaningful time series analysis (Edith Hodgen, pers. comm.). Collection of data over a much longer time span (decades), as part of a monitoring protocol, would allow more robust time series analysis tests to be performed, which may be able to detect other longer term natural variation. Longer term natural cycles have been found in some species such as rock lobster, where variability in natural recruitment cycles are not evident over the course of years, but decades (John Booth, pers. comm.). However, it is unlikely that an area would be monitored repetitively throughout the year for this type of timeframe, due to financial, political and logistical reasons. Annual monitoring over a period of many years may be enough to provide some general trends.

\section{$\underline{3.5 .4 \text { Algal damage }}$}

For Lessonia variegata the time/damage interaction was significant in explaining variation between sites. As the interaction between these two factors was found to be significant, the effect of time or damage alone is difficult to interpret. Looking at the figures of the algal damage (Appendix 1) data suggested that Princess Bay was the site with the most Lessonia variegata damage, however most of this damage was found in a single survey period. Breaker Bay was the only site that showed stipe damage but also, the alga was not present in each survey. The other sites showed a small amount of damage, but there was no discernible pattern.

Ecklonia radiata and Carpophyllum maschalocarpum showed no significant difference for the time/damage interaction, but they did show a significant difference for the site/damage interaction. A significant difference in the amount of damage at different sites could well be attributed to the different species abundance at these sites, if in fact this damage is due to herbivore grazing. This is indicated by Babcock and Cole (1993) 
who noted grazing of kina on Ecklonia radiata and made the observation that butterfish are dependant on Ecklonia radiata as food. However, the damage observed may not be due to herbivore grazing, but a fungal infection (Babcock and Cole., 1993) or an amphipod that lives inside the Ecklonia radiata stipes and damages the plant in the process (Haggitt, 1999). However, on examination of the figures, there is little overall damage evident in any of these species, so these results are probably not indicative of any meaningful patterns in species interactions or natural processes affecting these algae.

\subsubsection{Comparison to previous data}

There were no significant differences in species size and abundance between the two different sampling periods (i.e. the survey carried out by the team of UK navy divers in 1997 and the present investigation which surveyed from 1998-2000). This is as expected, since reservation had not been achieved in the interim between the two surveys. It also indicates that no significant changes occurred between the two studies, that might have been due to natural or seasonal variation. This is as expected because when seasonal variation was tested for, no significant differences were found.

\section{$\underline{\text { 3.5.6 General discussion }}$}

A statement by Crowder et al. (2000) summarizes why a study such as this, that gathers information on the biota before reservation is important: "it is incorrect to attribute changes in fish production to a reserve effect if no data were gathered before the reserve was established." Chapman and Kramer (1999), Edgar and Barrett (1999), Conover et al. (2000) and Dayton et al. (2000) all concur. This was reinforced during the present study as significant differences among sites on the south coast of Wellington were recorded and results showed evidence of an environmental gradient. As has been shown by many studies, reservation can achieve more than increased species size and abundance. Shifts in community structure (Babcock et al., 1999), differences in percent cover of algae (Shears and Babcock, 2000) and changes in fish behaviour (Davidson, in submission) are very difficult to quantify, let alone without information on their status before reservation. Even though control sites may help alleviate this problem, no reference sites are true controls, as physical conditions will always differ between each reference site and all impacted sites due to environmental variability (Edgar and Barrett, 1997). If the Taputeranga Marine Reserve had been established and then monitored without the data from this investigation, differences in sites such as Palmer Head (which would be a control site) and The Sirens (which would be a reserve site) could easily erroneously be attributed to 
reservation, whereas we now know that there are intrinsic pre-reserve differences. Therefore, magnitude of difference, or change over time within the same site, would be a better indication of change due to reservation status.

Habitat heterogeneity is often ignored when marine reserves are established. For example, viewing all habitat as equally important to fish is a gross oversimplification (Crowder et al., 2000). But since establishment of reserves is, in practice, often a compromise between political, scientific and community groups, this is no doubt partially the reason reserves are established in less than ideal areas. The areas that eventually become reserves may not be ideal in terms of their unique biota or habitat (or lack thereof), their value as aggregation grounds for species (or lack thereof) or in terms of accessibility. For example also, the theory of sources and sinks holds that there are areas of high productivity and larval export because the density of larvae or adult fish, is so high that it cannot support the population (i.e. birth rates are greater than death rates and emigration is greater than immigration). These are known as "sources". "Sinks" are areas of high immigration that accept these larval imports and provide a place to settle and recruit (i.e. death rates are greater than birth rates and immigration is greater than emigration). The theory states that "sources" would be ideal candidates for marine reserves as these areas which are then protected will lead to a large amount of "spillover" to adjacent areas (Crowder et al., 2000). Unfortunately it is often sinks that are offered as reserves as the compromise, because these areas have lack of opposition from fishers (Dayton et al., 2000). At least detailed knowledge of the area and understanding of the natural processes, the relationships between species and their seasonal movements and natural aggregations will enable effective management of the fish habitat (Peterson et al., 2000) and identification of effects occurring due to protection.

Inevitably, the baseline dataset collected during the present investigation missed some survey periods due to inclement weather, lack of personnel or equipment which prevented sampling. Even under these constraints, however, the study has provided an overall picture of the most common species on the south coast, their locations and distributions over a three year period. From published data, as mentioned previously, which cites examples of increases in fish and invertebrate size and abundance in many temperate marine reserves, it is therefore expected that similar impacts will become evident after implementation of the reserve on the south coast of Wellington. Increases in species size and abundance, particularly in paua, rock lobster and particular fish species, especially 
those targeted by fishermen (e.g. blue moki, butterfish and tarakihi) should occur in the reserve sites. There may be a change in percent algal cover, or a change in a dominant species as a secondary effect to reservation. This phenomonen may be seen as a relationship between Ecklonia radiata and Carpophyllum flexuosum based on observations made during the present study. However, it is difficult to predict the exact nature of these changes, as it has been found with many reserves, that the outcome of reservation is often different from expected (Jones et al., 1992). Roberts and Hawkins (2000) stated that well protetected reserves can be expected to begin to supply fisheries within five years of creation, and that benefits are likely to keep increasing for up to 1020 years. However, they also stated that population increases among exploited species within a year or two. Based on this past experience from the literature, provided there is adequate policing against poaching, changes in particular species size and abundances in the Taputeranga Marine Reserve, should start to become evident within 1-2 years after establishment. Any community changes may take in the order of decades and represent flow on effects from changes at a species level.

The baseline data gathered in the present study which includes a list of many of the species occurring in this area, a description of percent algal cover as well as describing the existence of a natural gradient provides the ideal dataset for establishing change due to reservation. Long term monitoring over a period of years has reduced the possibility that natural seasonal variation will be interpreted as a reserve effect. Based on the power analysis, the monitoring protocol used in the present study is, in most cases, powerful enough to detect any changes that may occur.

The area surveyed includes both control and future reserve sites. With all these criteria (long term monitoring, description of the habitat and detailed data on the current state of species assemblages) filled the present investigation provides the "before" part of a true BACI survey. Marine reserve studies often cited as examples of reservation (Cole et al., 1990, MacDiarmid and Breen, 1992, Russ and Alcala, 1996, Edgar and Barrett, 1999) did not have the advantage of a description of the biota before reservation, therefore basing their conclusions purely on reserve vs control comparisons, or sometimes comparisons between surveys conducted at different times after reserve establishment. Jones et al. (1992) cited examples from more than 14 studies on the effects of marine reserves and only one of these studies indicated the availability of data collected before protection, and this was only from one site. To my knowledge, only one study in New Zealand exists 
(Davidson and Chadderton, 1994) that tested differences amongst potential marine reserve sites before establishment of a marine reserve. However, this was based on macroalgae and herbivore composition only, and sites tested were not contiguous along the whole coastline.

\subsubsection{Summary and Future Recommendations}

In summary, there are significant differences amongst the sites examined on the south coast in terms of species abundances. There is evidence for an east to west gradient. The initial data collected in this study will allow subsequent studies to "control" for this natural spatial variability.

Following methodology used in this investigation, future monitoring on the south coast should include the key species paua, kina, rock lobster, blue moki, Ecklonia radiata, Lessonia variegata, and additionally Carpophyllum flexuosum (which was not monitored in the present investigation) should be monitored. Data collected using this sampling regime will have a high enough power to detect a change should it occur. More detailed monitoring of rock lobster is recommended (i.e. gathering size data and sampling at different depth ranges to account for potential seasonal movements (MacDiarmid, 1991)). Species interactions and associations of species with certain habitat types should be examined in detail to increase understanding of natural processes.

The data collected during this study did not detect a distinct seasonal variation despite frequent monitoring over the course of three years. This indicates that species in this area do not necessarily show seasonal changes. There is a possibility, however, that these results may be confounded by abnormal weather patterns due to the fact that this study was carried out during an ENSO (El Nino Southern Oscillation) event. These phenomena are known to affect marine communities by disrupting normal recruitment and reproductive patterns (Tegner and Dayton, 1987, Allison et al., 1998). If data were collected over a much longer time span, more robust time series analysis tests could be performed which may be able to detect other longer term natural variation. This suggests the need for long term, regular monitoring of coastal areas, especially those that are being examined for change. 
CHAPTER 4

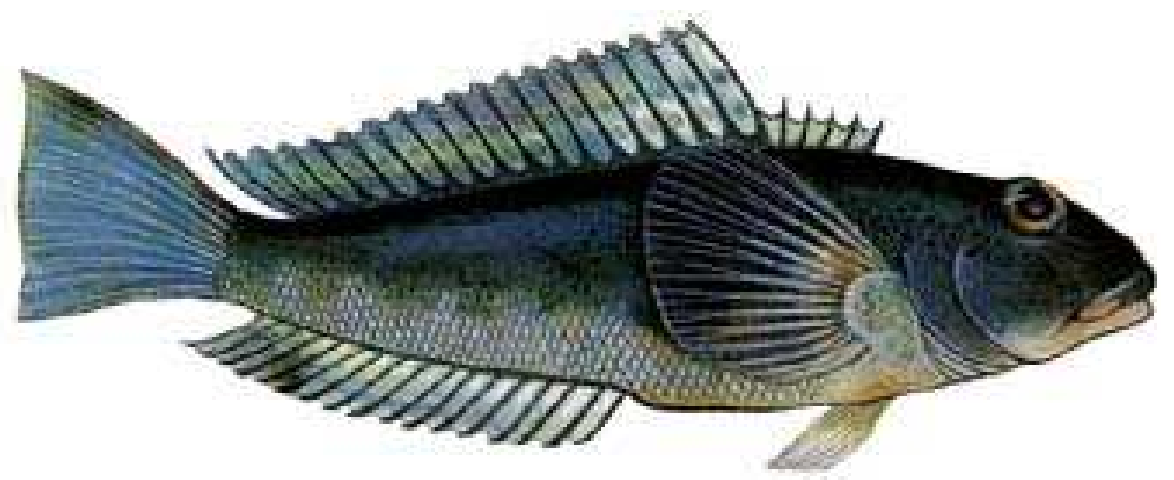

KAPITI MARINE RESERVE 


\section{CHAPTER 4 - KAPITI MARINE RESERVE}

\subsection{Introduction}

Kapiti marine reserve was gazetted in April 1992, and formalised in May 1992. A survey of the marine habitats and communities of Kapiti Island was carried out by NIWA (National Institute of water and Atmospheric research) in January 1992 to establish a qualitative and quantitative database to enable detection of any changes in these communities after reservation status (Battershill et al., 1993). This was a one-off survey only.

Long term monitoring is important to account for any naturally occurring seasonal variation. Short, one-off surveys may come to conclusions that are incorrect because the variation of natural populations in time is great. Seasonal patterns have a great influence on assemblages of organisms and over longer time scales there can be 'pulse' or 'press' responses. Therefore replication in time, often over periods of greater than one year, is crucial (Kingsford and Battershill, 1998).

Thus, the current investigation monitored the reserve and control areas over a period of three years. This lengthy sampling period has allowed the build up of an extensive database. This will provide a further comparison for data collected in the future. The sites monitored in this investigation were some of sites used by Battershill et al. (1993), to enable comparison to the 1992 data.

This study aims to detect any changes that may have occurred over the period of time sampled, establish whether there are any obvious seasonal variations and to determine whether any significant changes have occurred since the establishment of the reserve based on the data collected in 1992 (Battershill et al., 1993). An appropriate monitoring regime will also be established based on the analysis of the data collected in this investigation.

\subsection{Study Area}

Kapiti Marine Reserve is based around Kapiti Island. Kapiti Island is located off the west coast of the North Island, New Zealand. It is approximately $50 \mathrm{~km}$ north of Wellington 
and is $5 \mathrm{~km}$ offshore. Kapiti is a convergence zone for the cold, clear Southland current and the warm, turbid and saltier d'Urville current. Depending on the state of the tides, these two currents alternately dominate each other, thus resulting in a zone of overlap in marine plant and animal communities generally found in colder or warmer waters respectively. The Kapiti Marine Reserve provides a link between the Kapiti Island Nature Reserve and the Waikanae Estuary Scientific Reserve on the adjacent mainland shore (DOC publication, April 2000).

The reserve is divided into two parts. The larger section of the reserve is on the eastern side of the island and extends all the way to the mainland. It is $17.5 \mathrm{~km}^{2}$ creating a triangle between Honeymoon Bay to Waterfall Bay, around Passage Rocks and meeting at the Waikanae River on the mainland. The western section of the reserve is smaller and does not reach as far offshore. It covers an area of $3.4 \mathrm{~km}^{2}$ from a northern point between Tokahaki Point and Arapawaiti Point, to Trip Point in the south. This section extends 750 $\mathrm{m}$ out from shore. (see Fig. 4.1.). The eastern side of the reserve is mainly soft sediment and sandy bottom, whereas the western side is mostly shallow broken reef habitat covered with brown macroalgae and red corraline algae (Battershill et al., 1993, pers. obs.). The surveys in this investigation were carried out only in the western reserve side of the island, with appropriate control sites, as the aim was to concentrate on examining reef habitats.

The waters on the eastern side of the island are fairly sheltered as they are in the lee of the island and between the island and the mainland. The western side is more exposed to high seas and strong winds. Any sort of westerly or northerly wind renders the western waters rough and often not diveable. Kapiti Island is subject to swell from the south and southwest, which is the predominant wind direction and is therefore a high energy environment. It is also exposed to locally generated eastwards and northwards directed storm waves (Heath, 1985).

Visibility in the waters surrounding the island can be greatly affected by the nearby Waikanae river. After periods of heavy rain, water from the river containing a large amount of suspended sediment, runs into the water mass surrounding the island. This suspended sediment decreases visibility considerably, rendering it as low as one metre. The sediment then settles on the macroalgae and a SCUBA diver might easily stir it up decreasing the visibility even as much as a week after the rains (pers. obs.). 


\subsection{Methods}

Refer to Chapter Two

\subsection{Results}

All tests were performed on count data for sixteen species and size data for nine species as marked on Table 2.4., Chapter 2.

\subsubsection{Kruskal-Wallis tests}

$\mathrm{H}_{0}=$ There is no difference in species abundance (or size) among sites at Kapiti Marine Reserve.

$\mathrm{H}_{0}=$ There is no difference in species abundance (or size) between reserve and control sites at Kapiti Marine Reserve.

A Kruskal-Wallis test was performed on each species individually to test for differences amongst the sites surveyed at Kapiti Marine Reserve. Both average abundance and size data (where applicable) were tested. The tests were also performed by pooling data from the 2 reserve and the 2 control sites, to test for significant differences between reserve and control areas. Significant results are presented in Tables 4.1 and 4.2. 
Table 4.1. Significant Kruskall-Wallis test results (before and after correction for multiple testing) after testing for differences in species abundance and size among sites at Kapiti Marine Reserve.

\begin{tabular}{lll}
\hline Species & Data tested & $P$-value \\
\hline Ecklonia radiata & count & $0.000^{*}$ \\
Banded wrasse & count & $0.000^{*}$ \\
Blue cod & count & $0.000^{*}$ \\
Butterfish & count & 0.008 \\
Butterfish & size & 0.012 \\
Scarlet wrasse & count & $0.002^{*}$ \\
Spotty & count & 0.007 \\
Black foot paua & count & 0.014 \\
Kina & count & $0.000^{*}$ \\
Kina & size & 0.012 \\
\hline
\end{tabular}

*denotes significance after correction for multiple testing.

Ecklonia radiata, banded wrasse, blue cod, scarlet wrasse, and kina were significantly different in abundance among the four sites at Kapiti Marine Reserve.

Table 4.2. Significant Kruskall-Wallis test results (before and after correction for multiple testing) after testing for differences in species abundance and size between reserve and control sites at Kapiti Marine Reserve.

\begin{tabular}{lll}
\hline Species & Data tested & $P$-value \\
\hline Banded wrasse & count & $0.001^{*}$ \\
Blue cod & count & $0.002^{*}$ \\
Butterfish & count & 0.006 \\
Butterfish & size & $0.002^{*}$ \\
Scarlet wrasse & count & 0.013 \\
Blue moki & size & 0.017 \\
Kina & size & 0.008 \\
\hline$*$ denotes significance after correction for multiple testing.
\end{tabular}

Banded wrasse and blue cod were significantly different in abundance between reserve and control sites. The results showed that butterfish were significantly different in size between reserve and control sites. 


\subsubsection{Analysis of variance tests}

$\mathrm{H}_{0}=$ There is no difference in species abundance (or size) among sites at Kapiti Marine Reserve.

$\mathrm{H}_{0}=$ There is no difference in species abundance (or size) among reserve and control sites at Kapiti marine reserve.

After data transformation (as described in Chapter Two) Analysis of Variance (ANOVA) tests were performed.

The significant results of the ANOVA tests performed on $\log _{\mathrm{e}}$ transformed count data are presented in Tables 4.3-4.5.

Table 4.3. Significant ANOVA results (before and after correction for multiple testing)after testing for differences in species abundance among sites at Kapiti Marine Reserve.

\begin{tabular}{ll}
\hline Species & $P$-value \\
\hline Ecklonia radiata & $0.000^{*}$ \\
Banded wrasse & $0.000^{*}$ \\
Blue cod & $0.000^{*}$ \\
Butterfish & 0.008 \\
Scarlet wrasse & $0.000^{*}$ \\
Spotty & 0.013 \\
Black foot paua & 0.017 \\
Kina & $0.001 *$ \\
Spotty & 0.013 \\
Black foot paua & 0.017
\end{tabular}

*denotes significance after correction for multiple testing.

Data for Ecklonia radiata, banded wrasse, blue cod, scarlet wrasse and kina showed a significant difference in abundance among sites at Kapiti Marine Reserve. 
Table 4.4. Average count values $\left(\right.$ per $\mathrm{m}^{2}$ ) \pm standard error, at each site at Kapiti Marine Reserve, for those species where ANOVA tests showed a significant difference in abundance among sites.

\begin{tabular}{lllll}
\hline Species & $\begin{array}{l}\text { Arapawaiti Point } \\
\text { (reserve) }\end{array}$ & $\begin{array}{l}\text { Onepoto Point } \\
\text { (reserve) }\end{array}$ & $\begin{array}{l}\text { Tokahaki Point } \\
\text { (control) }\end{array}$ & $\begin{array}{l}\text { Kaiwharawhara } \\
\text { Point (control) }\end{array}$ \\
\hline Ecklonia radiata & $8.74 \pm 2.05$ & $29.47 \pm 3.098$ & $20.57 \pm 1.12$ & $21.90 \pm 2.25$ \\
& & & & \\
Banded wrasse & $0.0465 \pm 0.0076$ & $0.0086 \pm 0.0021$ & $0.0062 \pm 0.0015$ & $0.0093 \pm 0.0014$ \\
Blue cod & $0.0571 \pm 0.018$ & $0.0138 \pm 0.0034$ & $0.0167 \pm 0.006$ & $0.0050 \pm 0.0014$ \\
Scarlet wrasse & $0.0266 \pm 0.0062$ & $0.0038 \pm 0.0011$ & $0.0047 \pm 0.0015$ & $0.02 \pm 0.0072$ \\
Kina & $0.2222 \pm 0.046$ & $0.036 \pm 0.006$ & $0.0632 \pm 0.018$ & $0.2806 \pm 0.14$ \\
\hline
\end{tabular}

Post Hoc Tukey tests (pairwise comparisons) were performed to try to establish the location of these differences among sites. Line diagrams (Figs. 4.1.-4.5.) are used to show which sites were significantly different from each other. Sites joined by a line are not significantly different from each other, but those sites that are never grouped together (i.e. are never joined by a line) are significantly different from each other.

Sites are coded

$1=$ Arapawaiti Point

$2=$ Kaiwharawhara Point

$3=$ Onepoto Point

$4=$ Tokahaki Point

1 and 3 are reserve sites, and 2 and 4 are control sites. 
Fig. 4.1. Line diagram showing significant differences in abundance among sites for Ecklonia radiata at Kapiti Marine Reserve..

\begin{tabular}{|r|r|}
\hline Ecklonia \\
1 & $\mid$ \\
4 & \\
2 & \\
3 & \\
\hline
\end{tabular}

(site 1 is significantly different to all the others)

Fig. 4.2. Line diagram showing significant differences in abundance among sites for banded wrasse at Kapiti Marine Reserve.

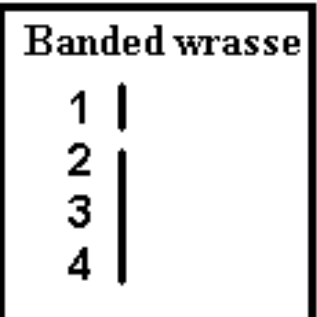

(site 1 is significantly different from all the others)

Fig 4.3. Line diagram showing significant differences in abundance among sites for blue cod at Kapiti Marine Reserve.

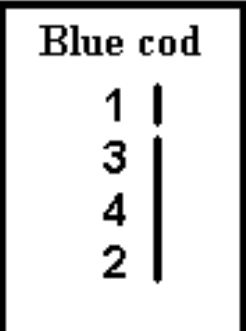

(site 1 is significantly different from all the others) 
Fig. 4.4. Line diagram showing significant differences in abundance among sites for scarlet wrasse at Kapiti Marine Reserve.

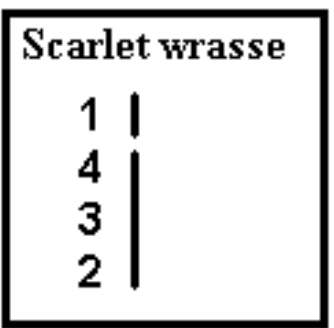

(site 1 is significantly different from all the others)

Fig. 4.5. Line diagram showing significant differences in abundance among sites for kina at Kapiti Marine Reserve.

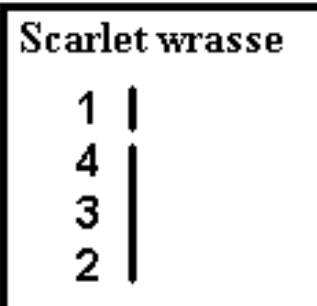

(sites 1 and 2 are significantly different from sites 4 and 3).

Table 4.5. Significant ANOVA results (before and after correction for multiple testing) after testing for differences in species abundance, using site nested with reserve as a factor.

\begin{tabular}{ll}
\hline Species & $P$-value \\
\hline Ecklonia radiata & $0.000^{*}$ \\
Banded wrasse & $0.000^{*}$ \\
Blue cod & 0.015 \\
Marblefish & 0.082 \\
Scarlet wrasse & $0.001^{*}$ \\
Spotty & $0.004^{*}$ \\
Black foot paua & 0.031 \\
Kina & $0.000^{*}$ \\
\hline
\end{tabular}

*denotes significance after correction for multiple testing. 
Using site nested within reserve and testing for differences again, data for Ecklonia radiata, banded wrasse, scarlet wrasse, spotty and kina showed a significant difference amongst sites. These mean counts for these species at each site are shown in Figs. 4.64.10. Categories on the $\mathrm{x}$-axis of these charts (and all hereafter), represent each survey period, in sequential time order. Error bars represent one standard error.

Fig. 4.6. Abundance of banded wrasse at all 4 sites at Kapiti Marine Reserve for each survey period.

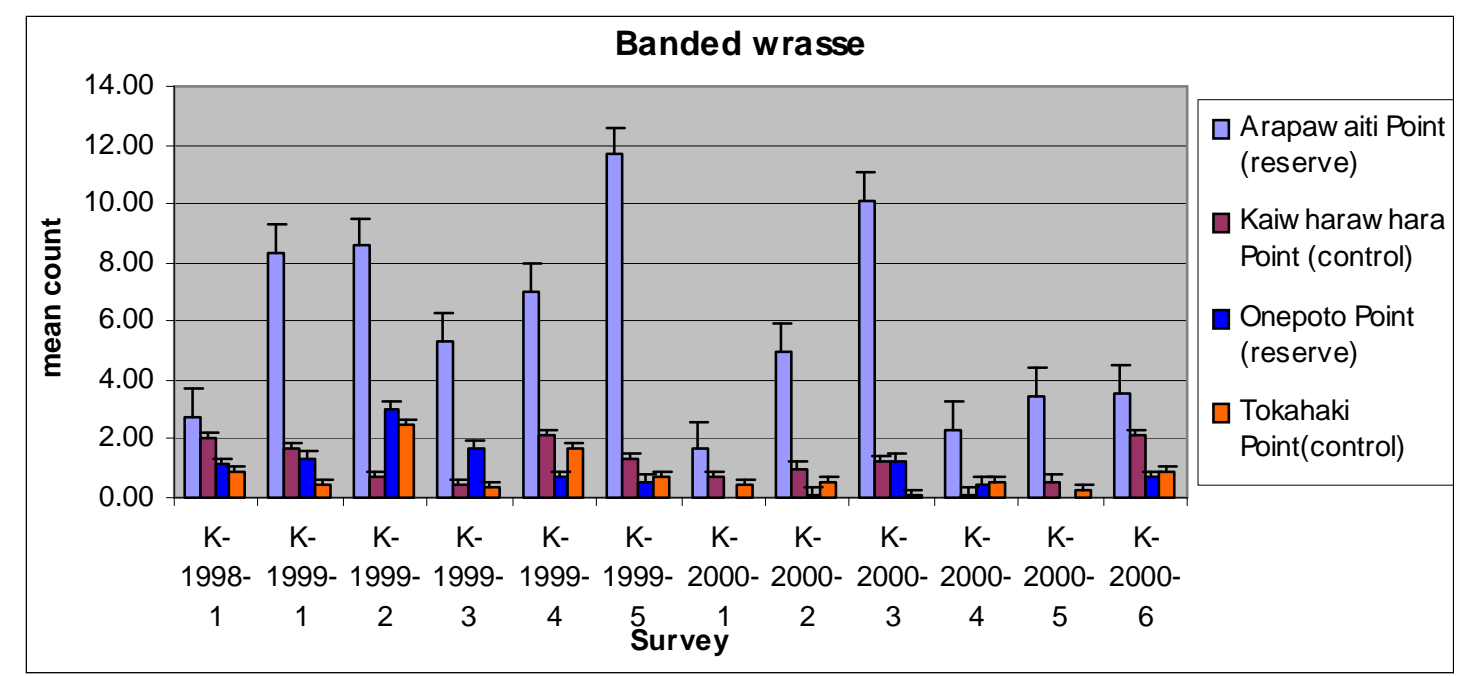

Fig. 4.7. Abundance of blue cod at all 4 sites at Kapiti Marine Reserve for each survey period.

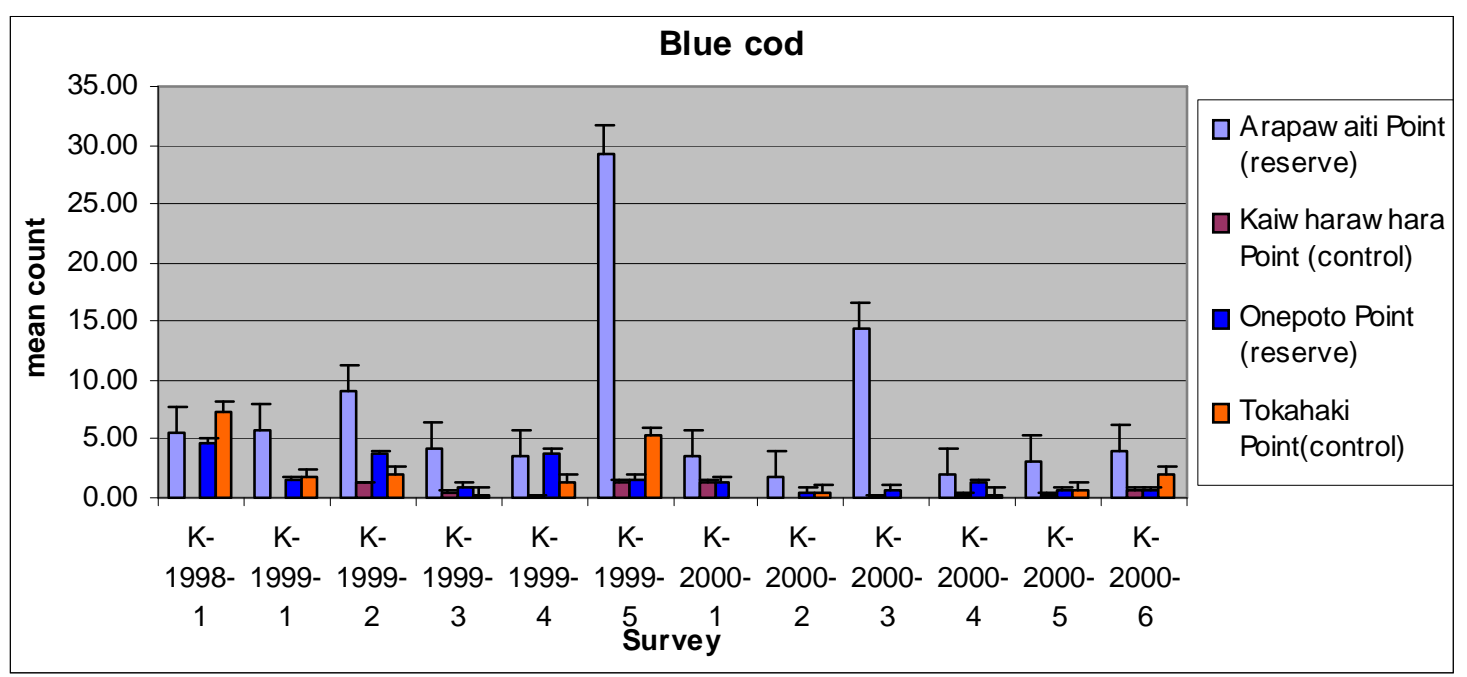


Fig. 4.8. Abundance of scarlet wrasse at all 4 sites at Kapiti Marine Reserve for each survey period.

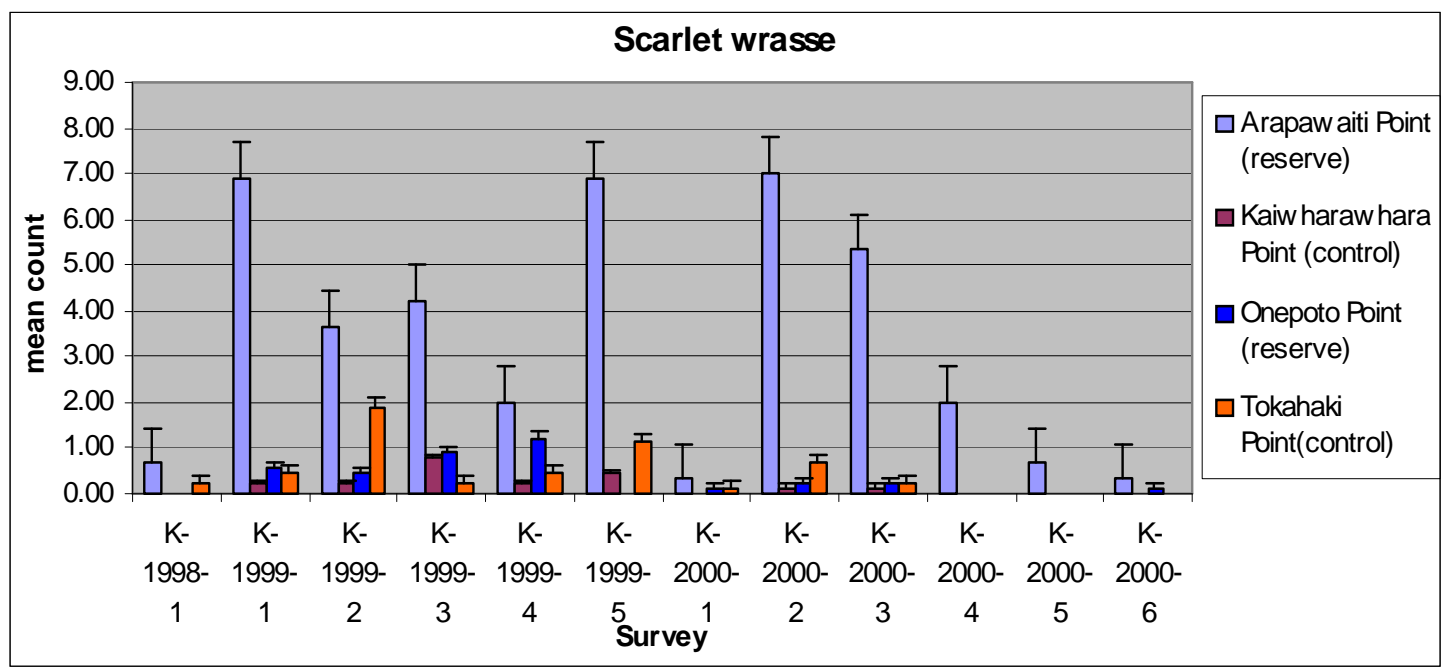

Fig. 4.9. Abundance of kina at all 4 sites at Kapiti Marine Reserve at each survey period.

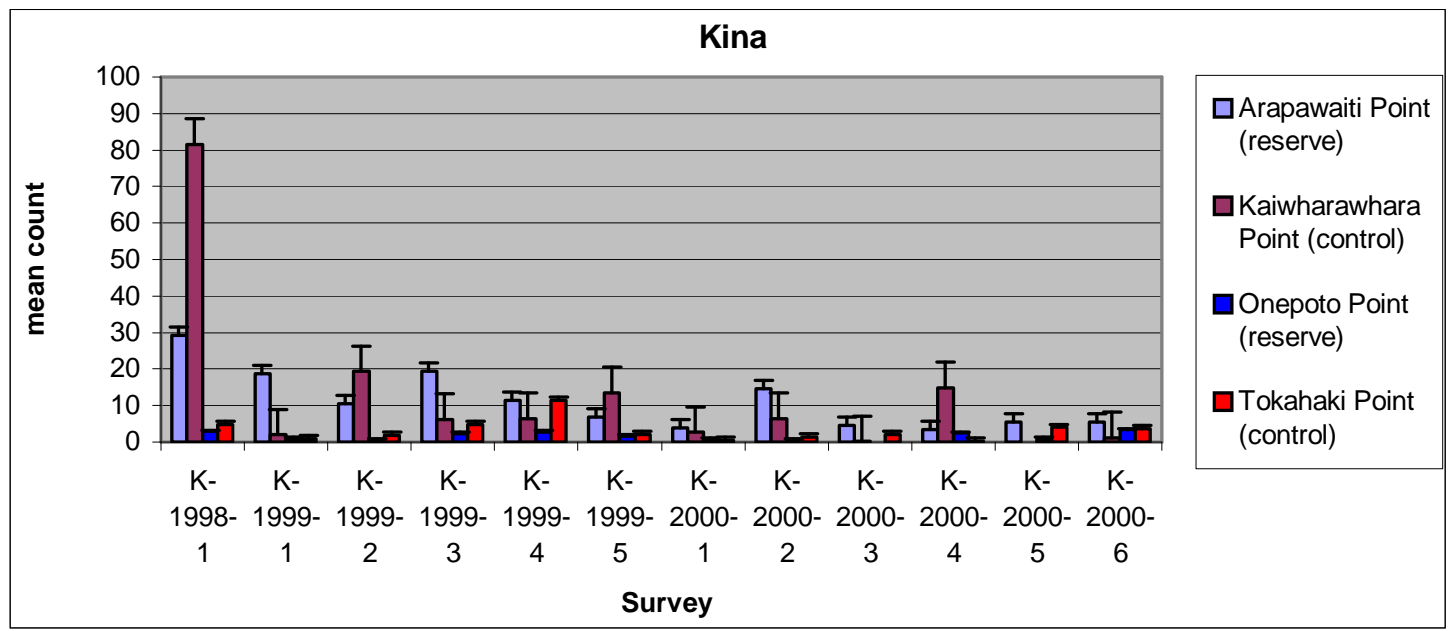


Fig. 4.10. Abundance of Ecklonia radiata at all 4 sites at Kapiti Marine Reserve for each survey period.

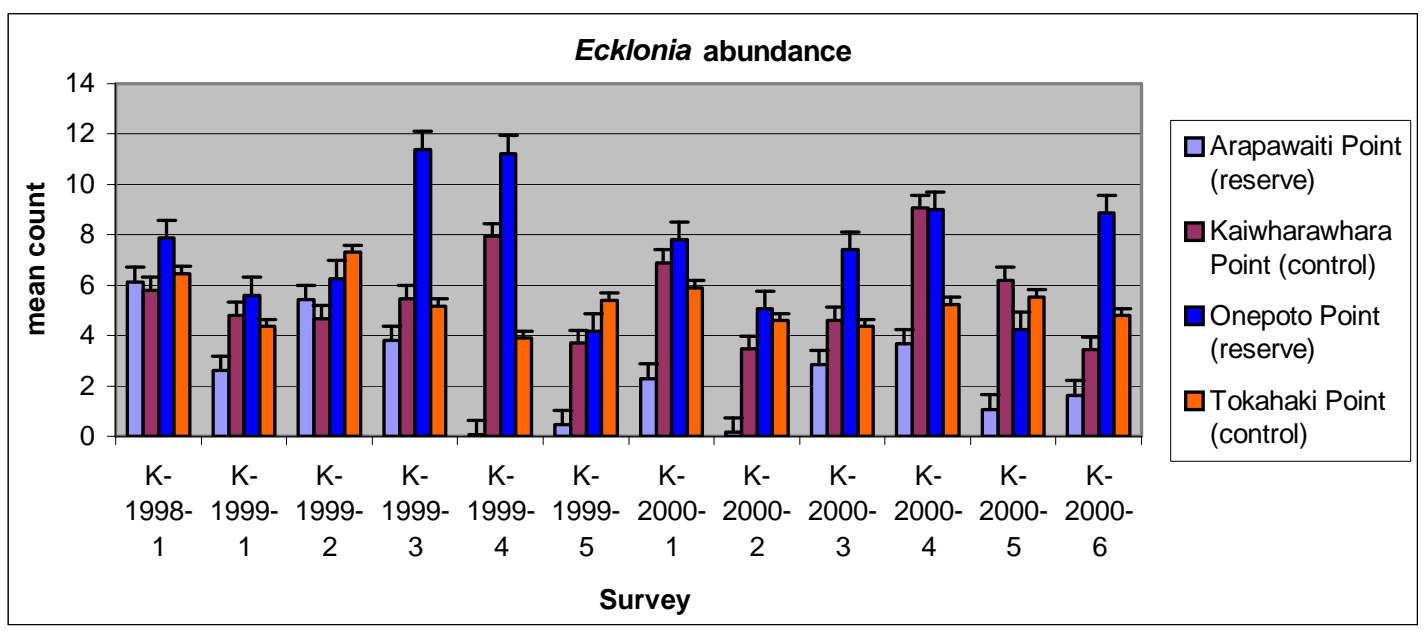

Table 4.6. Significant ANOVA results (before and correction for multiple testing) testing for differences in species abundance between reserve and control sites at Kapiti Marine Reserve.

\begin{tabular}{ll}
\hline Species & $P$-value \\
\hline Carpophyllum maschalocarpum & 0.026 \\
Banded wrasse & $0.001^{*}$ \\
Blue cod & $0.001^{*}$ \\
Butterfish & 0.009 \\
Scarlet wrasse & 0.008
\end{tabular}

*denotes significance after correction for multiple testing.

Banded wrasse and blue cod abundance show a significant difference between reserve and control sites. The mean counts for these species inside and outside the reserve are shown in Figs. 4.11. and 4.12. 
Fig. 4.11. Blue cod abundance at reserve and control sites at Kapiti Marine Reserve at each survey period.

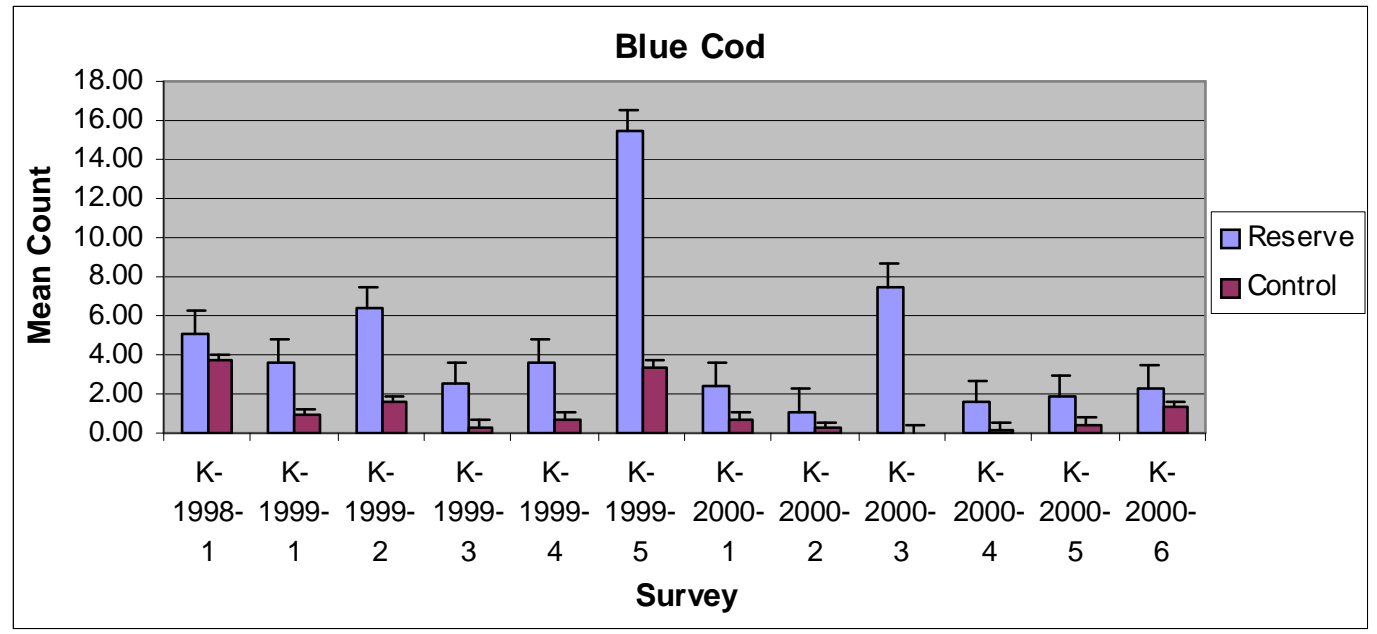

Fig. 4.12. Banded wrasse abundance at reserve and control sites at Kapiti Marine Reserve at each survey period.

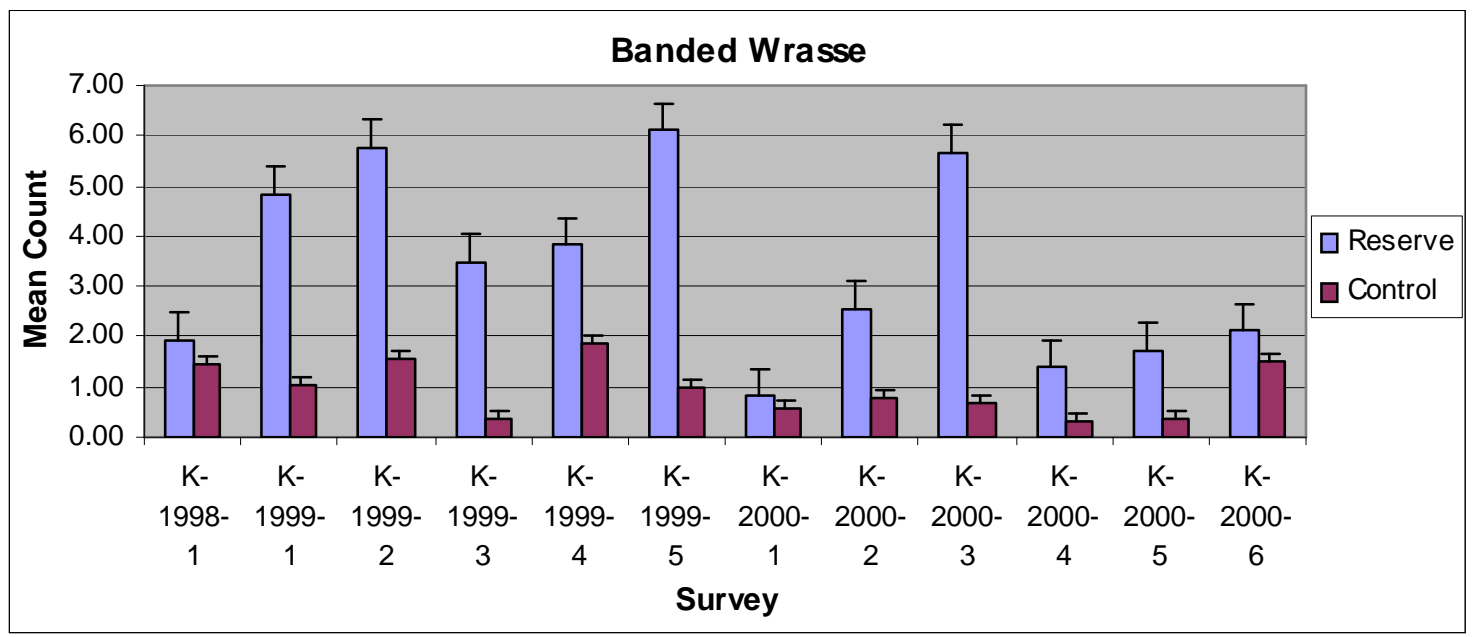

ANOVA tests were then carried out on square root transformed size data to test for differences among sites. Significant results are presented in Tables 4.7. and 4.8. 
Table 4.7. Significant ANOVA results (before and after multiple testing) from testing for differences in species size amongst sites at Kapiti Marine Reserve.

\begin{tabular}{ll}
\hline Species & $P$-value \\
\hline Butterfish & 0.009 \\
Blue moki & 0.012 \\
\hline
\end{tabular}

Data for butterfish and blue moki showed a difference in size amongst sites, but these were not significant after multiple testing, therefore no post hoc tests were performed.

None of the data for species tested showed a significant difference in size when tested for differences amongst sites nested within reserve.

Table 4.8. Significant ANOVA results (before and after correction for multiple testing) from testing for differences in size, in reserve versus control sites at Kapiti Marine Reserve.

\begin{tabular}{ll}
\hline Species & $P$-value \\
\hline Kina & 0.036 \\
Butterfish & $0.001^{*}$ \\
Blue moki & $0.006^{*}$
\end{tabular}

*denotes significance after correction for multiple testing.

Results for butterfish and blue moki showed a significant difference in size in control vs reserve sites.

The mean sizes for these species inside and outside the reserve are shown in Figs. 4.134.14 . 
Fig. 4.13. Mean sizes for butterfish in reserve and control sites at Kapiti Marine Reserve at all survey periods.

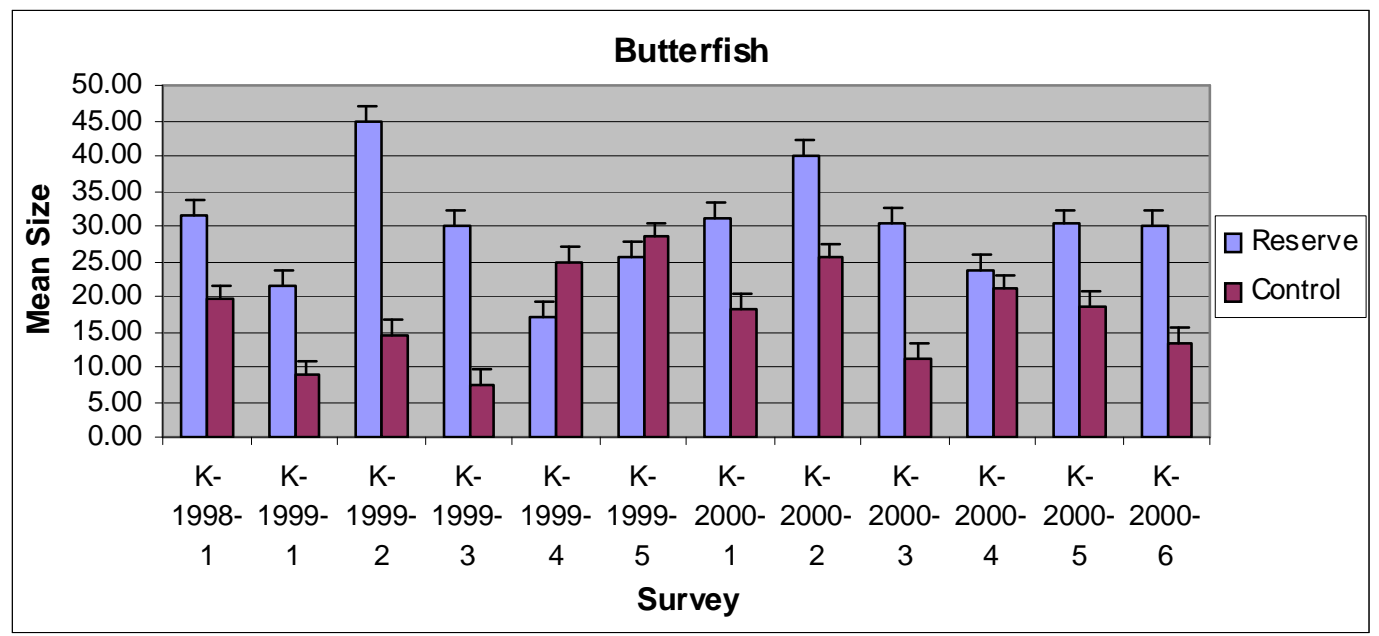

Fig. 4.14. Mean sizes for blue moki in reserve and control sites at Kapiti Marine Reserve at all survey periods.

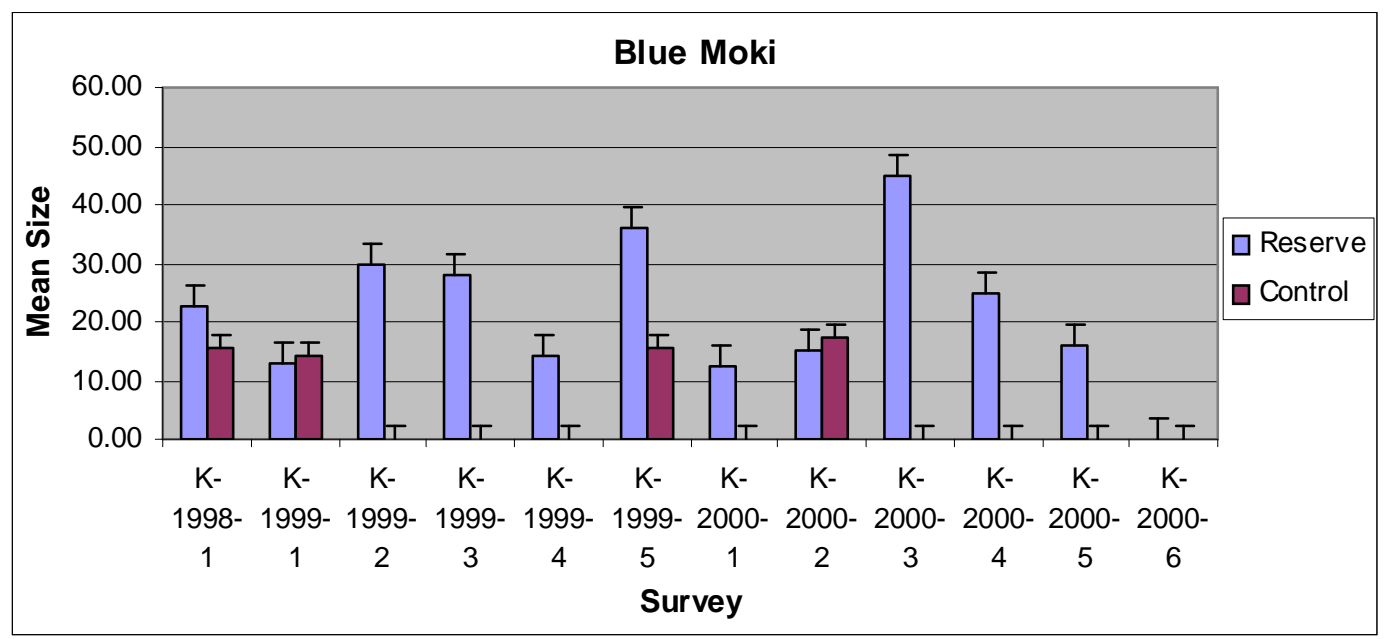




\subsubsection{Power analysis}

These ANOVA results were run through a power analysis to test whether the data collected from this investigation would be powerful enough to detect a change in species abundance should it occur.

The power analysis was performed using the results from ANOVA on $\log _{\mathrm{e}}$ transformed count data only.

Table 4.9. Power of the data using the sampling regime in this investigation to detect a change in species abundance at Kapiti Marine Reserve.

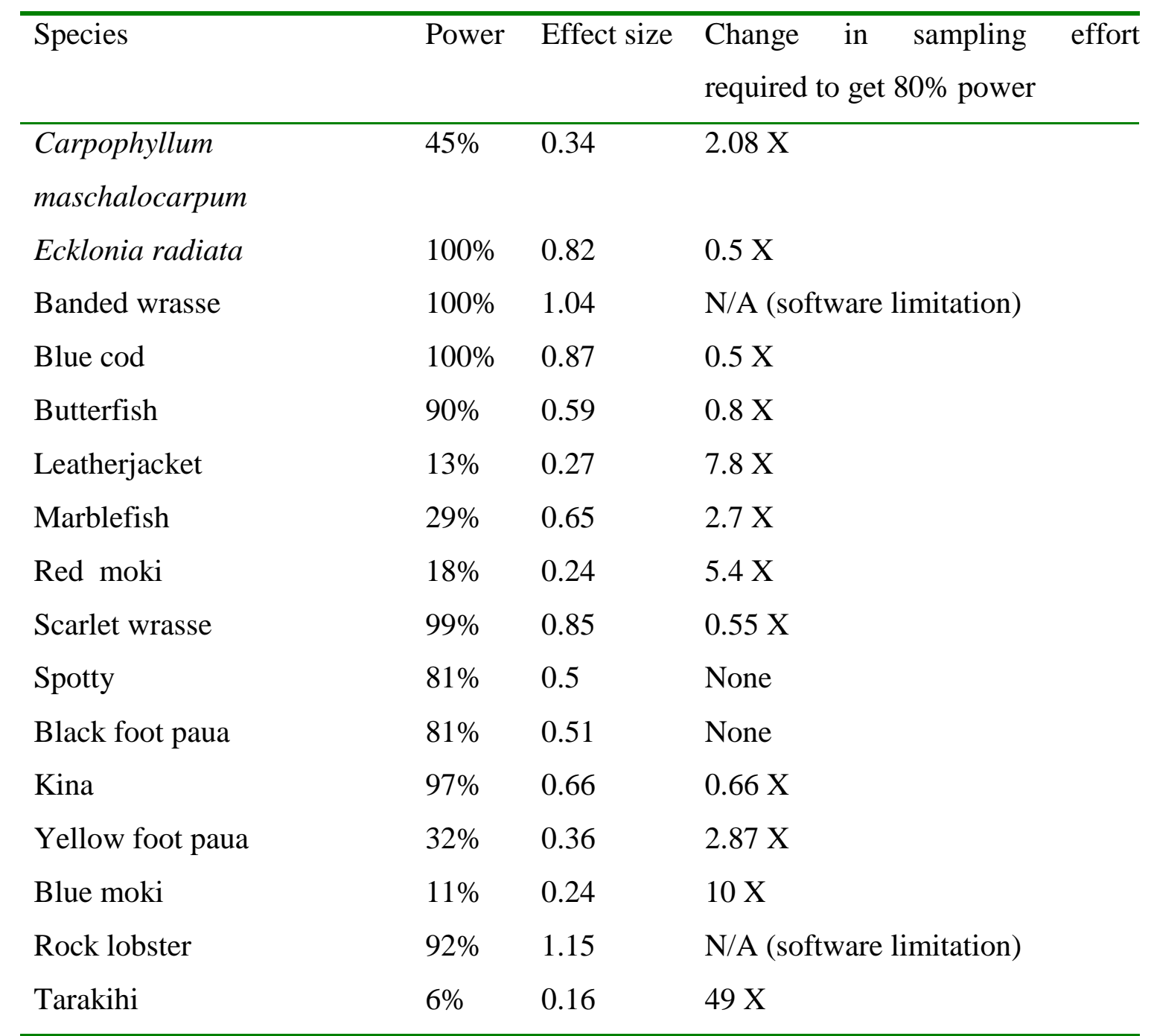

These results show that the data collected for Ecklonia radiata, spotty, banded wrasse, blue cod, butterfish, scarlet wrasse, spotty, black foot paua, kina and rock lobster have a 
power of more than $80 \%$ (which is the standard power considered suitable) to detect a significant change in species abundance (i.e. the present monitoring regime for these species is enough to enable detection of changes in these species). Power of the data for the other species falls well below the threshold mark of $80 \%$ (i.e. sampling effort would need to be increased in order to have an $80 \%$ chance of detecting any changes in these species).

\subsubsection{Multidimensional Scaling}

$\mathrm{H}_{0}=$ All sites are equally similar or dissimilar to one another.

Multidimensional scaling was used to examine relationships among the four sites examined, using abundance data from all species, across all time periods. The MDS procedure was then repeated using only the data from fish, invertebrates and algae separately to examine the relationships among sites for each of these groups alone.

Reserve sites $=\mathrm{AP}$ and $\mathrm{OP}$, control sites $=\mathrm{TP}$ and $\mathrm{KP}$.

Fig. 4.15. MDS of sites surveyed at Kapiti Marine Reserve using average abundance data from all species, across all time periods.

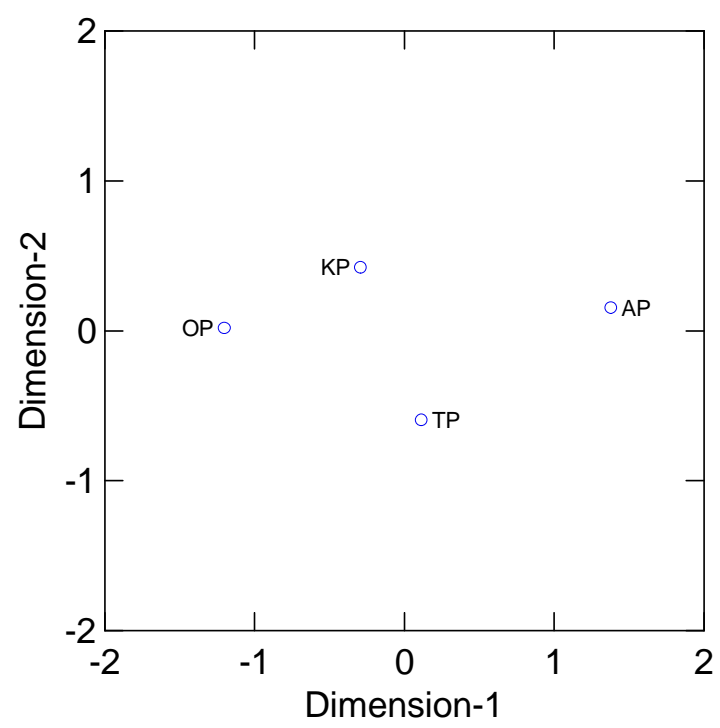


Fig. 4.16. MDS of all sites surveyed at Kapiti Marine Reserve using average fish abundance data (across all time periods) only.

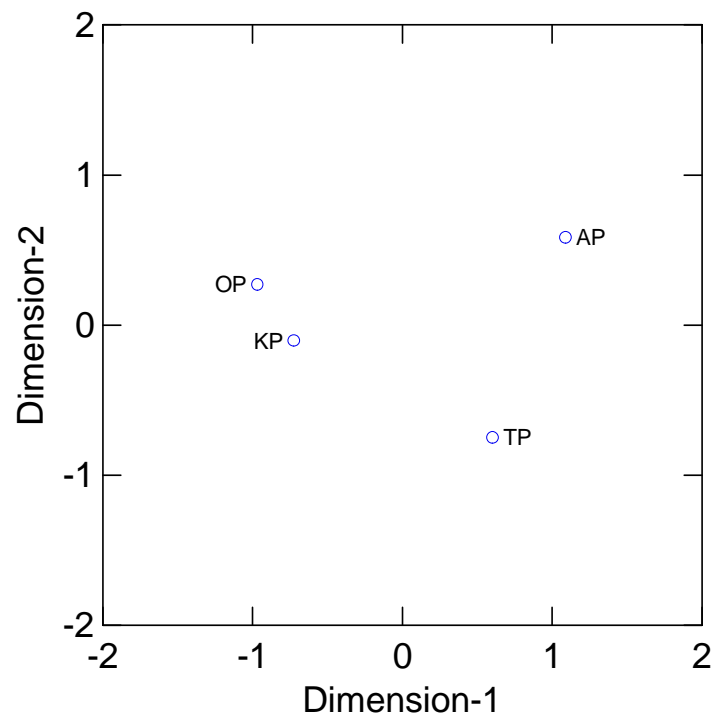

Fig. 4.17. MDS of all sites surveyed at Kapiti Marine Reserve using average algae abundance data (across all time periods) only.

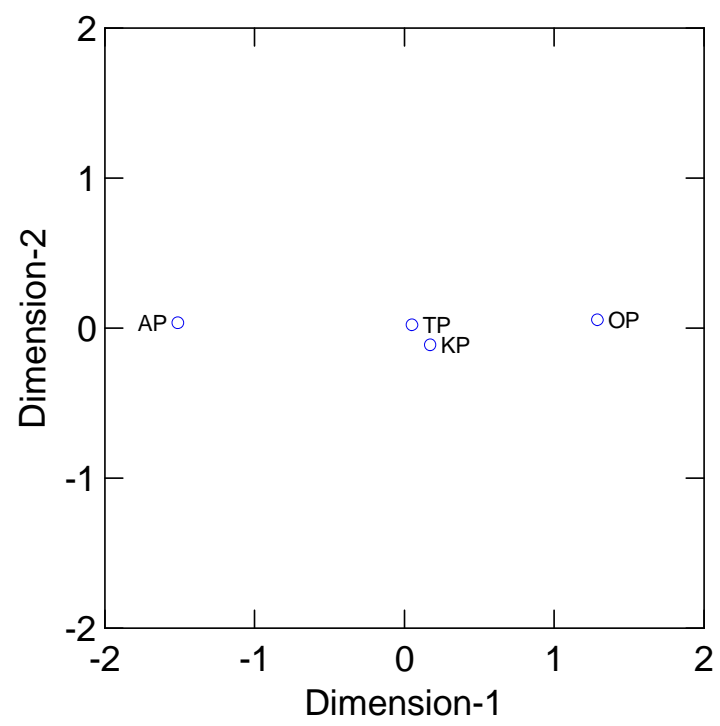


Fig. 4.18. MDS of all sites surveyed at Kapiti Marine Reserve using average invertebrate abundance data (across all time periods) only.

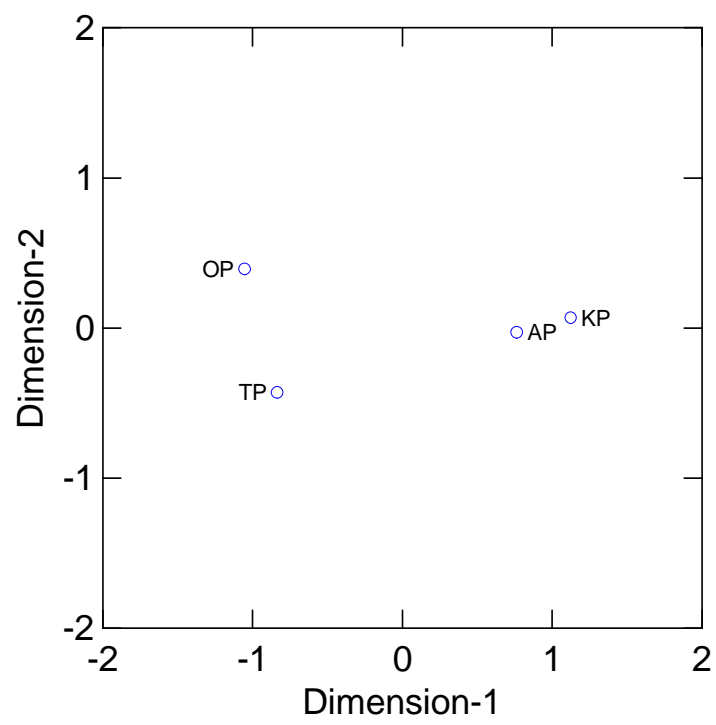

Looking at these figures one can see that when all species are included (Fig. 4.15.) the sites are all fairly well distributed and there is no immediately obvious similarity or dissimilarity between any given pair of sites. Using just the average fish data (Fig. 4.16.) Onepoto Point and Kaiwharawhara point are grouped closely together on dimension one. However, both Onepoto Point and Arapawaiti Point (the two reserve sites) are close on dimension two, as are the two control sites. Just using algae data (Fig. 4.17.), all the sites are closely clustered along dimension two, with Tokahaki point and Kaiwharawhara point being close together on dimension one also. The invertebrate data alone (Fig. 4.18.) shows Arapawaiti point being similar to Kaiwharawhara Point both on dimension one and dimension two. The other two sites are separated from these sites along dimension one, and are also reasonably well spaced on dimension two.

\subsubsection{Seasonal variation}

$\mathrm{H}_{0}=$ There is no significant difference in species abundance among time periods. 
Fig. 4.19. Actual sea surface temperatures recorded over the course of this study vs the average temperatures historically recorded.

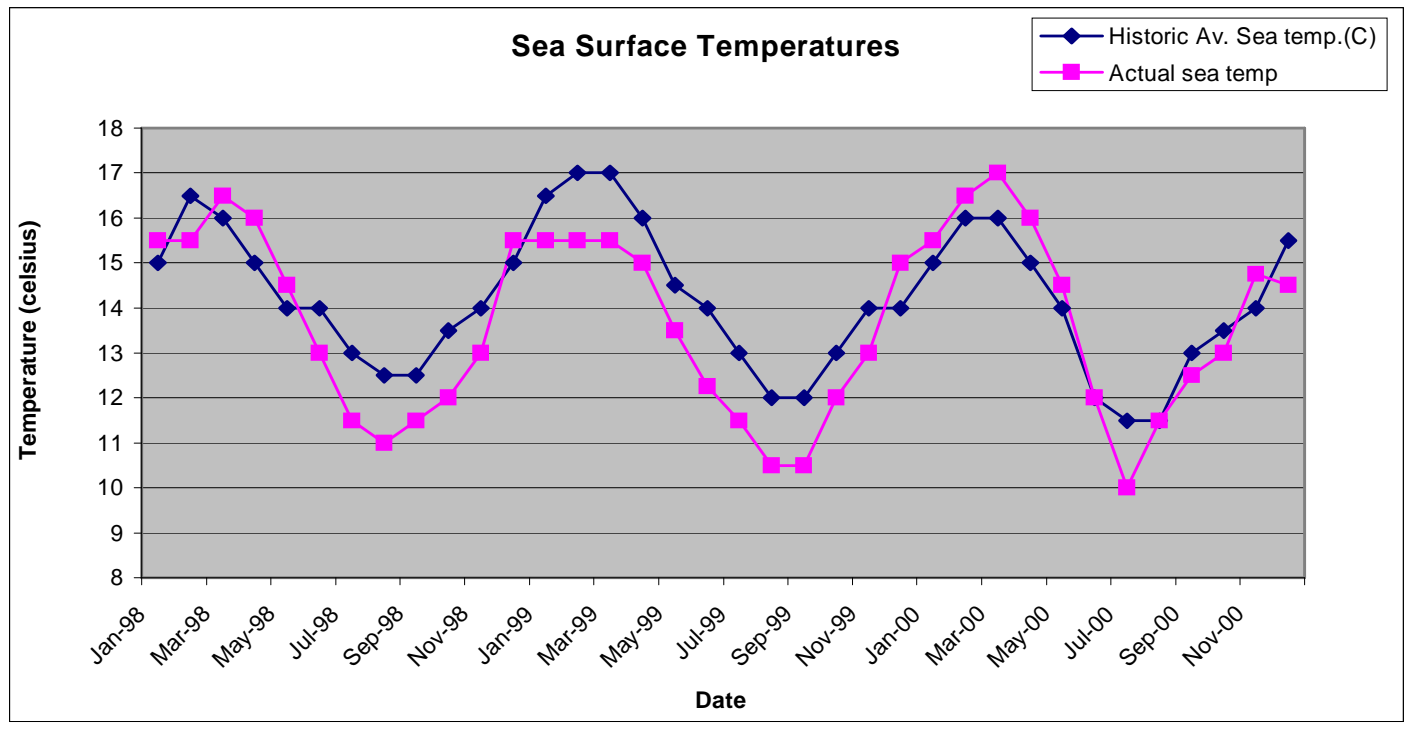

The correlation analysis found a significant correlation between $\log _{\mathrm{e}}$ transformed count data and sea surface temperature (Fig. 4.19) for six species, so it was included in the model. The first model using time as a factor was:

Time

Site(reserve)

Reserve

Time* ${ }^{*}$ site(reserve)

Sea surface temperature

The whole model was significant for the following species:

Kina

Black foot paua

Carpophyllum maschalocarpum

Ecklonia radiata 
Scarlet wrasse

Spotty

Banded wrasse

Blue cod

Butterfish

For these 8 species the stepwise analysis was performed to determine which of the factors contributed significantly to the model.

Table 4.10. Results of 3-factor ANCOVA for scarlet wrasse at Kapiti Marine Reserve, indicating which factors are significant in explaining variability.

\begin{tabular}{lll}
\hline Factor & $P$-value & Significance \\
\hline Time & $>0.05$ & NS \\
Site(reserve) & $<0.05$ & Sig \\
Reserve & 0.008 & Sig \\
Time*site(reserve) & $>0.05$ & NS \\
Sea Surface temperature & $>0.05$ & NS \\
\hline
\end{tabular}

Table 4.11. Results of 3-factor ANCOVA for kina at Kapiti Marine Reserve, indicating which factors are significant in explaining variability.

\begin{tabular}{lll}
\hline Factor & $P$-value & Significance \\
\hline Time & $>0.05$ & NS \\
Site(reserve) & $<0.05$ & Sig \\
Reserve & 0.665 & NS \\
Time*site(reserve) & $>0.05$ & NS \\
Sea Surface temperature & $>0.05$ & NS \\
\hline
\end{tabular}


Table 4.12. Results of 3-factor ANCOVA for spotty at Kapiti Marine Reserve, indicating which factors are significant in explaining variability.

\begin{tabular}{lll}
\hline Factor & $P$-value & Significance \\
\hline Time & $>0.05$ & NS \\
Site(reserve) & $<0.05$ & Sig \\
Reserve & 0.993 & NS \\
Time*site(reserve) & $>0.05$ & NS \\
Sea Surface temperature & $>0.05$ & NS \\
\hline
\end{tabular}

Table 4.13. Results of 3-factor ANCOVA for Black foot paua at Kapiti Marine Reserve, indicating which factors are significant in explaining variability.

\begin{tabular}{lll}
\hline Factor & $P$-value & Significance \\
\hline Time & $>0.05$ & NS \\
Site(reserve) & $<0.05$ & Sig \\
Reserve & 0.111 & NS \\
Time*site(reserve) & $<0.05$ & Sig \\
Sea Surface temperature & $>0.05$ & NS \\
\hline
\end{tabular}

Table 4.14.Results of 3-factor ANCOVA for Carpophyllum maschalocarpum at Kapiti Marine Reserve, indicating which factors are significant in explaining variability.

\begin{tabular}{lll}
\hline Factor & $P$-value & Significance \\
\hline Time & 0.781 & NS \\
Site(reserve) & 0.770 & NS \\
Reserve & 0.049 & Sig \\
Time*site(reserve) & 0.670 & NS \\
Sea Surface temperature & 0.900 & NS \\
\hline
\end{tabular}


Table 4.15. Results of 3-factor ANCOVA for Ecklonia radiata at Kapiti Marine Reserve, indicating which factors are significant in explaining variability.

\begin{tabular}{lll}
\hline Factor & $P$-value & Significance \\
\hline Time & 0.379 & NS \\
Site(reserve) & 0.007 & Sig \\
Reserve & 0.445 & NS \\
Time*site(reserve) & 0.976 & NS \\
Sea Surface temperature & 0.384 & NS \\
\hline
\end{tabular}

Table 4.16. Results of 3-factor ANCOVA for banded wrasse at Kapiti Marine Reserve, indicating which factors are significant in explaining variability.

\begin{tabular}{lll}
\hline Factor & $P$-value & Significance \\
\hline Time & 0.425 & NS \\
Site(reserve) & $0.000^{*}$ & Sig \\
Reserve & $0.000^{*}$ & Sig \\
Time*site(reserve) & 0.684 & NS \\
Sea Surface temperature & 0.436 & NS \\
\hline
\end{tabular}

Table 4.17. Results of 3-factor ANCOVA for blue cod at Kapiti Marine Reserve, indicating which factors are significant in explaining variability.

\begin{tabular}{lll}
\hline Factor & $P$-value & Significance \\
\hline Time & 0.148 & NS \\
Site(reserve) & 0.012 & Sig \\
Reserve & 0.000 & Sig \\
Time*site(reserve) & 0.550 & NS \\
Sea Surface temperature & 0.892 & NS \\
\hline
\end{tabular}


Table 4.18. Results of 3 -factor ANCOVA for butterfish at Kapiti Marine Reserve, indicating which factors are significant in explaining variability.

\begin{tabular}{lll}
\hline Factor & $P$-value & Significance \\
\hline Time & 0.092 & NS \\
Site(reserve) & 0.042 & Sig \\
Reserve & 0.001 & Sig \\
Time*site(reserve) & 0.182 & NS \\
Sea Surface temperature & 0.005 & Sig \\
\hline
\end{tabular}

Time was not a significant factor in explaining the variability for any of these species in this model. Site nested within reserve was significant for most species, except Carpophyllum maschalocarpum. This indicates a difference amongst sites, but it cannot be separated from "reserveness". Butterfish, blue cod, banded wrasse, Carpophyllum maschalocarpum and scarlet wrasse showed reserve alone to be a significant factor. This indicates that the reserve sites support significantly different abundances of these species from control sites. Only black foot paua had time as an interaction with site nested with reserve to be a significant factor, however this means that one cannot interpret the exact effect of either time or site(reserve) as a factor to explain variability by itself, as the interaction confounds these interpretations. Butterfish was the only species where sea surface temperature was significant, and thus might be a factor in explaining differences in abundance in this species.

\subsubsection{Algal Damage}

$\mathrm{H}_{0}=$ There is no difference in algal damage among sites.

$\mathrm{H}_{0}=$ There is no difference in algal damage among reserve and control sites.

ANOVA tests on algal damage were run using the following model.

Site (reserve)

Reserve

Time

Damage

Damage*reserve

Time*Damage (interaction)

Site(reserve)*Damage (interaction) 
Site(reserve)*Damage*Time

Sea surface temperature

The whole model was significant only for Ecklonia radiata.

The results were as follows.

Table 4.19. Results of a 4-factor ANCOVA for damage to Ecklonia radiata plants at Kapiti Marine Reserve, indicating which factors explain variability.

\begin{tabular}{lll}
\hline Factor & $P$-value & Significance \\
\hline Site(reserve) & 0.005 & Sig \\
Reserve & 0.820 & NS \\
Time & 0.105 & NS \\
Sea surface temperature & $>0.05$ & NS \\
Damage & 0.000 & Sig \\
Damage*reserve & $<0.05$ & Sig \\
Damage*time & $<0.05$ & Sig \\
Damage*site(reserve) & $>0.05$ & $\mathrm{NS}$ \\
Damage*site(reserve)*time & $<0.05$ & Sig \\
\hline
\end{tabular}

The interaction between damage and reserve and the interaction between damage and time are significant. Therefore the effect of any of these factors alone cannot be interpreted as they are affected by their relationship to other factors. The site nested with reserve factor is also significant, but this as an interaction with damage is not. This indicates that there is a difference among sites, but this cannot be considered independently without taking reserve into account. However, the fact that the three way interaction between site(reserve), damage and time is significant means that there are no easily interpretable patterns in any of these three factors and the variaton may be due to any combination of two of the three factors.

This is displayed graphically below in Figs. 4.20.-4.23. 
Fig 4.20. Abundance of algal (Ecklonia radiata) damage at Arapawaiti Point, at all survey periods, at Kapiti Marine Reserve.

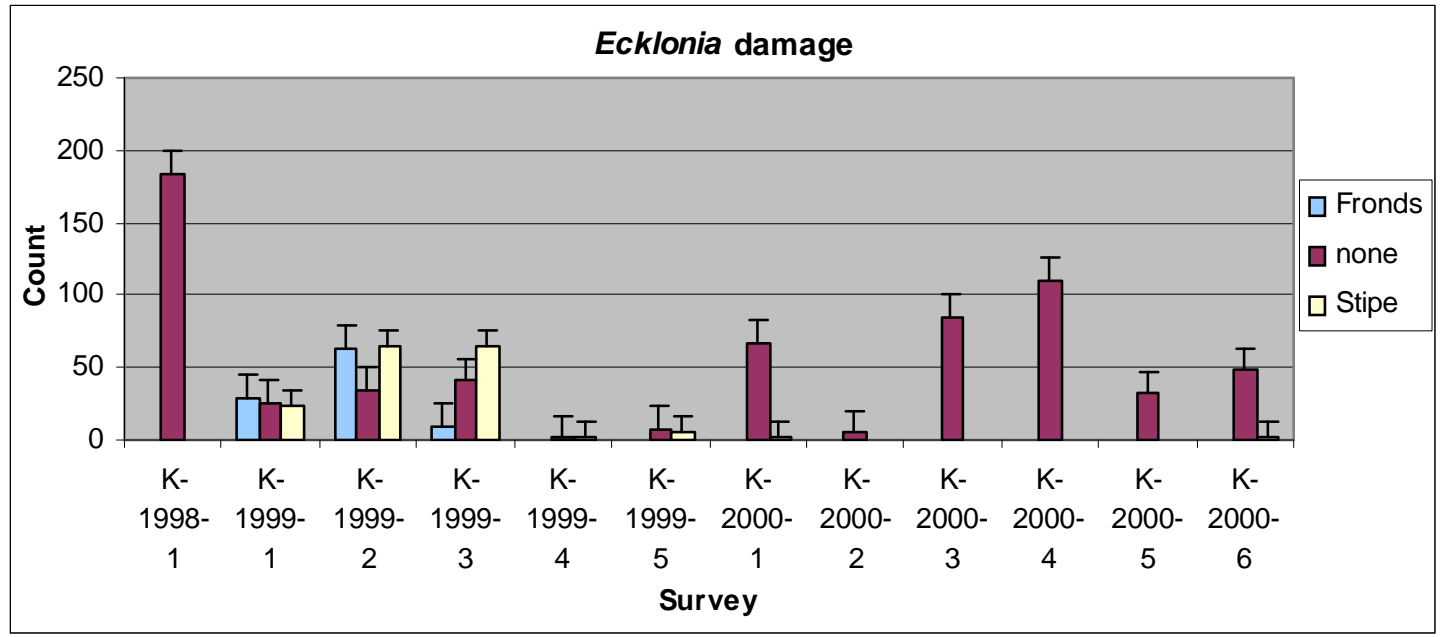

Fig. 4.21. Abundance of algal (Ecklonia radiata) damage at Onepoto point, at all survey periods, at Kapiti Marine Reserve.

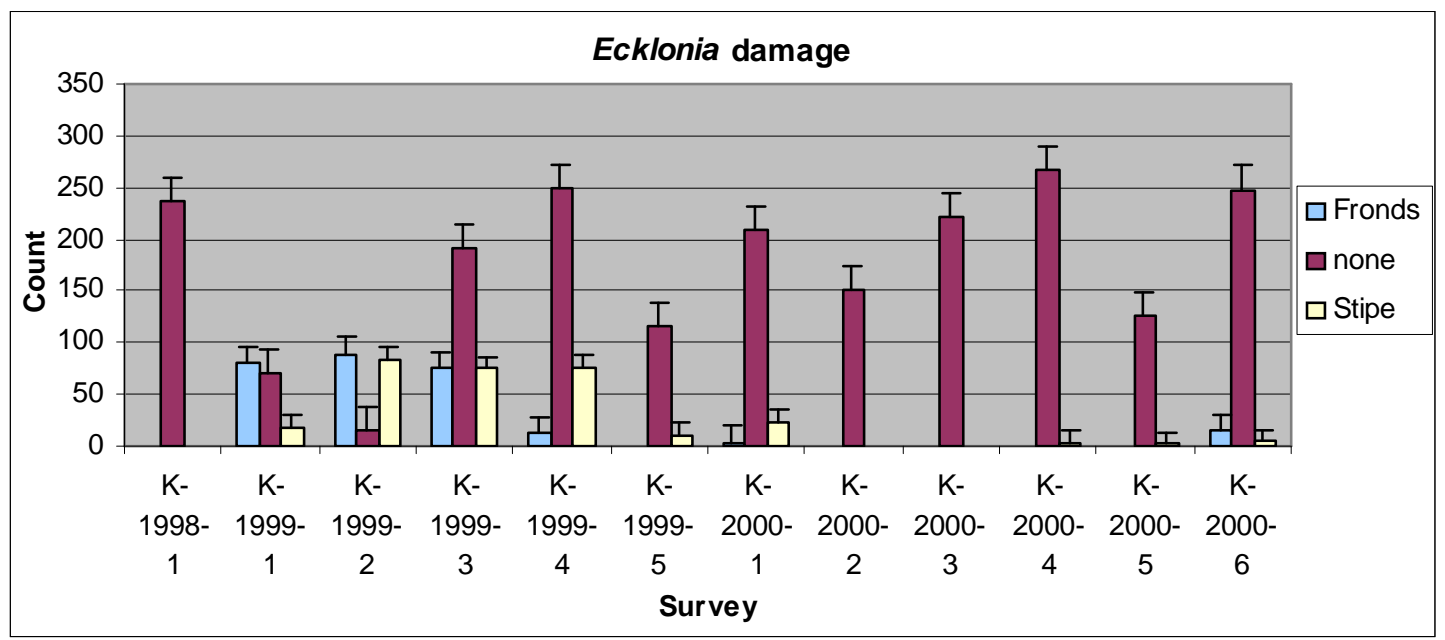


Fig. 4.22. Abundance of algal (Ecklonia radiata)damage at Kaiwharawhara Point, at all survey periods, at Kapiti Marine Reserve.

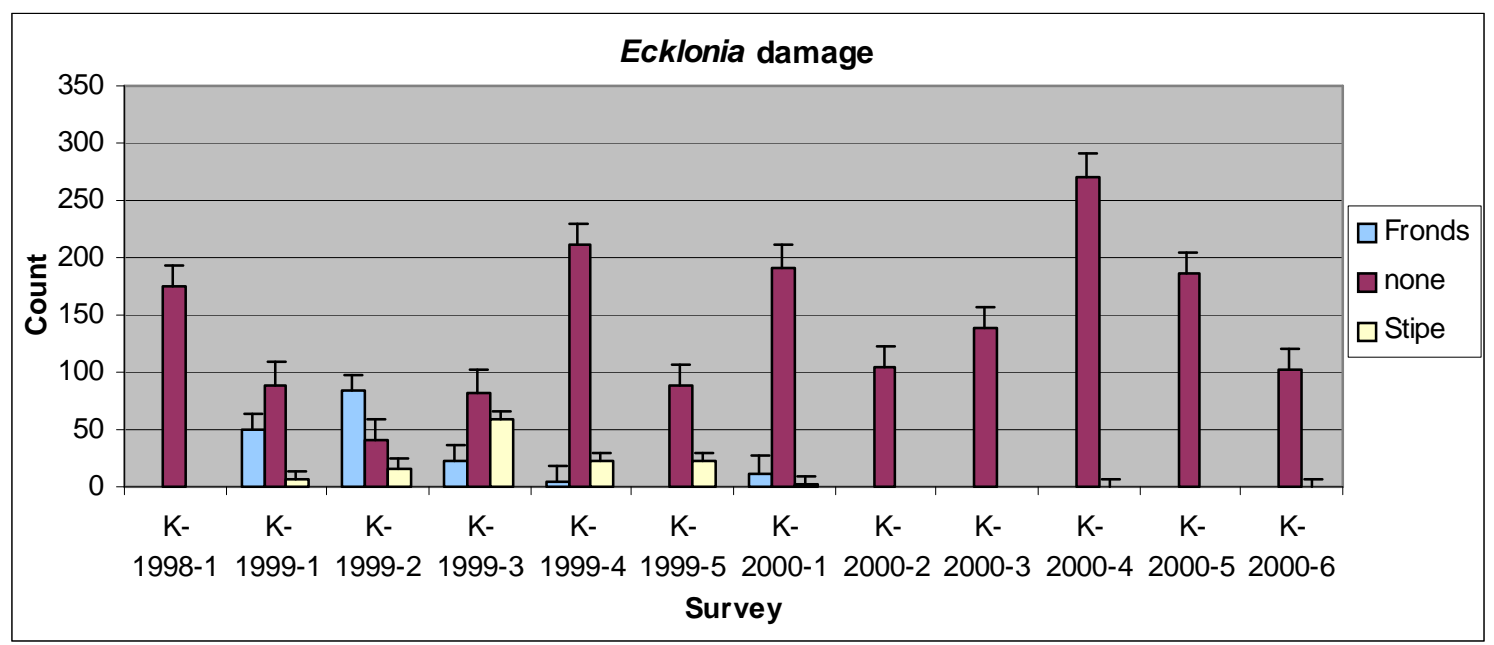

Fig. 4.23. Abundance of algal (Ecklonia radiata) damage at Tokahaki Point at all survey periods at Kapiti Marine Reserve.

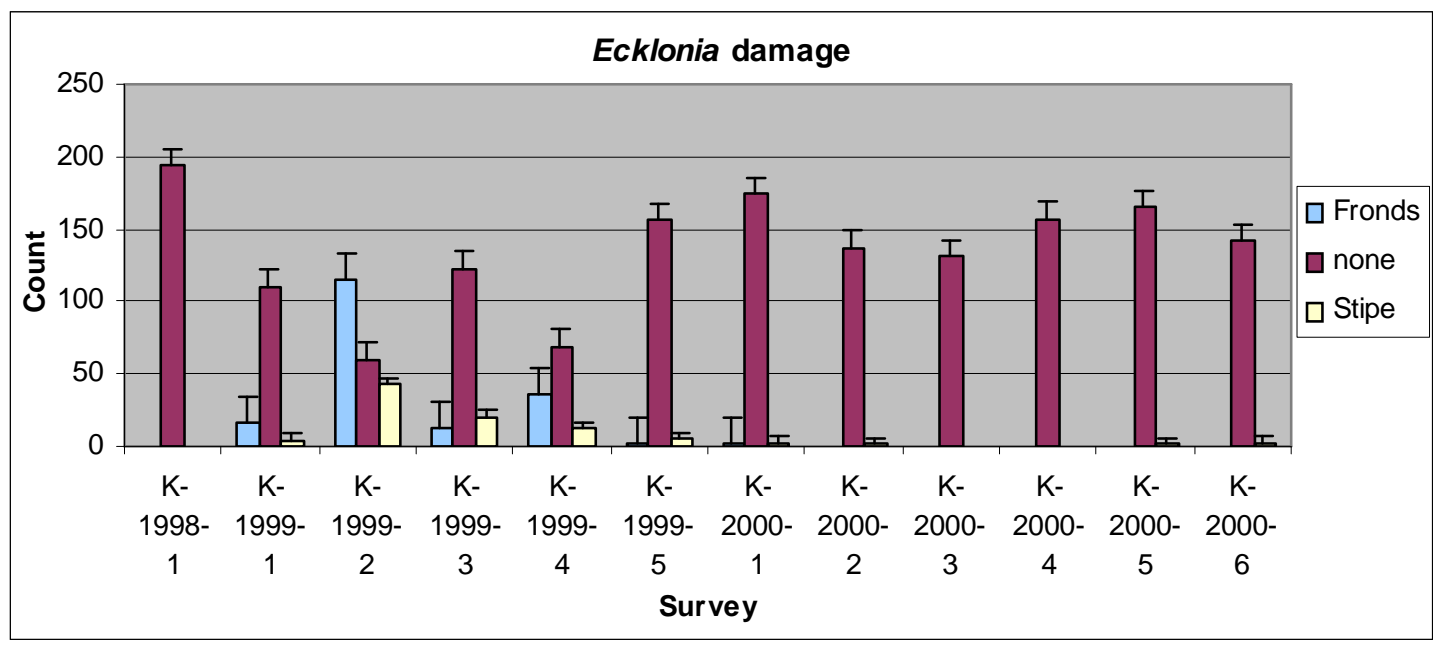


4.4.6 Comparison to previous data

The data collected in this investigation were compared to data collected in 1992 (Battershill et al., 1993). ANOVA testing for differences in size and abundance was performed separately for each site for the species common to both surveys.

Results for ANOVA tests performed on $\log _{\mathrm{e}}$ transformed count data are presented below:

Table 4.20. Results of ANOVA testing for differences in species abundance, at Arapawaiti Point, between 1992 and this investigation.

\begin{tabular}{lll}
\hline Species & $P$-value & Significance \\
\hline Banded wrasse & 0.855 & NS \\
Blue cod & 0.258 & NS \\
Butterfish & 0.05 & NS \\
Blue moki & 0.887 & NS \\
Kina & 0.776 & NS \\
Leatherjacket & 0.767 & NS \\
Scarlet wrasse & 0.543 & NS \\
Tarakihi & 0.830 & NS \\
\hline
\end{tabular}

Table 4.21. Results of ANOVA testing for differences in species abundance, at Onepoto Point, between 1992 and this investigation.

\begin{tabular}{lll}
\hline Species & $P$-value & Significance \\
\hline Blue cod & 0.019 & NS \\
Butterfish & 0.073 & NS \\
Kina & 0.667 & NS \\
Red moki & 0.2 & NS \\
Scarlet wrasse & 0.209 & NS \\
\hline
\end{tabular}


Table 4.22. Results of ANOVA testing for differences in species abundance, at Kaiwharawhara Point, between 1992 and this investigation.

\begin{tabular}{lll}
\hline Species & $P$-value & Significance \\
\hline Banded wrasse & 0.505 & NS \\
Butterfly perch & 1.00 & NS \\
Kina & 0.380 & NS \\
\hline
\end{tabular}

Table 4.23. Results of ANOVA testing for differences in species abundance, at Tokahaki Point, between 1992 and this investigation.

\begin{tabular}{lll}
\hline Species & $P$-value & Significance \\
\hline Banded Wrasse & $0.000^{*}$ & Sig \\
Butterfly perch & 0.641 & NS \\
Butterfish & 0.880 & NS \\
Kina & 0.333 & NS \\
Scarlet wrasse & 0.531 & NS
\end{tabular}

*denotes significance after correction for multiple testing.

In most cases there was no difference between the data collected in 1992 and that collected in this study. Banded wrasse abundance data for Tokahaki Point were significantly different between the two surveys.

For those species where size estimates were made, the data was square root transformed and ANOVA was used to test for differences in mean size between the two surveys. 
Table 4.24. Results of ANOVA testing for differences between 1992 and this investigation, in average species size at Arapawaiti Point.

\begin{tabular}{lll}
\hline Species & $P$-value & Significance \\
\hline Banded wrasse & 0.434 & NS \\
Blue cod & 0.223 & NS \\
Blue moki & 0.198 & NS \\
Butterfish & 0.758 & NS \\
Tarakihi & 0.136 & NS \\
Kina & 0.239 & NS \\
\hline
\end{tabular}

Table 4.25. Results of ANOVA testing for differences between 1992 and this investigation, in average species size at Onepoto Point.

\begin{tabular}{lll}
\hline Species & $P$-value & Significance \\
\hline Blue cod & 0.656 & NS \\
Butterfish & 0.758 & NS \\
Kina & 0.537 & NS \\
Red moki & 0.452 & NS \\
Scarlet wrasse & 0.667 & NS \\
\hline
\end{tabular}

Table 4.26. Results of ANOVA testing for differences between 1992 and this investigation, in average species size at Kaiwharawhara Point.

\begin{tabular}{lll}
\hline Species & $P$-value & Significance \\
\hline Banded wrasse & 0.087 & NS \\
Butterfly perch & 0.667 & NS \\
Kina & 0.678 & NS \\
\hline
\end{tabular}


Table 4.27. Results of ANOVA testing for differences between 1992 and this investigation, in average species size at Tokahaki Point.

\begin{tabular}{lll}
\hline Species & $P$-value & Significance \\
\hline Banded wrasse & 0.158 & NS \\
Butterfly perch & 0.943 & NS \\
Butterfish & 0.604 & NS \\
Kina & 0.065 & NS \\
\hline
\end{tabular}

No species showed any significant differences in average size between the two sampling periods (i.e. Battershill et al., 1993 data and the data collected in this investigation).

\subsection{Discussion}

\subsubsection{Site Similarity}

Post Hoc Tukey pairwise comparisons for the ANOVA tests showed, with some exceptions, Arapawaiti point to be almost consistently significantly different from all of the other sites. The results showed that the reserve sites supported higher numbers and larger sizes of these species than the control sites, but Figs. 4.6-4.9 also show that in most cases Arapawaiti Point is the reserve site that supports higher numbers.

Based on observations while SCUBA diving, Arapawaiti Point appears different from the other sites. The reef habitat gives way to a rubble slope, which then becomes a sand and broken shell/cobble substrate. This is known as a common habitat for blue cod (Davidson, 1995). It was therefore not surprising to find a large number of blue cod at this site compared to the other study sites. Furthermore, there are large Ecklonia radiata stands at Arapawaiti Point. This feature may be important to several species of fish, especially labrids, that have been shown to be shelter-dependant as juveniles and feed on micro crustaceans found in macro algal stands. Later they form schools and become less dependant on algal cover (Jones, 1984, Choat and Ayling, 1987, Babcock and Cole, 1993, Anderson, 1994). Since there is a mixture of both algae and rubble habitats at Arapawaiti Point, it probably explains the high abundance of banded wrasse, as the habitat is suitable for both adults and juveniles. Figs. 4.13. - 4.16. show the difference in abundance and 
size between reserve and control sites, although it can be seen from Figs.4.6.-4.8. that Arapawaiti Point is generally the reserve site that supports a higher abundance, whereas Onepoto Point (the other reserve site) does not show such a marked difference. Onepoto Point is slightly different in habitat; it is a shallow broken reef that is created by large boulders lodged next to each other interspersed with small patches of big cobble. There is no obvious distinction between shallow reef leading onto cobble bottom like there is with Arapawaiti Point.

Results from statistical tests showed that the reserve sites supported larger average sizes for particular species, while other species showed greater abundance than in control sites. The magnitude of the difference, however, is possibly skewed by Arapawaiti Point which naturally supported a greater abundance and species diversity than all other sites and this result may not be attributable to reserve status. Local fisherman reported good fishing at Arapawaiti Point and objected to the establishment of the Kapiti Marine Reserve because they felt they believed they would be lose a valuable fishing ground. Even before establishment of the reserve, locals that had dived Arapawaiti Point, stated that it supported a rich fish community compared to other areas around the island (Robert Williamson pers. comm.). Battershill et al. (1993) reported a high species abundance and diversity and a unique and spectacular subtidal habitat at this site. Their results showed that Arapawaiti Point supported the largest number of fish species and the largest mean fish species abundance of all the sites surveyed. The present study confirms these findings. Arapawaiti Point also supports a bryozoan characterised reef which is unique to the west coast of the North Island (Battershill et al., 1993). However, this was located at a depth strata of about $18-25 \mathrm{~m}$. This depth stratum was not surveyed in the present investigation. In addition, Arapawaiti Point is the only one of the sites surveyed that supports a small New Zealand fur seal colony. This may influence both abundance, type and behaviour of the fish seen in this area due to predation of reef fish by the seals.

Additionally, the abundance of many reef fish is correlated with variation in reef characteristics, such as topographic complexity. Chapman and Kramer (1999) tried to control for potential habitat correlates of fish when examining the effect of the Barbados Marine Reserve, so that the effect of habitat variables did not mask the effects of reservation. They found that there were no significant differences in habitat characteristics between reserve and control sites, but stated that this still did not rule out the possibility that differences in fish density could be due to habitat differences. 
Chapman and Kramer (1999) commented that reserve sites are often chosen because of the high initial habitat quality and abundance of fish. Evidence that habitat quality can affect reserve performance is seen in the example cited by Roberts (2000). The Hol Chan Marine Reserve in Belize is centred around a passage in the outer reef. Before the reserve was closed to fishing, it was known as a prime fishing spot. After four years this reserve supported a very high biomass of predatory fish. Part of the Saba Marine Park in the Netherlands Antilles was closed to fishing at the same time as the Hol Chan Marine Reserve. The increase in biomass at Saba Marine Park was less than at Hol Chan Marine Reserve and peaked at a level well below that of the Hol Chan Marine Reserve. Roberts (2000) attributed this to the fact that the Hol Chan Marine Reserve was placed in a site where there were high import levels of nutrients from lagoonal and offshore habitats during tidal flushing, but the fully protected portion of Saba Marine Park did not receive any such inputs. Similarly, at Kapiti Marine Reserve, it seems likely that Arapawaiti Point being so different from the other sites would confound the reserve effect in any analysis performed.

Battershill et al. (1993) found evidence for a tendency of greater species diversity at the northern tip of Kapiti Island with decreasing diversity towards the south. They attributed this phenomonen to decrease in shelter. Sites located towards the northern end of the island tend to be less subject to harsh wave conditions and strong currents. Since the island is orientated SW-NE, the northern sites, especially those on the western side of the island, are not exposed to rough sea conditions due to the predominant southerly winds. Since Arapawaiti Point is situated further north than Onepoto Point, this could be another reason to explain why the Onepoto Point reserve station showed less dramatic increases/differences than Arapawaiti Point. A similar pattern was found on the south coast of Wellington (chapter three, this thesis) where more sheltered sites generally supported a greater species abundance.

The MDS plot using average abundance data from all species showed all sites to be relatively similar or dissimilar to each other. The plots using abundance data from only fish, invertebrates or algae were not as well spaced out, but no distinct patterns were obvious. In all the plots the sites were very close on dimension two and more spread apart on dimension one. This may indicate that dimension one accounted for most of the variability in the data. However, it is not clear what aspect of the sites dimension one may represent. This analysis showed no clear differences or patterns in reserve sites vs control 
sites. This is likely to be due to variability in the data, and the fact that only two reserve and two control sites were surveyed. With only four sites it is difficult to determine whether true clustering exists or not. If more sites had been surveyed and subsequently included in the analysis, there is a possibility that Arapawaiti Point may have been significantly separated from the other sites. More sites, both reserve and control, would have more clearly indicated a difference between reserve and control sites.

\subsubsection{Power Analysis}

Data for most species surveyed had a relatively high power to detect a change. The best species to use as indicator species to detect a change in this reserve would be blue cod, butterfish, kina, black foot paua, rock lobster and Ecklonia radiata. While performing visual fish censuses, it is possible to record many species without an increase in sampling effort. Therefore, it is recommended that any ongoing monitoring include all species observed. Data for some species, such as red moki and blue moki, that have a low power to detect change now, may increase in power to detect a change if the fish abundance increases in response to reservation. Similarly, data collected for species such as banded wrasse, scarlet wrasse and spotty, although not commercially or recreationally fished species, have a high power to detect change. These species may not be expected to show a very marked response to reservation as they are not subject to as much fishing pressure as the other species, but they may provide information on changes occurring in populations not subject to fishing pressure. Jouvenel and Pollard (2001) noted that the demographic structure of fish populations in reserves is different from fished areas. The authors suggested that this might be because fish show conditioned responses to fishing pressure and move to deeper waters. However, in reserves, when this fishing pressure is removed, these species may move back to shallower waters. This is similar to the response that Castilla (1989) found in Las Cruces, central Chile, where species previously considered as subtidal, became prevalent in intertidal areas when protected from human foraging.

Battershill et al. (1993) reported that in general, all mobile invertebrates were uncommon at Kapiti Marine Reserve. The authors reported that paua and kina were abundant, but only in small localised patches. In the present study, the data for paua and kina had a high enough power to detect a change. This could be indicative of change in the reserve since the 1993 survey was carried out. If the abundance was still as low and patchy as reported by Battershill et al. (1993) the data probably would have had a very low power. These species are relatively sessile so the results would not be confounded by movement of 
these species between sites or easily crossing reserve boundaries. As mentioned in section 3.5.2., the investigation of marine reserves in Tasmania by Edgar and Barrett (1999) showed that the effectiveness of a marine reserve depended on the mobility of the target species, hence species like abalone were more likely to be protected in a small reserve compared to more mobile species. Therefore, this potential increase in paua and kina abundance at Kapiti Marine Reserve was not unexpected.

The type of community shift where kelp forests regenerated in the Cape Rodney-Okakari Point Marine Reserve due to increased predation on kina (described in section 3.5.2.) has not occurred in the Kapiti Marine Reserve. Since urchin barrens are not a common feature in this marine reserve, even at the control sites, this was not a likely response to reservation.

Rock lobster were not surveyed as intensively in the current investigation as compared to the Battershill et al. (1993) survey. This was due to logistical restrictions related to diving time (safety). Therefore, further surveys in the present investigation were not feasible. Since rock lobster is a commercially important species, it is recommended that they be monitored more intensively. This could involve surveying a greater area than in the current or the previous investigation and the divers should be trained to sex and size the lobsters visually while minimising disturbance. Sizing is usually an estimate of carapace length as in MacDiarmid (1991), MacDiarmid and Breen (1992) and Davidson (in submission). Collecting this additional information will allow seasonal migrations and changes in depth distributions (MacDiarmid, 1991) to be detected and therefore will not confound the reserve effect in any subsequent analysis. Fishing pressure has also been shown to skew sex ratios in rock lobster (and other species) and monitoring of sexes will help determine whether reservation is changing the ratios of the sexes in populations( MacDiarmid, 2001, Roberts and Hawkins, 2000)

The same apparent relationship between abundance of Ecklonia radiata and Carpophyllum flexuosum was observed at the Kapiti Marine Reserve as was observed on the south coast of Wellington (see section 3.5.2). As the abundance of Ecklonia radiata decreased, the abundance of Carpophyllum flexuosum increased.At Kapiti Marine Reserve, like the Wellington south coast, Carpophyllum flexuosum was not monitored from the start of this investigation and it was not added to the suite of species investigated. Therefore the interaction between these two species could not be tested. 
Future monitoring should include this species and the data tested for a shift in the algal community. Since Ecklonia radiata has been shown to be an important food source for several species such as butterfish (Odax pullus) and kina (Babcock and Cole, 1993), a potential change in the dominant alga, could subsequently lead to a change in abundance of these species.

\section{$\underline{4.5 .3 \text { Seasonal variation }}$}

Testing for seasonal variation did not show any obvious patterns. Time was not a significant factor in explaining the variation in the model for any of the species tested. The models showed that the only significant factors in explaining the variability were site and/or reserve factors. These factors obviously have a greater role in explaining the variability of the data than time. Shears and Babcock (2000) found obvious temporal variation in community structure, especially in abundance of the dominant species, between years in the Cape Rodney-Okakari Point Marine Reserve. These patterns were mostly attributed to small scale patchiness of certain species, except in the case of Ecklonia radiata and Carpophyllum maschalocarpum, where variation in recruitment caused obvious temporal patterns. This temporal variation in any species, however, did not obscure patterns seen between reserve and control sites.

An explanation for the lack of seasonal trends at Kapiti Marine Reserve have been discussed in relation to the south coast of Wellington in section 3.5.3.

\subsubsection{Algal Damage}

Time as an interaction with reserve was a significant factor in explaining the variation in the amount of damage in Ecklonia radiata plants. Ecklonia radiata was the only algal species, where algal damage, was found to be significant. Ecklonia radiata was the most commonly seen alga of those algae that were surveyed, therefore this was not unexpected. Figs. 4.22.-4.25. show that the greatest amount of algal damage to plants at all sites occurred during 1999, and the extent of the damage tapered off in 2000. Algal damage was not surveyed in 1998. As mentioned earlier, the abundance of Ecklonia radiata plants appeared inversely linked to the abundance of Carpophyllum flexuosum plants. When the abundance of Ecklonia radiata decreased dramatically and there were large numbers of severely "damaged" plants, Carpophyllum flexuosum became the dominant species. However no quantitative data were collected on the abundance of Carpophyllum flexuosum, so this is based purely on observation. 
As mentioned before (section 4.5.3.), investigators in central Chile (Castilla, 1989) had found that the intertidal communities that developed in areas protected from human disturbances showed little similarity to those previously considered 'normal'. Species previously thought only to occur in subtidal depths became prevalent in the intertidal area, and those previously considered rare became dominant. A similar situation might be occurring here in the shallow subtidal region with Carpohyllum flexuosum becoming prevalent where it is not necessarily expected. According to Cole and Babcock (1993) usually Carpophyllum flexuosum does not recruit well on to vacant areas of rock below $10 \mathrm{~m}$ depth, but after several Ecklonia radiata die back events, a better opportunity may exist for species such as Carpophyllum flexuosum to recruit, since they can establish their own "gametophyte bank". The authors stated that there was evidence of this occurring in the Hauraki gulf after several Ecklonia radiata die back events. This may indicate a comparable case at Kapiti Marine Reserve. These Ecklonia radiata die back events have been observed in other areas such as Little Barrier Island and Cape Rodney- Okakari Point Marine Reserve (Cole and Babcock, 1993). Originally the cause for damage to fronds to Ecklonia radiata plants was thought to be due to herbivorous fish such as butterfish that are known to feed on Ecklonia radiata plants (Babcock and Cole, 1993, Choat and Clements, 1993, Clements and Choat, 1993) and are present in relatively large numbers. It has also been shown that the sea urchin, Evechinus chloroticus, feeds on Ecklonia radiata stands (Babcock and Cole, 1993, Babcock et al., 1999, Shears and Babcock, 2000). Several other possible causes of the algal damage have been suggested. These include potential pathogens such as bacteria, fungi or viruses, environmental effects related to temperature and phytoplankton blooms and normal demographic processes associated with Ecklonia radiata (Babcock and Cole, 1993). Babcock and Cole (1993) suggested that the periodicity of these Ecklonia radiata die back events may have been enhanced by factors such as ENSO (El Nino Southern Oscillation) events in the past that coincided with the die back events. It is of note that this investigation was also carried out during an ENSO event. Since sea surface temperature changes can be associated with ENSO events, this was tested as a covariate with algal damage, however it was not found significant. This type of damage is often associated with the stipe boring amphipod Orchomenella aahu which has been found present in the Ecklonia radiata plants in Cape Rodney-Okakari Point Marine Reserve (Haggitt 1999, pers. comm.). Subsequently some Ecklonia radiata samples were collected from the control sites around Kapiti Marine Reserve and dissected looking for these amphipods. Amphipods were 
found and also identified as being Orchomenella aahu. Therefore, this amphipod species may play an important role in the Ecklonia radiata damage observed at Kapiti Marine Reserve.

\subsubsection{Comparison to previous data}

Comparing the data from this investigation to data collected by Battershill et al. (1993) showed that apart from banded wrasse there were no significant differences in sizes or abundances of species tested. Banded wrasse were more abundant at Tokahaki Point in the present investigation than the previous one. No species showed a significant difference in size between the two data sets. Tokahaki Point is a control site and since banded wrasse at this site showed an increase in abundance, these differences are unlikely to be due to reservation, but are more likely to be due to variability in the data.

The data in 1992 was collected over one short monitoring period and therefore may not be representative of the average numbers/sizes at that time. The data from 1992 was compared with data from this investigation collected over similar months so that any seasonal variation (if there was any) would not confound the results. Battershill et al. (1993) found no significant difference amongst reserve and control sites. The fact that differences were found amongst sites, and amongst reserve and control sites in this study is likely to be due to reservation status.

\subsubsection{General discussion}

A review by Halpern (in press), of 89 "no-take" marine reserves found that population densities of species in marine reserves were on average $91 \%$ higher, biomass was $192 \%$ higher, average organism size was $31 \%$ higher and species diversity was $23 \%$ higher, compared to control sites, regardless of reserve size. Furthermore, the author stated that these high values were reached in one to two years after protection. Evidence suggested that marine reserves were contributing significantly to recruitment and thus providing substantial export to areas adjacent to those reserves. The Kapiti Marine Reserve does show an increase in species size and abundance and as such appears to conform to this finding. In the Mombasa Marine National Park in Kenya, Catch Per Unit Effort (CPUE) at the marine reserve boundaries was found to be $25 \%$ higher than elsewhere in the fishing grounds, consequently fishers were targeting this area. Fishers might be finding that fishing close to Kapiti Marine Reserve boundaries is yielding a better CPUE than 
elsewhere, as it has been observed that there are often fishing boats very near the reserve boundaries (pers. obs.).

When examining the effects of marine reserves, several considerations must be taken into account. Response times to protection varies depending on the species. For species very vulnerable to overfishing, which tend to be long lived and late reproducing (k-selected) benefits are low until a high level of protection is achieved. For smaller, shorter lived and early reproducing fish (r-selected), benefits build up steadily as the level of protection builds up (Roberts, 2000). The r-selected species are usually the first to show a response to protection from fishing, whereas the k-selected species will take longer to reappear inside reserves (Roberts and Hawkins, 2000). To date in the Kapiti Marine Reserve, not all species have shown an effect, but this is probably due to the fact that response times vary from species to species. The statistical tests performed in the present investigation showed differences between reserve and control sites for species such as blue cod and several species of wrasse. These are all quickly maturing and fast growing species (Francis, 1996). From personal observation, species such as red and blue moki and butterfish, which are slower growing, long lived and slower to mature (Francis, 1996) are starting to become more abundant and large individuals were present. This is in direct accordance with the responses that Roberts (2000) predicted about species with different life histories. Follow-on effects of reservation seem to be becoming evident at Kapiti Marine Reserve. Battershill et al. (1993) reported that the algal stands at Arapawaiti point were in good condition so the damage to the plants seen in the present investigation may be a secondary effect of the change in species abundance. Therefore, it is clear that the success of any particular marine reserve depends on the objective of its establishment (Conover et al., 2000) and the response times of the organisms within it.

Whilst conducting visual censuses of fish in marine reserves is the most commonly accepted form of gathering data on fish abundance, it has been noted that in some marine reserves fish behaviour towards divers may change (for example the fish may become accustomed to them and thus more fish may be sighted by divers than previously) (Cole, 1994, Davidson, in submission.). Although no marked differences in fish behaviour between reserve and control sites at Kapiti Marine Reserve were observed in the present investigation, this is a point of note for future surveys. 
Also important is the fact that "all marine protected areas are poached to varying degrees" (Attwood et al., 1997b). For example the Mombasa Marine National Park in Kenya was set up in 1987. However, fishers remained in the area and poaching continued to be a problem until 1992. In 1992 night-time patrols effectively decreased poaching in the reserve and so it was not until this time that it was truly protected from fishing (Roberts and Hawkins, 2000). The amount of poaching that occurs in a marine reserve, can affect the changes occurring in a reserve. During the present investigation a few nets were found (and pulled out) in the reserve. Amongst level of protection, location, shape, size and proximity to other reserves, compliance is a critical factor greatly influencing the efficacy of any marine reserve.

Tokahaki Point, which was used as a control site in this survey, was deemed by Battershill et al. (1993) to be inappropriate as a control, as the habitat it supports is slightly different from the sites on the western side of the island. However, the similarity tests they performed clustered all these sites together. It was used as a control site for this investigation as it was less exposed and provided a safer dive site than Maraetakaroo Point (which was another one of the sites surveyed by NIWA (Fig. 4.2.). This was an important logistical consideration as time in which to conduct surveys was limited. Only four sites were used, to enable a complete survey to be carried out in a day.

The results in the present investigation were effectively based on an 'in versus out' (or 'reserve versus control') comparison. Although there was a small amount of baseline data available, comparisons using this data did not show any change, although it is clearly occurring. This indicates that simply having data from a survey done before reserve establishment is not enough to ensure detection of a change post establishment. As is stated by Underwood and Atkinson (1992) " It is imperative that sufficient information is collected to be able to establish the magnitude of natural fluctuations in densities of populations." According to the power analysis performed, the methodology used to collect data in the current investigation should be able to detect any change. The fact that no difference was detected between the two studies must therefore be attributed to inadequate baseline data. This is unsurprising as the early study was a one-off survey with no temporal replication and very little spatial replication. A one-off survey should have large amounts of spatial replication (i.e. transects), otherwise the chances of collecting enough data to show statistically significant changes are unlikely. 
However, the slightly different methodology employed during the two studies may be partially at fault. I used methodology consistent with that used for the monitoring of the south coast for logistical reasons as explained in chapter two. Descriptions of benthic quadrats and reef stratifications, and comprehensive species lists provided by the Battershill et al. (1993) survey were not followed up in this investigation. If these were followed up, maybe a difference in community composition would become apparent. The lesson to take from this is that follow up surveys should where possible use identical methodology as the initial survey. It also suggests that collection of pre-reserve data allows fine tuning of the methodology to be used.

\subsubsection{Summary and future recommendations}

Future monitoring should include the same sites adopted in this investigation to detect protection related changes on the western side of the island. Additionally, the other sites on the western side of the island surveyed in Battershill et al. (1993) should be included as this would give a better indication of change inside and outside the reserve, since it would include three reserve sites and four control sites (and therefore increasing spatial replication). There is a possibility that Arapawaiti Point may bias the magnitude of the change occurring inside the reserve as it supports a unique habitat, and surveying an extra reserve site would serve to balance out this bias, should there be one.

Algal damage should continue to be monitored as this may be a cyclic occurrence. In addition to Ecklonia radiata, Carpophyllum flexuosum should be quantitatively surveyed as there seems to be an interaction between these two species. Following methodology used in the present study, key species to be monitored should include butterfish, blue cod, black foot paua and kina. Data collected for these species using this methodology has been shown to be adequate to detect any changes. Monitoring of rock lobster should include collection of size data, and sampling at different depth ranges as well as an increase in sampling effort. Species interactions and associations of species with certain habitat types should be examined to increase understanding of natural processes.

In summary, Kapiti Marine Reserve is having a positive effect on particular species surveyed in this investigation. For some species, abundance is increasing and the population demographics (i.e. size structure) of other species present is changing. No distinct seasonal patterns were detected despite frequent monitoring (possibly due to abnormal weather patterns due to El Nino and La Nina years). Continued monitoring 
should use the same methodology with the suggested additions and important indicator species are identified. Further continual monitoring of this reserve may allow more robust time series analysis to be performed to detect longer term natural variation than the span of the present investigation. It would also determine if the magnitude of the effect of the marine reserve continues to increase with time. 


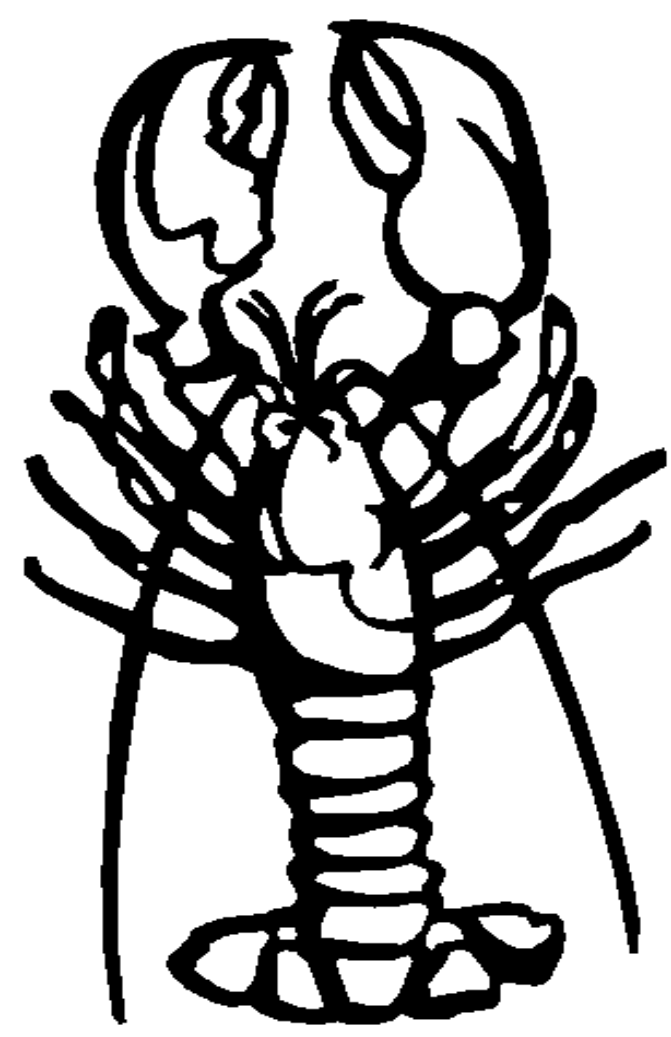

THE EFFECTS OF NEW ZEALAND MARINE RESERVES ON THE MEAN SIZE AND ABUNDANCE OF BLUE COD AND ROCK LOBSTER:

A META-ANALYSIS. 


\section{CHAPTER 5 - THE EFFECTS OF NEW ZEALAND MARINE RESERVES ON THE MEAN SIZE AND ABUNDANCE OF BLUE COD AND ROCK LOBSTER: A META-ANALYSIS.}

\subsection{Introduction}

As mentioned in the general introduction, there are currently 16 marine reserves in New Zealand. They are spread throughout New Zealand and range in age from 26 years to 2 years. There are also three other marine protected areas that are under a different legislation to reserves, and two marine mammal sanctuaries. There are 9 marine reserves located in the North Island plus the Kermadec Islands and 6 marine reserves in the South Island. Three of the reserves in the South Island are at the northern tip of the South Island. The degree of protection and size of these marine protected areas differs considerably. All of New Zealand's marine reserves totally prohibit commercial, traditional and recreational fishing. See Table 5.1. for a list of New Zealand marine reserves. Most of the literature talks about 'marine protected areas', which is effectively any part of the sea where special regulations to protect biotic and abiotic resources might apply (Attwood et al., 1997a, Ballantine,1997). In this investigation I will refer to marine reserves as being areas where any form of extraction is banned.

There have been many studies conducted on the effects of marine reserves on particular species (Cole et al., 1990, Creese and Jeffs, 1992, MacDiarmid and Breen, 1992, Russ and Alcala, 1996, Davidson, 1997, Edgar and Barrett, 1997, Babcock et al., 1999, Chapman and Kramer, 1999). Each of these studies has been conducted using methodology tailored to the species and the marine reserve in question. Key species studied are generally common reef fish, especially those of commercial or recreational value. Rock lobster and paua (abalone) have also been the subject of such studies as they are also of commercial importance. Kina, although commercially less important, are often investigated as they have been shown to have dramatic effects on the surrounding habitat when present in large numbers, and change in their abundance within a reserve area would show a corresponding change in habitat (Babcock et al., 1999, Shears and Babcock, 2000). Investigations of reserves overseas also tend to concentrate on monitoring large predatory reef fish, rock lobster, abalone and sea urchins (Buxton and Smale, 1989, Russ and Alcala, 1996, Edgar and Barrett, 1999, Jouvenel and Pollard, 2001). Studies investigating the effectiveness of a marine reserve involve the comparison 
of a reserve with a non-reserve (i.e.control) area. This is a way of trying to establish whether the communities inside the reserve area differ significantly from those in a similar habitat outside a reserve area. This means that the reserve and control areas must be comparable in terms of habitat type and physical oceanography (i.e. currents, wave exposure and water temperature) so as not to confound the results.

The individual marine reserve studies may reach the conclusion that a particular marine reserve is having the effect of increasing species abundance and/or size within the reserve in question, but they do not address how that translates to being able to make a statement about marine reserves in general. To date, each marine reserve study has been investigated separately and there has been no comparison or link made between them.

Marine reserve studies are ideal candidates for comparative methods such as a metaanalysis as the results are variable across studies (although there are many factors that could influence these results). The sample sizes are often limited due to weather conditions or funding making large amounts of data collection infeasible (Arnqvist and Wooster 1995). Although there have been many review papers (Creese and Jeffs, 1992, Jones et al., 1992, Allison et al., 1998, Garcia-Charton and Perez-Ruzafa 1999) on the overall effects of marine reserves, a formal statistical analysis has never been done before. Besides the many published studies on marine reserves in New Zealand there is a lot of unpublished data. This study is the first attempt at combining data from New Zealand marine reserves in a formal statistical meta-analysis to investigate the effectiveness of marine protected areas. This has not been done internationally or within another region before. Benjamin Halpern (2001) from the University of California performed an in depth review of empirical studies on marine reserves to try and address the impacts of marine reserves on several biological measures. This was similar to a meta analysis, however, all the analyses was based on published numbers and results. The values were also not weighted as is required by a true meta analysis.

Meta-analysis is used to combine the results from several studies in an attempt to come to an overall conclusion (Arnqvist and Wooster, 1995, Adams et al., 1997, Schafer 1999). Traditionally, methods such as narrative reviews or "vote-counting" have been used as ways of summing up findings from many separate studies. These methods can be seriously flawed and thus produce misleading results because they tend to be subjective and do not take into account relative importance or detail of the studies looked at 
(Arnqvist and Wooster, 1995, Adams et al., 1997). Meta-analysis is a quantitative synthesis and analysis of a collection of experimental studies (Osenberg et al., 1999). Meta-analysis allows a more objective appraisal of the evidence than traditional reviews, and because it is quantitative, is more informative since it provides a set of numbers and probabilities as results that can be used as reference points for future research (Arnqvist and Wooster, 1995, Egger et al., 1997).

Meta-analysis methods have recently been incorporated into a common statistical framework (Arnqvist and Wooster, 1995). These procedures are similar to standard statistical methods, but conventional tests should not be applied to such data because of problems related to the distribution of variance (e.g heterogeneous variances). No two studies in a set of research investigations are equally reliable, so this is accounted for by using weighted averages, usually according to sample size (Arnqvist and Wooster, 1995, Egger et al., 1997). Different statistical methods exist to combine data, but there is no single 'correct' method. Individual results need to be standardised to allow for comparison between studies. Graphical representation allows a visual examination of heterogeneity between studies (Egger et al., 1997).

Meta-analysis techniques are now being widely used in the fields of medicine and social sciences, but the potential use for ecological data is only now being realised (Adams et al., 1997). Community and behavioural ecology are two areas that often qualify for metaanalysis because of the nature of the data and how it is collected (Arnqvist and Wooster, 1995).

The present study combined data collected by a variety of researchers at several New Zealand marine reserves at different times over the last two decades. Statistical analysis has been applied to these data to investigate the effects of different marine reserves and whether they have a significant impact on the communities or species within them. A measurable way of defining marine reserve "success" is problematical. A marine reserve is generally thought to have a "positive" effect in terms of protecting unique or endangered species, protecting breeding stocks and have "spillover" into neighbouring areas (Jones et al., 1992). There are many complex ecosystem interactions occurring in a marine reserve and without complete information about these interactions, the responses to reservation may well be different from expected, however to allow natural processes to survive is a type of "success" (Attwood et al., 1997a). "Success" is typically considered 
to be an increase in commercial species abundance and/or size. For further definitions of ways to define marine reserve "success" see chapter 1. Although marine reserves may have many other noticeable effects, average species size and abundance are the variables considered here as they are simple to use as indicators of an effect. This study therefore investigates the null hypotheses that there is no difference in the amount of change in size or abundance of the key species, relative to control sites, within marine reserves in New Zealand.

Table 5.1. Marine Reserves in New Zealand.

\begin{tabular}{lll}
\hline Reserve & Date of Establishment & Size (ha) \\
\hline Cape Rodney-Okakari Point & 1977 & 518 \\
Poor Knights Islands & 1981 & 2400 \\
Kermadec Islands & 1990 & 748000 \\
Kapiti & 1992 & 2167 \\
Te Whanganui A Hei (Cathedral Cove) & 1992 & 840 \\
Tuhua (Mayor Island) & 1992 & 1060 \\
Long Island-Kokomohua & 1993 & 619 \\
Piopiotahi (Milford Sound) & 1993 & 690 \\
Te Awaatu (The Gut) & 1993 & 93 \\
Tonga Island & 1993 & 1835 \\
Te Tai Tapu (Westhaven or Whanganui & 1994 & 536 \\
Inlet) & & \\
Motu Manawa-Pollen Island & 1995 & 500 \\
Long Bay- Okura & 1995 & 980 \\
Te Angiangi & 1997 & 446 \\
Pohatu & 1999 & 215 \\
Te Tapuwae o Rongokako & 1999 & 2450 \\
\hline
\end{tabular}




\subsection{Methods}

Meta-analysis methods follow those as presented in Rosenthal (1987), Egger et al. (1997) and Schafer (1999).

Data collected from seven marine reserves around New Zealand were collated and reviewed. Two key species, common to all these studies, were selected as indicator species(i.e. the reef fish blue cod (Parapercias colias) and the rock lobster (Jasus edwardsii). These species were also chosen because they are both commercially and recreationally important species and they are widespread throughout New Zealand, as opposed to being specifically warm temperate or cold temperate species. Insufficient data on other species meant they could not be included in the analysis.

The blue cod meta-analysis used data from four different New Zealand marine reserves. One of these marine reserves was investigated at two separate time periods by two different investigators. These two data sets were treated as separate studies making the total number of studies in this meta-analysis five (Table 5.2.). Where the data were collected over a period of years, results were pooled and treated as one large data set. It was sensible to do this because noticeable effects of marine reserves do not occur immediately and the data that were combined spanned a maximum period of five years. Additionally, the data set collected in each of those years was generally quite small and collected over a very short time span (i.e. one week to one month). Each of these data sets included data from the marine reserve itself and the corresponding control area, to enable a reserve versus a control comparison. 
Table 5.2. Studies used in blue cod meta-analysis.

\begin{tabular}{llll}
\hline Reserve & Date of Study & Investigator & Report \\
\hline Long Island- & $1992-1997$ & Rob Davidson & Davidson, 1997 \\
Kokomohua & & & \\
Te Angiangi & $1995 / 1998 / 1999$ & Clinton Duffy/ Debbie & Freeman and \\
& & Freeman & Duffy, in prep \\
Tonga Island & $1994-1999$ & Rob Davidson & Davidson, 1999 \\
Kapiti & 1999 & Ali McDiarmid & Unpublished \\
& & & data \\
Kapiti & $1998-2000$ & Anjali Pande & This thesis 2001 \\
\hline
\end{tabular}

The rock lobster meta-analysis used data from six different New Zealand marine reserves, two of which were monitored at different times by different groups and were thus treated as separate studies. This brought the total number of rock lobster studies to eight (Table 5.3.). For these studies data were also pooled if collected over a period of years. These data sets also included data from the reserve and the corresponding control area. 
Table 5.3. Studies used in rock lobster meta-analysis.

\begin{tabular}{llll}
\hline Reserve & Date of Study & Investigator & Report \\
\hline Long Island-Kokomohua & $1992-1997$ & Rob Davidson & Davidson, 1997 \\
Kapiti & $1992-1999$ & Ali MacDiarmid & Unpublished \\
& & & data \\
Kapiti & $1998-2000$ & Anjali Pande & This thesis 2001 \\
Tonga Island (abundance & $1998-2000$ & Russell Cole & Davidson, \\
only) & & & Villouta, Cole \\
& & & and Barrier, in \\
& & & prep \\
Cape Rodney-Okakari & 1985 & Ali McDiarmid & MacDiarmid and \\
Point & & & Breen, 1993 \\
Cape Rodney-Okakari & 1995 & Ali McDiarmid & Unpublished \\
Point & & & data \\
Poor Knights & 1995 & Ali McDiarmid & Unpublished \\
Te Angiangi & & & data \\
& $1998-2000$ & Clinton Duffy/ Debbie & Freeman and \\
& & Freeman & Duffy, in prep. \\
\hline
\end{tabular}

Both blue cod and rock lobster data sets were examined for changes in abundance and size. One rock lobster study (Tonga Island) only provided abundance data. This study was therefore omitted from the size analysis.

The meta-analysis for both the abundance and size data was performed in three stages.

1) The studies were compared to determine if there was a significant difference in terms of the "effect sizes" offered by the different reserves. ("Effect size" is a statistical term. It is defined as the amount of change, or magnitude of the effect, caused by the reserve. This is measured by a standardised mean difference \{in abundance or size \}between reserves and controls).

2) Where there was no significant difference in "effect size" among studies, the studies were then combined to give an overall significance and "effect size".

3) Where there was a significant difference in "effect size" among studies, the studies were investigated for particular patterns that may have resulted in the difference. So 
called "focussed" tests were performed to see if "effect size" varies regularly with North-South location (i.e. latitude) and age of the reserve.

The calculations used were as follows:

For any particular study

\section{$\underline{\text { Step } 1}$}

Hedge's $g$ was calculated by the formula:

$$
g=\frac{\overline{x_{1}}-\overline{x_{2}}}{s_{p}}
$$

where:

$$
s_{p}^{2}=\frac{\left(n_{1}-1\right) s_{1}{ }^{2}+\left(n_{2}-1\right) s_{2}{ }^{2}}{n_{1}+n_{2}-1}
$$

for which:

Abundance

$x=$ Average number of individuals seen

$n=$ Number of transects

\section{Size}

$$
\begin{aligned}
& x=\text { Average size of individuals } \\
& n=\text { Number of individuals seen }
\end{aligned}
$$

In both cases the subscripts $1=$ reserve, $2=$ control

$s=$ standard deviation

Note that Hedge's $g$ computes the number of standard deviations difference between the reserve averages and the control averages (i.e. the standardised gain offered by the reserve).

The $t$-value is then calculated by the following formula:

$$
t=\frac{g}{\sqrt{1 / n_{1}+1 / n_{2}}}
$$


This $t$-value is then used to compute the $w$-value, to allow the comparison of studies for which the formula is:

$$
w=\frac{2 n_{1} n_{2}\left(n_{1}+n_{2}-2\right)}{\left(n_{1}+n_{2}\right)\left[t^{2}+2\left(n_{1}+n_{2}-2\right)\right]}
$$

where $t, n_{1}$ and $n_{2}$ are defined above.

Following this the test statistic $T_{c}$ is computed to compare the studies.

$$
T_{c}=\sum_{j=1}^{S} w_{j}\left(g_{j}-\bar{g}\right)^{2}
$$

where

$S=$ number of studies

$w_{j}=\mathrm{w}$-value for study $\mathrm{j}$ (from equation 4)

$g_{j}=\mathrm{g}$ for study $\mathrm{j}$ (from equation 1 )

and

$$
\bar{g}=\frac{\sum_{j=1}^{s_{j}} w_{j} g_{j}}{\sum_{j=1}^{S} w_{j}}
$$

where $S, w_{j}$ and $g_{j}$ are defined as above.

The test statistic has a $\chi^{2}$ distribution with $\mathrm{S}-1$ degrees of freedom, under the null hypothesis of no difference in "effect size" among the reserves.

\section{$\underline{\text { Step } 2}$}

In cases where there is no significant difference in "effect size", it is sensible to combine studies to obtain an overall "effect size" and significance level. This is to find an "effect size" for all these studies in general (i.e to define the magnitude of the effect the reserves are having). 
Defining $t_{j}$ as the $t$-value for study $j$ (from equation 3) an overall, weighted $z$-value can be obtained by

$$
z_{w}=\frac{\sum_{j=1}^{s} w_{j} t_{j}}{\sqrt{\sum_{j=1}^{s} w_{j}^{2}}}
$$

Where $S$ is the number of studies and $w_{j}$ is a weight for study $j$ (we use the number of individuals in study $j$ for size data and the total area sampled \{i.e. number of transects $x$ area per transect\} for abundance data) to determine the weight. Note the possible confusion between the use of $w_{j}$ as a weight in equation (7) and the $w$-value of equation (4). However we keep this notation to match standard texts on the subject.

The overall significance or $p$-value is then obtained by comparing $z_{w}$ to the $\mathrm{N}(0,1)$ distribution.

To obtain an overall effect a weighted combination of Hedge's $g$ values is used, i.e.

$$
g_{w}=\frac{\sum_{j=1}^{s_{j}} w_{j} g_{j}}{\sum_{j=1}^{S} w_{j}}
$$

Where $g_{j}$ is Hedge's $g$ for study $j$ (from equation 1 ) and $w_{j}$ is the weight discussed above. The overall significance or $p$-value is then obtained by comparing $z_{w}$ to the $\mathrm{N}(0,1)$ distribution.

\section{$\underline{\text { Step } 3}$}

The studies were ordered north to south to test for a linear decrease in "effect size" as one moves south by using a focussed comparison (Table 5.4.). This was to test the hypotheses that reserves at northern latitudes have faster, more pronounced responses to reservation status. Many studies on marine reserves in the North indicate marked respones (Babcock et al., 1999, Kelly et al., 1999, Kelly et al., 2000). 
Table 5.4. Distances of marine reserves used in this meta analysis from the North Cape in $\mathrm{km}$.

\begin{tabular}{ll}
\hline Ordered N-S & Distance from North Cape $(\mathrm{km})$ \\
\hline Poor Knights & 140 \\
Cape Rodney-Okakari Point & 280 \\
Te Angiangi & 600 \\
Kapiti & 850 \\
Tonga Island & 900 \\
Long Island-Kokomohua & 930 \\
\hline
\end{tabular}

A new test statistic for this "focussed" comparison is:

$$
T_{f}=\frac{\sum_{j=1}^{s} \lambda_{j} g_{j}}{\sqrt{\sum_{j=1}^{s} \lambda_{j}^{2} / w_{j}}}
$$

where $w_{j}$ is the w-value for study $j$ (from equation 4 ) and $g_{j}$ is the Hedge's $g$ for study $j$ (from equation 1) and

$S=$ number of studies

$\lambda=$ the following:

If $\mathrm{S}$ is even $-(\mathrm{S}-1),-(\mathrm{S}-3), \ldots \ldots,-3,-1,1,3, \ldots . .(\mathrm{S}-3),(\mathrm{S}-1)$

North............... $\lambda_{1}, \lambda_{2}$ $\lambda_{\mathrm{S}} \ldots$. South

If $\mathrm{S}$ is odd $-((\mathrm{S}-1) / 2), \ldots \ldots-2,-1,0,1,2, \ldots \ldots((\mathrm{S}-1) / 2)$

So, for example, if there are 6 studies being used they would be numbered 1-6, 1 being the northern most study and the 6 the southernmost. Therefore, following the $\lambda$ calculations for an even number of studies, $\lambda$ for study 1 would be $-(6-1)=-5$

$\lambda$ for study 2 would be $-(6-3)=-3$

$\lambda$ for study 3 would be $-(6-5)=-1$ etc. 
An equation used to describe these values would be:

$$
\lambda=j-\frac{(S+1)}{2}
$$

where $S=$ number of studies, where the number is ODD

And $j=$ number of each study.

Where $\mathrm{S}$ is EVEN the formula is:

$$
\lambda=2 j-S-1
$$

Note that the actual distances could be used to construct the $\lambda$ coefficients but these simple coefficients are preferred since they represent the ordering of locations and may be expected to be more robust. The test statistic $T_{f}$ has an approximate $\mathrm{N}(0,1)$ distribution under the null hypothesis of no trend.

Since the northernmost reserve would always be study 1 and the southernmost reserve would be study 6 - a positive or a negative test statistic would explain the direction of the trend.

Tables 5.5. and 5.6. show the summary values of the data sets used in these metaanalyses. 
Table 5.5. Summary of mean size and average abundance $\left(\mathrm{per}^{2}\right)$ values from each reserve and their respective control sites for blue cod.

\begin{tabular}{|c|c|c|c|c|c|c|c|c|}
\hline \multirow[t]{2}{*}{ Marine reserve } & \multirow{2}{*}{$\begin{array}{l}\text { Reserve } \\
\text { Mean size }(\mathrm{cm})\end{array}$} & \multicolumn{2}{|c|}{ Sample size and Reserve } & \multicolumn{2}{|c|}{ Sample size and Control } & \multicolumn{2}{|c|}{ Sample size and Control } & \multirow{2}{*}{$\begin{array}{l}\text { Sample size and } \\
\text { Std Deviation }\end{array}$} \\
\hline & & Std Deviation & $\begin{array}{l}\text { Mean number } \\
\left(\text { per } \mathrm{m}^{2}\right)\end{array}$ & Std Deviation & Mean size $(\mathrm{cm})$ & Std Deviation & $\begin{array}{l}\text { Mean number } \\
\left(\text { per } \mathrm{m}^{2}\right)\end{array}$ & \\
\hline \multirow[t]{2}{*}{ Kapiti 99} & 28.05 & $\mathrm{~N}=119$ & 0.015 & $\mathrm{~N}=120$ & 22.16 & $\mathrm{~N}=101$ & 0.00868 & $\mathrm{~N}=104$ \\
\hline & & $\mathrm{SD}=8.04$ & & $\mathrm{SD}=5.13$ & & $\mathrm{SD}=6.10$ & & $\mathrm{SD}=4.5$ \\
\hline Island- & 28.33 & $N=1566$ & 0.064 & $\mathrm{~N}=963$ & 26.59 & $\mathrm{~N}=1874$ & 0.04267 & $\mathrm{~N}=468$ \\
\hline Kokomohua & & $\mathrm{SD}=5.02$ & & $\mathrm{SD}=3.73$ & & $\mathrm{SD}=3.90$ & & $\mathrm{SD}=2.57$ \\
\hline \multicolumn{9}{|l|}{ 93-97 } \\
\hline Tonga Island & 23.61 & $\mathrm{~N}=18$ & 0.00082 & $\mathrm{~N}=5$ & 23 & $\mathrm{~N}=25$ & 0 & $\mathrm{~N}=0$ \\
\hline $93-00$ & & $\mathrm{SD}=2.3$ & & $\mathrm{SD}=0.26$ & & $\mathrm{SD}=2.5$ & & $\mathrm{SD}=0$ \\
\hline Te Angiangi & 22.35 & $\mathrm{~N}=121$ & 0.0035 & $\mathrm{~N}=114$ & 22.42 & $\mathrm{~N}=62$ & 0.00234 & $\mathrm{~N}=62$ \\
\hline 95/98/99 & & $\mathrm{SD}=7.47$ & & $\mathrm{SD}=2.97$ & & $\mathrm{SD}=8.06$ & & $\mathrm{SD}=1.91$ \\
\hline \multirow[t]{2}{*}{ Kapiti 98-00 } & 24.86 & $\mathrm{~N}=149$ & 0.0372 & $\mathrm{~N}=920$ & 24.16 & $\mathrm{~N}=63$ & 0.00864 & $\mathrm{~N}=214$ \\
\hline & & $\mathrm{SD}=10.80$ & & $\mathrm{SD}=10.8$ & & $\mathrm{SD}=8.85$ & & $\mathrm{SD}=3.51$ \\
\hline All Reserves & 25.44 & & 0.0241 & & 23.66 & & 0.01247 & \\
\hline
\end{tabular}


Table 5.6. Summary of mean size and average abundance $\left(\mathrm{per}^{2}\right.$ ) values from each reserve and their respective control sites for rock lobster.

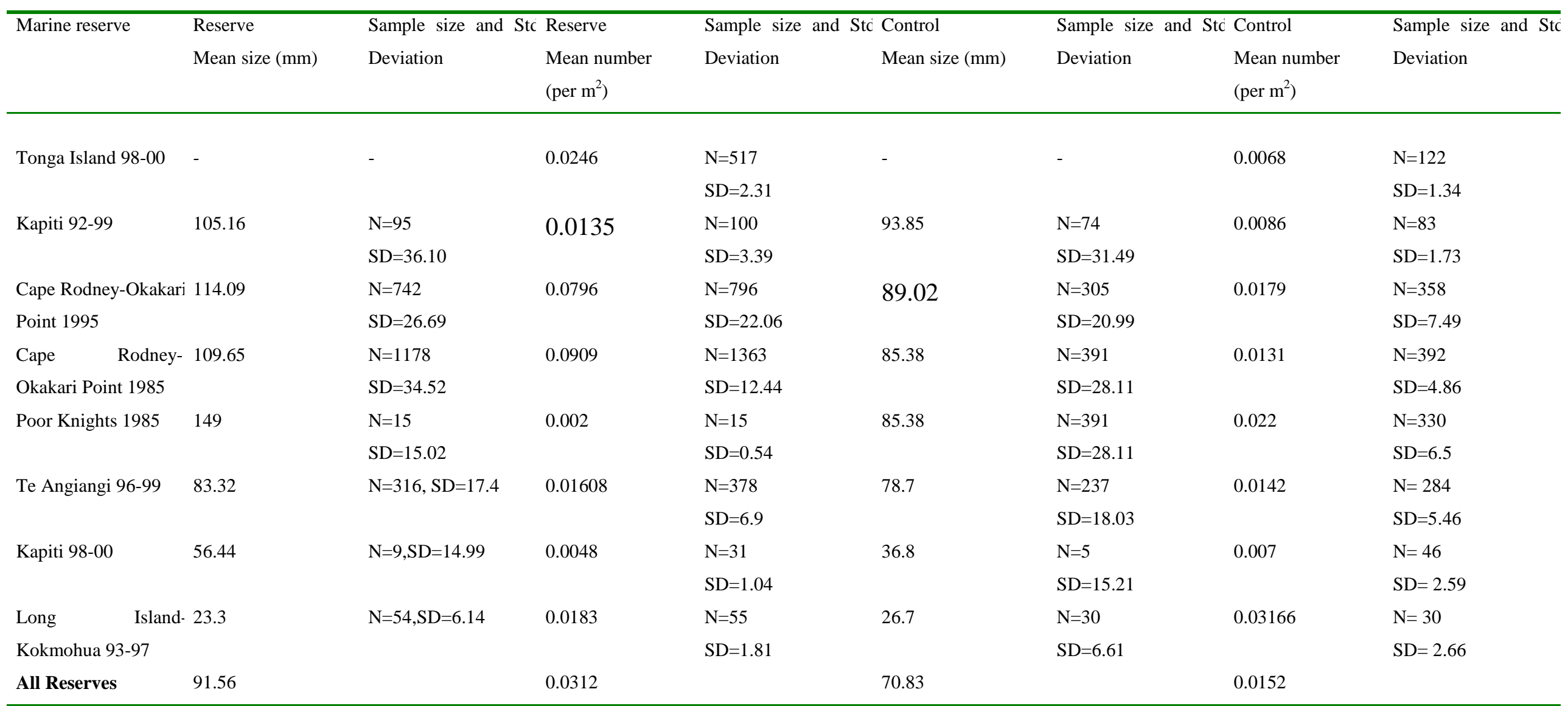


First a pictorial representation of the meta-analysis was created by plotting a 'measure' (in this case average difference in size/abundance of the target species) against a 'timeline" of a certain variable. The variables used were reserve size, reserve age and latitude(or distance from the North Cape.) (Table 5.7.).

Table 5.7. Variables used in pictorial "time line" of marine reserves.

\begin{tabular}{llll}
\hline Marine Reserve & Size (ha) & $\begin{array}{l}\text { Age of reserve at time of } \\
\text { study (years) }\end{array}$ & $\begin{array}{l}\text { Distance from North } \\
\text { cape (km) (latitude) }\end{array}$ \\
\hline Kapiti & 2167 & $8 / 9$ & 850 \\
Long Island & 619 & 4 & 930 \\
Tonga Island & 1835 & 3.5 & 900 \\
Cape Rodney-Okakari & 518 & $10 / 20$ & 280 \\
Point (CR-OP) & & & 140 \\
Poor Knights & 2400 & 4 & 600 \\
Te Angiangi & 446 & 2 &
\end{tabular}

N.B. Where two ages are given - they are the ages of the reserves at the times of the two different studies on the same reserve.

In these figures a positive $t$-value indicates that the marine reserve showed greater abundance/larger average sizes than the corresponding control area, and a negative $t$ value shows that the control area had a greater abundance/average size. The error bars are \pm 2 SD.

The relevant $P$-values from the following calculations are displayed in table format with the significance levels in the results section. Usual convention is followed and the $\alpha$-level 0.05 is accepted as being significant.

\subsection{Results}

\subsubsection{Graphics}

\subsubsection{Blue Cod}

Figures for blue cod showed that there was no obvious trend in the effect of reserve size (Fig. 5.1.), age (Fig. 5.2.) or latitude (Fig. 5.3.)on blue cod size, relative to each other. 
However, in most cases the reserves supported more blue cod of a larger size than at the control sites. This is shown by positive $t$-values. The only exception to this is the reserve at Te Angiangi which showed a low negative $t$-value in all cases. All the reserves had positive $t$-values when measuring the effect of reserve size, age and location on blue cod abundance (Figures 5.4.-5.6.). This indicates that the reserves do support a greater abundance of blue cod than control areas.

Fig. 5.1. Reserve size as a variable for effects on blue cod size.

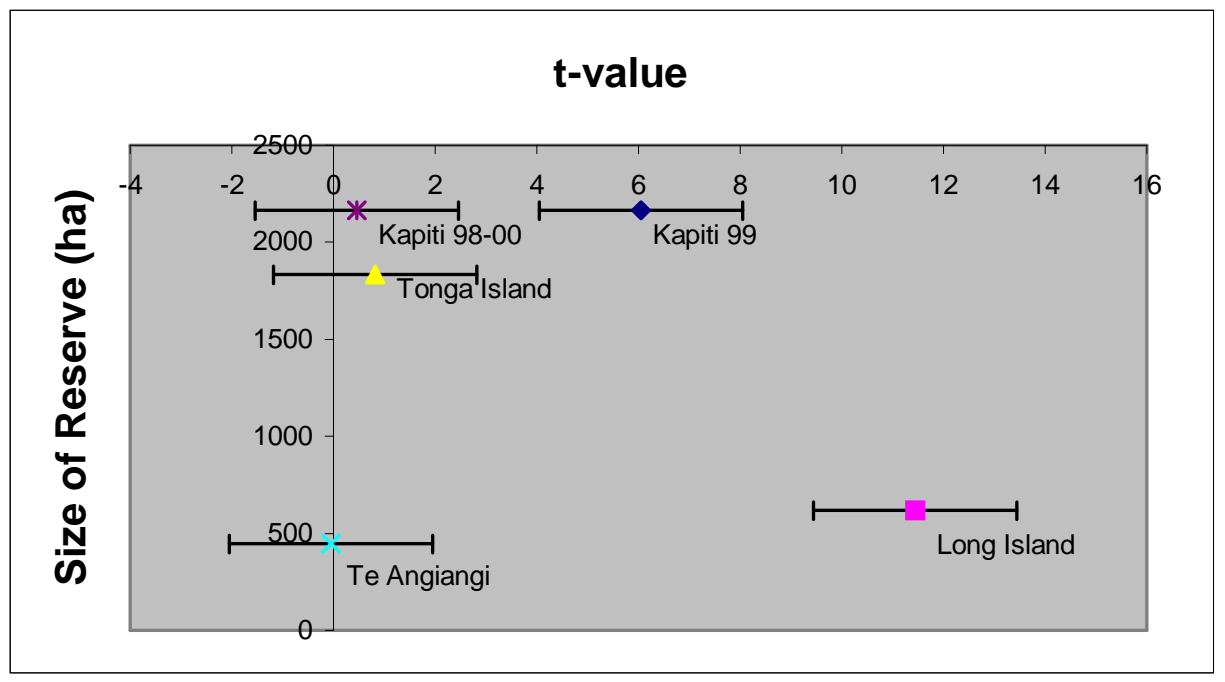

Fig. 5.2. Age of reserve as a variable for effects on blue cod size.

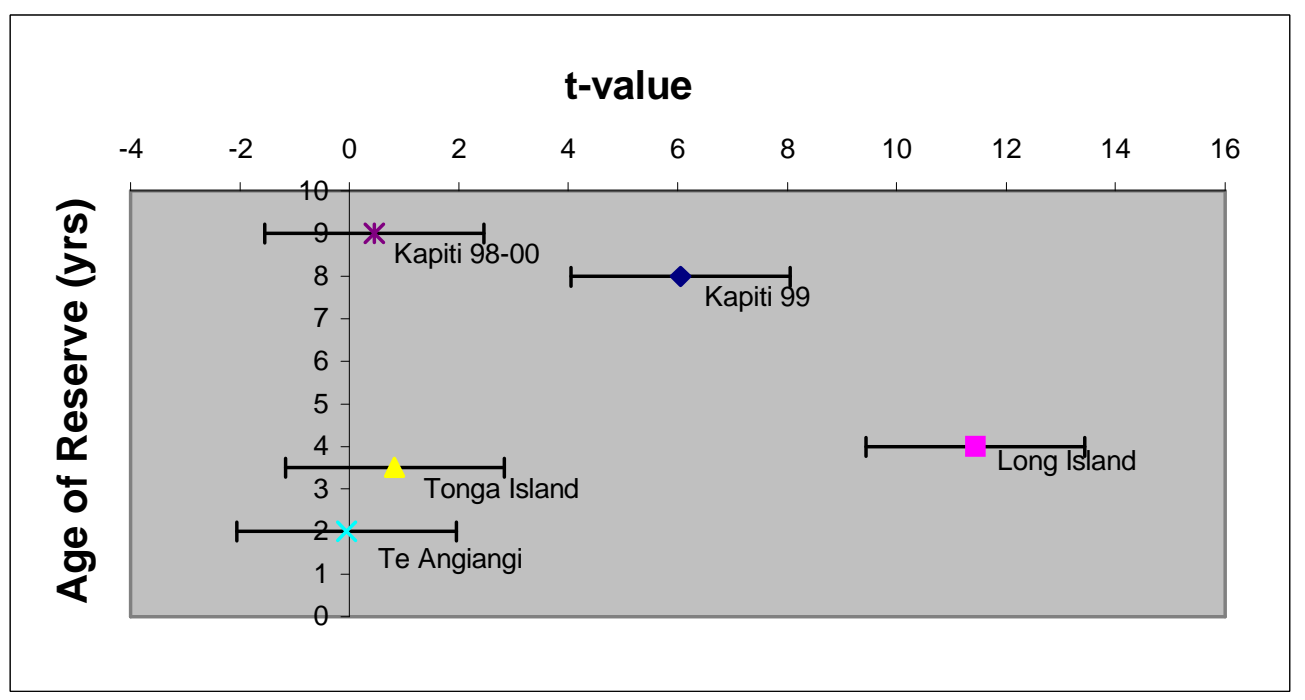


Fig. 5.3. Location of reserve as a variable for effects on blue cod size.

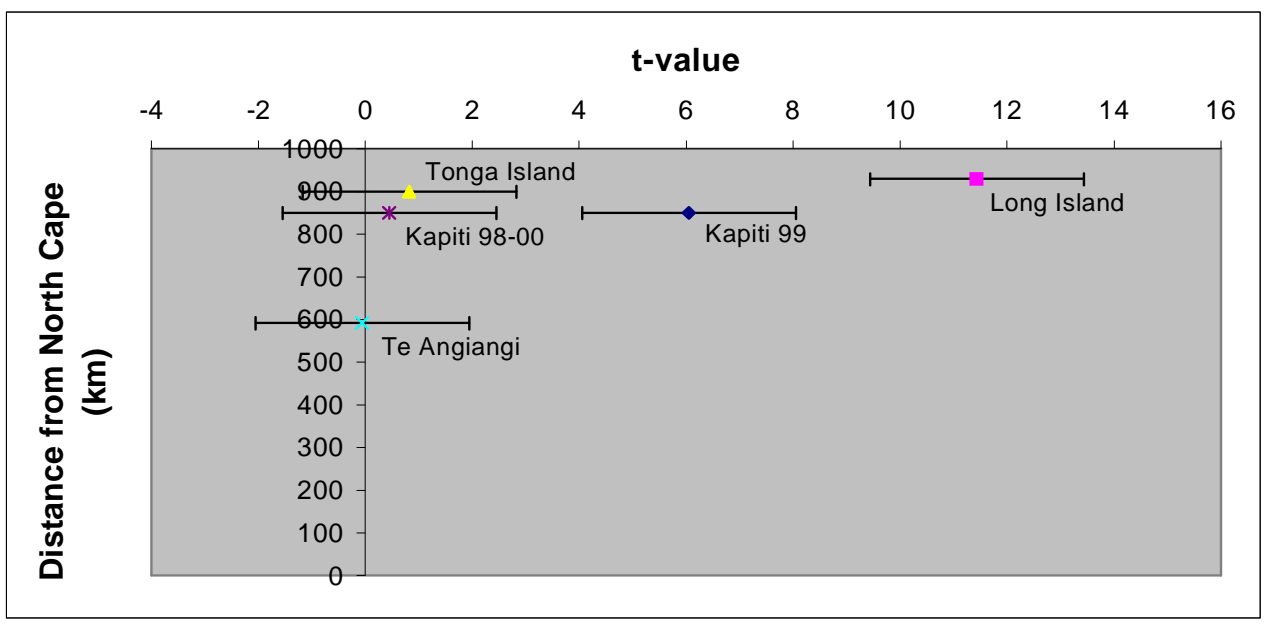

Fig. 5.4. Reserve size as a variable for effects on blue cod abundance.

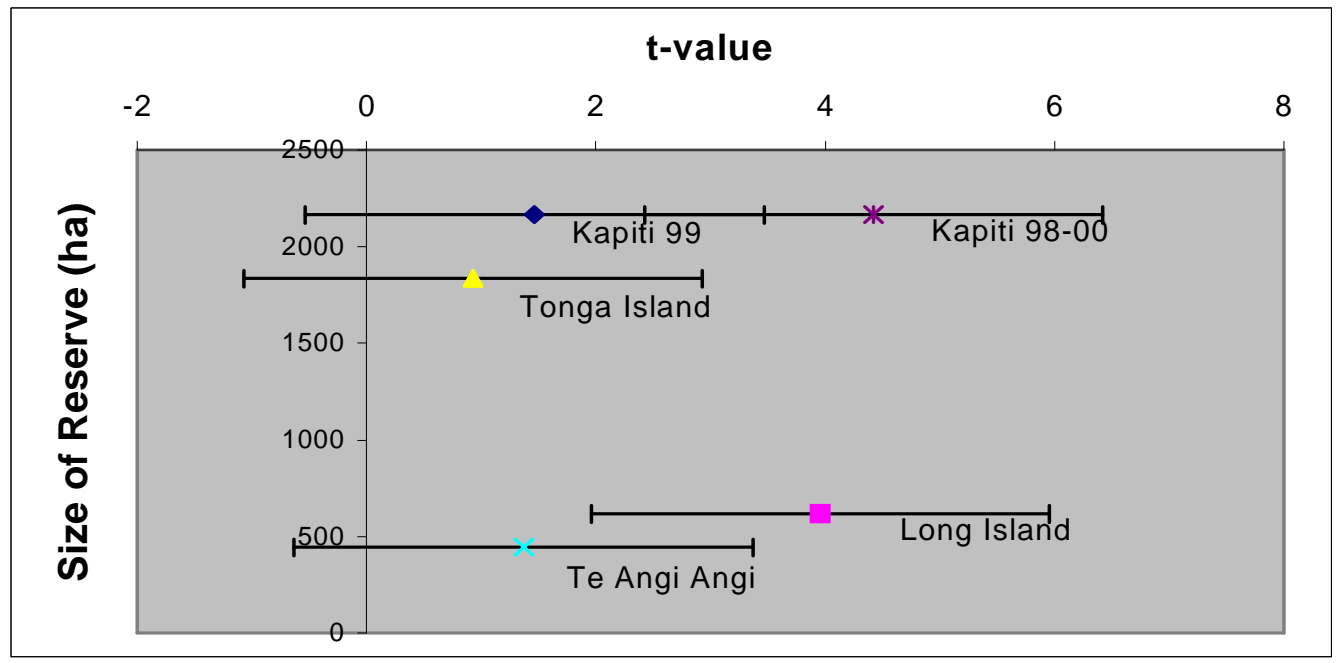

Fig. 5.5. Age of reserve as a variable for effects on blue cod abundance.

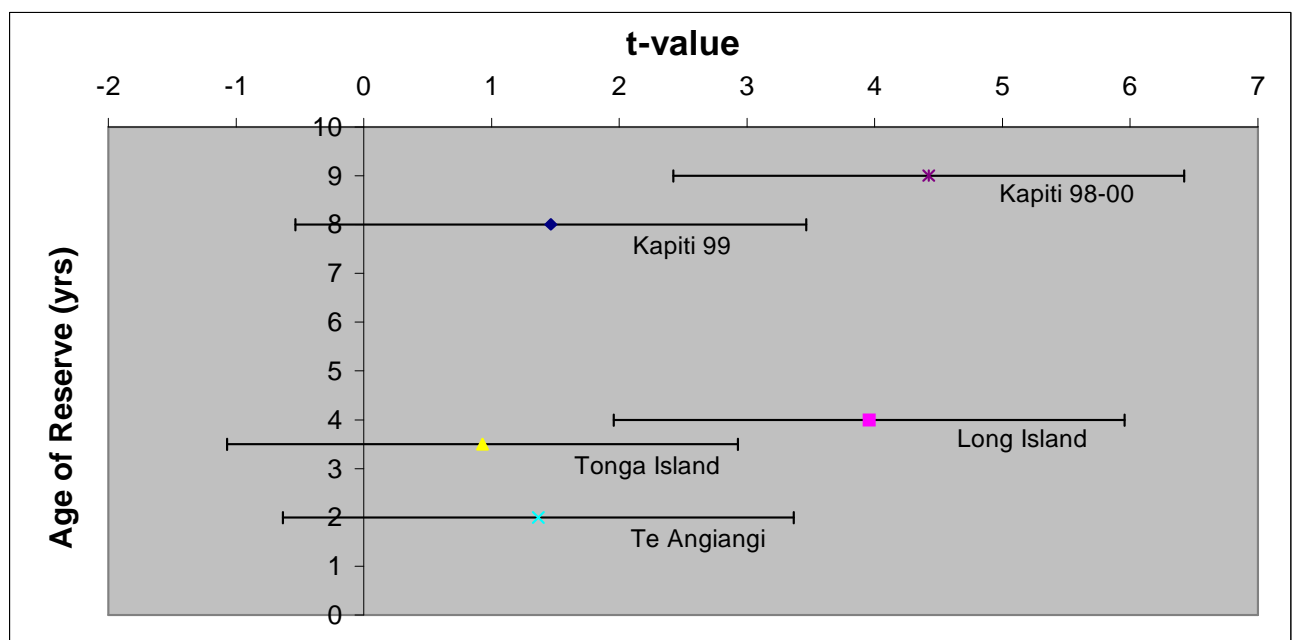


Fig. 5.6. Location of reserve as a variable for effects on blue cod abundance.

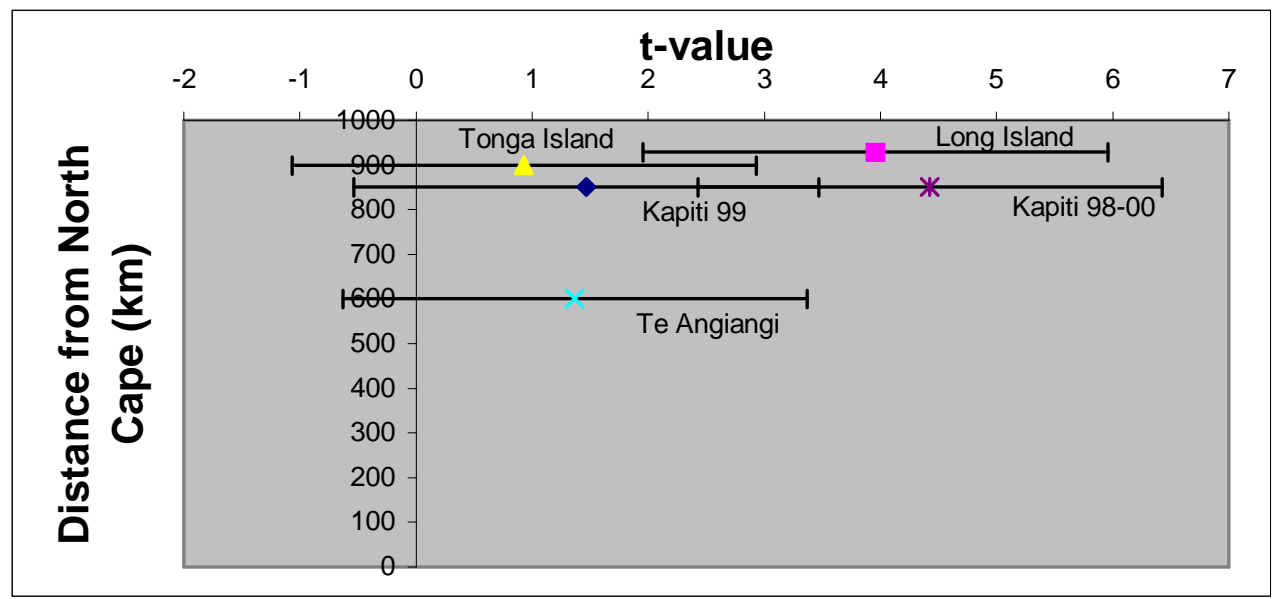

\section{$\underline{\text { 5.3.1.2 Rock Lobster }}$}

Rock lobster showed slightly different results from those of blue cod. Cape Rodney Okakari Point (CR-OP), showed the most positive result (i.e biggest difference between the reserve and control sites). For all the marine reserves, there were no obvious trends for reserve size, however there was an indication of a trend from north to south in location (ie the further north the reserve is the bigger the effect on lobster size and abundance.) In general, reserve sites supported larger rock lobsters and in greater abundance than the control sites, the only exception being Long Island-Kokomohua marine reserve. Generally, the effect was seen to be positive by the positive $t$ values.(Figs. 5.7.- 5.12.).

Fig. 5.7. Age of reserve as a variable for effects on rock lobster size.

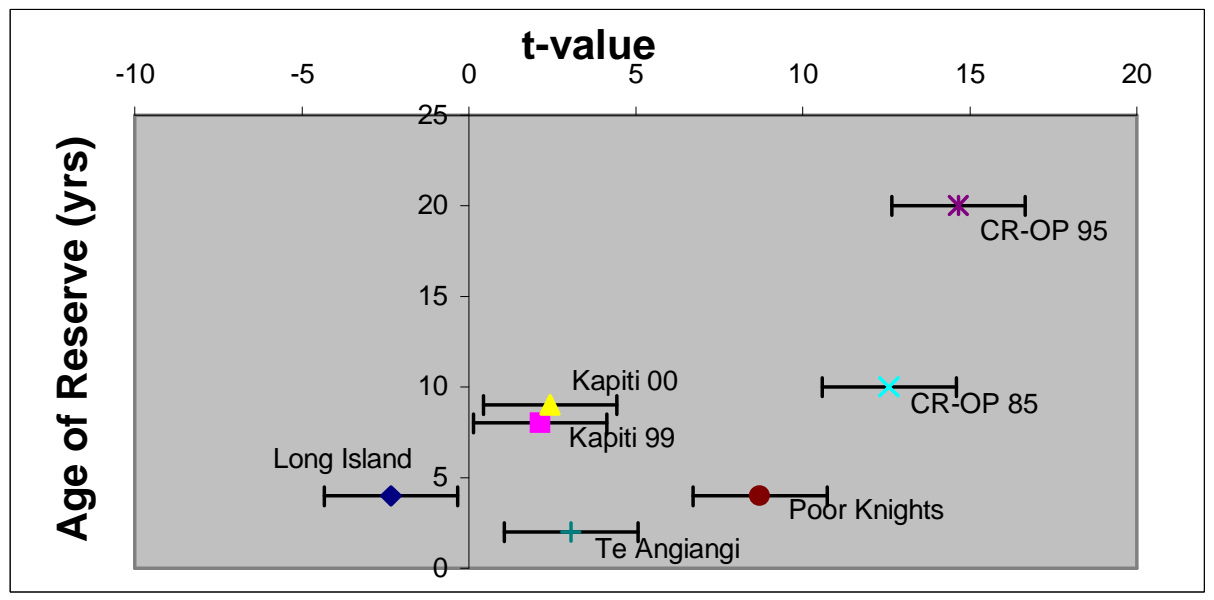


Fig. 5.8. Reserve size as a variable for effects on rock lobster size.

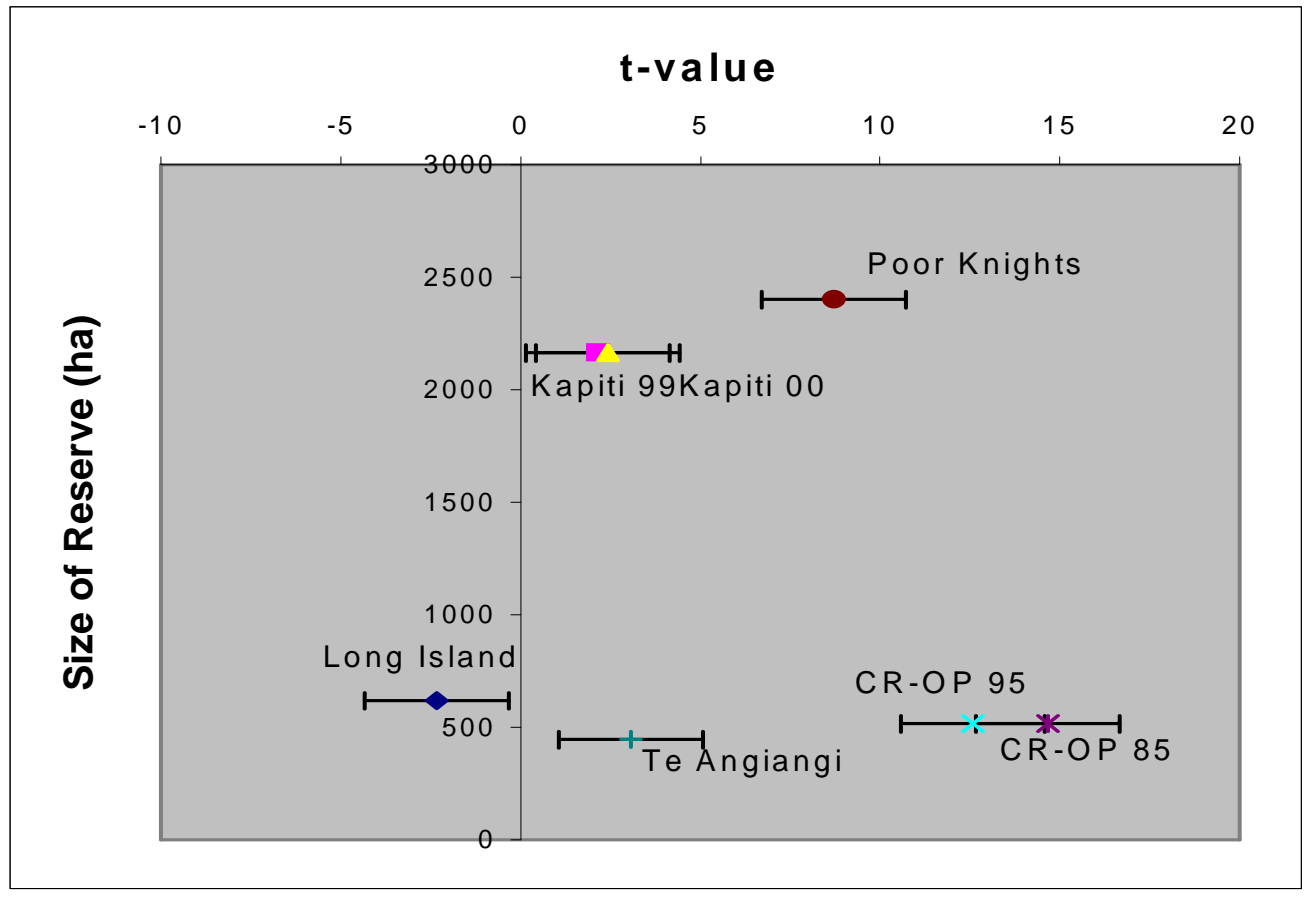

Fig. 5.9. Location of reserve as a variable for effects on rock lobster size.

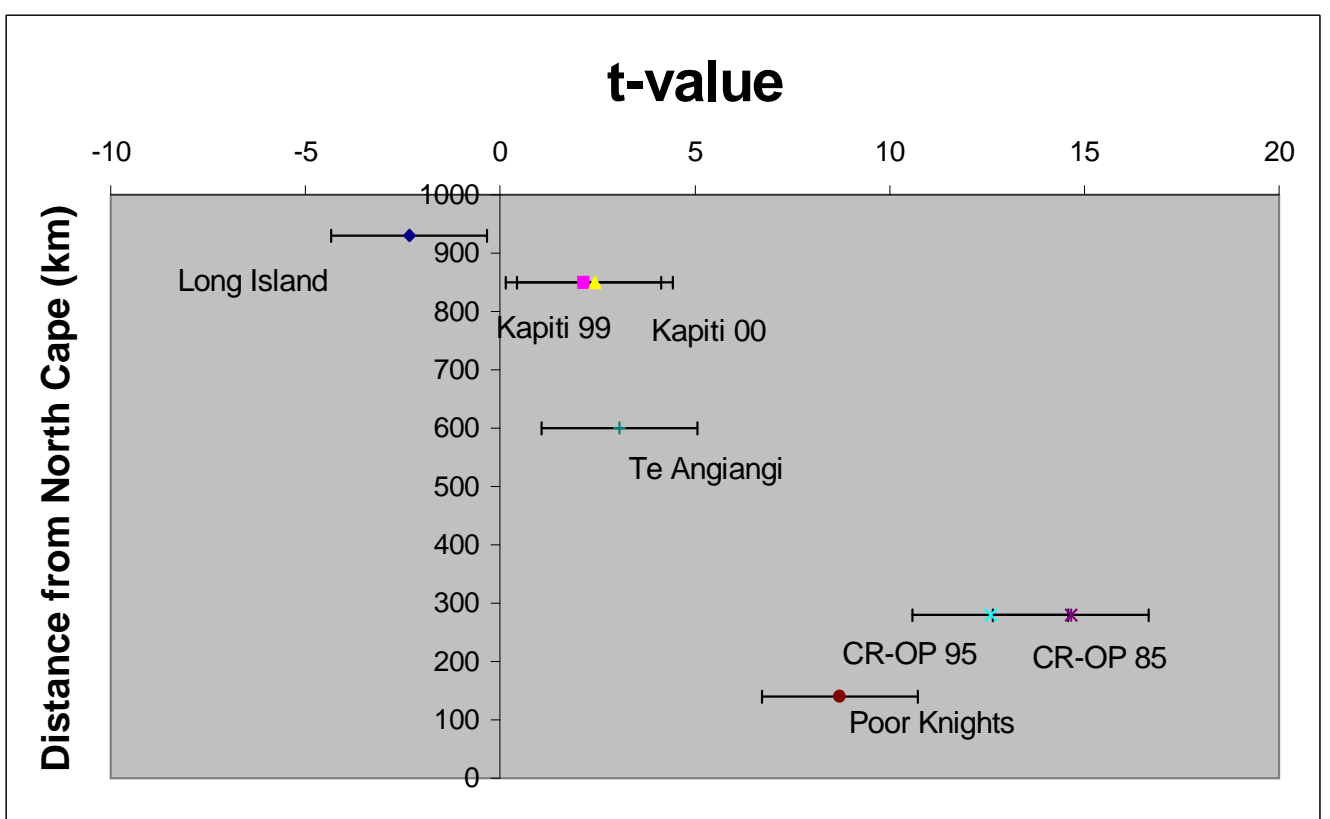


Fig. 5.10. Age of reserve as a variable on the effects on rock lobster abundance.

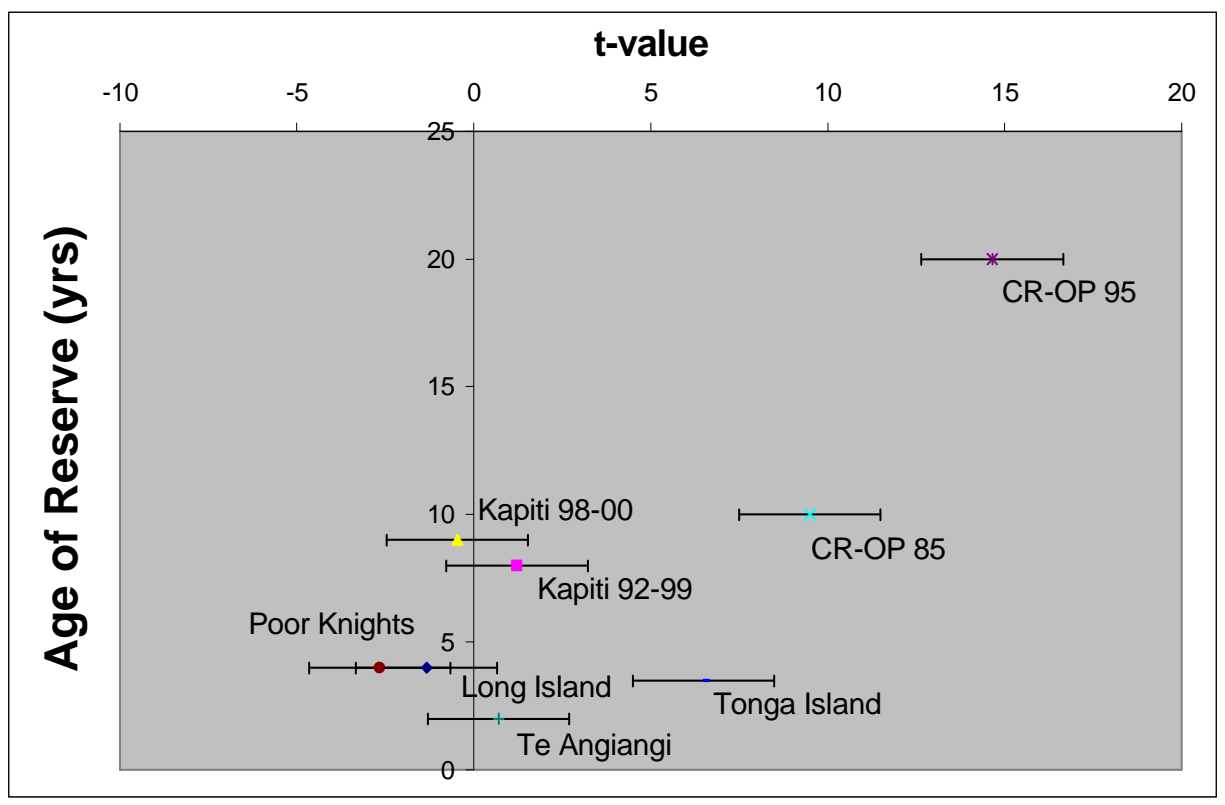

Fig. 5.11. Size of reserve as a variable for effects on rock lobster abundance.

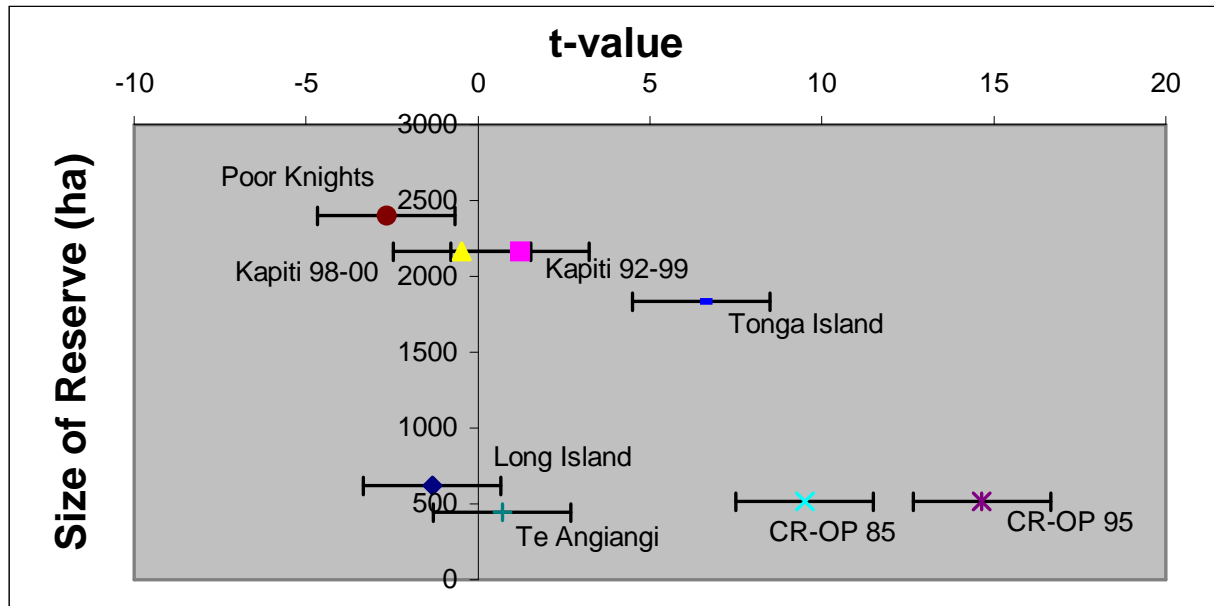


Fig. 5.12. Location of reserve as a variable for effects on rock lobster abundance.

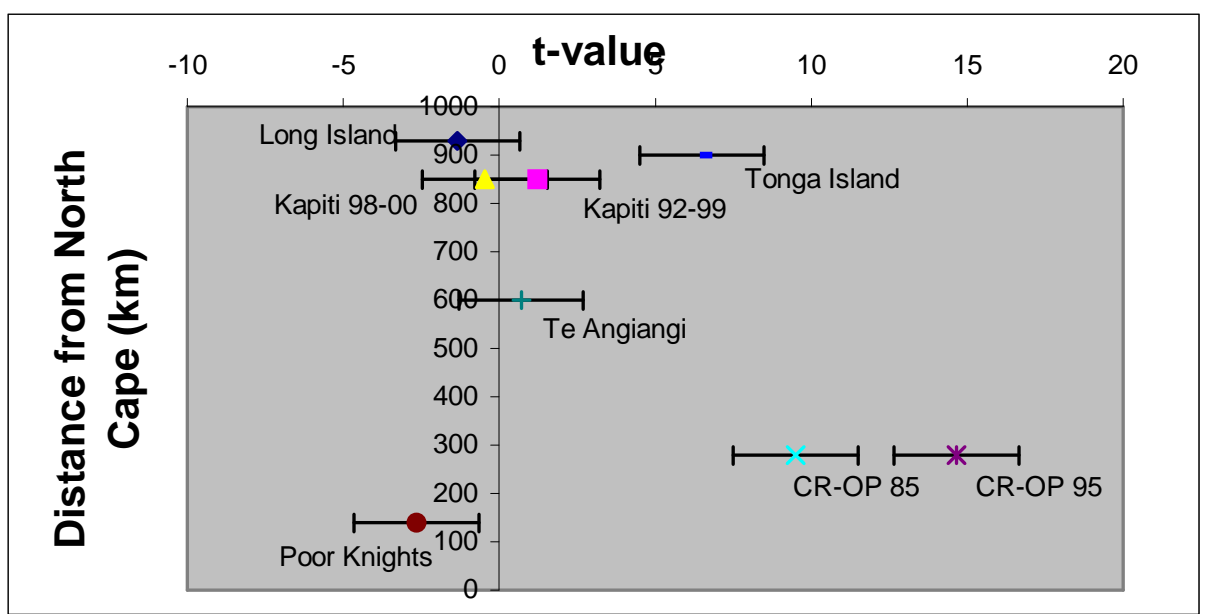

\section{$\underline{\text { 5.3.2 Comparing Sites }}$}

The second step in this meta-analysis was a series of calculations to test for differences in "effect size" among reserves for each of the target species. This was done for both size and abundance of the target species.

Table 5.8. Comparison of "effect size" of marine reserves.

\begin{tabular}{lllll}
\hline & Degrees of Freedom & $T_{c}$-value & $P$-value & Sig/NS \\
\hline Blue cod abundance & 4 & 1.49112 & 0.833 & $\mathrm{NS}$ \\
Rock lobster abundance & 7 & 110.0086 & $<0.0001$ & $\mathrm{Sig}^{* * *}$ \\
Blue cod size & 4 & 21.97481 & 0.000202 & $\mathrm{Sig}^{* * *}$ \\
Rock lobster size & 6 & 111.6829 & $<0.0001$ & $\mathrm{Sig} * * *$ \\
\hline
\end{tabular}

*denotes level of significance

\subsubsection{Blue cod abundance}

The comparison amongst reserves (Table 5.8.) shows that there is no significant difference in the effect that each reserve is having relative to the other reserves.(i.e no single reserve has significantly more blue cod than any other). As a consequence the overall $T_{c}$-value is positive, which indicates that reserves are having an overall positive 
effect on blue cod abundance, compared to control areas. The result for each individual reserve is positive (see Figs. 5.4.-5.6.). This is seen by the fact that each individual reserve also has a positive $t$-value.

\subsubsection{Blue cod size}

There was a significant difference among the effects that individual reserves are having on average size of blue cod (Table 5.8.). This indicates that some reserves are having a significantly greater effect (i.e have significantly larger individuals) than other reserves. Although most reserves have resulted in an increase in blue cod size (Figs. 5.1.-5.3. show mostly positive $t$-values), the size of the effect that each reserve is having is significantly different. The $T_{c}$-value is positive so the effect across all studies is positive compared to control areas.

\subsubsection{Rock Lobster}

For rock lobster the effects that reserves are having on both abundance and size are significantly different relative to each other (Table 5.8.). This means that some reserves are showing a markedly different effect to the other reserves in both abundance and size of rock lobster present in the reserve.

Despite showing significant differences amongst the reserves - the $T_{c}$-value is positive in both cases, which suggests an overall positive effect in sizes and abundances found in marine reserves as compared to controls.

\section{$\underline{\text { 5.3.3 Combining results }}$}

Since the comparison of effects of marine reserves on blue cod abundance showed no significant difference in "effect size", results were combined as per the methods in equations 7 and 8 . This serves to give an overall significance to the effect that marine reserves in general are having on blue cod abundance. This test cannot be applied to the other variables because there was a significant difference in the effects that the individual reserves were having. 
Table 5.9. Combined results for blue cod abundance

\begin{tabular}{lll}
\hline $\mathrm{Z}_{\mathrm{w}}$ & $P$-value & $\mathrm{g}_{\mathrm{w}}$ \\
\hline 5.222 & 0.0987 & 0.3408
\end{tabular}

This $z_{w}$ is compared to the $\mathrm{N}(0,1)$ distribution.

The $P$-value of 0.0987 is significant at the $10 \%$ level (i.e $\alpha=0.10$ ) only.

The weighted Hedge's $g$ value indicates that there is an overall difference of 0.3408 std deviations between reserve and control sites. Since the $T_{c}$-value for blue cod abundance was positive in Table 5.8., this indicates that this is a positive difference (i.e. the marine reserves have a greater abundance of blue cod). However, it is borderline statistically significant at the $10 \%$ level $(\alpha=0.10)$ and non significant at the $5 \%$ level $(\alpha=0.05)$.

\section{$\underline{\text { 5.3.4 Focussed comparisons }}$}

A further test was performed in the form of a focussed comparison. As there was indication of a trend from north to south (latitude), especially for rock lobster, the effect of this variable on marine reserve "effect size" was tested. Calculations test for a linear decrease in "effect size" with increasing distance from North Cape as described in equation 9. Thus the null hypotheses being tested is that "there is no change in "effect size" with increasing distance from North Cape".

Table 5.10. Results for a focussed comparison to test for a latitudinal trend (decreasing effect further south) in "effect size".

\begin{tabular}{llll}
\hline & $P$-value & $\mathrm{T}_{\mathrm{f}}$-Value & Sig/NS \\
\hline Blue cod abundance & 0.5927 & 0.234628 & $\mathrm{NS}$ \\
Blue cod size & 0.9950 & 2.576662 & $\mathrm{Sig}$ \\
Rock lobster abundance & 0.0035 & -2.69948 & $\mathrm{Sig}$ \\
Rock lobster size & 0.0000 & -8.19878 & $\mathrm{Sig}$ \\
\hline
\end{tabular}

\subsubsection{Blue Cod}

Results for blue cod abundance were not significant indicating no latitudinal trend. Blue cod size, however, showed a significant result, indicating that the southern reserves may 
support blue cod of a larger average size (A positive test statistic indicates the direction of the trend is increasing to the South).

\subsubsection{Rock Lobster}

Rock lobster abundance and size data produced a significant result, indicating the presence of a latitudinal trend. Both results have negative values indicating a trend to the North (i.e that the northern reserves support both a greater abundance and a larger average size of rock lobster than southern reserves). This agrees with the pictorial representation of lobster sizes, which indicated a trend for increasing effect on lobster size as one moved further north. This resulted is supported by the Hedge's $g$-values.

The possibility that these results are biased by the fact that Cape Rodney-Okakari Point (i.e it is known to show a very large effect on lobster abundance and size (MacDiarmid and Breen, 1992)) was tested. The calculations for the focussed comparison were repeated without the data from each marine reserve in turn, to determine whether the data from Cape Rodney-Okakari Point were skewing the results. Calculations done without each reserve showed that excluding both Cape Rodney-Okakari Point and Long Island had non significant results for lobster abundance, indicating that both these reserve disproportionately influence the outcome. For rock lobster size the result was always significant irrespective of which reserve was excluded.

\subsection{Discussion}

\section{$\underline{5.4 .1 \text { Blue cod }}$}

Comparisons of the "effect size" of marine reserves showed that typically reserves supported more blue cod than control sites. This is seen in the pictorial representation where all the individual $t$-values were positive. The comparison of "effect sizes" among reserves for blue cod abundance also had a positive $T_{c}$-value $\left(T_{c}=1.49\right)$, indicating that reserves generally support more blue cod than a control area. The $P$-value $(P=0.833)$ for the tests comparing "effect sizes" of each reserve, was not statistically significant at the $\alpha=0.05$ level. This shows that there is no difference, among reserves, on the effect they are having on blue cod abundance. Looking at the raw data (Table 5.5.) this seems to hold true. This indicates that reserves in New Zealand are having the desired effect of increasing abundance of blue cod. 
Because there was no significant difference between effects of different marine reserves on blue cod abundance, these results were combined to give an overall significance to the effect of marine reserves on blue cod abundance. Combining the results for blue cod abundance gave a $P$-value of 0.0987 . This is significant at the $10 \%$ level (i.e $\alpha=0.10$ ). Normally statistical significance is indicated by a $P$-value of less than 0.05 (i.e. there is only a 5\% likelihood that such an extreme result occurred merely by chance). This result is significant at the $10 \%$ level and could well be biologically meaningful (i.e suggests a genuine effect), even if it is not a common protocol for statistical analyses. As established from the previous calculations this result is positive (i.e. marine reserves show greater abundance of blue cod than control areas).

The pictorial representation of comparisons of blue cod size within reserves also showed that in most cases the $t$-values were positive, indicating that the reserve areas in most comparisons did support larger blue cod than the control areas. The reserve at Te Angiangi (on the central east coast of the North Island of New Zealand) was the only exception to this. It actually showed low negative $t$-values, consistent with the raw data (Table 5.5.). This negative result may be explained by the fact that where blue cod were sampled at the Te Angiangi reserve, there was a higher than normal proportion of juvenile fish recorded (Freeman, 1999). This pulse in juvenile fish may have masked any increase in the size of adult blue cod that might be occurring at Te Angiangi marine reserve. Te Angiangi marine reserve is one of the most recently established marine reserves and may not yet be showing a detectable response to reservation status. It is possible that difference in species size and abundance between reserve and control sites may not become apparent for several years. For example, Davidson (1997) did not record a significant increase in blue cod abundance in Long Island-Kokomohua marine reserve until four years after it's establishment. The statistical comparison amongst marine reserves found that there was a significant difference between the effects that reserves were having on average size of blue cod (i.e. that the magnitude of the effect that each reserve was having on blue cod size is different).

\section{$\underline{5.4 .2 \text { Rock lobster }}$}

For rock lobster size the effect of marine reserves was also positive overall. The graphical depiction showed that all reserves had positive $t$-values with the exception of Long Island-Kokomohua Marine Reserve. The raw data (Table 5.6.) indicate the same. The comparison amongst reserves showed significantly different "effect size"s (i.e. the 
magnitude of the effect that reservation status is having on rock lobster abundance is different in each reserve), but the $T_{c}$ values were positive, indicating that the New Zealand marine reserves in this analysis typically had larger rock lobsters than control areas, but because there are significant differences amongst the reserves, no overall significance level can be attributed to this "effect size".

The figures for rock lobster abundance showed similar results to the rock lobster size data. Most reserves had positive $t$-values with the exception of Long Island-Kokomohua reserve and also the Poor Knights marine reserve. The more recent Kapiti study also showed low negative $t$-values. This agrees with the raw data as seen on Table 5.6. These results might be explained by the fact that Long Island-Kokmohua marine reserve shows an abnormally low number of lobsters compared to other reserves. Davidson (1997) suggested that this may have been due to two reasons. Firstly the author stated that much of the reserve was characterised by habitat unsuitable for sustaining large populations of crayfish. The "rubble bottom" habitat is composed of small broken boulders and cobbles interspersed with soft sediment (i.e shell and sand). Secondly, Davidson (1997) stated that for the areas where good rock lobster habitat existed, the lack of any increase in size or abundance, may have been due to separation of the island marine reserve from the mainland (i.e. separation of nearly $2 \mathrm{~km}$ ).

The other marine reserves where increases in rock lobster abundance and/or size occurred have considerable areas of habitat regarded as suitable for rock lobsters and are contiguous with the mainland of New Zealand. The negative $t$-value for Long IslandKokomohua also indicates that the control areas have higher numbers of rock lobsters than the reserve. In any case where a reserve is being compared with a control area, the habitat of the two areas needs to be identical. Sometimes it is extremely difficult to find areas of identical habitat both within and outside the reserve. If the control area that is being compared with the reserve is in fact better habitat for rock lobster than the reserve itself, this would also lead to a negative $t$-value.

The data from the Poor Knights Marine Reserve is from 1985, which is now 16 years ago (the reserve was established in 1981). Should more recent data be used for this type of analysis the results might well be different as there has been a long time for rock lobster abundance to show a response to reserve implementation. In the case of the more recent Kapiti study, the fact that it showed a low negative $t$-value, whereas the previous study 
was positive is likely to be due to the difference in sampling methodology. A larger area was searched for rock lobster in the previous study and also deeper depth strata. Recreational fishermen have often remarked that more rock lobster are found at deeper depths than those in which the more recent survey was carried out. Also, rock lobster have been shown to undergo marked seasonal depth changes (MacDiarmid, 1991).

\subsubsection{Trends in "effect size"}

Testing the effect of latitudinal location of marine reserve by means of the focussed comparison confirmed that there was an association between latitude and "effect size". Blue cod size data showed a significant trend indicating that there are larger blue cod in the southern reserves. However this meta-analysis is lacking data for blue cod from the northernmost reserves and perhaps this caused the result to be skewed by the data from Long Island-Kokomohua Marine Reserve where increase in cod size and abundance within the reserve is highly significant (Davidson, 1995).

Data for both rock lobster size and abundance showed significant trends towards the north (i.e. that there are larger and more abundance of rock lobster in the northern than the southern reserves). Tests for latitudinal trends were repeated without each reserve in turn. Excluding both Cape Rodney-Okakari Point Marine Reserve and Long Island Marine Reserve showed non significant results for the trend for lobster abundance (i.e. there was no indication of a trend associated with latitude). The fact that the trend was non significant when excluding Long Island Marine Reserve, even though previous data had shown this reserve to have a negative effect on rock lobster abundance, might be due to the fact that excluding the negative effect of this reserve made the mean difference amongst the other reserves less significant. The exclusion of Cape Rodney-Okakari Point Marine Reserve showing a non-significant result does indicate that the very strong positive effect of this reserve biases the trend towards the north.

The differing ages of the marine reserves may also confound the results found while testing for trends associated with latitude, however without access to data from each marine reserve at a certain age, this is not easily solvable.

\section{$\underline{5.4 .4 \text { General discussion }}$}

This is the first published meta-analysis on the effects of marine reserves. This should only be seen as a snapshot of what could potentially be achieved with meta analysis techniques, but in summary this meta-analysis shows that for the two selected key 
species, blue cod and rock lobster, marine reserves in New Zealand generally appear to be supporting higher average densities and sizes of these species than control sites. The power of the tests in this investigation was unable to be determined, however, the results still imply that marine reserves generally show a larger average abundance and size of these species than controls.

This is encouraging given that this is the first time the importance of marine reserve effects has been demonstrated via meta-analysis and that a positive effect was found despite the small number of studies used. Several of the marine reserves used in this meta analysis have only been implemented fairly recently, so this result also implies that a positive response to reservation status can be seen in a relatively short time.

There are indications for trends in the relative effectiveness of these reserves depending on certain factors. For example, if the reserve habitat is suitable for the target species, the reserve is more likely to have a significant impact on this species. Size, design and location of the reserve could affect the effectiveness of the reserve. There may also be an effect related to island vs mainland reserves.

Benjamin Halpern (2000) has tried to address these issues with an in depth review of 89 "no take" marine reserves from around the world. He found that the diversity of communities and the average size of the organisms in a reserve are between 20 and $30 \%$ higher relative to control areas regardless of the size of the reserve. He suggests that the relative impacts of reserves are independent of reserve size, however larger reserves lead to larger absolute differences. These findings were based on a review of published data. This indicates the potential that a meta-analysis has to provide even more concrete evidence, and maybe provide some answers about best reserve design. However, to determine optimal design, the final goal of the marine reserve must be kept in mind.

Implementation of reserves has always been justified for many reasons such as research, conservation and management purposes. The value of marine protected areas, particularly reserves, and the importance of gaining information on coastal marine environments is being recognised by both politicians and scientists more than in previous years (Attwood et al., 1997a, Kingsford and Battershill, 1998, Conover et al., 2000). If meta-analyses such as these can confirm the positive effects of reservation then the use of marine 
reserves as management tools both for fisheries and conservation may gain greater importance. 
CHAPTER 6

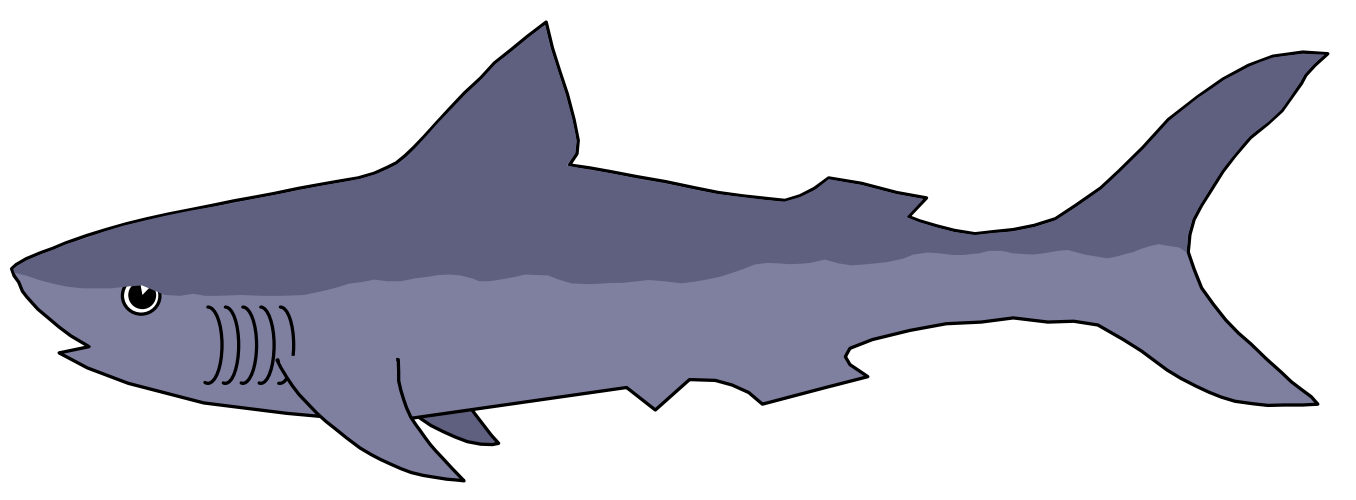

GENERAL DISCUSSION 


\section{CHAPTER 6 - GENERAL DISCUSSION}

\subsection{Summary of findings}

The present investigation aims to address techniques to evaluate marine reserves and their effects on the inhabitant biota. It addresses the importance of baseline surveys before the implementation of marine reserves and the role that marine reserves play in conservation.

In the literature there are many examples of studies trying to assess the effects of marine reserves, that are located in many different countries and with varying habitats. The effects the marine reserves have had on their inhabitant species also vary. A large proportion of studies deal with marine reserves on coral reefs. Those that have been mentioned in this thesis are but a few, namely the Barbados Marine Reserve (Chapman and Kramer, 1999), Exuma Cays Land and Sea Park, Bahamas (Chiappone and Sealey, 2000), The Hol Chan Marine Reserve in Belize and the Saba Marine Park in the Netherlands Antilles (Roberts, 2000), The Mombasa Marine National Park in Kenya (MacClanahan, 1994) and Apo and Sumilon Island Reserves in the Phillipines (Russ and Alcala 1996). These have all been shown to have greater biomass, greater productivity and more larval export or increased abundance of species in the reserve than control areas. Fewer studies have been conducted on marine reserves on temperate reefs, but those that have, have also shown responses similar to the reserves in more tropical locations. Striking changes have been shown to occur both in the Cape Rodney-Okakari Point Marine Reserve in Northern New Zealand (Babcock et al., 1999) and the Maria Island Marine Reserve in Tasmania (Edgar and Barret, 1999) both of which have been discussed in this thesis.

However, one thing that all these studies had in common was the lack of baseline data. Conclusions made about the effect that these reserves have had on the inhabitant species was based on comparisons between control and reserve sites, and in some cases differing time periods after establishment of the reserve. The current investigation is an example of why baseline data is important when measuring effectiveness of a marine reserve and is to date, to my knowledge, the first real baseline dataset collected before establishment of a marine reserve (i.e. for the Taputeranga Marine Reserve). This data will be invaluable for comparisons made to data collected in the future. Analysing the data in the present investigation has shown that there are intrinsic differences (i.e. an environmental gradient) along a contiguous stretch of coast (the Wellington south coast), which must be 
quantified and taken into account to determine the "reserve" effect as measured at a later date. The present investigation also determined that the sampling methodology used for data collection, was, in most cases, adequate to detect any change that might occur on the south coast (for example after reservation).

The portion of this investigation that examines changes in an established marine reserve shows that baseline data alone is not enough to gain a true estimate of a "reserve" effect, but that the baseline data must be of a suitable quantity, that the power to detect any change occurring in the future is high enough (i.e. statistically the power of the data should be at least $80 \%$ ). There was a small amount of data available for the Kapiti Marine Reserve before it had gained reservation status. However, comparisons between this data, and that collected in the present investigation did not detect any significant changes, despite the fact that the reserve and control comparisons from surveys collected in the current study did show evidence of increased species size and abundance inside the reserve. From the literature, this is the type of change that is to be expected in a marine reserve. Therefore, this study of a temperate marine reserve confirms the findings that marine reserves do have a "positive" effect on the inhabitant species. This also demonstrates the importance of temporal comparisons, as results from reserve versus control comparisons can be confounded by pre-existing habitat differences.

A new method for assessing the effectiveness of marine reserves was trialled in the present investigation. Most reviews (Creese and Jeffs, 1992, Jones et al., 1992, Allison et al., 1998, Garcia-Charton and Perez-Ruzafa 1999) of multiple marine reserves have been of the narrative type and collating and comparing results from the marine reserves investigated. Halpern (in press) has performed an in-depth review of 89 'no-take' marine reserves, but this was also not a true mathematical meta-analysis. The meta-analysis performed in the current investigation used true statistical methods to confirm that the six New Zealand marine reserves used in this analysis were all showing an increase in blue cod and rock lobster size and abundance. Although only performed on a small subset of marine reserve data, it has been shown that a meta-analysis could be a useful tool to investigate effects of marine reserves world over. Any associations between "effect size" of the reserve and other factors (such as habitat, reserve size and location) can also be tested. If baseline data had been available for all established marine reserves, then data from the reserve at a certain age could have been used for an analysis such as this, thus ensuring that the differing ages of marine reserves tested did not confound the results. 


\subsection{Suggestions for future studies}

The current legislation in New Zealand means marine reserves are established mainly for scientific reasons. Overseas, marine reserves are often created as a fisheries tool. Although on its own a marine reserve is not enough to ensure protection against fishing stock depletion it is considered a valuable part of fisheries management (Conover et al., 2000). Legislation in New Zealand may change to encompass protection of a depleted fishing stock as a reason to establish marine reserves. In this case, it would be even more important that detailed information be gathered on the biota of the area, especially species impacted by fishing, to maximise benefit gained from a protected area. More detailed information leads to better informed decisions about reserve location and size.

Additionally, Jennings et al. (1996) suggested the need to include collection of habitat data in order to reduce unexplained variance associated with visual censuses. Since visual census is the commonly accepted way to perform these monitoring surveys, it is likely that some biases will arise from correlations between species surveyed and natural environmental factors.

I believe that, currently the monitoring protocols of marine reserves in New Zealand do not take environmental variables into account. As a way to determine whether environmental factors are affecting the results found, these should also be monitored. Gathering information on abiotic factors would in most cases, be simple. For example;

- Data on water temperature, depth and current strength can in most cases be recorded from a depth sounder/GPS (Global Positioning Satellite) on board a boat.

- Current direction can be noted with a buoy in the water. The direction that the diver performing counts is swimming in, should also be noted, as this in relation to current direction may show some patterns. (i.e. if fish tend to swim into the current then a diver swimming with the current will see more fish than a diver swimming into the current, as fish coming from behind the diver are not usually counted in visual census techniques). Some indication of this type of pattern has been observed at the Long Island-Kokomohua Marine Reserve (R. Davidson, pers.comm.).

- Water clarity can be recorded from a boat with a secchi disc. Water clarity has been shown to affect fish behaviour (Willis and Babcock, 1997). 
- $\quad$ Salinity and dissolved oxygen can be measured with calibrated meters.

- $\quad$ Particulate matter and chlorophyll content can be assessed in water samples from each site. This would provide some information about nutrient content of the water and primary productivity.

Subsequently, performing ANCOVA analyses or MDS ordinations with these environmental variables and count data of various species surveyed may show some correlations or patterns in their distribution. Each marine reserve is in a different environment, and different factors specific to that area may be affecting species distribution and abundance (e.g. as has been determined in the present investigation there is an environmental gradient present on the south coast and this gradient could be due to a number of factors such as current strength, wave exposure and/or nutrient levels).

Another factor that may affect results of monitoring surveys is the time of day when the survey is carried out. Mobile species may behave differently at varying times of day, perhaps feeding at certain times and remaining cryptic during other times. Ideally, surveys should be carried out at the same time of day, but since this is unrealistic, recording the differences may allow any trends that exist to become evident. One should consider the merits of nighttime fish counts, if logistics allow it. It is likely that some fish species are mainly active at night and would rarely if ever be sighted during the day.

Just as Hockey and Branch (1997) have suggested COMPARE (Criteria and Objectives for Marine Protected Area Evaluation) for marine protected areas in South Africa, I would like to suggest a national monitoring protocol for marine reserve monitoring in New Zealand based on my findings in the current investigation. COMPARE is aimed at helping with decision making involved in proclaiming marine reserves, and is therefore a guideline at management level, different from a national monitoring protocol which is a guideline at fieldwork level, and would come into play as soon as a reserve proposal is conceptualised.

This could be useful as most political parties are now aiming at protecting $10 \%$ of New Zealands coastline, and therefore it is to be expected that more marine reserves will soon be implemented. Suggestions are as follows: 
1) A baseline study needs to be conducted as soon as the application process starts, over a minimum of three years, with 4 surveys per year (this is at least one survey per season, i.e. every three months).

2) An initial survey consisting of video transects to quantify percent algal cover and describe habitat should be untertaken. This also assists with familiarising whomever is conducting the survey with the area, and allows the identification of some key species.

3) Key species monitored should always include rock lobster and blue cod, since there is much data nationally already available on these species (if the habitat is unsuitable to use these species as key species, they should still be recorded whenever sited).

4) Multiple sites should be surveyed inside and outside the proposed reserve area to provide for likely boundary changes. Where possible different depth strata should be monitored (dependent on habitat).

5) Start with 9 fish transects (surveying all reef fish), 6 invertebrate transects (Black foot paua, kina and crayfish (which should be sized and sexed)) and 20 algal qudrats per site. After initial surveys, conduct power analysis and then adjust sampling regime accordingly. This must be the best compromise available to allow for a multi species survey. (This methodology will require several trained divers, or longer periods of settled weather). These suggestions for transect numbers are based on the sampling methodology used in the current investigation.

6) Collect data on: sea surface temperature, current strength and direction (and direction that diver performing visual censuses is swimming), water clarity, chlorophyll content, particulate matter, depth of transects, time of day, height and state of tide should be recorded.

7) Analysis of data could include: correlation analysis, ANOVA, ANCOVA and MDS to test for differences between sites and then subsequently between reserve and control sites for each species, and also between time periods, if the same monitoring protocol is continued after reserve establishment. 
A national monitoring protocol such as this would allow meaningful comparisons within reserves on a temporal scale, to isolate reserve versus habitat effects as much as possible. It would also allow comparisons between reserves via a meta-analysis which would not be confounded by differing reserve ages, if data is available at each reserve, at all times before and after reservation.

Video surveys were suggested as they could be a useful tool in baseline (and follow up) surveys as it is an easy and quick method by which one can accurately describe the algal communities in any given area. This especially, could be a way to compare potential reserve sites with potential control sites, in order to establish the similarity of the areas (in terms of percent algal cover), before quantitative monitoring begins. It would aid in site selection.

Willis and Babcock (1997) observed that although this type of methodological standardisation is the ideal, it does not necessarily provide the best data for multiple species, and that ideally a species by species approach should be used. However, this is expensive and time consuming. In order to gather information on a whole assemblage of species, a cost-effective compromise such as this is probably the best solution.

The study area itself and its characteristics will determine to a large degree how intensively an area can be monitored. If inclement weather and bad diving conditions are likely then a monitoring regime that is intense, that can be applied in short windows of opportunity, is vitally important. If an area has stable weather patterns and good diving conditions then more detailed data can be collected.

The monitoring protocol I have suggested takes into account logistical difficulties, and based on the data I have been able to collect during the course of the present investigation, I think it is feasible to carry out this type of survey.

\subsection{Specific Conclusions}

There is an east to west environmental gradient present on the south coast of Wellington. 
Following the methodology used for monitoring of the south coast of Wellington in the current study, the following species should be used as indicator species on the south coast:

Blue moki

Black foot paua

Yellow foot paua

Kina

\section{Ecklonia radiata}

Additionally Carpophyllum flexuosum should be monitored.

Commercial species that should be monitored on the south coast of Wellington but where the methodology used in this thesis needs some adjustment are:

Rock lobster (transect number should be increased to 9, size data should be collected also).

Red moki (transect number should be 18).

Blue cod, butterfish, trevally and tarakihi (transect number needs to be 27 to bring the power to $80 \%$. 27 transects may be infeasible, but it certainly indicates a need for increase in sampling effort to detect changes in these species, which are all prone to fishing pressure. However, continued monitoring over time may show the power to increase, if their abundance is increasing).

The same sites on the south coast of Wellington as used in this investigation should be monitored. When the reserve is implemented, more sites may be added (inside or outside the reserve as necessary) to balance sampling design.

> The Kapiti Marine Reserve is increasing average species abundance, but results may be skewed by Arapawaiti Point, therefore more reserve and control sites should be monitored in the western reserve section.

Following the methodology described in this thesis, the following species should be monitored at Kapiti Marine Reserve as indicator species:

Blue cod

Butterfish

Kina

Black foot paua

Rock lobster (additionally size data should be collected, and more depth strata surveyed if possible).

Meta analysis techniques can be applied to marine reserve data, and from the New Zealand data it has been applied to here, one can conclude that in the case of blue cod 
and rock lobster marine reserves are having a positive effect. The meta analysis also shows some indication of a latitudinal trend. 


\section{References Cited}

Abel Tasman National Park Marine Reserve discussion documents. 1)Abel Tasman National Park Marine Reserve Discussion Paper.2)Tonga Marine Reserve Application 3)Abel Tasman National Park Marine Reserve: Summary of submissions, December 1992. Department of Conservation reports.

Adams, N 1994. Seaweeds of New Zealand, an illustrated guide. Canterbury University Press.

Adams, D.C, Gurevitch, J, Rosenberg, M.S, 1997. Resampling tests for meta-analysis of ecological data. Ecology 78 (5): 1277-1283.

Agardy, T, 2000. Information needs for marine protected areas: scientific and societal. Bulletin of Marine Science, Proceedings of the second William R. and Lenore Mote International Symposium in Fisheries Ecology 66(3): 875-888.

Allison, G.W, Lubchenco, J, Carr, M.H 1998. Marine reserves are necessary but not sufficient for marine conservation. Ecological Applications 8 (Suppl.):S79-S92

Anderson, T 1994. Role of macroalgal structure in the distribution and abundance of a temperate reef fish. Marine Ecology Progress Series 113: 279-290.

Arnqvist, G and Wooster, D, 1995. Meta-analysis: synthesizing research findings in ecology and evolution. Tree 10 (6): 236-240.

Attwood, C.G, Harris, J.M, Williams, A.J 1997a. International experience of marine protected areas and their relevance to South Africa. South African Journal of Marine Science 18: 311-332.

Attwood, C. G, Mann, B.Q, Beaumont, J, Harris, J.M, 1997b. Review of the state of marine protected areas in South Africa. South African Journal of Marine Science 18: 341367. 
Babcock, R.C and Cole, R.G 1993. The extent of dieback of the kelp Ecklonia radiata in the Cape Rodney- Okakari Point marine reserve. Report to the Department of Conservation.

Babcock, R.C, Kelly,S, Shears,N.T, Walker,J.W, Willis,T.J 1999. Changes in community structure in temperate marine reserves. Marine Ecology Progress Series 189: 125-134.

Ballantine, B, 1994. Networks of "no-take" marine reserves are practical and necessary. Marine Protected Areas and Sustainable Fisheries. Edited by N.L Shackell and J.H.M Willison, Science and Management of protected areas association. Wolfville, Nova Scotia, Canada. 1995. Being the proceedings of a symposium held during the $2^{\text {nd }}$ International Conference on Science and the management of Protected Areas in May 1994. Pp: 13-20.

Ballantine, W, J, 1995. The New Zealand experience with "no-take" marine reserve. In: Review of the use of Marine Fishery Reserves in the US Southeastern Atlantic. Edited by C.M. Roberts. W.J, Ballantine, C.D. Buxton et al. Pp. 15-31. NOAA Technical Memo. NMFS-SEFSC-376.

Ballantine, B, 1997. Design principles for systems of "no-take" marine reserves. Paper presented at workshop on: The design and monitoring of marine reserves at Fisheries Center, University of British Columbia, Vancouver, 1997.

Ballantine, B, 1998. Marine reserves: time for a new approach? Paper presented at an invited seminar to the Department of Conservation, Wellington.

Battershill, C.N, Murdoch, R.C, Grange, K.R, Singleton, R.J, Aaron, E.S, Page, M.J and Oliver, M.D 1993. A survey of the marine habitats and communities of Kapiti Island. A report prepared for the Department of Conservation, Wellington.

Bohnsack, J.A 1998. Application of marine reserves to reef fisheries management. Australian Journal of Ecology 23: 298-304.

Borenstein,M, Rothstein, H and Cohen, J 1997. A computer program for statistical power analysis and confidence intervals - Power and Precision. Biostat software products. 
Bowman, M.J, Kibblewhite,A.C, Chiswell, S.M, Murtagh, R.A 1983a. Shelf fronts and tidal stirring in greater Cook Strait, New Zealand. Oceanologica 5(2): 119-129.

Bowman, M.J, Kibblewhite, A.C, Murtagh, R.A, Chiswell, S.M, Sanderson, B.G 1983b. Circulation and mixing in greater Cook Strait, New Zealand. Oceanologica 6(4): 383391.

Buxton, C.D and Smale, M.J, 1989. Abundance and distribution patterns of three temperate marine reef fish (teleostei: sparidae) in exploited and unexploited areas off the southern cape coast. Journal of Applied Ecology 26: 441-451.

Castilla, J.C, 1989. Human exclusion from rocky intertidal of Las Cruces, central Chile: Effects on Durvillea antarctica (Phaeophyta, Durvilleales). Marine Ecology Progress Series 50: 203-214.

Carter, L and Lewis, K 1995. Variability of the modern sand cover on a tide and storm driven inner shelf, south Wellington, New Zealand. New Zealand Journal of Geology and Geophysics 38: 451-470.

Carter, L and Heath, R.A, 1975. Role of mean circulation, tides, and aves in the transport of bottom sediment on the New Zealand continental shelf. New Zealand Journal of Marine and Freshwater Research 9: 423-448.

Chapman, M.R and Kramer, D.L 1999. Gradients in coral reef fish density and size across the Barbados marine reserve boundary: effects of reserve protection and habitat characteristics. Marine Ecology Progress Series 181: 81-96.

Chiappone, M and Sealey, K.M.S, 2000. Marine reserve design criteria and measures of success: lessons learned from the Exuma Cays Land and Sea Park. Bulletin of Marine Science, Proceedings of the second William R. and Lenore Mote International Symposium in Fisheries Ecology 66(3): 691- 706.

Choat, J.H and Ayling, A.M 1987. The relationship between habitat structure and fish faunas on New Zealand reefs. Journal of Experimental Marine Biology and Ecology 110: 257-284. 
Choat, J.H and Clements, K.D 1993. Daily feeding rates in herbivorous labroid fishes. Marine Biology 117: 205-211.

Choat, J.H and Schiel, D. R. 1982. Patterns of distribution and abundance of large brown algae and invertebrate herbivores in subtidal regions of Northern New Zealand. Journal of Experimental Marine Biology and Ecology 60: 129-162.

Clements, K.D and Choat, J.H 1993. Influence of season, ontogeny and tide on the diet of the temperate marine herbivorous fish Odax pullus (Odacidae).Marine Biology 117: 213220.

Cole, R.G, Ayling, T.M, Creese, R.G 1990. Effects of marine reserve protection at Goat Island, northern New Zealand. New Zealand Journal of Marine and Freshwater Research 24:197-210.

Cole, R.G 1994. Abundance, size structure, and diver-oriented behaviour of three large benthic carnivorous fishes in a marine reserve in northeastern New Zealand. Biological Conservation 70: 93-99.

Cole, R.G, Villouta, E, Davidson, R, 2000. Direct evidence of limited dispersal of the reef fish Parapercis colias (Pinguipedidae) within a marine reserve and adjacent fished areas. Aquatic Conservation: Marine and Freshwater Ecosystems 10: 421-436.

Conover, D,O, Travis, J, Coleman, F,C 2000. Essential fish habitat and marine reserves:an introduction to the Second Mote symposium in Fisheries Ecology. Bulletin of Marine Science, Proceedings of the second William R. and Lenore Mote International Symposium in Fisheries Ecology 66(3): 527-534.

Cotsilinis, M, 1999. Intertidal community responses following the decommissioning of a sewage outfall:Owhiro Bay, Wellington. Unpublished Msc thesis, Victoria University, Wellington.

Creese, R.G and Jeffs, A 1992. Biological research in New Zealand marine reserves. Proceedings of the Second International Temperate Reef Symposium Pp 15-22. 
Crowder, L.B, Lyman, S.J, Figueira,W.F and Priddy, J. 2000. Source-sink population dynamics and the problem of siting marine reserves. Bulletin of Marine Science, Proceedings of the second William $R$. and Lenore Mote International Symposium in Fisheries Ecology 66(3): 799-820.

Davidson, R.J and Chadderton, L 1994. Marine reserve site selection along the Abel Tasman National Park coast, New Zealand: consideration of subtidal rocky communities. Aquatic Conservation: Freshwater and Marine Ecosystems 4: 153-167.

Davidson, R.J, 1995. Long Island-Kokomohua Marine Reserve: subtidal biological baseline report. Department of Conservation. Nelson/Marlborough Conservancy Occasional publication $17,83 \mathrm{p}$.

Davidson, R.J, 1997. Biological monitoring of Long Island-Kokomohua Marine Reserve, Queen Charlotte sound, Marlborough sounds: update september 1993 - April 1997. Report prepared for DOC.

Davidson, R.J 1999. Tonga Marine Reserve. Subtidal biological baseline report. Report prepared for Department of Conservation, Nelson.

Davidson R.J (in submission). Blue cod (Parapercias colias) recovery in Long IslandKokomohua Marine Reserve, Marlborough Sounds, New Zealand. In submission to Aquatic Conservation: Marine and Freshwater Ecosystems..

Davidson, R.J, Villouta, E, Cole, R.G, Barrier, R,G,F (in submission). Effects of marine reserve protection on spiny lobster abundance and size at Tonga Island Marine Reserve, New Zealand. To be submitted to Aquatic Conservation: Marine and Freshwater Ecosystems.

Dayton, P.K, Sala, E, Tegner, M.J, Thrush, S, 2000. Marine reserves: parks, baselines, and fisheries enhancement. Bulletin of Marine Science, Proceedings of the second William R. and Lenore Mote International Symposium in Fisheries Ecology 66(3): 617634. 
Edgar,G.J and Barrett, N.S 1997. Short term monitoring of biotic change in Tasmanian marine reserves. Journal of Experimental Marine Biology and Ecology 213: 261-279.

Edgar, G,J and Barrett, N,S 1999. Effects of the declaration of marine reserves on Tasmanian reef fishes, invertebrates and plants. Journal of Experimental Marine Biology and Ecology 242: 107-144.

Egger, M, Smith, G.D, Phillips, A.N, 1997. Meta-analysis, principles and procedures. British Medical Journal 315: 1533-1537.

Francis, M. 1996 ( $2^{\text {nd }}$ edition). Coastal fishes of New Zealand. Kingstime Printing Press Ltd, Hong Kong. 72 pp.

Freeman, D.J and Duffy, C.A.J, (in Prep). Monitoring of Te Angiangi Marine Reserve, Central Hawke's Bay. Department of Conservation Report, East Coast Hawke's Bay Conservancy.

Garcia-Charton, J.A and Perez-Ruafa, A, 1999. Ecological heterogeneity and the evaluation of the effects of marine reserves. Fisheries Research 42: 1-20

Haggitt, T, 1999. Relationship between the kelp Ecklonia radiata and the stipe boring amphipod Orchomenella aahu. Paper presented to the New Zealand Marine Sciences Society in 1999.

Halpern, B, in press. The impact of marine reserves: do reserves work and does reserve size matter? Ecological Applications In Press.

Harvey, E. S, 1989. Underwater Stereo-video: A tool for minimising biases in visual censuses of reef fish. Unpublished PhD thesis, University of Otago, New Zealand.

Hay, C and Luckens, P.A, 1987. The asian kelp Undaria pinnatifida (phaeophyta: laminariales) found in a New Zealand harbour. New Zealand Journal of Biology 25: 329332. 
Heath, R.A, 1985. A review of the physical oceanography of the seas around New Zealand - 1982. New Zealand Journal of Marine and Freshwater Research 19: 79-124.

Hockey, P.A.R and Branch, G.M 1997. Criteria, objectives and methodology for evaluating marine protected areas in South Africa. South African Journal of Marine Science 18: 369-383.

Jennings, S, Boulle, D.P, Polunin, N.V.C 1996. Habitat correlates of the distribution and abundance of Seychelles' reef fishes. Environmental Biology of Fishes 46: 15-25.

Jones, R.S and Thompson, M.J, 1978. Comparison of Florida Reef reef fish assemblages using a rapid visual technique. Bulletin of Marine Science 28:159-172.

Jones,G.P, Cole,R.C, Battershill,C.N, 1992. Marine reserves: do they work?. Proceedings of the Second International Temperate Reef Symposium Pp 29 - 44.

Jones, G.P 1984. The influence of habitat and behavioural interactions on the local distribution of the wrasse, Pseudolabrus celidotus. Environmental Biology of Fishes 10(1/2): 43-58.

Jouvenel, J.Y and Pollard, D.A, 2001. Some effects of marine reserve protection on the population structure of two spearfishing target-fish species, Dicentrarchus labrax (Moronidae) and Sparus aurata (Sparidae), in shallow inshore waters, along a rocky coast in the northwestern Mediterranean Sea. Aquatic Conservation: Marine and Freshwater Ecosystems 11: 1-9.

Kapiti Marine Reserve, DOC publication, information pamphlet.

Kelly, S, Babcock, R. C, MacDiarmid, A.B 2000a. Impact of marine reserves on spiny lobsters (Jasus edwardsii) and the lobster fishery. Report prepared for the Department of Conservation.

Kelly, S, Scott, D, MacDiarmid, A.B, Babcock, R.C, 2000b. Spiny lobster, Jasus edwardsii, recovery in New Zealand marine reserves. Biological Conservation 92: 359369. 
Kingsford, M and Battershill, C, 1998. Studying temperate marine environments. A handbook for ecologists. Canterbury University Press. 335 pp.

Lubchenco, J, 1997. Developing the theory of marine reserves. NCEAS working group web projects report.

MacClanahan, T.R, 1994. Kenyan coral reef lagoon fish. Effects of fishing, substrate complexity, and sea urchins. Coral Reefs 13: 231-241.

MacClanahan, T.R. and Kaundra-Arara, B, 1996. Fishery Recovery in a coral-reef marine park and its effects on the adjacent fishery. Conservation Biology 10: 1187-1199.

MacDiarmid, A.B, 1991. Seasonal changes in depth distribution, sex ratio and size frequency of spiny lobster Jasus edwardsii on a coastal reef in northern New Zealand. Marine Ecology Progress Series 70: 129-141.

MacDiarmid, A.B and Breen, P.A, 1992. Spiny lobster population change in a marine reserve. Proceedings of the Second International Temperate Reef Symposium Pp 47-56.

MacDiarmid, A.B, 2001. Effects on egg production of a male based fishery for rock lobsters. Paper presented at "A showcase of Jasus lobster research in New Zealand" April, 2001.

McCormick, M. I. and Choat, J.H, 1987. Estimating total abundance of a large temperatereef fish using visual strip-transects. Marine Biology 96: 469-478.

Osenberg, C.W, Sarnelle, O, Goldberg, D.E, 1999. Meta-analysis in ecology: concepts, statistics and applications. Ecology 80 (4): 1103-1104.

Petersen, C.H, Summerson, H.C, Thomson, E, Lenihan, H.S, Grabowski, J, Manning, L, Michelli, F, Johnson, G, 2000. Synthesis of linkages between benthic and fish communities as a key to protecting essential fish habitat. Bulletin of Marine Science, Proceedings of the second William $R$. and Lenore Mote International Symposium in Fisheries Ecology 66(3): 759-774. 
Rakitin, A and Kramer, D.L 1996. Effect of a marine reserve on the distribution of coral reef fishes in Barbados. Marine Ecology Progress Series 131: 97-113.

Roberts, C.M and Polunin, N.V.C, 1991. Are marine reserves effective in the management of reef fisheries? Reviews in Fish Biology and Fisheries 1: 65-91.

Roberts, C, M 2000. Selecting marine reserve locations: optimality versus opportunism. Bulletin of Marine Science, Proceedings of the second William R. and Lenore Mote International Symposium in Fisheries Ecology 66(3): 581-592.

Roberts, C, M and Hawkins, J.P, 2000. Fully-protected marine reserves: a guide. WWF Endangered Seas Campaign, $125024^{\text {th }}$ St, MW, Washington, DC 20037, USA and Environment Department, University of York, York, Tyo10 5DD, UK.

Rosenthal, R, 1987. Judgement studies: design, analysis and meta-analysis. Cambridge University Press.

Russ, G.R and Alcala, A.C, 1996. Marine reserves: rates and patterns of recovery and decline of large predatory fish. Ecological Applications 6 (3): 947-961.

Schafer, W.D, 1999. Methods, plainly speaking. An overview of meta-analysis. Measurement and evaluation in counseling and development 32 (1); 43-61.

Schmitt, E.F and Sullivan, K.M, 1996. Analysis of a volunteer method for collecting fish presence and abundance data in the Florida Keys. Bulletin of Marine Science 59 (2): 404416.

Shears, N and Babcock, R, 2000. Cape Rodney to Okakari Point marine reserve benthic monitoring program -1999/2000. Report to the Department of Conservation.

Stephen and Fitzmaurice Consulting Civil and Sanitary Engineers (editors), 1976. A review of waste water treatment and disposal in New Zealand. A report prepared for the Hutt Valley Drainage Board. 
Tegner, M. J and Dayton, P.K, 1987. El Nino effects on Southern California kelp forest communities. Advances in Ecological Research 17: 243-279.

Thompson, A.A and Mapstone, B.D, 1997. Observer effects and training in underwater visual surveys of reef fishes. Marine Ecology Progress Series 154: 53-63.

Underwood, A.J, 1981. Techniques of analysis of variance in experimental marine biology and ecology. Oceanographic Marine Biology Annual Review 19: 513-605.

Underwood, A.J and Atkinson, M.H 1992. Beyond the baseline: Where should we go from here? Proceedings of the second international temperate reef symposium pp 115120.

Warner, R. R, Swearer, S.E, Caselle, J.E, 2000. Larval accumulation and retention: implications for the design of marine reserves and essential habitat. Bulletin of Marine Science, Proceedings of the second William R. and Lenore Mote International Symposium in Fisheries Ecology 66(3): 821- 830.

Warwick, R. M, Clarke, K.R, Suharsono, 1990. A statistical analysis of coral community responses to the 1982-83 El Nino in the Thousand Islands, Indonesia. Coral Reefs 8: 171179.

Willis, T.J and Babcock, R.C 1997. Investigation of methods for assessing reef fish populations and the effects of marine reserve protection. Report to the Department of Conservation. 


\section{APPENDIX ONE}

Graphs of Algal Damage at the 8 sites on the Wellington South Coast. Each error bar represents one standard error.

Fig. 1. Proportions of different types of Carpophyllum maschalocarpum damage at Barretts Reef at each survey period.

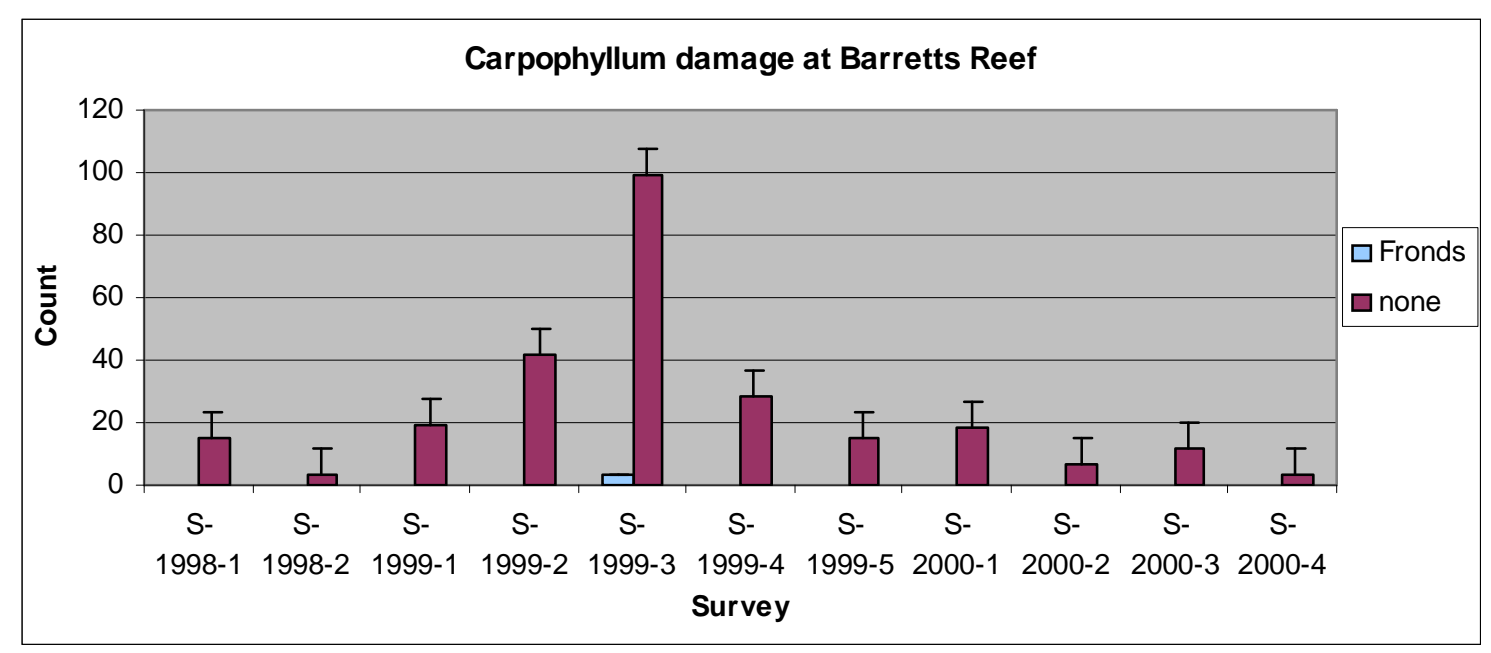

Fig. 2. Proportions of different types of Carpophyllum maschalocarpum damage at Breaker Bay at each survey period.

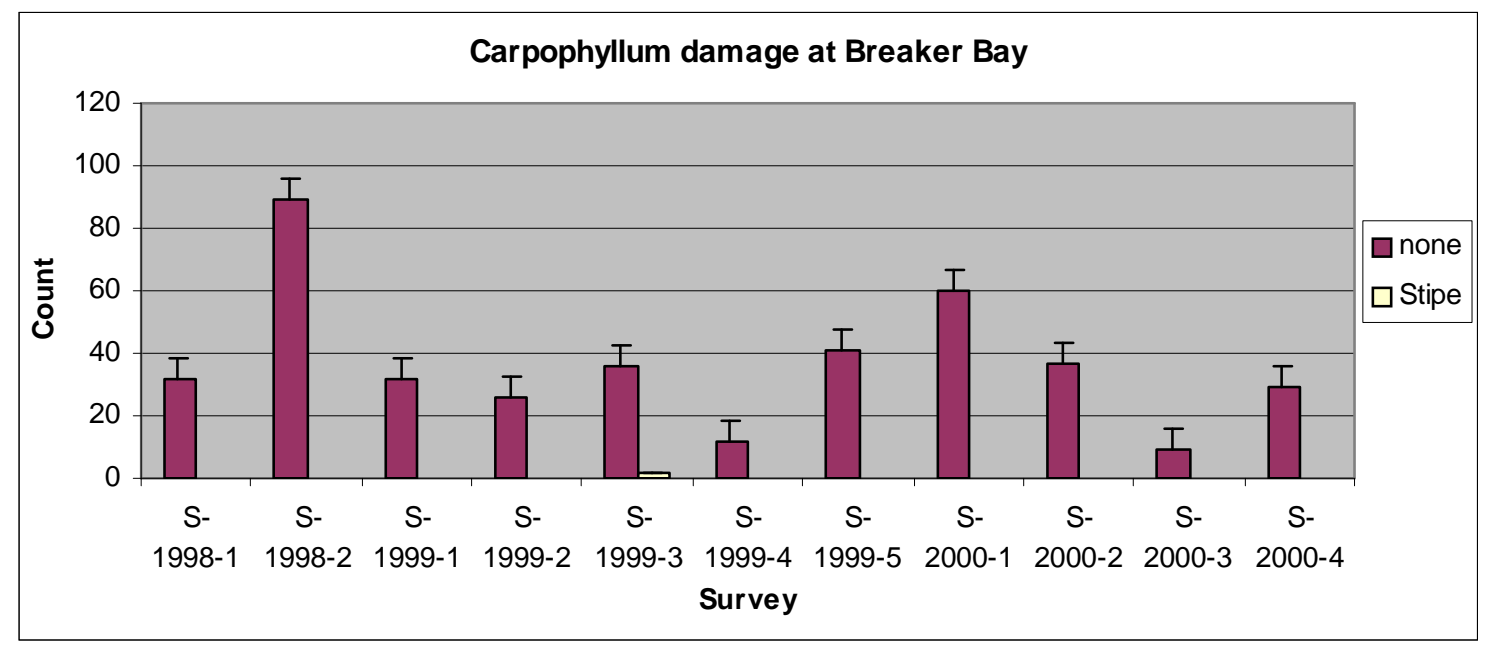


Fig. 3. Proportions of different types of Carpophyllum maschalocarpum damage at Palmer Head at each survey period.

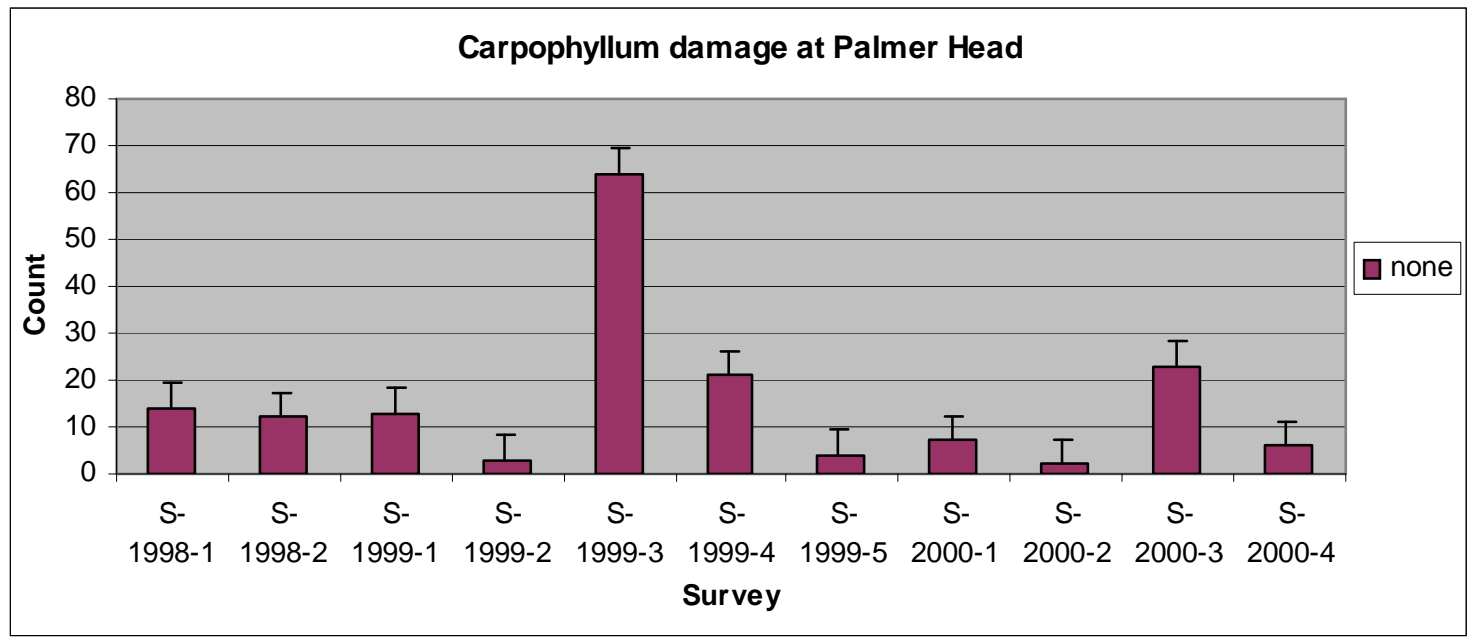

Fig.4. Proportions of different types of Carpophyllum maschalocarpum damage at Princess Bay at each survey period.

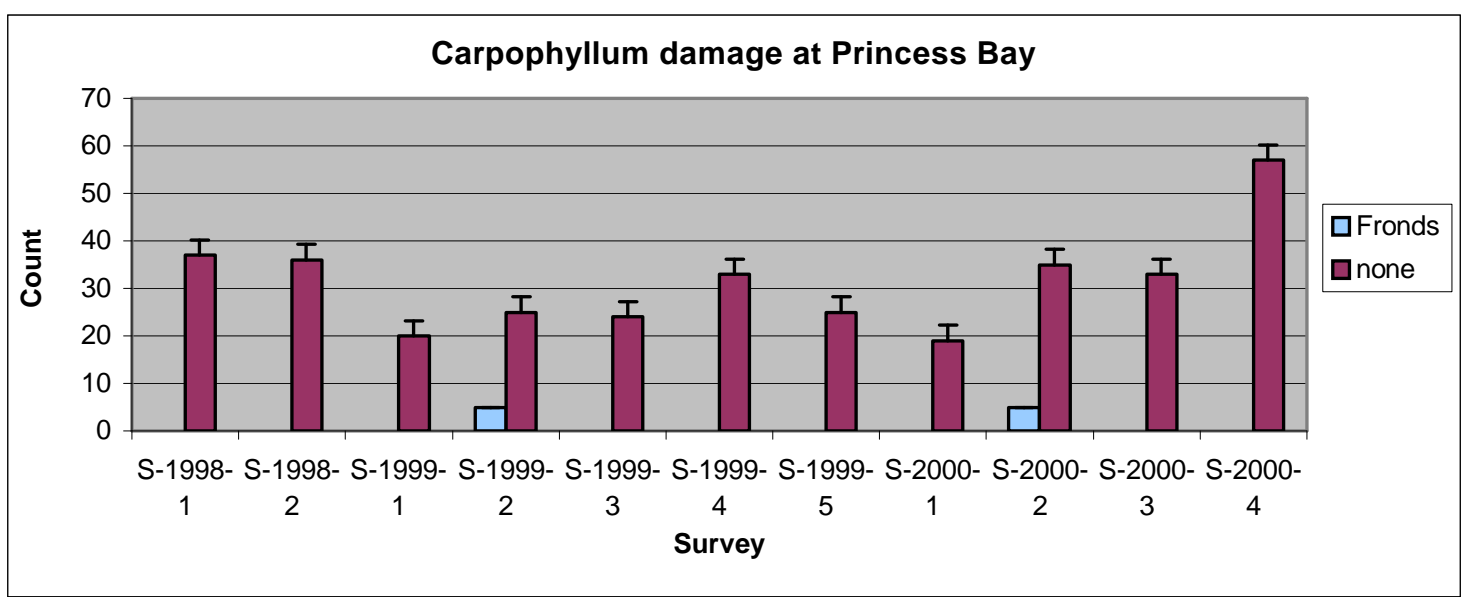


Fig. 5. Proportions of different types of Carpophyllum maschalocarpum damage at Red Rocks at each survey period.

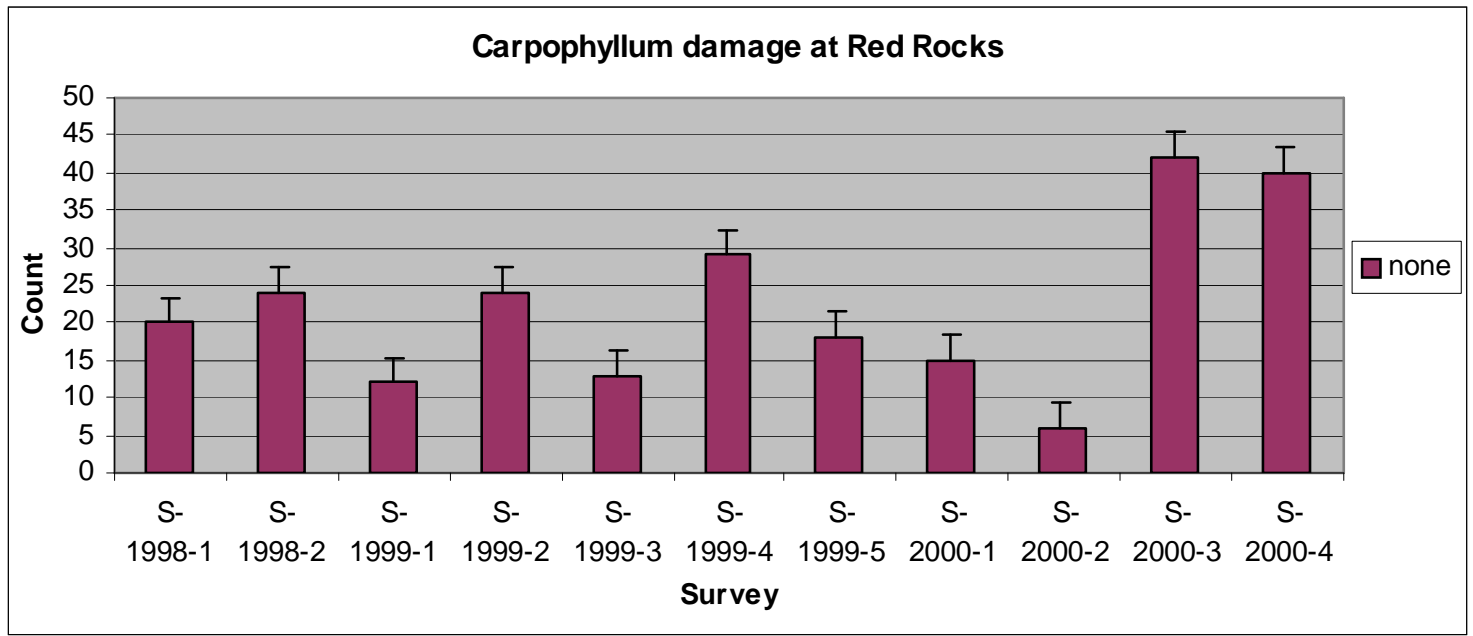

Fig. 6. Proportions of different types of Carpophyllum maschalocarpum damage at Sinclair Head at each survey period.

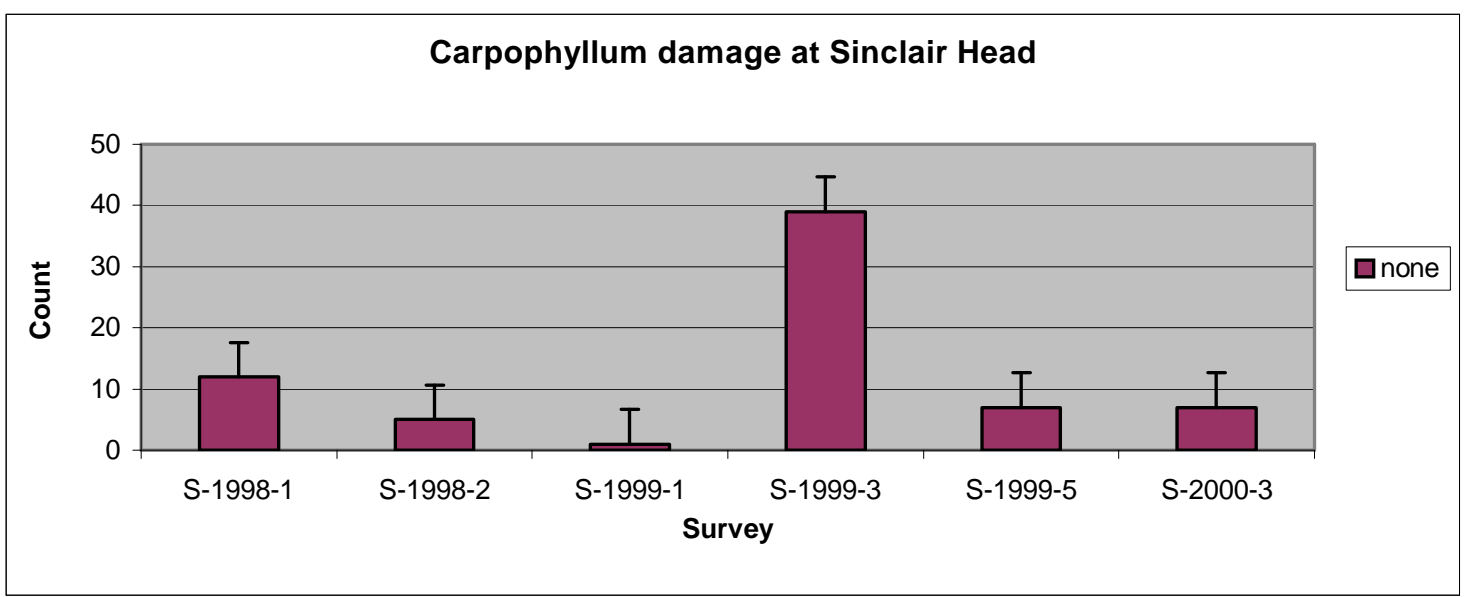


Fig. 7. Proportions of different types of Carpophyllum maschalocarpum damage at The Sirens at each survey period.

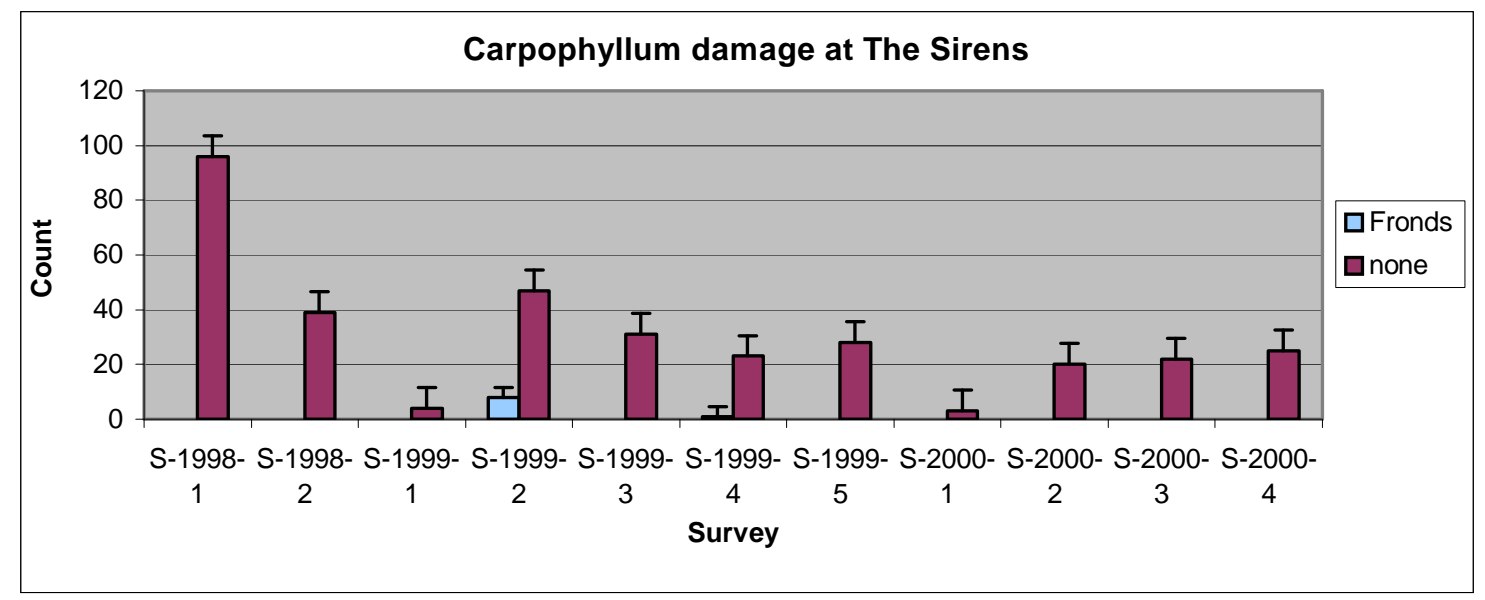

Fig. 8. Proportions of different types of Carpophyllum maschalocarpum damage at the Yungh Pen at each survey period.

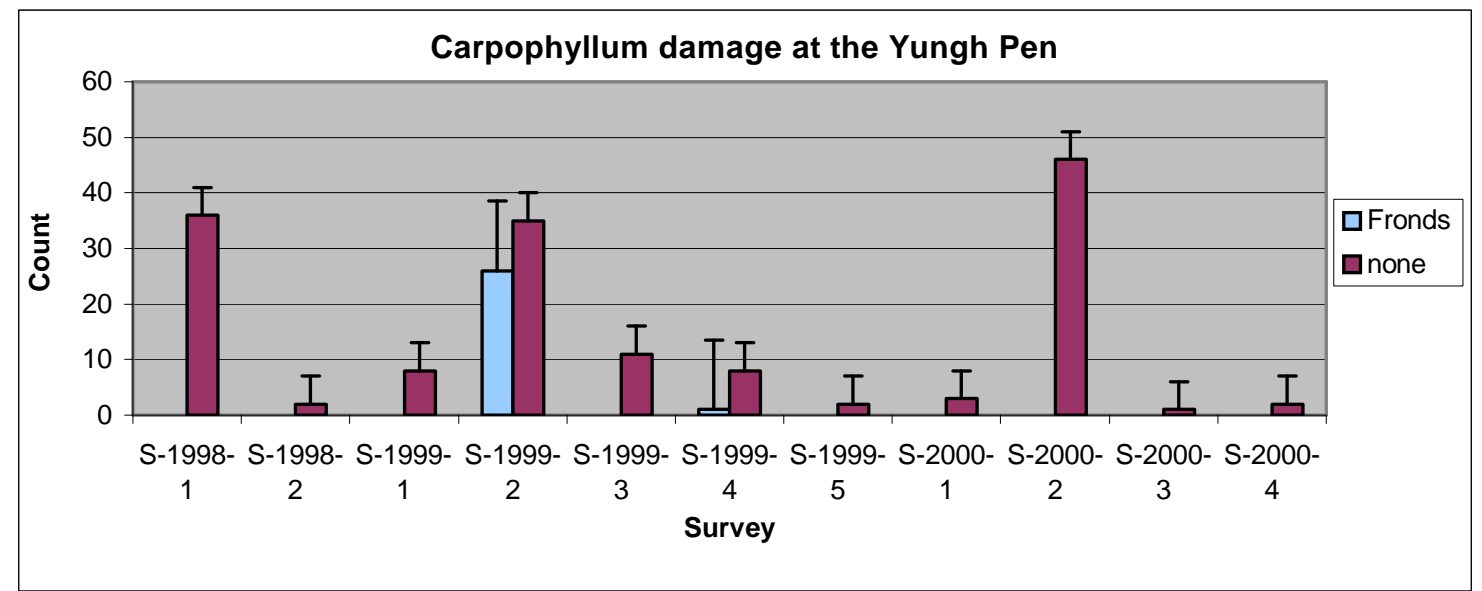


Fig. 9. Proportions of different types of Ecklonia radiata damage at Barretts Reef at each survey period.

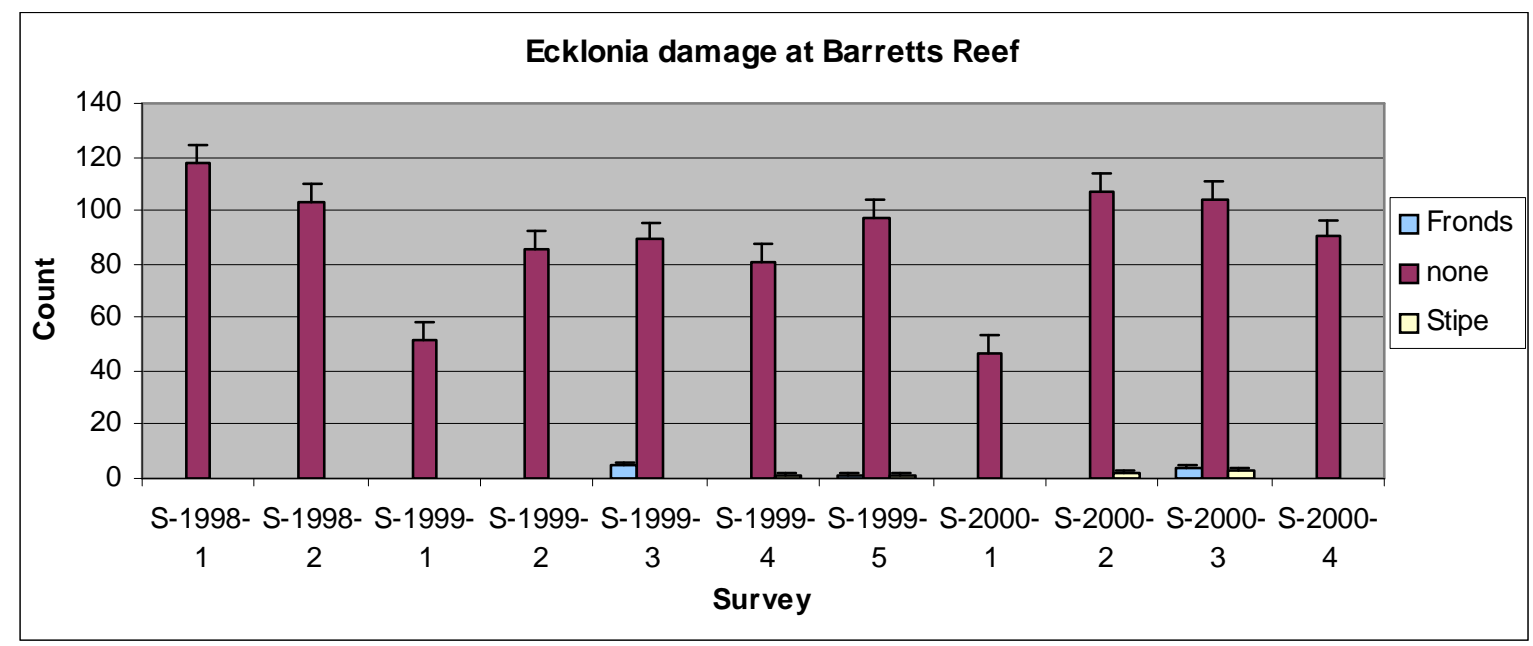

Fig.10. Proportions of different types of Ecklonia radiata damage at Breaker Bay at each survey period.

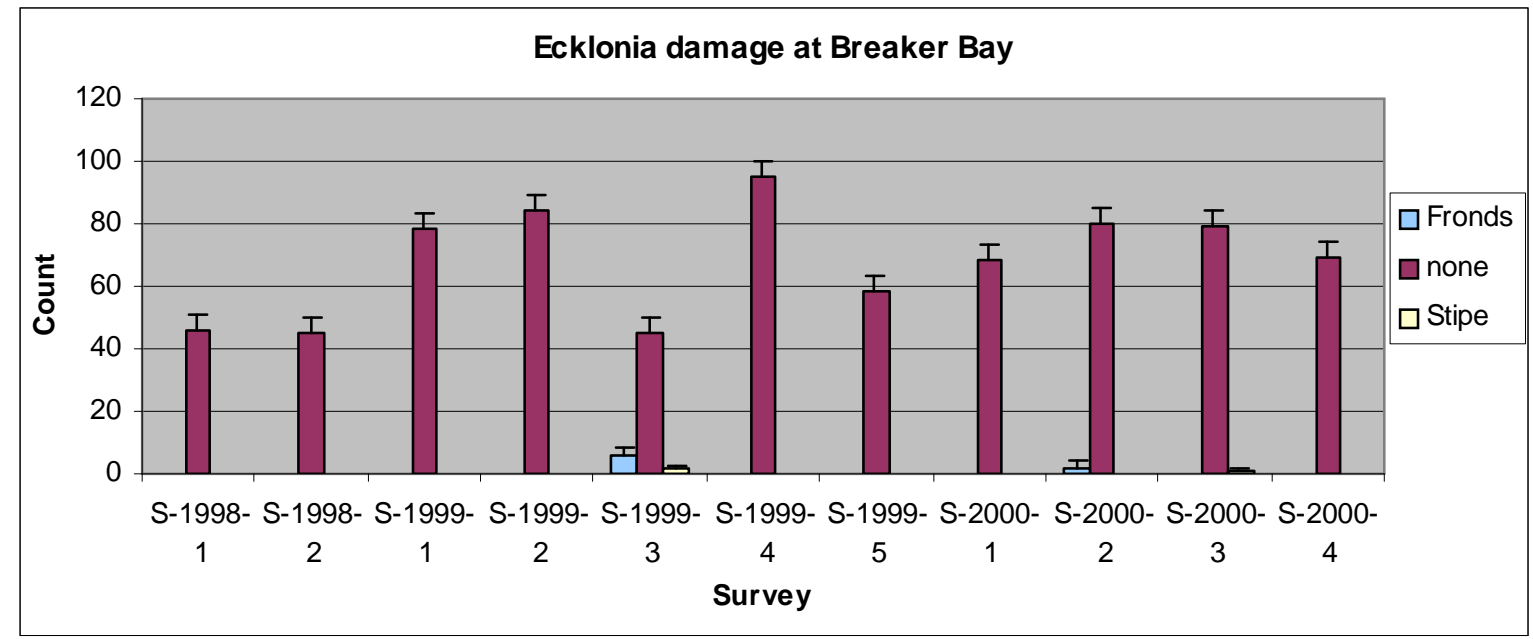


Fig. 11. Proportions of different types of Ecklonia radiata damage at Palmer Head at each survey period.

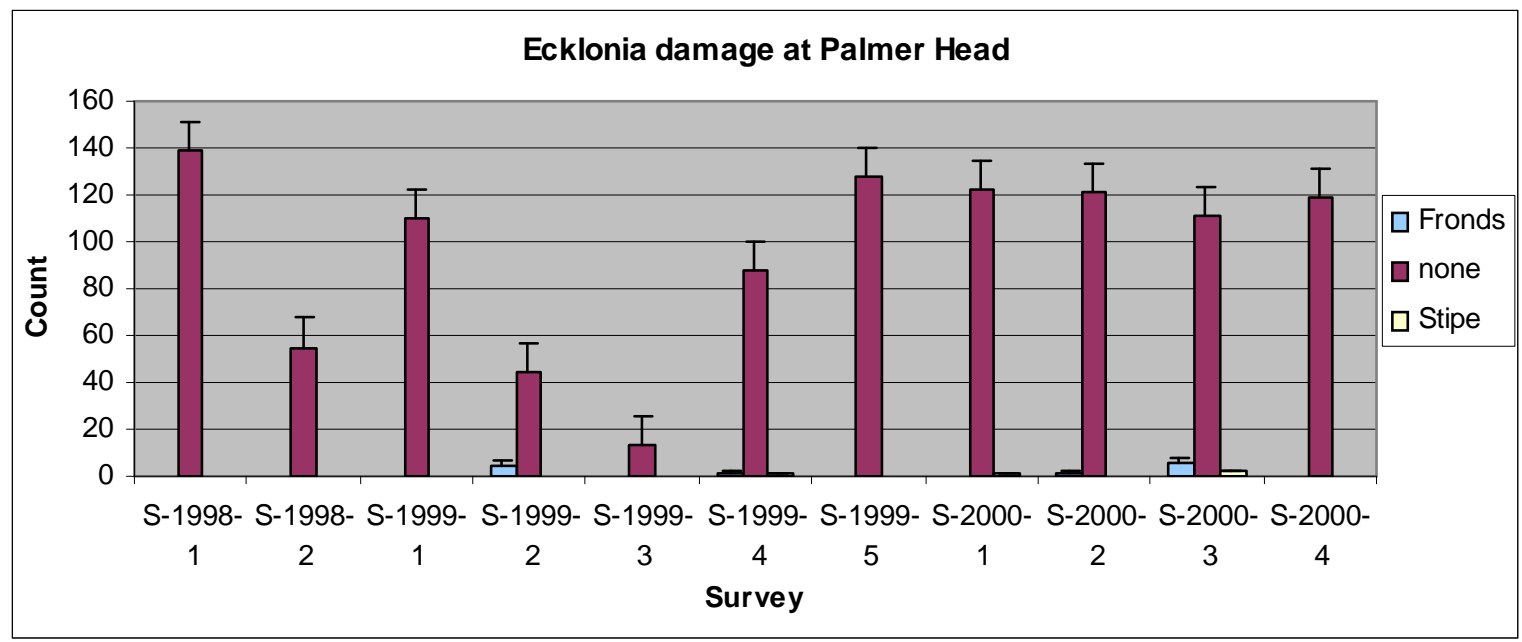

Fig. 12. Proportions of different types of Ecklonia radiata damage at Princess Bay at each survey period.

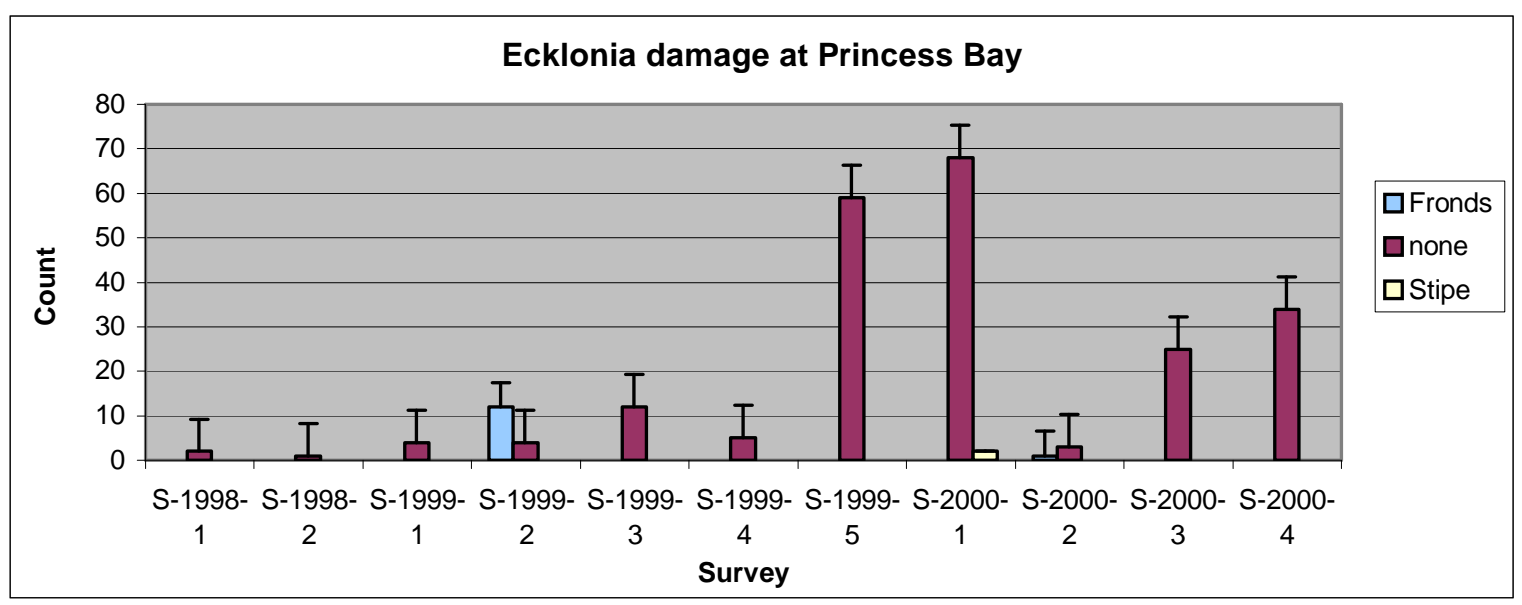


Fig. 13. Proportions of different types of Ecklonia radiata damage at Red Rocks at each survey period.

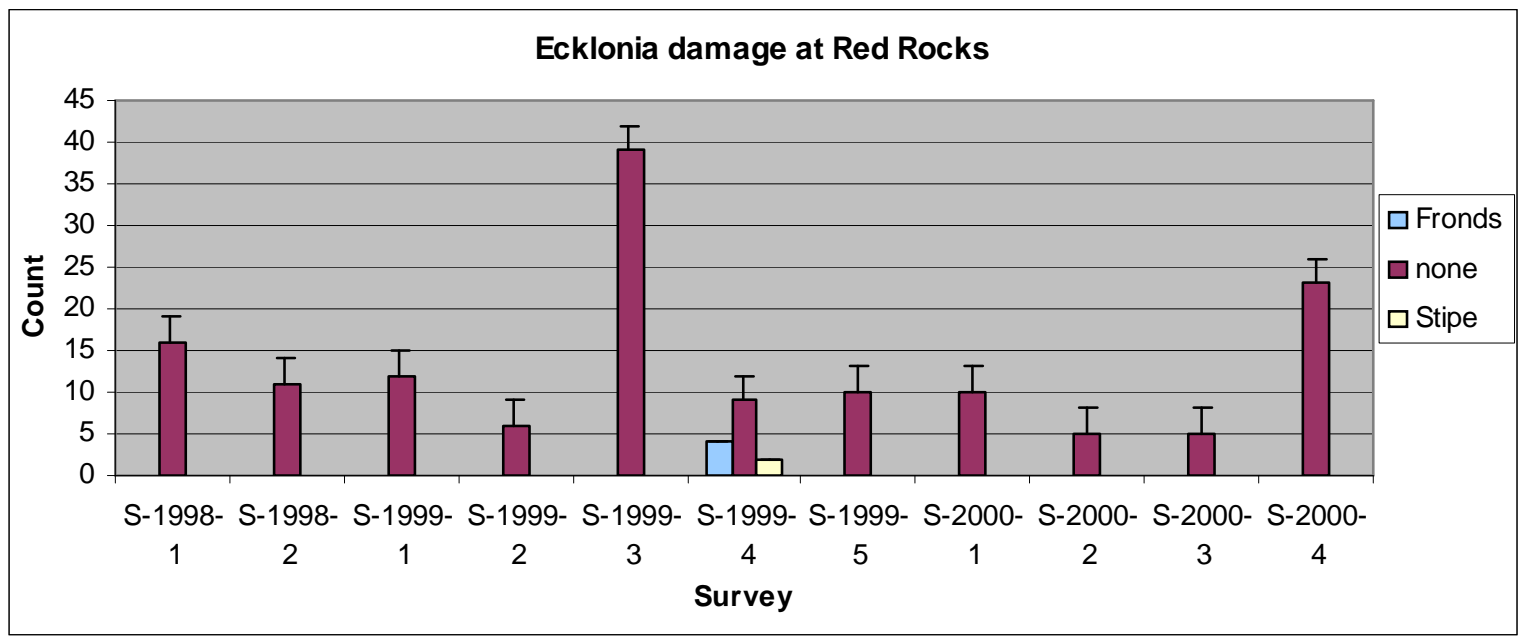

Fig. 14. Proportions of different types of Ecklonia radiata damage at Sinclair Head at each survey period.

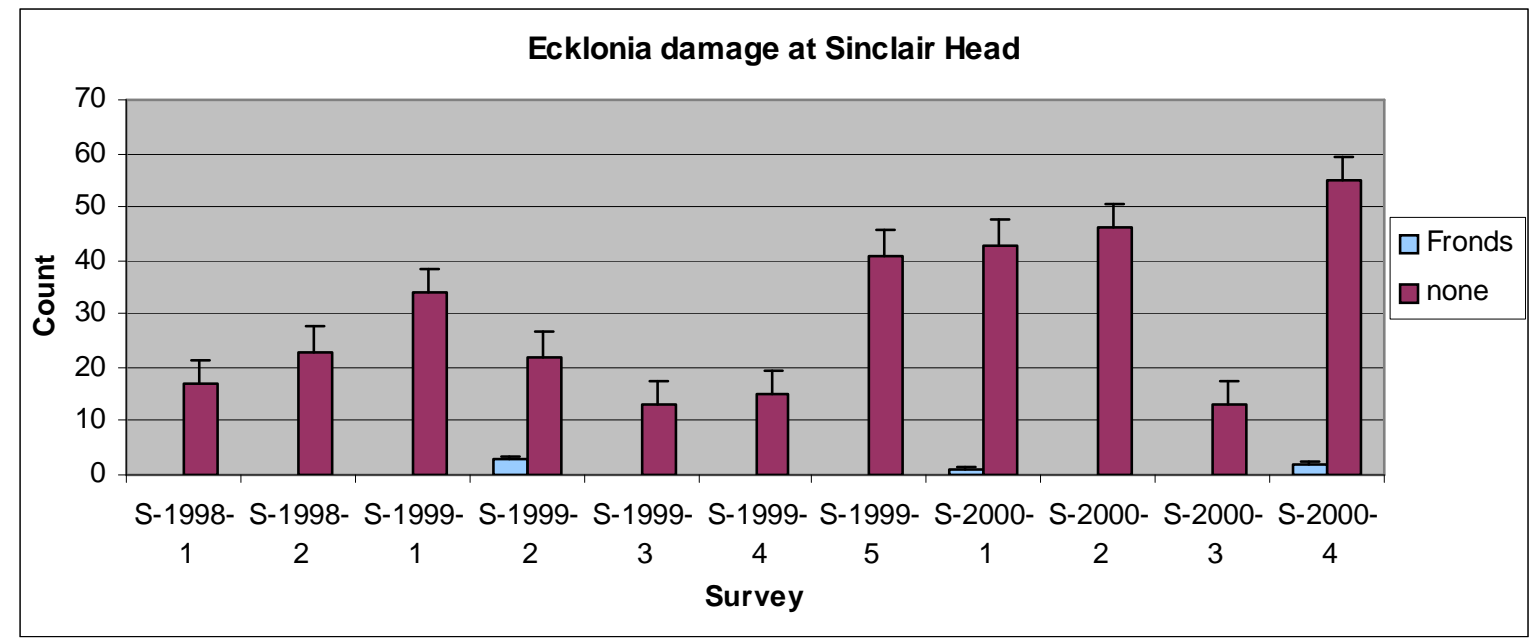


Fig. 15. Proportions of different types of Ecklonia radiata damage at The Sirens at each survey period.

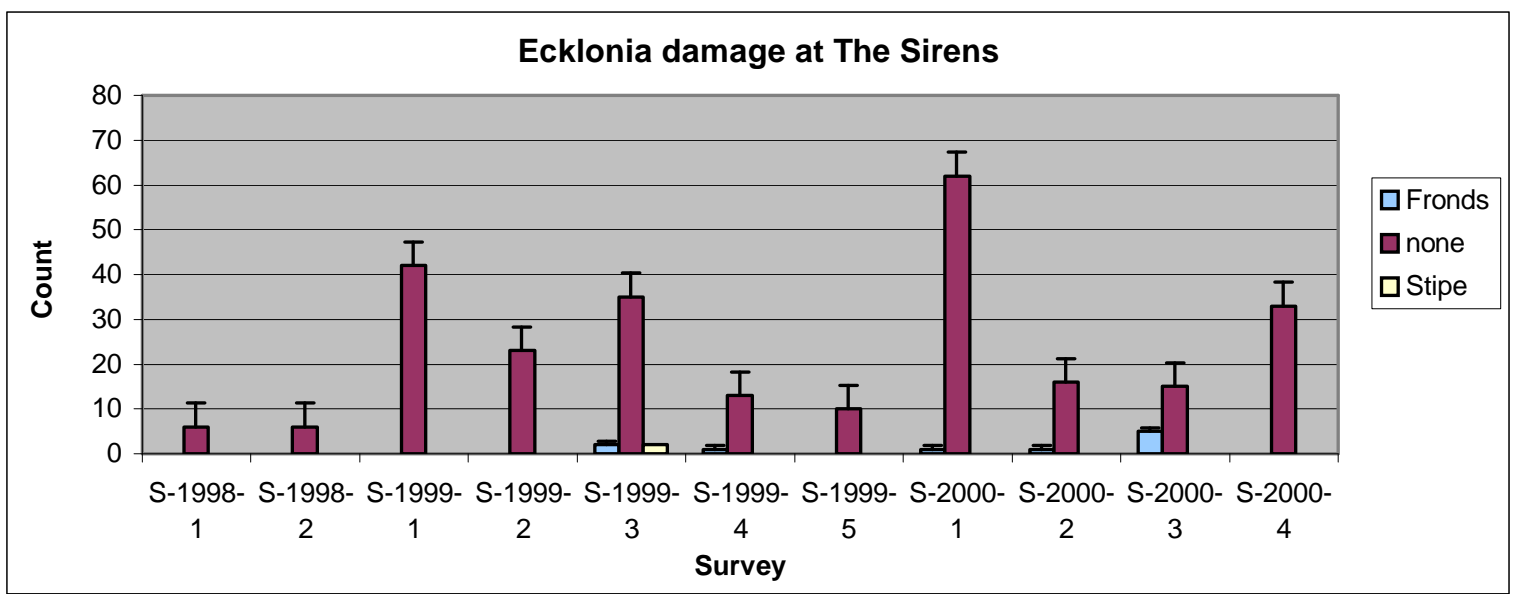

Fig. 16. Proportions of different types of Ecklonia radiata damage at the Yungh Pen at each survey period.

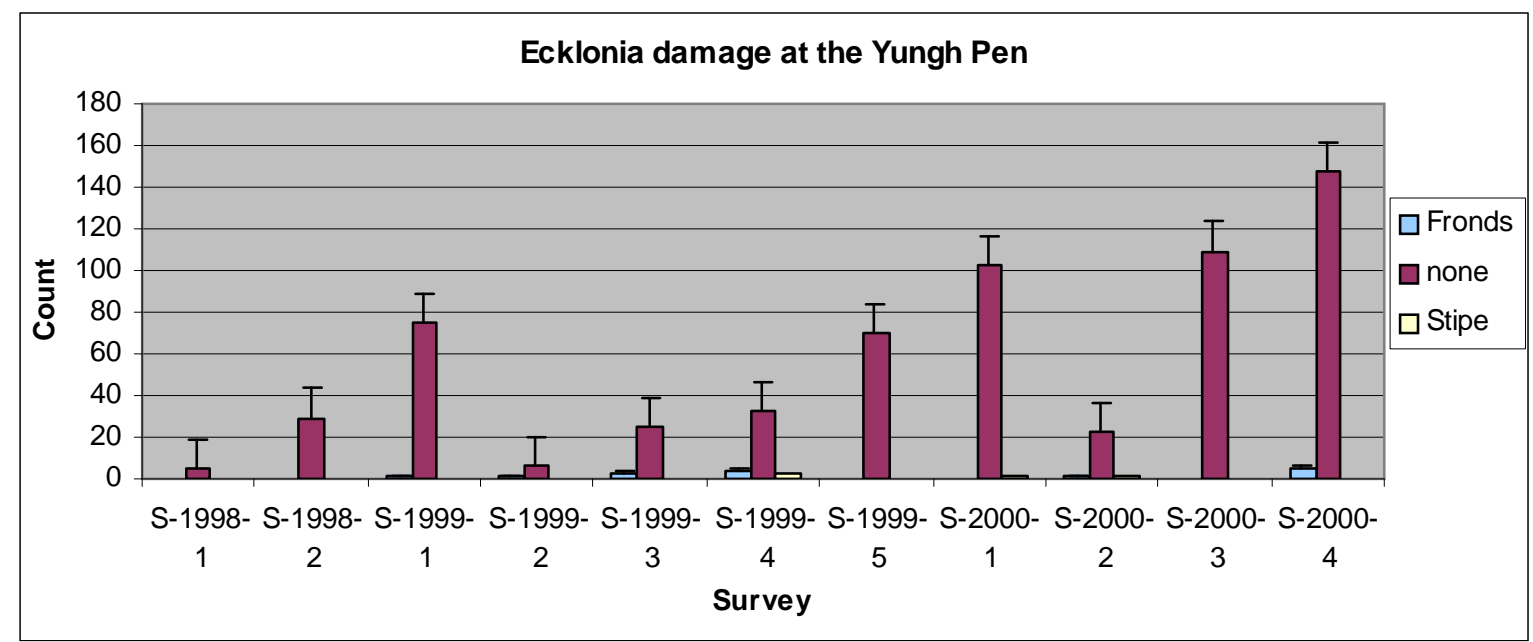


Fig. 17. Proportions of different types of Lessonia variegata damage at Barretts Reef at each survey period.

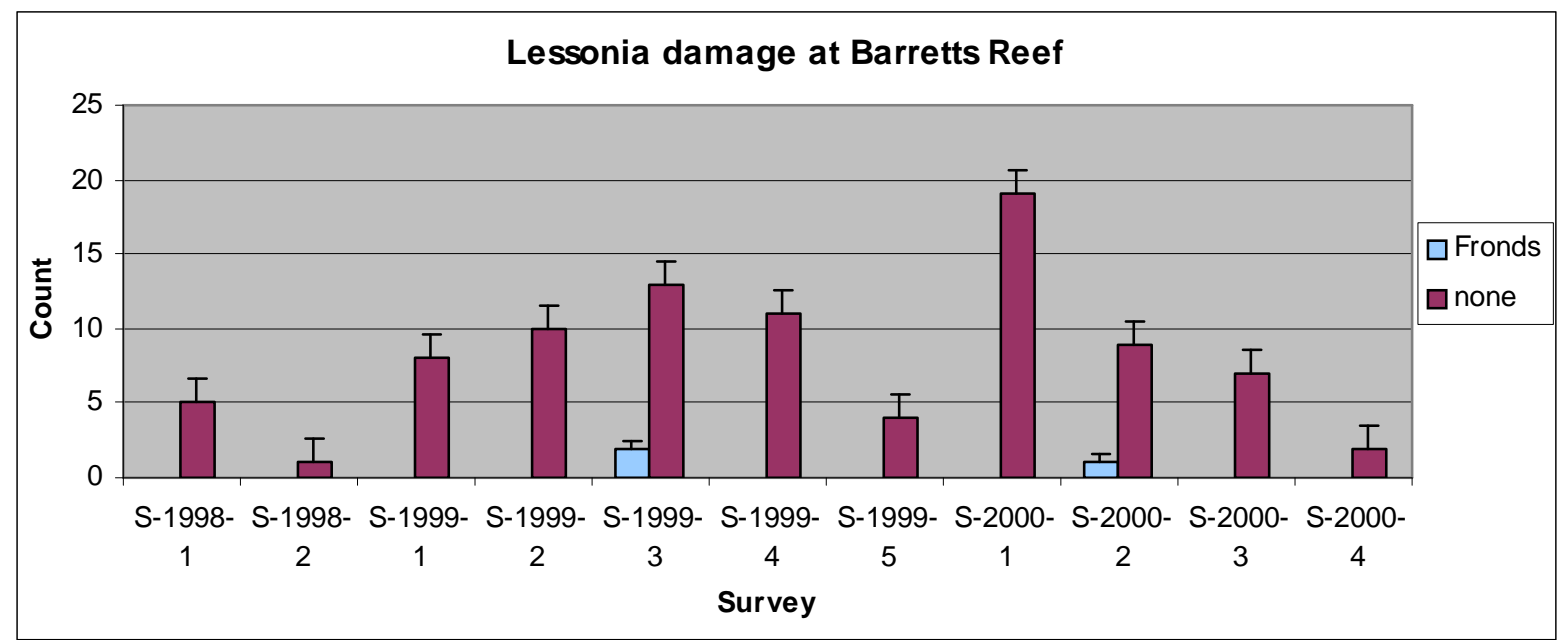

Fig. 18. Proportions of different types of Lessonia variegata damage at Breaker Bay at each survey period.

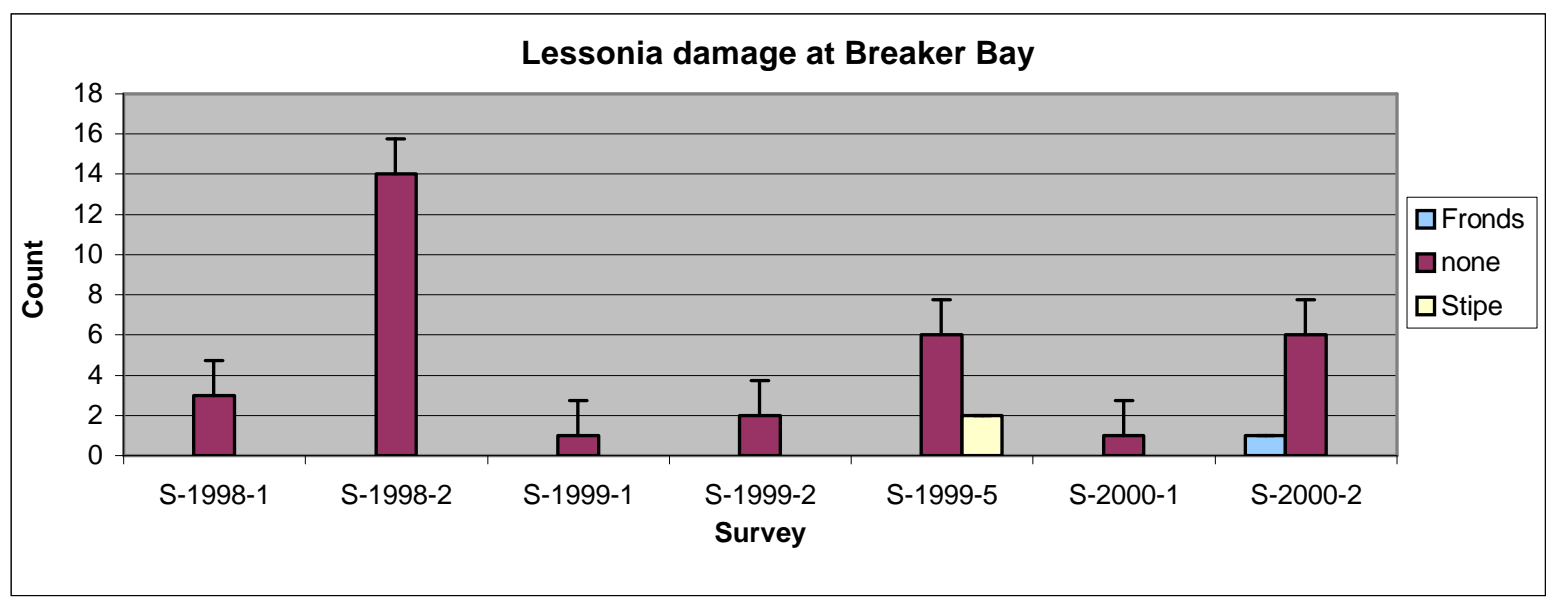


Fig. 19. Proportions of different types of Lessonia variegata damage at Barretts Reef at each survey period.

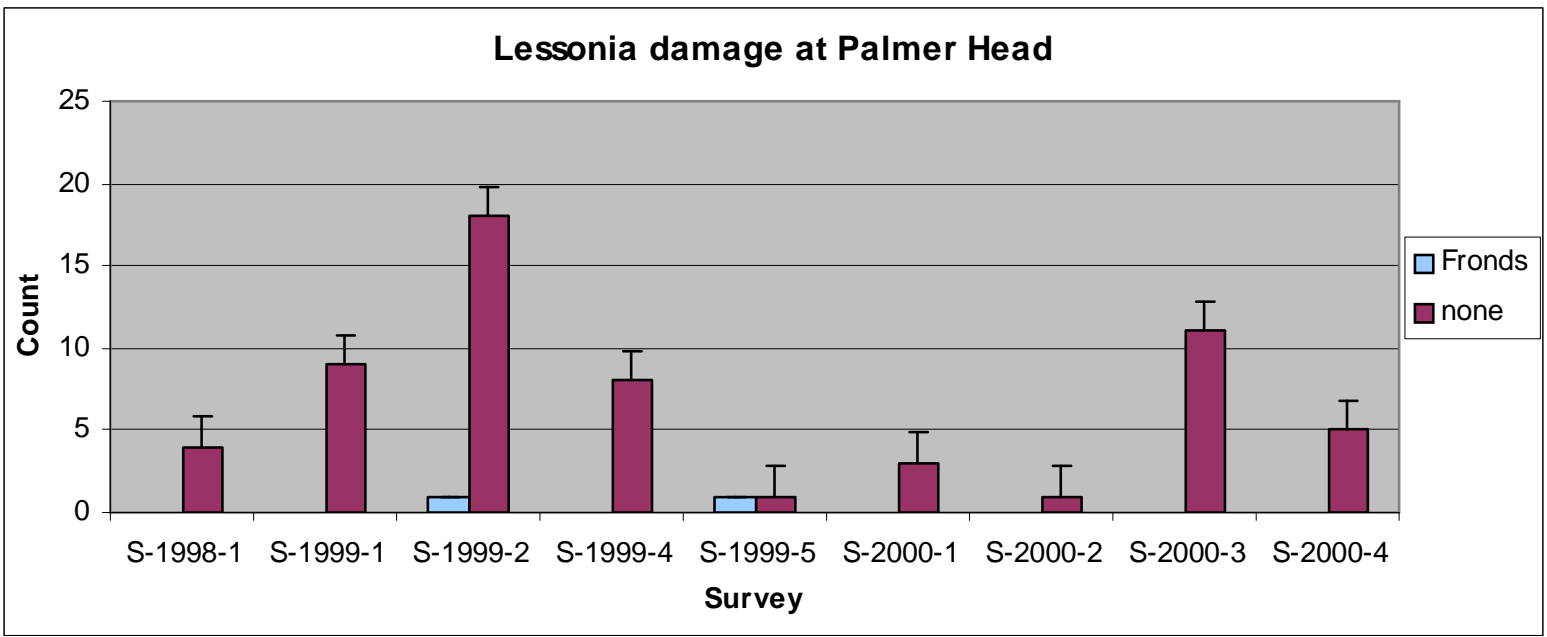

Fig. 20. Proportions of different types of Lessonia variegata damage at Princess Bay at each survey period.

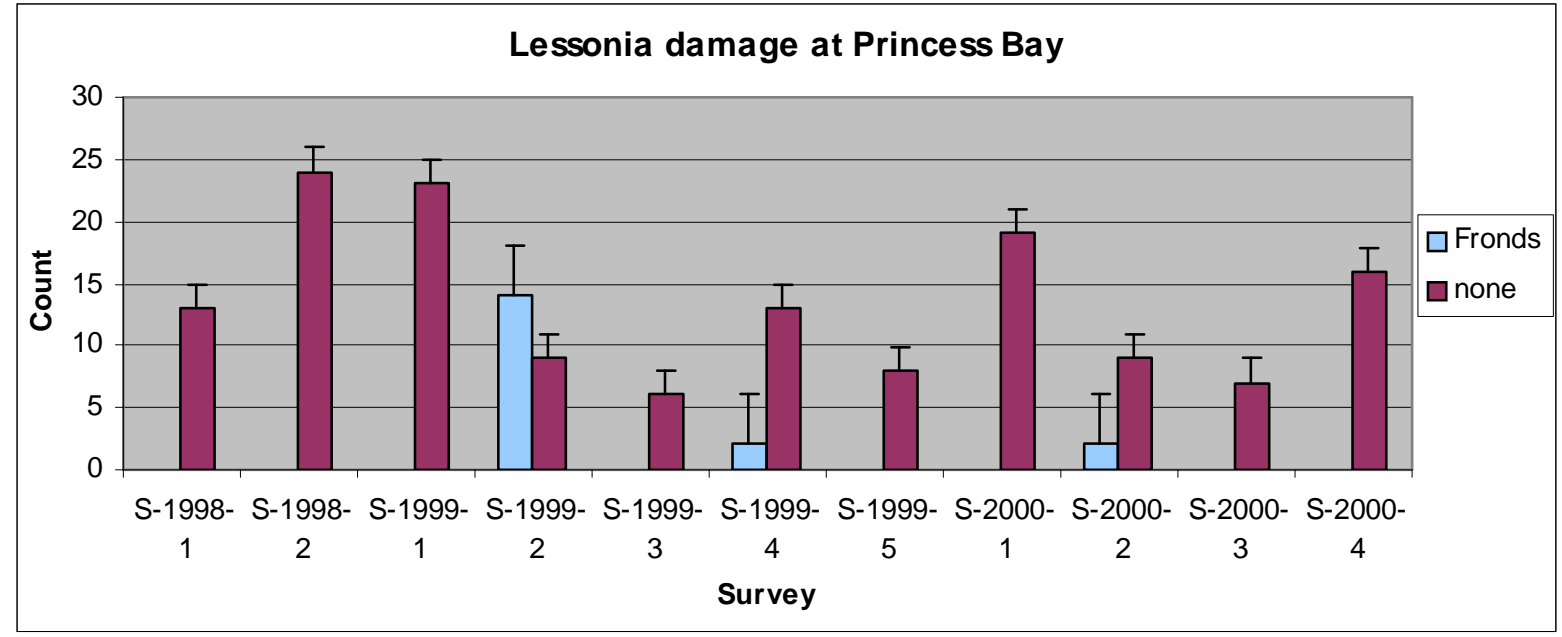


Fig. 21. Proportions of different types of Lessonia variegata damage at Red Rocks at each survey period.

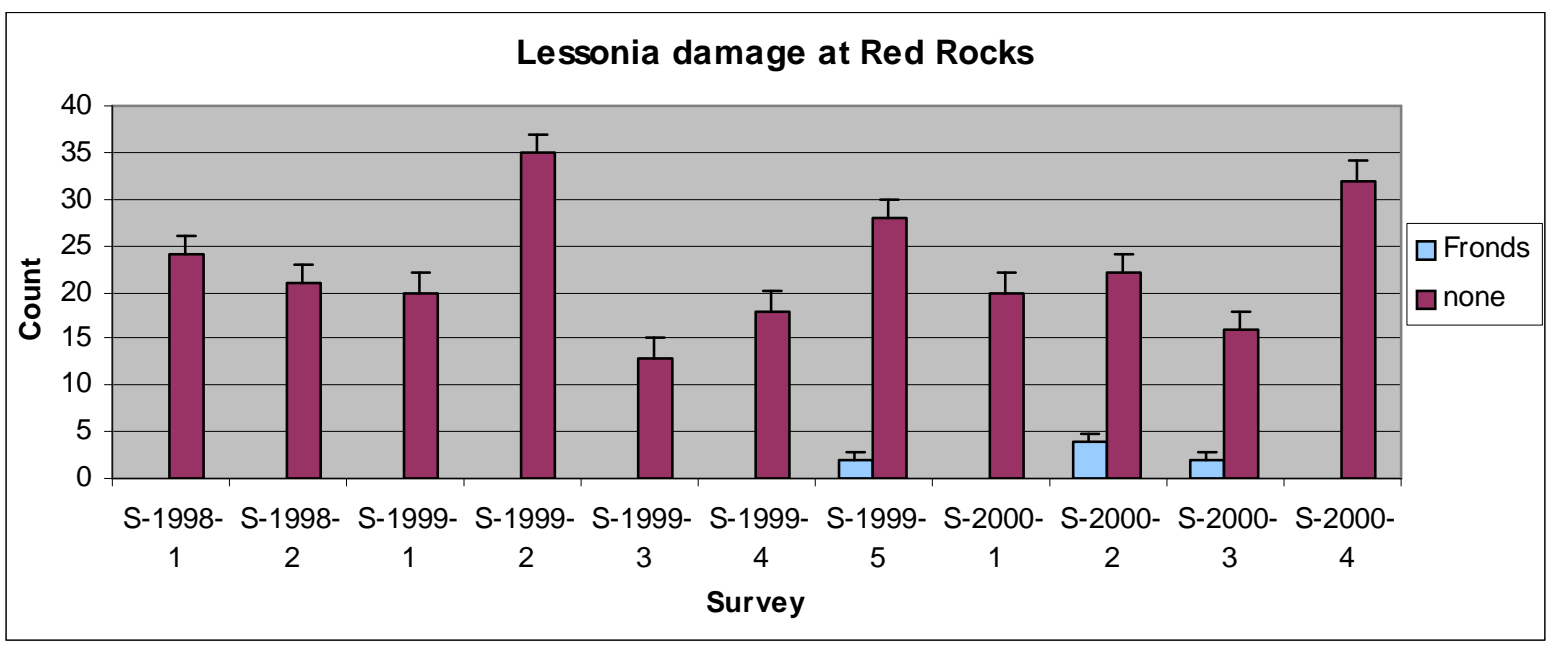

Fig. 22. Proportions of different types of Lessonia variegata damage at Sinclair Head at each survey period.

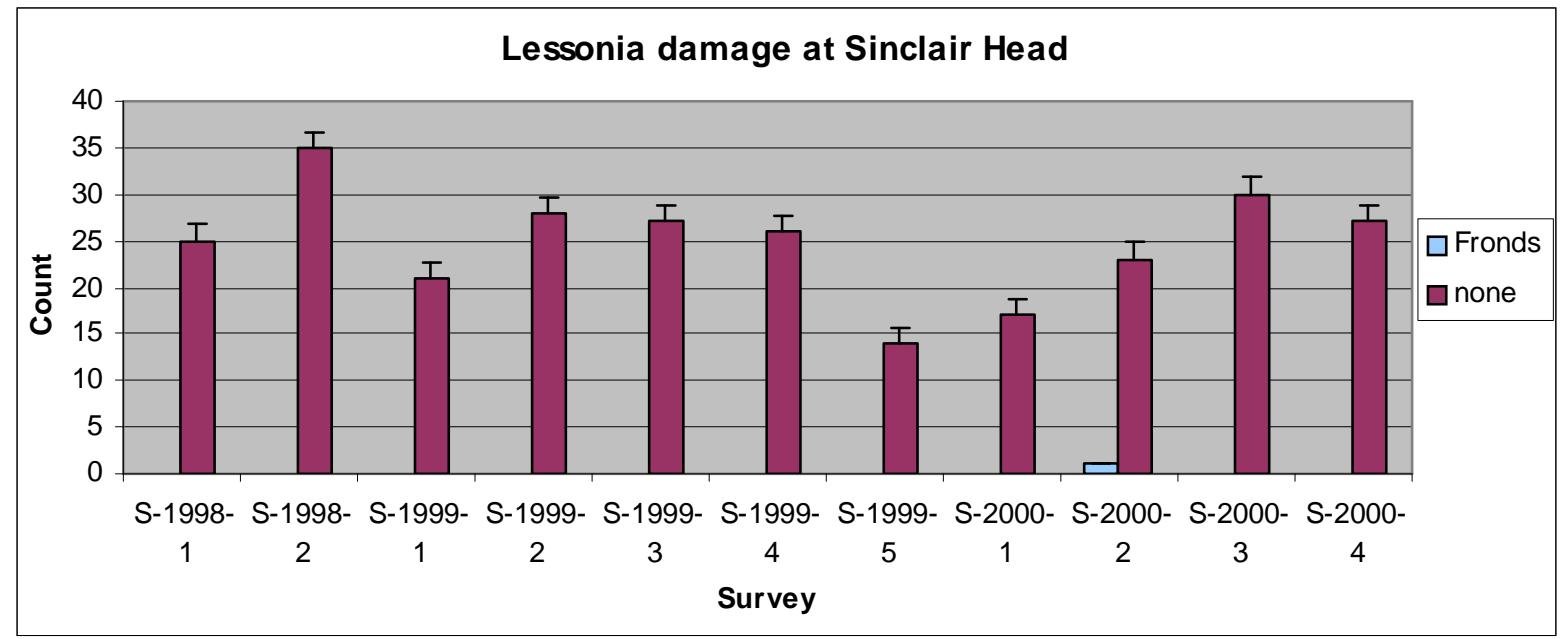


Fig. 23. Proportions of different types of Lessonia variegata damage at The Sirens at each survey period.

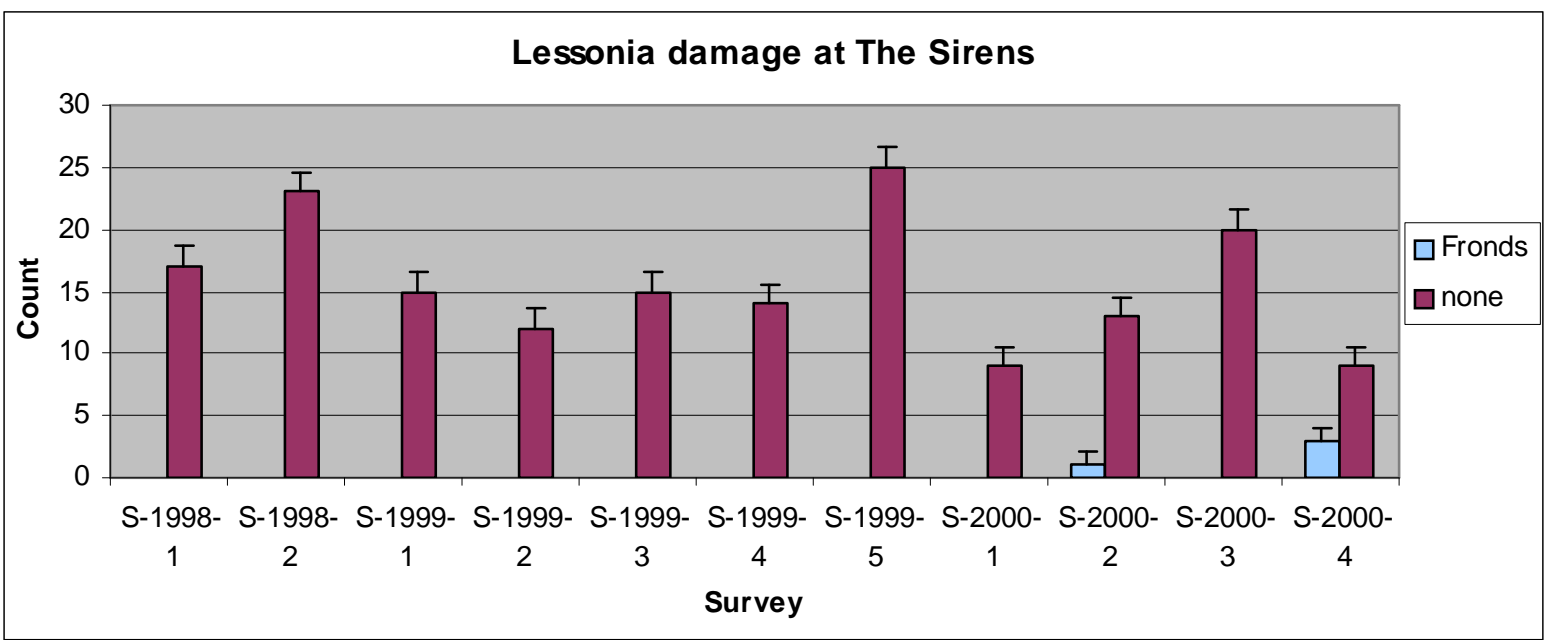

Fig. 24. Proportions of different types of Lessonia variegata damage at the Yungh Pen at each survey period.

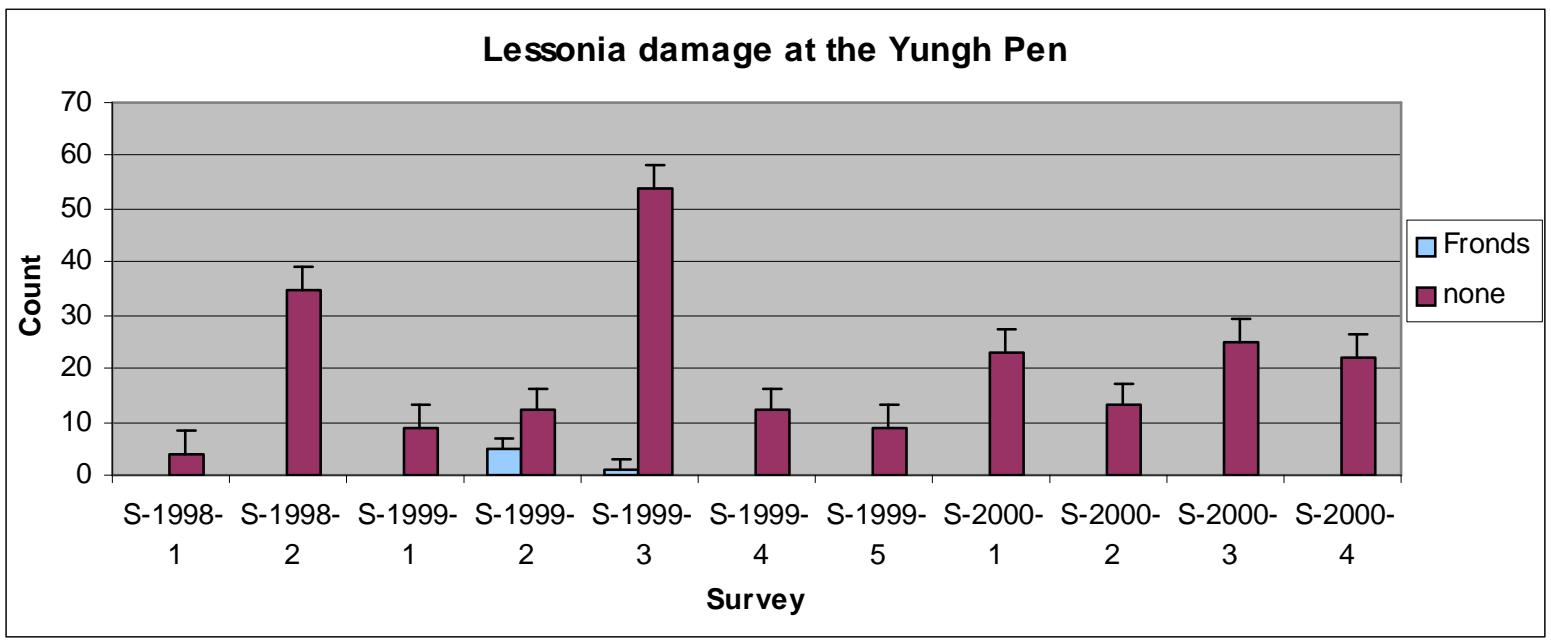




\section{APPENDIX TWO}

\section{Summary statistics}

Table 1: Average count $\left(\right.$ per $\mathrm{m}^{2}$ ) of each fish species at each site on the South Coast of Wellington at each site, with standard error (se).

\begin{tabular}{|c|c|c|c|c|c|c|c|c|}
\hline Species (av. per Sq m) & Barretts Reef & Breaker Bay & Palmer Head & Princess Bay & Red Rocks & Sinclair Head & The Sirens & Yungh Pen \\
\hline Spotty & 0.03911 & 0.06182 & 0.02820 & 0.01762 & 0.01228 & 0.00921 & 0.01576 & 0.01067 \\
\hline se & 0.01276 & 0.02228 & 0.00665 & 0.00404 & 0.00224 & 0.00198 & 0.00392 & 0.00217 \\
\hline Banded Wrasse & 0.01624 & 0.00582 & 0.00840 & 0.00602 & 0.00703 & 0.00840 & 0.00501 & 0.01013 \\
\hline se & 0.00391 & 0.00103 & 0.00156 & 0.00126 & 0.00102 & 0.00180 & 0.00072 & 0.00190 \\
\hline Blue cod & 0.00311 & 0.00190 & 0.00231 & 0.00597 & 0.00196 & 0.00648 & 0.00356 & 0.00216 \\
\hline se & 0.00133 & 0.00063 & 0.00077 & 0.00342 & 0.00033 & 0.00361 & 0.00058 & 0.00043 \\
\hline Blue moki & 0.00111 & 0.00365 & 0.00400 & 0.00190 & 0.00409 & 0.00227 & 0.00329 & 0.00286 \\
\hline se & 0.00022 & 0.00109 & 0.00225 & 0.00056 & 0.00070 & 0.00052 & 0.00068 & 0.00103 \\
\hline Butterfish & 0.00356 & 0.00193 & 0.00344 & 0.00853 & 0.00190 & 0.00454 & 0.00317 & 0.00792 \\
\hline se & 0.00106 & 0.00042 & 0.00072 & 0.00677 & 0.00041 & 0.00128 & 0.00102 & 0.00300 \\
\hline Butterfly Perch & 0.00178 & 0 & 0 & 0 & 0 & 0 & 0 & 0 \\
\hline se & 0 & 0 & 0 & 0 & 0 & 0 & 0 & 0 \\
\hline Copper Moki & 0 & 0.00089 & 0 & 0 & 0 & 0 & 0 & 0 \\
\hline se & 0 & 0 & 0 & 0 & 0 & 0 & 0 & 0 \\
\hline Girdled wrasse & 0.00089 & 0.00415 & 0.00489 & 0 & 0 & 0 & 0.00089 & 0.00533 \\
\hline se & 0 & 0.00165 & 0.00400 & 0 & 0 & 0 & 0 & 0.00444 \\
\hline Jack mackerel & 0 & 0 & 0 & 0 & 0.01067 & 0 & 0 & 0.11111 \\
\hline
\end{tabular}




\begin{tabular}{|c|c|c|c|c|c|c|c|c|}
\hline se & 0 & 0 & 0 & 0 & 0 & 0 & 0 & 0.06667 \\
\hline Kawhai & 0 & 0 & 0 & 0 & 0.04444 & 0 & 0 & 0 \\
\hline se & 0 & 0 & 0 & 0 & 0 & 0 & 0 & 0 \\
\hline Leatherjacket & 0.00089 & 0.00415 & 0 & 0.00133 & 0 & 0 & 0 & 0 \\
\hline se & 0 & 0.00180 & 0 & 0.00044 & 0 & 0 & 0 & 0 \\
\hline Marblefish & 0.00089 & 0 & 0.00119 & 0.00089 & 0.00089 & 0.00178 & 0.00089 & 0.00200 \\
\hline se & 0 & 0 & 0.00030 & 0 & 0 & 0.00051 & 0 & 0.00067 \\
\hline Maori Chief & 0 & 0 & 0 & 0 & 0.00089 & 0 & 0 & 0 \\
\hline se & 0 & 0 & 0 & 0 & 0 & 0 & 0 & 0 \\
\hline Parorae & 0 & 0 & 0 & 0.00178 & 0 & 0 & 0 & 0 \\
\hline se & 0 & 0 & 0 & 0 & 0 & 0 & 0 & 0 \\
\hline Pigfish & 0 & 0.00089 & 0 & 0 & 0 & 0 & 0 & 0 \\
\hline se & 0 & 0 & 0 & 0 & 0 & 0 & 0 & 0 \\
\hline Red Banded Perch & 0 & 0.00089 & 0.00089 & 0 & 0 & 0 & 0 & 0 \\
\hline se & 0 & 0 & 0 & 0 & 0 & 0 & 0 & 0 \\
\hline Red Cod & 0 & 0 & 0 & 0.00267 & 0 & 0.00089 & 0.00089 & 0 \\
\hline se & 0 & 0 & 0 & 0 & 0 & 0 & 0 & 0 \\
\hline Red Moki & 0.00178 & 0.00089 & 0.00244 & 0.00089 & 0.00107 & 0.00133 & 0.00122 & 0.00133 \\
\hline se & 0 & 0 & 0.00128 & 0 & 0.00018 & 0.00044 & 0.00016 & 0.00026 \\
\hline Scarlet Wrasse & 0.00356 & 0.00244 & 0.00178 & 0.00196 & 0.00343 & 0.00284 & 0.00222 & 0.00394 \\
\hline se & 0.00267 & 0.00065 & 0.00049 & 0.00033 & 0.00180 & 0.00065 & 0.00057 & 0.00102 \\
\hline Scorpionfish & 0.00178 & 0 & 0 & 0 & 0.00089 & 0 & 0 & 0 \\
\hline se & 0 & 0 & 0 & 0 & 0 & 0 & 0 & 0 \\
\hline Sweep & 0 & 0.00978 & 0.00622 & 0 & 0 & 0 & 0.01778 & 0.00711 \\
\hline
\end{tabular}




\begin{tabular}{|l|r|r|r|r|r|r|r|r|}
\hline se & 0 & 0 & 0.00267 & 0 & 0 & 0 & 0 & 0.00622 \\
\hline Tarakihi & 0.00089 & 0.01800 & 0.00178 & 0.00178 & 0.00178 & 0.00089 & 0.00133 & 0.00111 \\
\hline se & 0 & 0.01511 & 0 & 0 & 0.00063 & 0 & 0.00044 & 0.00022 \\
\hline Trevally & 0.00119 & 0.00244 & 0 & 0.00089 & 0.00089 & 0.00107 & 0.00444 & 0.03052 \\
\hline se & 0.00030 & 0.00128 & 0 & 0 & 0 & 0.00018 & 0.00161 & 0.02963 \\
\hline Yellow eyed mullet & 0 & 0.17778 & 0 & 0 & 0 & 0 & 0 & 0 \\
\hline se & 0 & 0 & 0 & 0 & 0 & 0 & 0 \\
\hline
\end{tabular}

Table 2: Average size $(\mathrm{cm})$ of each fish species for which size was recorded at each site on the South Coast of Wellington, with standard error (se).

\begin{tabular}{|c|c|c|c|c|c|c|c|c|}
\hline Species (av.size (cm)) & Barretts Reef & Breaker Bay & Palmer Head & Princess Bay & Red Rocks & Sinclair Head & The Sirens & Yungh Pen \\
\hline Banded wrasse & 23.53116 & 26.48128 & 24.66239 & 22.82850 & 19.50018 & 22.46434 & 20.34697 & 22.31432 \\
\hline se & 1.58523 & 1.60853 & 1.49148 & 2.18640 & 2.14602 & 2.61865 & 1.22961 & 2.36076 \\
\hline Blue cod & 14.50000 & 24.26190 & 24.26667 & 28.34975 & 26.50000 & 23.38479 & 22.52708 & 23.34524 \\
\hline se & 4.50000 & 1.36270 & 2.87885 & 3.08859 & 4.38178 & 4.50898 & 1.31476 & 3.32053 \\
\hline Blue moki & 28.25000 & 23.48291 & 21.25000 & 26.75000 & 27.16381 & 22.67222 & 23.25488 & 24.25926 \\
\hline se & 6.23665 & 2.81744 & 1.25000 & 4.24159 & 2.08201 & 3.59213 & 1.34531 & 1.40748 \\
\hline Butterfish & 29.49603 & 28.04167 & 27.66161 & 26.98500 & 20.60714 & 19.87879 & 30.18622 & 27.46510 \\
\hline se & 3.94183 & 3.60001 & 2.98614 & 3.54807 & 3.33079 & 1.98292 & 10.34861 & 2.70262 \\
\hline Red moki & 42.50000 & 17.50000 & 20.10714 & 20 & 25.30000 & 25.33333 & 20.37500 & 23.12500 \\
\hline se & 0 & 2.50000 & 3.52029 & 5.00000 & 4.38064 & 5.09357 & 2.43624 & 5.89624 \\
\hline Tarakihi & 27.50000 & 19.93662 & 12.50000 & 14.00000 & 23.81250 & 10 & 22.50000 & 22.50000 \\
\hline se & 2.50000 & 0.76562 & 0 & 0 & 4.49001 & 5.00000 & 7.50000 & 9.46485 \\
\hline
\end{tabular}




\begin{tabular}{|l|r|r|r|r|r|r|r|r|}
\hline Trevally & 9.33333 & 15.39286 & 0 & 20 & 12.00000 & 17.60000 & 18.25500 & 21.68317 \\
\hline se & 1.76383 & 1.67248 & 0 & 0 & 0 & 1.93907 & 3.13987 & 4.40650 \\
\hline
\end{tabular}

Table 3: Average count (per $\mathrm{m}^{2}$ ) of each fish species at each site at the Kapiti Marine Reserve at each site, with standard error (se).

\begin{tabular}{|l|r|r|r|r|}
\hline Species (av. per sq m) & Arapawaiti Point & Kaiwharawhara Point & Onepoto Point & Tokahaki Point \\
\hline Banded Wrasse & 0.04652 & 0.00926 & 0.00862 & 0.00615 \\
\hline se & 0.00757 & 0.00160 & 0.00208 & 0.00154 \\
\hline Blue Cod & 0.05711 & 0.00504 & 0.01385 & 0.01662 \\
\hline se & 0.01805 & 0.00141 & 0.00336 & 0.00605 \\
\hline Blue Moki & 0.00329 & 0.00244 & 0.00391 & 0.00222 \\
\hline se & 0.00135 & 0.00076 & 0.00118 & 0.00133 \\
\hline Butterfish & 0.00889 & 0.00257 & 0.01446 & 0.00773 \\
\hline se & 0.00205 & 0.00056 & 0.00473 & 0.00251 \\
\hline Butterfly Perch & 0.00089 & 0.00504 & 0.02726 & 0.00326 \\
\hline se & 0 & 0.00258 & 0.00941 & 0.00194 \\
\hline Common Roughy & 0 & 0.00089 & 0 & 0 \\
\hline se & 0 & 0 & 0 & 0 \\
\hline Girdled Wrasse & 0.00089 & 0.00133 & 0.00119 & 0.00267 \\
\hline se & 0 & 0.00044 & 0.00030 & 0.00178 \\
\hline Jack Mackerel & 0.22222 & 0.17778 & 0.00356 & 0.14222 \\
\hline se & 0.13333 & 0 & 0 & 0.05333 \\
\hline Kawhai & 0.00089 & 0 & 0.09067 & 0.01422 \\
\hline
\end{tabular}




\begin{tabular}{|c|c|c|c|c|}
\hline se & 0 & 0 & 0.08711 & 0.01244 \\
\hline Kingfish & 0.00089 & 0 & 0 & 0.00089 \\
\hline se & 0 & 0 & 0 & 0 \\
\hline Koheru & 0.01778 & 0 & 0 & 0 \\
\hline se & 0 & 0 & 0 & 0 \\
\hline Leatherjacket & 0.03251 & 0.02104 & 0.01556 & 0.00571 \\
\hline se & 0.02470 & 0.01475 & 0.01092 & 0.00350 \\
\hline Mao mao & 0 & 0 & 0.00533 & 0 \\
\hline se & 0 & 0 & 0 & 0 \\
\hline Marblefish & 0.00302 & 0.00244 & 0.00165 & 0.00089 \\
\hline se & 0.00077 & 0.00050 & 0.00041 & 0 \\
\hline Maori Chief & 0 & 0.00089 & 0.00089 & 0 \\
\hline se & 0 & 0 & 0 & 0 \\
\hline Red Banded Perch & 0 & 0 & 0.00089 & 0 \\
\hline se & 0 & 0 & 0 & 0 \\
\hline Red Cod & 0 & 0 & 0.00089 & 0 \\
\hline se & 0 & 0 & 0 & 0 \\
\hline Red Moki & 0.00302 & 0.00211 & 0.00218 & 0.00216 \\
\hline se & 0.00053 & 0.00056 & 0.00037 & 0.00043 \\
\hline Scarlet Wrasse & 0.02667 & 0.00241 & 0.00378 & 0.00474 \\
\hline se & 0.00620 & 0.00072 & 0.00114 & 0.00153 \\
\hline Spotty & 0.08644 & 0.03289 & 0.01919 & 0.10741 \\
\hline se & 0.02373 & 0.01009 & 0.00397 & 0.06096 \\
\hline Sweep & 0.00489 & 0.10667 & 0.00444 & 0.00689 \\
\hline
\end{tabular}




\begin{tabular}{|c|c|c|c|c|}
\hline se & 0.00222 & 0 & 0 & 0.00236 \\
\hline Tarakihi & 0.00356 & 0 & 0.00747 & 0 \\
\hline se & 0.00105 & 0 & 0.00409 & 0 \\
\hline Telscope Fish & 0.03000 & 0 & 0.00622 & 0 \\
\hline se & 0.00493 & 0 & 0 & 0 \\
\hline Trevally & 0.00089 & 0.00178 & 0.00267 & 0.00133 \\
\hline se & 0 & 0 & 0.00178 & 0.00044 \\
\hline Yellow eyed mullett & 0.02667 & 0 & 0 & 0 \\
\hline se & 0 & 0 & 0 & 0 \\
\hline
\end{tabular}

Table 4: Average size (cm) of each fish species for which size was recorded at each site at Kapiti Marine Reserve, with standard error (se).

\begin{tabular}{|l|r|r|r|r|}
\hline Species (av. size (cm)) & Arapawaiti Point & Kaiwharawhara Point & Onepoto Point & Tokahaki Point \\
\hline Banded wrasse & 23.51475 & 20.15998 & 20.25865 & 20.40682 \\
\hline se & 0.74781 & 0.99082 & 1.55678 & 1.75412 \\
\hline Blue cod & 22.51325 & 22.01515 & 26.64650 & 23.93269 \\
\hline se & 0.53160 & 1.56270 & 1.58941 & 1.70053 \\
\hline Blue moki & 34.44137 & 24.95833 & 33.88889 & 12.50000 \\
\hline se & 3.49701 & 3.27050 & 4.04069 & 2.50000 \\
\hline Butterfish & 31.72559 & 24.40741 & 30.06195 & 20.50672 \\
\hline se & 3.16699 & 1.72633 & 2.76330 & 1.80371 \\
\hline Red moki & 27.25595 & 28.58333 & 33.30303 & 30.48810 \\
\hline se & 2.86370 & 4.94594 & 3.36056 & 5.22700 \\
\hline
\end{tabular}




\begin{tabular}{|c|c|c|c|c|}
\hline Tarakihi & 21.17188 & 0 & 26.37143 & 0 \\
\hline se & 1.67221 & 0 & 2.31658 & 0 \\
\hline Trevally & 30 & 45.00000 & 36.66667 & 25.75000 \\
\hline se & 0 & 0 & 14.81366 & 4.25000 \\
\hline
\end{tabular}

Table 5: Average count $\left(\right.$ per $\mathrm{m}^{2}$ ) of each invertebrate species at each site on the Wellington South Coast, with standard error (se).

\begin{tabular}{|l|r|r|r|r|r|r|r|r|}
\hline Species (av. count per Sq m) & Barretts Reef & Breaker Bay & Palmer Head & Princess Bay & Red Rocks & Sinclair Head & The Sirens & Yungh Pen \\
\hline Black Foot Paua & 0.16697 & 0.03444 & 0.13364 & 0.07788 & 0.02750 & 0.02433 & 0.08133 & 0.03500 \\
\hline se & 0.03351 & 0.00991 & 0.03441 & 0.01990 & 0.00570 & 0.01162 & 0.02437 & 0.00951 \\
\hline Rock Lobster & 0.00714 & 0.00500 & 0.02238 & 0.00333 & 0.01067 & 0.01500 & 0.00667 & 0.00556 \\
\hline se & 0.00381 & 0.00167 & 0.00637 & 0 & 0.00476 & 0.00500 & 0 & 0.00222 \\
\hline Kina & 0.18364 & 0.03121 & 0.09758 & 0.03367 & 0.02208 & 0.02167 & 0.04667 & 0.05788 \\
\hline se & 0.04049 & 0.00793 & 0.02723 & 0.00759 & 0.00531 & 0.00660 & 0.02996 & 0.01330 \\
\hline Yellow Foot Paua & 0.03242 & 0.04667 & 0.02400 & 0.05633 & 0.01533 & 0.01733 & 0.05700 & 0.02133 \\
\hline se & 0.00551 & 0.01902 & 0.00711 & 0.01553 & 0.00469 & 0.00289 & 0.01250 & 0.00797 \\
\hline
\end{tabular}


Table 6: Average size $(\mathrm{cm})$ of each invertebrate species for which size was recorded at each site on the Wellington South Coast, with standard error (se).

\begin{tabular}{|l|r|r|r|r|r|r|r|r|}
\hline Species (av. size (cm)) & Barretts Reef & Breaker Bay & Palmer Head & Princess Bay & Red Rocks & Sinclair Head & The Sirens & Yungh Pen \\
\hline Black foot paua & 14.03948 & 12.48724 & 14.78588 & 13.20195 & 14.59678 & 14.61749 & 11.32943 & 12.23929 \\
\hline se & 0.28749 & 0.77340 & 0.36541 & 0.40101 & 1.16447 & 0.94602 & 1.36376 & 1.17842 \\
\hline Kina & 11.22716 & 10.48243 & 12.76936 & 10.18259 & 11.55908 & 12.59712 & 11.04827 & 11.53591 \\
\hline se & 0.39359 & 0.37516 & 0.44207 & 0.48427 & 0.86107 & 0.61823 & 0.85334 & 0.56544 \\
\hline Yellow foot paua & 8.08809 & 6.28998 & 7.47176 & 7.21583 & 7.51292 & 8.17697 & 7.89027 & 8.14859 \\
\hline se & 0.63903 & 0.64434 & 0.41538 & 0.20111 & 0.50866 & 0.32127 & 0.32962 & 0.37642 \\
\hline
\end{tabular}

Table 7: Average count $\left(\right.$ per $\mathrm{m}^{2}$ ) of each invertebrate species at each site at Kapiti Marine Reserve, with standard error (se).

\begin{tabular}{|l|r|r|r|r|}
\hline Species (av. count per sq m) & Arapawaiti Point & Kaiwharawhara Point & Onepoto Point & Tokahaki Point \\
\hline Black Foot Paua & 0.02833 & 0.04222 & 0.00857 & 0.08889 \\
\hline se & 0.00322 & 0.02778 & 0.00228 & 0.02852 \\
\hline Rock Lobster & 0.00333 & 0.02444 & 0.01333 & 0.08000 \\
\hline se & 0 & 0.01947 & 0.00504 & 0 \\
\hline Kina & 0.22222 & 0.28061 & 0.03606 & 0.06333 \\
\hline se & 0.04613 & 0.13997 & 0.00616 & 0.01772 \\
\hline Yellow Foot Paua & 0.00875 & 0.00417 & 0.00571 & 0.01303 \\
\hline se & 0.00199 & 0.00083 & 0.00188 & 0.00457 \\
\hline
\end{tabular}


Table 8: Average size $(\mathrm{cm})$ of each invertebrate species for which size was recorded at each site at Kapiti Marine Reserve, with standard error (se).

\begin{tabular}{|l|r|r|r|r|}
\hline \multicolumn{1}{|c|}{ Species (av.size (cm)) } & Arapawaiti Point & Kaiwharawhara Point & Onepoto Point & Tokahaki Point \\
\hline Black foot paua & 12.88146 & 12.46362 & 11.72619 & 12.24166 \\
\hline se & 0.46380 & 0.83785 & 0.55952 & 0.46887 \\
\hline Kina & 12.97632 & 11.69201 & 13.60332 & 11.27416 \\
\hline se & 0.28946 & 1.27865 & 0.71833 & 0.39527 \\
\hline Yellow foot paua & 9.13125 & 9.00000 & 9.55714 & 8.58540 \\
\hline se & 0.90390 & 3.18852 & 0.95665 & 0.38378 \\
\hline
\end{tabular}

Table 9: Average count (per $\mathrm{m}^{2}$ ) of each algal species at each site on the Wellington South Coast, with standard error (se).

\begin{tabular}{|c|c|c|c|c|c|c|c|c|}
\hline Species (av. per Sq m) & Barretts Reef & Breaker Bay & Palmer Head & Princess Bay & Red Rocks & Sinclair Head & The Sirens & Yungh Pen \\
\hline Ecklonia radiata & 12.01212 & 9.18788 & 12.93333 & 2.81212 & 1.84242 & 3.97576 & 3.30909 & 7.76970 \\
\hline se & 0.91893 & 0.66726 & 1.62486 & 0.96240 & 0.39831 & 0.61806 & 0.71392 & 1.91269 \\
\hline Carpophyllum maschalocarpum & 3.20000 & 4.90909 & 2.04848 & 4.29091 & 2.94545 & 1.57778 & 4.20606 & 2.19394 \\
\hline se & 1.13437 & 0.88932 & 0.70697 & 0.43329 & 0.45605 & 0.74985 & 1.03831 & 0.84736 \\
\hline Lessonia variegata & 1.11515 & 0.68571 & 0.91852 & 2.00000 & 3.11515 & 3.32121 & 2.13333 & 2.71515 \\
\hline se & 0.21892 & 0.24244 & 0.25087 & 0.26667 & 0.27104 & 0.23610 & 0.19612 & 0.58348 \\
\hline Macrocystis pyrifera & 0.20000 & 0.37778 & 0 & 0.13333 & 0 & 0 & 0.13333 & 0.13333 \\
\hline se & 0.06667 & 0.10564 & 0 & 0 & 0 & 0 & 0 & 0 \\
\hline Undaria pinnatifida & 0.53333 & 0 & 0 & 0.20000 & 0 & 0 & 0 & 0 \\
\hline se & 0 & 0 & 0 & 0.06667 & 0 & 0 & 0 & 0 \\
\hline
\end{tabular}


Table 10: Average count (per $\mathrm{m}^{2}$ ) of each algal species at each site at Kapiti Marine Reserve, with standard error (se).

\begin{tabular}{|l|r|r|r|r|}
\hline \multicolumn{1}{|c|}{ Species (av. per sq m) } & Arapawaiti Point & Kaiwharawhara Point & Onepoto Point & Tokahaki Point \\
\hline Ecklonia radiata & 8.73939 & 21.90303 & 29.46667 & 20.56970 \\
\hline se & 2.05487 & 2.24748 & 3.09849 & 1.11946 \\
\hline Carpophyllum maschalocarpum & 5.22667 & 4.09697 & 1.62667 & 3.34545 \\
\hline se & 2.18383 & 0.96099 & 0.50078 & 0.48922 \\
\hline Lessonia variegata & 0 & 0.13333 & 0 & 0 \\
\hline se & 0 & 0 & 0 & 0 \\
\hline
\end{tabular}

